UNIVERSIDADE DE SÃO PAULO

INSTITUTO DE ASTRONOMIA, GEOFÍSICA E CIÊNCIAS ATMOSFÉRICAS

\title{
CLIMATOLOGIA DE BLOQUEIOS ATMOSFÉRICOS NO HEMISFERIO SUL: OBSERVAÇÕES, SIMULAÇÕES DO CLIMA DO SÉCULO XX E CENÁRIOS FUTUROS DE MUDANÇAS CLIMÁTICAS
}

FLAVIO NATAL MENDES DE OLIVEIRA

TESE DE DOUTORADO

ORIENTADORA: Profa. Dra. LEILA MARIA VESPOLI DE CARVALHO CO-ORIENTADOR: Prof. Dr. TÉRCIO AMBRIZZI

SÃO PAULO 


\section{CLIMATOLOGIA DE BLOQUEIOS ATMOSFÉRICOS NO \\ HEMISFERIO SUL: OBSERVAÇÕES, SIMULAÇÕES DO CLIMA DO SÉCULO XX E CENÁRIOS FUTUROS DE MUDANÇAS CLIMÁTICAS.}

Versão Corrigida da Tese conforme resolução CoPGr 5890

O original se encontra disponível na unidade do IAG-USP

Tese apresentada ao Instituto de Astronomia, Geofísica e Ciências Atmosféricas da Universidade de São Paulo para a obtenção do título de Doutor em Ciências.

Programa: Meteorologia

Orientadora: Profa. Dra. Leila Maria Vespoli de Carvalho.

Co-Orientador: Prof. Dr. Tércio Ambrizzi.

SÃO PAULO 
À memória de meu Pai, Carlos

A minha mãe, Osmilda, minhas irmãs e irmãos e a minha esposa, Elisângela

Pela Vida, pela Dedicação e pelo Amor. 
Nunca deixe que lhe digam que não vale à pena acreditar no sonho que se tem

Renato Russo 


\section{AGRADECIMENTOS}

Primeiramente a Deus, pela força espiritual necessária para a realização deste trabalho. A meu pai (in memoriam) e minha mãe e minhas irmãs pela vida e ensinamentos.

A Elisangela Carvalho de Oliveira (esposa), pela dedicação, força e compreensão ao longo dos quatro anos.

Aos meus orientadores, Profa. Leila Maria Vespoli Carvalho e Prof. Tércio Ambrizzi por acreditarem no meu potencial.

Ao Prof. Antônio Divino Moura pelo apoio e incentivo há 4 anos atrás onde optei ao doutorado.

Ao Prof. Charles Jones pela ajuda em programação de IDL, ao Prof. Adilson Wagner Gandu pelo excelente exame de qualificação e a minha relatora, Profa. Maria Assunção pela paciência com os relatórios.

Aos colegas e amigos GEManíacos do Laboratório GEM, Michel, Ana, Rodrigo, Nathalie, Fabio, Tatiane e Ana Carolina. Aos demais amigos(as), Clênia Alcântara, Enver, Jônatan Tatsch, Raupp (hoje professor), Martinha, Ricardo Acosta, Clara e Maria, que presentes ou a distância proporcionaram momentos especiais de descontração e divertimento.

Aos funcionários da Secretária, Sônia, Bete e Ana e aos analistas de informártica, Samuel, Sebastião e Fagner que de alguma forma contribuíram com a conclusão deste trabalho.

A CAPES, ao CNPQ (processo 140627/2009) e a CLARIS/PLB pelo suporte financeiro para esta pesquisa.

Na concessão de dados, meus agradecimentos: Ao NCEP/NCAR pelos dados de reanálise; Ao Dr. Ceita Emori, Dr. Toru Nazawa e Dr. Manabu ABE do Center for Global Environmental Research (CGER), Japão, pela concessão de dados do MIROC 3.2; Ao Max Planck Institut 
for Meteorology pela concessão de dados do ECHAM5/MPI-OM via o portal World Data Center (WDC) de Hamburgo, Alemanha.

E aos amigos das padarias, Anderson "Gaúcho Gordo", Gigio, Douglas, Pastor, Bel e Zé pelas churrascadas e companheirismo que foram essenciais fora da USP. 


\section{RESUMO}

Este estudo discute uma climatologia de 59 anos (1949-2007) de bloqueios no Hemisfério Sul (SH) usando dados de altura geopotencial em 500-hPa das reanálises do National Center for Environmental Prediction / National Center for Atmospheric Research (NCEP-NCAR). A variabilidade espaçotemporal dos eventos de bloqueio e associações com o El Niño/Oscilação do Sul (ENOS) também foram examinadas. Adicionalmente, os bloqueios foram investigados em dois Modelos de Circulação Geral Acoplados Atmosfera-Oceano de clima (MCGAO) do Intergovernamental Painel for Climate Change (IPCC), o ECHAM5/MPI-OM e o MIROC 3.2. Dois cenários simulados foram analisados: O clima do século XX e o cenário de emissão A1B. Os episódios do ENOS foram identificados usando dois métodos. O primeiro foi o Índice Oceânico Mensal do Niño (ONI) do Climate Prediction Center (CPC-NCEP). O segundo método foi baseado em Funções Empíricas Ortogonais (EOF) e foi aplicado nos MCGAOs. Similarmente, também foi examinado a influencia combinada do ENOS e a Oscilação Antártica (AAO) na ocorrência e características dos bloqueios. O índice diário da AAO foi obtido pelo CPC-NCEP. Os índices convencionais de bloqueios detectam principalmente variações longitudinais. Este trabalho propõe um índice de bloqueio que detecta, além de variações longitudinais também as variações latitudinais dos bloqueios. Cinco setores relevantes de bloqueios foram examinados em detalhes: Indico Sudoeste (SB1), Pacífico Sudoeste (SB2), Pacífico Central (SB3), Pacífico Sudeste (SB4) e Atlântico Sudoeste (SB5). Além disso, foram investigados duas grandes regiões do Pacífico Sul: Pacífico Oeste e Pacífico Leste. Foi encontrado que a escala média típica dos eventos de bloqueio varia entre 1,5 e 2,5 dias. Além disso, a duração dos eventos depende da latitude, com eventos de maior duração observados em latitudes mais altas. Diferenças longitudinais estatisticamente significativas na frequiência do escoamento bloqueado foram observadas entre as fases Quente e Neutra do ENOS desde o outono a primavera. Episódios intensos da fase Quente do ENOS (isto é, moderados a fortes) tendem a modificar o local preferencial de bloqueio, mas não a freqüência. Por outro lado, os episódios fracos da fase Quente do ENOS estiveram associados relativamente com alta freqüência. Os Eventos de bloqueio durante o ENOS+ duram, em média, mais um dia relativamente aos episódios Neutros. Em contraste, a fase Fria do ENOS (ENOS-) caracterizou-se pela redução dos eventos de bloqueio sobre o setor do Pacífico Central, exceto durante os meses do verão austral. Entretanto, nenhuma diferença estatisticamente significativa foi detectada na duração dos eventos. Composições de anomalias de vento em $200-\mathrm{hPa}$ indicam que o enfraquecimento (fortalecimento) do jato polar em torno de $60^{\circ} \mathrm{S}$ durante a AAO negativa (positiva) em ambas as fases do ENOS tem uma importância significativa no aumento (redução) dos eventos de bloqueio. Um significativo aumento estatístico dos eventos sobre o setor do Pacífico Sudeste foi observado durante a AAO negativa em ambas as fases do ENOS. Ainda, um aumento (redução) dos eventos foi observado sobre a região do Pacífico Oeste na fase negativa (positiva) da AAO durante o ENOS-. Em contraste, durante o ENOS+ não houve diferenças estatisticamente significativas na distribuição longitudinal dos eventos separado de acordo com as fases opostas da AAO, embora haja um aumento (redução) dos eventos da região do Pacífico Oeste para o Pacífico Leste durante a fase negativa (positiva) da AAO. Os MCGAOs simularam corretamente a amplitude do ciclo anual observado. Também, ambos os MCGAOs simularam melhor a duração e o local preferencial do que freqüência. Nenhum MCGAO simulou adequadamente a freqüência durante a fase Neutra do ENOS. O ECHAM5/MPI-OM (rodada 2) mostra um erro sistemático que levam a uma superestimativa na freqüência de eventos sobre o Pacífico Leste durante as fases Neutra e Fria do ENOS. As diferenças entre as duas versões do MIROC 3.2 indicam que a alta resolução nos modelos melhora o desempenho em simular a frequiência de bloqueios.

Palavras-chave: Bloqueios Atmosféricos, El Niño/Oscilação do Sul, Oscilação Antártica, Modelos Acoplados do IPCC. 


\begin{abstract}
This study discusses 59-yr climatology (1949-2007) of Southern Hemisphere (SH) blockings using daily 500-hPa geopotential height data from National Center for Environmental Prediction / National Center for Atmospheric Research (NCEP-NCAR reanalysis. The spatiotemporal variability of blocking events and associations with El Nino/Southern Oscillation (ENSO) are examined. Additionally, blockings were examined in two Intergovernmental Panel for Climate Change (IPCC) Coupled General Circulation Models (CGCM), ECHAM5/MPI-OM and MIROC 3.2. Two sets of simulations were examined: the climate of the $20^{\text {th }}$ century and the A1B emission scenario. ENSO episodes were identified using two methods. The first method was the Monthly Oceanic Niño Index (ONI) from the Climate Prediction Center (CPC-NCEP). The second method was based on Empirical Orthogonal Function (EOF) and was applied to identify ENSO episodes in the CGCMs. Similarly, the combined influence of ENSO and the Antarctic Oscillation (AAO) on the occurrence and characteristics of blockings was also examined. The daily AAO index was obtained from CPC/NCEP. Most conventional blocking indices detect longitudinal variations of blockings. In this study we propose a new blocking index that detects longitudinal and latitudinal variations of blockings. The following relevant sectors of blocking occurrence were identified and examined in detail: Southeast Indian (SB1), Southwest Pacific (SB2), Central Pacific (SB3), Southeast Pacific (SB4) and Southwest Atlantic (SB5) oceans. In addition, we investigated two large regions of South Pacific: West Pacific and East Pacific. We found that the typical timescale of a blocking event is about $\sim 1.5-2.5$ days. Nonetheless, the duration of events depends on the latitude, with larger durations observed at higher latitudes. Statistically significant differences in the longitude of blockings are observed between Warm (ENSO+) and Neutral ENSO phases from the Austral fall to spring. Moderate to strong Warm ENSO episodes modulate the preferred locations of blockings but do not play a significant role for variations in their frequency. On the other hand, weak ENOS+ episodes were associated with relatively high frequency of blockings. Blocking events during ENSO+ last on average one more day compared to events that occur during Neutral episodes. In contrast, Cold (ENOS-) ENSO episodes are characterized by a decrease of blockings over the Central Pacific sector, except during the Austral summer months. However, no statistically significant differences are detected in the duration. Composites of $200-\mathrm{hPa}$ zonal wind anomalies indicate that the weakening (strengthening) of the polar jet around $60^{\circ} \mathrm{S}$ during negative (positive) AAO phases in both ENSO phases plays a major role for the relative increase (decrease) of blocking events. A statistically significant increase of events over Southeast Pacific is observed during negative AAO phases in both ENSO phases. Moreover, an increase (decrease) of events is observed over West Pacific region when negative (positive) AAO phases occur during ENSO-. In contrast, during ENSO+ there is no statistically significant difference in the longitudinal distribution of events separated according to opposite AAO phases, although there is an increase (decrease) in the events from West Pacific region to East Pacific during negative (positive) AAO phase. The CGCMs investigated in this study correctly simulated the amplitude of observed annual cycle of geopotential height in the extratropics. Also, both CGCMs show a better performance in simulating the duration and preferred locations of blockings than their frequency. None of these CGCMs simulated well the frequency during Neutral ENSO phase. The ECHAM5/MPI-OM (run2) shows systematic biases in some regions. For instance, this model overestimates the frequency of blockings over East Pacific region during Cold and Neutral ENSO phases. The differences between the two versions of MIROC 3.2 indicate that the increase in resolution improves the performance of the model in simulating the frequency of blockings.
\end{abstract}

Key words: Blocking, El Nino/Southern Oscillation, Antarctic Oscillation, IPCC Coupled Models 


\section{SUMÁRIO}

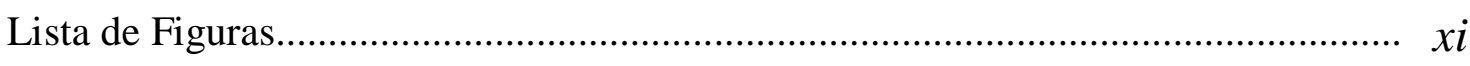

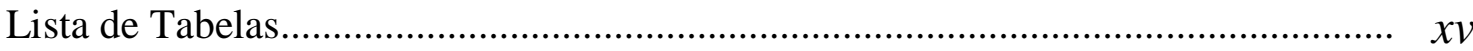

\section{CAPÍTULO 1}

Introdução e Objetivos..................................................................................

1.1 Climatologia e Critérios de Identificação de Bloqueios................................. 4

1.2 Aspectos Dinâmicos dos Bloqueios........................................................ 7

1.3 Oscilações Atmosféricas e Interações Trópicos-Extratrópicos......................... 10

1.4 Modelos Climáticos e Cenários Futuros..................................................... 15

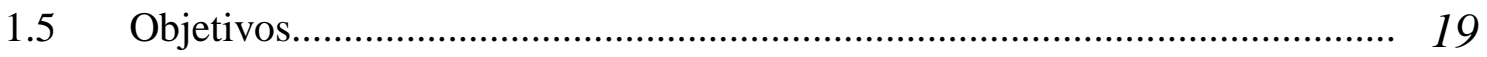

\section{CAPÍTULO 2}

Dados e Metodologia.................................................................................. 21

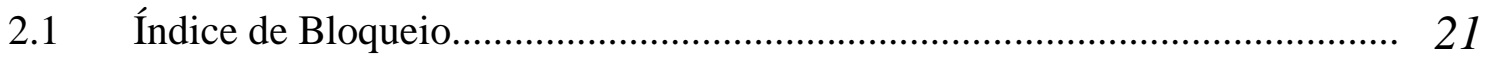

2.2 Setores de Ocorrência de Bloqueios.......................................................... 25

2.3 Variabilidade Interanual de Bloqueios e do ENOS...................................... 26

CAPÍTULO 3

CLIMATOLOGIA DE BLOQUEIOS NO HEMISFÉRIO SUL ............................. 28

3.1 Comparação com Outros Métodos.............................................................. 31

3.2 Bloqueios na Fase Neutra do ENOS........................................................ 34

3.3 Bloqueios nas Fases opostas do ENOS ................................................... 49

3.4 Oscilação Antártica e ENOS ...................................................................... 66

3.5 Variabilidade Interanual e Tendências..................................................... 77

CAPÍTULO 4

CLIMATOLOGIA DE BLOQUEIOS NOS MODELOS ACOPLADOS DO

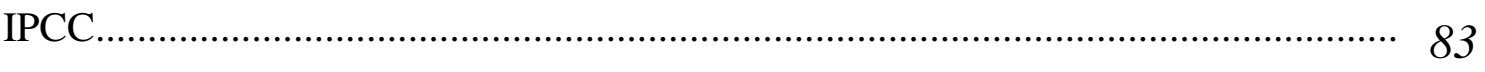

4.1 Modelos de Circulação Geral Acoplados.................................................... 83

4.2 Variabilidade Interanual do ENOS: Simulações para o Tempo Presente e 88 Futuro 
4.3 Bloqueios Atmosféricos: Simulações para o Tempo presente e Futuro.......... 102

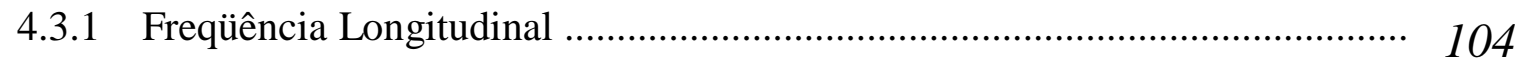

4.3.2 Escala de Tempo Típica nos MCGAOs................................................. 117

CAPÍTULO 5

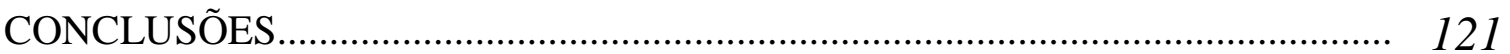

SUGESTÕES PARA TRABALHOS FUTUROS............................................... 125

REFERÊNCIAS BIBLIOGRÁFICAS....................................................... 128 


\section{Lista de Figuras}

Figura 1.1 - Estruturas típicas de bloqueios atmosféricos no Hemisfério Sul. a) Bloqueio do tipo dipolo, b) Bloqueio do tipo ômega invertido...............................................................

Figura 1.2 - Esquema para o Hemisfério Sul mostrando um quebramento de onda (a) ciclônico e (b) anticiclônico na alta troposfera. Estes exemplos mostram o caso particular da Temperatura Potencial na tropopausa dinâmica onde os contornos não são tão suavizados como na análise da altura geopotencial. Extraído de Berrisford et al., (2006)..

Figura 1.3 - Ilustração esquemática das famílias SRES. Fonte: site do IPCC http://sedac.ciesin.columbia.edu/ddc/observed/images/sres_tree_small.jpg. (Adaptado de

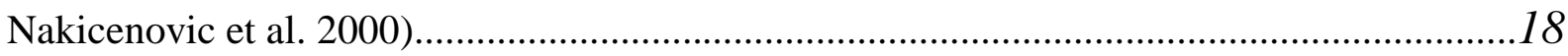

Figura 2.1 - Esquema representativo das bandas zonais do Índice de Bloqueio mostrando estruturas simples de bloqueios sobre diferentes latitudes. Na Figura, os números (1), (2) e (3) representam bloqueios sobre latitudes médias-baixas, médias e médias-altas, respectivamente e posicionados tal como são calculados. As linhas pretas grossas representam a variação latitudinal $(\Delta \phi)$. As linhas tracejadas indicam a perturbação no escoamento de oeste no entorno da estrutura de bloqueio. No centro da estrutura o escoamento é oposto ao escoamento de oeste, representando uma região com anomalias de leste

Figura 2.2 - Representação esquemática dos setores de bloqueio (SB1, SB2, SB3, SB4 e SB5) e as regiões (Pacífico Oeste e Pacífico Leste) sobre o Pacífico Sul.

Figura 3.1 - Distribuição do número total de detecções de eventos com escoamento bloqueado por ponto de longitude. a) Número total de detecções de eventos. b) Número total de detecções de eventos em escala logarítmica de base e. As legendas no topo (à direita) indicam as bandas zonais.

Figura 3.2 - Diagrama Howmöller (tempo-longitude) da intensidade do escoamento bloqueado ( $\mathrm{m} /{ }^{\circ}$ latitude) e o respectivo contador de dias bloqueados por ponto de longitude para os invernos austrais de 1986-1987: (a) Esquema T94; (b) banda das latitudes médias; (c) banda das latitudes médias-baixas e (d) banda das latitudes médias-altas do índice zonal (ver texto para detalhes). A linha sólida no centro do Howmöller representa a região de descontinuidade separando os invernos de 1986 e 1987. Linhas sólidas no gráfico contador representam a contagem de total eventos associado a banda zonal. Linhas tracejadas no gráfico contador representam a contagem total de eventos associada a cada banda de latitudes.

Figura 3.3 - Freqüência relativa do número total de detecções do escoamento bloqueado durante a fase Neutra do ENOS e variando latitudinalmente sobre as bandas zonais: Total (linha azul), médias-baixas (linha vermelha), médias (linha verde) e médias-altas (linha rosa). a) Outono, b) Inverno, c) Primavera e d) Verão. 36

Figura 3.4 - Bagplot [longitude $(\lambda)$ x duração $(\tau)$ ] da distribuição dos eventos de bloqueio com $\tau \geq 3$ dias pela reanálise do NCEP/NCAR. a) Outono, b) Inverno, c) Primavera, d) Verão. Foram retidos apenas o valor de máxima duração de um evento sobre um determinado ponto de longitude. A bolsa (região cinza) mostra a extensão longitudinal bivariada onde estão 50\% das observações. A cruz no centro da bolsa é a mediana de Tukey. A região branca que envolve a bolsa mostra os dados que estão no limite, similar as longas bigornas do Boxplot. 
As observações aberrantes são os pontos pretos que estão fora do laço poligonal convexo....39 Figura 3.5 - Média sazonal do comportamento do vento zonal de oeste em $200 \mathrm{hPa}$ no Hemisfério Sul durante o (a) outono, (b) inverno, (c) primavera e (d) verão. Unid:[m.s].

Figura 3.6 - Gráfico esquemático das relações entre a corrente de jato (setas sólidas em negrito) com os storm tracks (seta hachurada) e o impacto nos distúrbios transientes. Obtido de Trenberth (1986). Ver Trenberth (1986) para maiores detalhes.

Figura 3.7 - Campo médio das anomalias da altura geopotencial no nível de $500 \mathrm{hPa}$. O ciclo anual foi removido. As linhas cheias com regiões sombreadas são anomalias positivas e as linhas tracejadas são anomalias negativas. As linhas cheias grossas representam as áreas com significância estatística de $95 \%$ de confiança. Somente dias com $\tau \geq 3$ dias foram retidos.

Figura 3.8 - Campo médio das anomalias do vento zonal no nível de $200 \mathrm{hPa}$. O ciclo anual foi removido. As linhas cheias com regiões sombreadas são anomalias positivas e as linhas tracejadas são anomalias negativas. As linhas cheias grossas representam as áreas com significância estatística de $95 \%$ de confiança. Somente dias com $\tau \geq 3$ dias foram retidos.

Figura 3.9 - Campo médio do desvio padrão das anomalias do vento meridional no nível de $200 \mathrm{hPa}$. O ciclo anual foi removido. Regiões sombreadas mostram valores iguais ou maiores do que $12 \mathrm{~m} / \mathrm{s}$. Somente dias com $\tau \geq 3$ dias foram retidos. Unid: [m. $\mathrm{s}^{-1}$.

Figura 3.10 - Campo médio do desvio padrão das anomalias da altura geopotencial no nível de $500 \mathrm{hPaO}$ ciclo anual foi removido. Regiões sombreadas mostram valores iguais ou maiores do que $120 \mathrm{mgp}$. Somente dias com $\tau \geq 3$ dias foram retidos. Unid: [mgp]. 48

Figura 3.11 - Distribuição da freqüência do escoamento bloqueado durante o OUTONO. As áreas cheias cinzas representam a distribuição da frequência na fase Neutra do ENOS (referência de padrão). As linhas tracejadas representam episódios fracos, linhas pontilhadas representam os episódios moderados e linhas sólidas representam episódios fortes. As figuras dispostas à esquerda representam a fase Quente do ENOS e as figuras dispostas à direita representam a fase Fria.

Figura 3.12 - Similar a Figura 3.11, mas referente ao INVERNO.......................................53

Figura 3.13 - Similar a Figura 3.11, mas referente à PRIMAVERA...................................55

Figura 3.14 - Similar a Figura 3.11, mas referente ao VERÃO...........................................56

Figura 3.15 - Distribuição da freqüência sazonal do escoamento bloqueado no (a) Outono, (b) Inverno, (c) Primavera e (d) Verão. As áreas cheias cinzas representam a distribuição da frequência referente ao padrão na fase Neutra do ENOS. As linhas pretas sólidas representam a fase Quente do ENOS, enquanto as linhas pretas tracejadas representam a fase Fria.

Figura 3.16 - Diferenças entre medianas do escoamento bloqueado por ponto de longitude entre o ENOS+ e o padrão Neutro. (a) ENOS+ menos Neutro durante o Outono; (b) ENOS+ menos Neutro durante o Inverno; (c) ENOS+ menos Neutro durante a Primavera e (d) ENOS+ 
menos Neutro durante o Verão. Linhas grossas em negrito indicam pontos de longitude com significância estatística ao nível de $\mathrm{p}<0,05$.

Figura 3.17 - Diferenças entre medianas do escoamento bloqueado por ponto de longitude entre o ENOS- e o padrão Neutro. (a) ENOS- menos Neutro durante o Outono; (b) ENOSmenos Neutro durante o Inverno; (c) ENOS- menos Neutro durante a Primavera e (d) ENOSmenos Neutro durante o Verão. Linhas grossas em negrito indicam pontos de longitude com significância estatística ao nível de $\mathrm{p}<0,05$.

Figura 3.18 - Distribuição da frequência do escoamento bloqueado combinando o ENOS com a variabilidade diária da AAO durante o período de 1979 a 2000. (a) AAO-|ENOS-, (b) AAO|ENOS+, (c) AAO+|ENOS-, (d) AAO+|ENOS+. As linhas sólidas representam a banda zonal total, enquanto a linhas tracejadas representam latitudes médias-altas e as linhas pontilhadas representam latitude médias-baixas

Figura 3.19 - Padrões de teleconexões obtidos pelas anomalias do vento zonal em $200 \mathrm{hPa}$ durante as fases negativa (acima) e positiva (abaixo) da AAO. Figura extraída de carvalho et al., 2005

Figura 3.20 - Composições da média das anomalias do vento zonal em $200 \mathrm{hPa}$ durante os episódios de bloqueios com $\tau \geq 3$ dias para as combinações AAO-|ENOS- (à esquerda) e AAO+|ENOS- (à direita) sobre os setores do Pacífico Sudoeste (topo), Pacífico Central (meio) e Pacífico Sudeste (base). Unid: $\left[\mathrm{m} \cdot \mathrm{s}^{-1}\right]$. .73

Figura 3.21 - Composições da média das anomalias do vento zonal em $200 \mathrm{hPa}$ durante os episódios de bloqueios com $\tau \geq 3$ dias para as combinações AAO-|ENOS+ (à esquerda) e AAO+|ENOS+ (à direita) sobre os setores do Pacífico Sudoeste (topo), Pacífico Central (meio) e Pacífico Sudeste (base). Unid: $\left[\mathrm{m} . \mathrm{s}^{-1}\right]$.

Figura 3.22 - Composições da média das anomalias da altura geopotencial no nível de 500hPa durante os episódios de bloqueios com $\tau \geq 3$ dias para as combinações (a) AAO-|ENOS-, (b) AAO-|ENOS+, (c) AAO+|ENOS-, AAO+|ENOS+ sobre o Hemisfério Sul. Unid:[mgp]

Figura 3.23 - Boxplot com estatísticas da duração dos eventos de bloqueio com $\tau \geq 3$ dias para as quatro combinação do ENOS [+|-] com a AAO [+|-] sobre os setores de bloqueio do (a) Pacífico Sudoeste, (b) Pacífico Central e (c) Pacífico Sudeste. 76

Figura 3.24 - Distribuição trimestral dos eventos de bloqueio ao longo do ano nos setores do Indico Sudeste (a), Pacífico Sudoeste (b), Pacífico Central (c), Pacífico Sudeste (d), Atlântico Sudeste (e). Áreas amarelas representam o desvio padrão da série temporal. As linhas em negrito representam um filtro triangular 1-2-1. A reta pontilha representa a reta de regressão linear. No topo à direita de cada figura estão representada a equação da tendência. .78

Figura 3.25 - Distribuição trimestral dos eventos de bloqueio ao longo do ano no Hemisfério Sul. As duas retas tracejadas indicam os limites do desvio padrão. A linha sólida grosa indica a variância móvel para uma janela de 11 anos

Figura 3.26 - Análise do espectro de ondeleta "Morlet" aplicado nos dados trimestrais do número total de eventos de bloqueio com duração mínima de 3 dias. (a) Espectro da ondeleta, (b) Ondeleta global e (c) Variâncias médias em função do tempo, sendo linhas pontilhadas para a banda de 0,3-1,5 anos, linha cheia para a banda de 2,4 anos e linha tracejada para a banda de 6-12 anos. A área hachurada (a) representa o cone de influencia (COI), onde o efeito 
das bordas torna-se importante enquanto que a regiões pontilhadas representam regiões com 95\% de confiança estatística. Referências: Torrence, C. and G. P. Compo, 1998: A Practical Guide to Wavelet Analysis. Bull. Amer. Meteor. Soc., 79, 61-78.

Figura 4.1 - Projeção espacial da primeira EOF rotacionada (REOF-1) para os dados de TSM de baixa frequência na região de $30^{\circ} \mathrm{S}-30^{\circ} \mathrm{N}$ e $120^{\circ} \mathrm{E}-120^{\circ} \mathrm{W}$. Regiões em cinza com linhas pontilhadas são correlações negativas. Regiões claras com linhas sólidas são correlações positivas. (a) NCEP-NCAR, (b) ECHAM5_R1 20C, (c) ECHAM5_R1 A1B, (d) ECHAM5_R2 20C, (e) ECHAM5_R2 A1B, (f) MIROC 3.2-H 20C, (g) MIROC 3.2-H A1B, (h) MIROC 3.2-M 20C, (i) MIROC 3.2-M A1B.

Figura 4.2 - Relação entre os índices ONI e Coeficiente temporal REOF-1 ao longo do período de 1980 a 2000. A linha fina representa o índice ONI, enquanto que a linha grossa representa o Coeficiente da REOF-1. A correlação entre as duas séries temporais é de $\sim 0,97$

Figura 4.3 - Composição das anomalias das TSM mensais das reanálises do NCEP/NCAR referente ao período de 1980-2000. O ciclo anual foi removido. Linhas sólidas representam anomalias positivas e linhas tracejadas representam anomalias negativas. A linha do "zero" esta representada pela linha ponto-tracejadas. Devido às comparações com os MCGAOs, a escala vai de $-3,5$ a $3,5^{\circ} \mathrm{C}$.

Figura 4.4 - Composição das anomalias das TSM mensais dos modelos de clima ECHAM5/MPI-OM e MIROC 3.2 referente ao cenário simulado $20 \mathrm{C}$ dos modelos. O ciclo anual foi removido. Linhas sólidas representam anomalias positivas e linhas tracejadas representam anomalias negativas. A linha do "zero" esta representada pelas linhas ponto-tracejadas. A escala vai de $-3,5$ a $3,5^{\circ} \mathrm{C}$. As figuras à esquerda representam a fase Quente do ENOS e às figuras do lado direito representam a fase Fria do ENOS. No topo de cada figura está representado o modelo avaliado.

Figura 4.5 - Similar a Figura 4.4, mas referente ao cenário simulado A1B

Figura 4.6 - - Série temporal da REOF-1 para os MCGAOSs ECHAM5/MPI-OM e MIROC 3.2 para as simulações 20C (à esquerda) e A1B (à direita) que corrigido mostra o sinal positivo para o ENOS+ e o sinal negativo para o ENOS-. Os modelos analisados estão indicados no topo de cada figura. Linhas tracejadas representam o desvio médio.

Figura 4.7 - Resultado do ciclo anual e do primeiro harmônico simulado pelos MCGAOs. As simulações (linha vermelha) são comparadas com o ciclo harmônico observado na reanálise do NCEP/NCAR (linha azul). As figuras à esquerda representam o ciclo harmônico calculado sobre a longitude $180^{\circ} \mathrm{em} 50^{\circ} \mathrm{S}$. As figuras à direita são análogas sobre a longitude de $90^{\circ} \mathrm{W}$ em $50^{\circ} \mathrm{S}$. Do topo à base são representadas as simulações realizadas pelo (a) e (b) ECHAM5_R2, (c) e (d) MIROC 3.2-H e (e) e (f) MIROC 3.2-M.......................................103

Figura 4.8 - Freqüência do número de detecções do escoamento bloqueado por ponto de longitude para o cenário simulado 20C sobre a banda zonal total: a) Períodos Neutros, b) ENOS+, c) ENOS-. O observado e as simulações estão representados da seguinte forma: Observado NCEP/NCAR (linha preta), ECHAM5_R2 (linha marrom), MIROC 3.2-H (linha laranja) MIROC 3.2-M (linha amarela). 106

Figura 4.9 - Freqüência do número total de detecções do escoamento bloqueado por ponto de longitude para o cenário simulado $20 \mathrm{C}$ sobre as bandas de latitudes médias-altas (topo) e médias-baixas (base) e para a fase Neutra do ENOS (à esquerda, partes "a"e "d", fase Quente (no meio, partes "b" e "e", c), fase Fria (à direita, partes "c"e "f". O observado e as simulações estão representados da seguinte forma: Observado NCEP/NCAR (linha preta), 
ECHAM5_R2 (linha marrom), MIROC 3.2-H (linha laranja), MIROC 3.2-M (linha amarela).

Figura 4.10 - Freqüência do número de detecções do escoamento bloqueado por ponto de longitude comparando os cenários simulados 20C e A1B sobre a banda zonal total nos nas fases a) Neutra, b) Quente e c) Fria do ENOS. O simulado para o clima presente 20C é representado por linhas sólidas enquanto que o simulado para o cenário A1B é representado por linhas tracejadas. A legenda no topo à esquerda de cada figura indica o modelo.

Figura 4.11 - Freqüência total dos eventos de bloqueio para o observado NCEP/NCAR versus o cenário simulado 20C pelos MCGAOs (ECHAM5_R2, MIROC 3.2-H e MIROC 3.2-M) para os setores de bloqueio do a) Pacífico Sudoeste, b) Pacífico Central e c) Pacífico Sudeste. Asteriscos indicam que as proporções simuladas são estatisticamente diferentes ao nível de p $<0,05$ em comparação com as proporções obtidas para a reanálise.

Figura 4.12 - Freqüência total dos eventos de bloqueio distribuída dentro das fases do ENOS para o observado NCEP/NCAR versus o simulado 20C pelos MCGAOs (ECHAM5_R2, MIROC 3.2-H e MIROC 3.2-M) e para os setores de bloqueio: a) Pacífico Sudoeste, b) Pacífico Central e c) Pacífico Sudeste. A legenda no topo de cada figura identifica as fases do ENOS. Asteriscos indicam que as proporções simuladas são estatisticamente diferentes ao nível de $\mathrm{p}<0,05$ em comparação com as proporções obtidas para a reanálise. 113

Figura 4.13 - Freqüência total dos eventos de bloqueio distribuída dentro das fases do ENOS para o simulado 20C versus o simulado A1B pelos modelos (ECHAM5_R2, MIROC 3.2-H e MIROC 3.2-M) para os setores de bloqueio: a) Pacífico Sudoeste, b) Pacífico Central e c) Pacífico Sudeste. A legenda no topo identifica as fases do ENOS. Asteriscos indicam que as proporções simuladas entre os dois cenários são estatisticamente diferentes ao nível de $\mathrm{p}<0,05$ 114

Figura 4.14 - umero médio mensal dos dias com bloqueios com $\tau \geq 3$ dias na fase Neutra do ENOS (à esquerda), na fase Quente (no centro) e na fase Fria (à direita) nos setores de bloqueio do Pacífico Sudoeste ("a", “d”, e "g") Pacífico Central ("b", "e", e "h") e Pacífico Sudeste ("c", "f", e "i"). Barras de erros com 95\% de confiança são mostradas para cada mês.

Figura 4.15 - Comparação das escalas de tempo médias das simulações para o cenário simulado 20C pelos MCGAOs versus a reanálise do NCEP/NCAR. Nas figuras estão representas as escala típica de bloqueios para a) latitudes médias-baixas, b) latitudes médias e c) latitudes médias-altas. O gráfico (d) representa um resumo das figuras "a", "b"e "c" com intervalos do erro médio. 118

Figura 4.16 - Bagplot [longitude $(\lambda) \mathrm{x}$ duração $(\tau)$ ] da distribuição dos eventos de bloqueio com $\tau \geq 3$ dias pela reanálise do NCEP/NCAR. a) Observado NCEP/NCAR, b) ECHAM5_R2 20C, c) ECHAM5_R2 A1B, d) MIROC 3.2 20C, e) MIROC 3.2 A1B. Foram retidos apenas o valor de máxima duração de um evento sobre um determinado ponto de longitude. A bolsa (região amarela) mostra a extensão longitudinal bivariada onde estão 50\% das observações. A cruz no centro da bolsa é a mediana de Tukey. A região branca que envolve a bolsa mostra os dados que estão no limite, similar as longas bigornas do Boxplot. As observações aberrantes são os pontos pretos que estão fora do laço poligonal convexo 120 


\section{Lista de Tabelas}

Tabela 2.1 - Propriedades locais das bandas zonais, suas respectivas latitudes centrais de referência "constante", número de deltas (variação latitudinal) e os limites latitudinais para cada banda zonal aplicados ao Índice de Bloqueio.

Tabela 2.2 - Classificação das fases do ENOS de acordo como índice oceânico (ONI). Os anos entre "-" indicam episódios de longa duração, e os anos entre "/” indicam episódios de curta duração.

Tabela 3.1 - Distribuição sazonal do número total de dias com escoamento bloqueado, número de eventos com $\tau \geq 3$ dias e média de eventos/ano obtidos para os 59 anos da reanálise-I do NCEP/NCAR

Tabela 3.2 - Estatística do total e duração dos eventos de bloqueio de bloqueio para o OUTONO. As medidas de tendência central para os períodos das fases opostas do ENOS são representadas pela respectiva diferença ([Fases opostas]-[Fase Neutra]), para explicar visualmente o sinal da variabilidade detectada, caso a hipótese nula $\left(\mathrm{H}_{\mathrm{o}}\right)$ seja rejeitada. Nos episódios Neutros, as respectivas medidas estão dispostas em valores exatos. Os testes aplicados foram de proporção para a variável "eventos" e o teste-U de Mann-Whitney para a variável "duração". Os valores-p em "negrito" $e$ "negrito-itálico" indicam às regiões cujas estatísticas passaram nos testes com significância estatística ao nível de 90\% e 95\% de confiança, respectivamente

Tabela 3.3 - Análogo a Tabela 3.2, exceto que referente ao período do INVERNO............63

Tabela 3.4 - Análogo a Tabela 3.2, exceto que referente ao período da PRIMAVERA........64

Tabela 3.5 - Análogo a Tabela 3.2, exceto que referente ao período do VERÃO.

Tabela 3.6 - Distribuição do número de dias com escoamento bloqueado e o número total de eventos de bloqueio com $\tau \geq 3$ dias durante as combinações AAO|ENOS.

Tabela 4.1 - Resultados da análise da REOF observada (NCEP/NCAR). São mostradas a ordem (k) da REOF e a distancia entre os autovalores, a porcentagem e porcentagem acumulada da variância explicada.

Tabela 4.2 - Resultados da análise da REOF simulada pelo modelo ECHAM5/MPI-OM para o clima presente 20C. São mostradas a ordem (k) da REOF e a distancia entre os autovalores, a porcentagem e porcentagem acumulada da variância explicada. À esquerda são mostrados os resultados para o ECHAM5 R1 20C (topo) e ECHAM5 R1 A1B (base). No meio são mostrados os resultados para o ECHAM5 R2 20C (topo) e ECHAM5 R2 A1B (base). À direita são mostrados os resultados para o ECHAM5 R3 20C (topo) e ECHAM5 R3 A1B (base).

Tabela 4.3 - Resultados da análise da REOF simulada pelo modelo MIROC 3.2 para o clima presente 20C. São mostradas a ordem (k) da REOF e a distancia entre os autovalores, a porcentagem e porcentagem acumulada da variância explicada. À esquerda são mostrados os resultados para o MIROC 3.2-H 20C (topo) e MIROC 3.2-H A1B (base). À direita são mostrados os resultados para o MIROC 3.2-M 20C (topo) e MIROC 3.2-M A1B (base).

Tabela 4.4 - Resultados da análise do Coeficiente temporal da REOF-1 para a distribuição do 
ENOS. Os resultados foram determinados olhando para os campos da TSM, onde o Coeficiente temporal da REOF-1 persiste por 5 meses. São mostrados na sequiência os números relativos ao: total de anos/total de episódios/duração média de cada episódio. A tabela à esquerda representa os resultados para o experimento simulado $20 \mathrm{C}$ e a tabela à direita, o experimento simulado A1B.............................................................................101 


\section{CAPÍTULO 1}

\section{INTRODUÇÃO E OBJETIVOS}

Bloqueios atmosféricos são comumente observados onde o escoamento zonal característico de latitudes médias é interrompido por um intenso e persistente escoamento meridional, associado à estrutura de uma célula anômala de alta pressão quase-estacionária e barotrópica resultando na bifurcação do jato. Tais estruturas de bloqueio são, em grande parte, responsáveis pela persistência do tempo, induzindo a extremos climáticos que variam desde secas e ondas de calor a invasões de ar frio.

Dois tipos de bloqueio são frequentemente observados no HS conforme representados na Figura 1.1:

a) Bloqueio do tipo dipolo: Quando uma baixa fria desprendida ("cut-off low", em inglês) posiciona-se no flanco equatorial de uma alta de bloqueio, caracterizando uma estrutura de dipolo (Figura 1.1a). Associado a seus dois centros de altura geopotencial há uma zona de deformação, representado pelo ponto na Figura 1.1a. Este padrão é representado por uma corrente de ar anômala de leste para oeste com uma pluma difluente a oeste que reforça a zona de deformação. Corrente acima da região bloqueada e a oeste da zona de deformação o escoamento é tipicamente zonal, enquanto que no lado leste do bloqueio são esperados condições de calor e ar seco, típicos de uma crista progressiva.

b) Bloqueio do tipo ômega $(\Omega)$ : Trata-se de um tipo de bloqueio de grande extensão espacial e de grande longevidade, caracterizado pela combinação entre duas baixas frias desprendidas e uma alta de bloqueio que são similares em tamanho e intensidade, e cuja forma se assemelha à letra grega $\Omega$ (Omega invertido no caso do HS) (Figura1b). Associado a 
seus três centros de altura geopotencial, deverá haver duas zonas de deformação, representadas pelos pontos na Figura 1.1b. Neste padrão de bloqueio o escoamento de altos níveis é deslocado na direção oeste e para o flanco polar da primeira circulação ciclônica $\left(\mathrm{B}_{1}\right)$, criando a primeira zona de deformação. A segunda zona de deformação surge justamente ao norte da alta de bloqueio contornando anticiclônicamente a alta de bloqueio na direção dos pólos. Isto também se estende ciclônicamente na direção equatorial da segunda baixa fria $\left(B_{2}\right)$. A este tipo de bloqueio estão associados sistemas persistentes de tempo quente e seco e/ou frio e úmido sobre grandes áreas continentais e marítimas.

a) Bloqueio dipolo

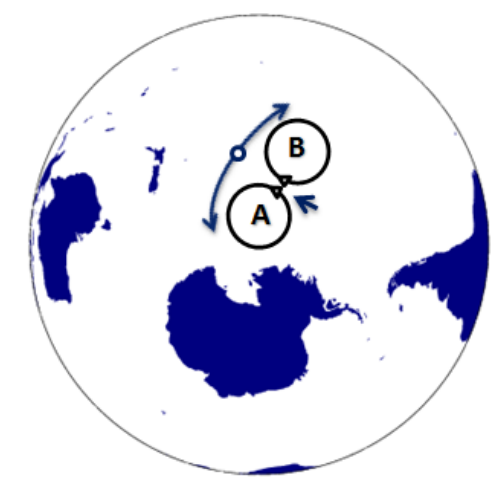

b) Bloqueio ômega

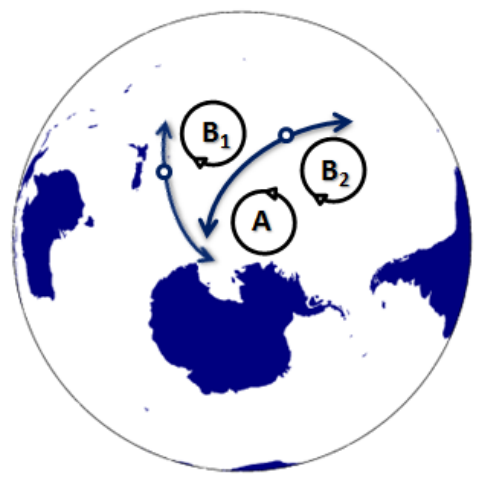

Figura 1.1 - Estruturas típicas de bloqueios atmosféricos no Hemisfério Sul. a) Bloqueio do tipo dipolo, b) Bloqueio do tipo ômega invertido.

Os primeiros estudos sobre bloqueios foram desenvolvidos no final da década de 1940. Por exemplo, Namias (1947) introduziu o conceito de índice zonal e foi o pioneiro ao descrever um evento de bloqueio particular ocorrido durante o inverno boreal. Willet (1949) mostrou que o escoamento de oeste nas latitudes médias varia constantemente entre as circulações com alto índice zonal e com baixo índice zonal. O padrão com baixo índice zonal corresponde àquelas situações com o escoamento zonalmente bloqueado. Berggren et al. (1949) representaram, talvez pela primeira vez, a estrutura térmica de um evento de bloqueio. Elliot e Smith (1949) forneceram exemplos para o Hemisfério Norte (HN). Rex (1950a,b) 
produziu o que se tornou a primeira climatologia de bloqueios. No entanto, no HS são poucos os trabalhos anteriores à década de 1980. Por exemplo, van Loon (1956) produziu a primeira climatologia de bloqueios; Taljaard (1972), Wright (1974) e Brown (1975) documentaram vários aspectos sinóticos descritivos importantes. A partir dos anos oitenta, houve um maior interesse nos estudos focados na atividade de bloqueios sobre o HS, basicamente motivados pela grande melhora na representatividade dos campos meteorológicos. Este interesse é evidenciado pelos trabalhos explorando a climatologia dos bloqueios como Casarin e Kousky (1982), Coughlan (1983), Lejeñas (1984), Trenberth e Mo (1985). Na década seguinte, destacam-se Kayano e Kousky (1990), Rutland e Fuenzalida (1991), Tibaldi et al. (1994), Marques e Rao (1996), Marques (1996), Sinclair (1996), Fuentes (1997), Nascimento (1998), Nascimento e Ambrizzi (2002), Wiedenmann et al. (2002) e mais recentemente Damião et al. (2008).

Marques (1996), Renwick (1998), Marques e Rao (2000), Wiedenman et al. (2002) e Damião et al. (2008) investigaram a influência do El Niño/Oscilação do Sul (ENOS) na frequiência dos eventos de bloqueio. Entretanto, nenhum destes estudos comparou possíveis diferenças na freqüência e posição preferencial de bloqueio como função da intensidade do fenômeno do ENOS. Outro modo importante nos extratrópicos é conhecido como Oscilação Antártica (AAO) (Gong and Wang, 1998). Não há nenhum estudo a respeito da influência da AAO na freqüência de ocorrência e manutenção dos eventos de bloqueio no HS.

Alguns estudos têm explorado o fenômeno de bloqueios usando modelos de clima específicos. Tibaldi et al. (1997) conduziram uma análise de episódios de bloqueios baseada em quatro integrações do modelo Atmosférico de Circulação Geral (MCGA) ECHAM3 com diferentes configurações do truncamento horizontal espectral e temperaturas de superfície oceânica. Todas as quatro versões do modelo mostraram uma tendência em subestimar a ocorrência de bloqueios. Posteriormente, D’Andrea et al. (1998) produziu até então o mais 
expressivo estudo intercomparativo para 15 modelos de circulação geral com o objetivo de diagnosticar e comparar a habilidade destes modelos na simulação de bloqueios. Estudos mais recentes (Pelly e Hoskins, 2003b) sugerem resultados consistentes com os estudos anteriores de Tibaldi et al. (1997) e D'Andrea et al. (1998), onde estes modelos, em geral, tendem a simular a localização preferencial com maior precisão do que freqüência de ocorrência e duração. No HS, Damião (2007) usando HADCM3 demonstrou que o modelo subestima a atividade de bloqueio sobre o Pacífico Sul. Matsueda et al. (2010), em estudo para o HS, usaram três integrações do modelo MRI com diferentes resoluções horizontais $(20 \mathrm{~km}, 60 \mathrm{~km}$ e $180 \mathrm{~km})$ e mostraram que a alta resolução horizontal do modelo é um aspecto importante para a melhor precisão na simulação de detecção de bloqueios.

\subsection{CLIMATOLOGIA E CRITÉRIOS DE IDENTIFICAÇÃO DE BLOQUEIOS}

Rex (1950a, b) publicou a primeira climatologia de bloqueios atmosféricos para o Hemisfério Norte (HN) usando um método subjetivo baseado nas propriedades cinéticas do escoamento em superfície e troposfera média. Muitas definições sobre bloqueios têm sido usadas, contudo as características consensuais parecem ser a bifurcação do jato e a quaseestacionaridade da estrutura. No HS, o primeiro estudo abrangente sobre climatologia de bloqueios foi elaborado por van Loon (1956) usando uma metodologia similar a de Rex (1950a,b). Wright (1974) e Casarin e Kousky (1982) forneceram uma revisão compreensiva dos aspectos sinóticos de bloqueios sobre o Pacífico Sul, sendo que o primeiro focou basicamente na região de bloqueios da Australásia. Os principais aspectos sinóticos destes estudos são descritos abaixo: 
(a) Van Loon (1956):

- 1) O deslocamento do sistema de bloqueios, dado pelo movimento do centro de alta, não deve exceder $25^{\circ}$ de longitude em $45^{\circ} \mathrm{S}$ durante todo o período do mesmo; 2) $\mathrm{O}$ centro do anticiclone de bloqueio deve estar pelo menos, $10^{\circ}$ de latitude mais ao sul do cinturão de altas pressões subtropicais; 3) O bloqueio deve durar pelo menos seis dias.

(b) Wright (1974):

- 1) $\mathrm{O}$ escoamento básico de oeste (em $500 \mathrm{hPa}$ ) deve se dividir em dois ramos; $\mathrm{A}$ média de 5 dias da posição da crista em $500 \mathrm{hPa}$ em $45^{\circ} \mathrm{S}$ (definindo a longitude do bloqueio) deve ter uma taxa de progressão de menos de $20^{\circ}$ de longitude por semana e não deve progredir mais do que $30^{\circ}$ de longitude durante toda a duração do evento; 2) A crista na longitude do bloqueio deve estar pelo menos $7^{\circ}$ de latitude mais ao sul que a posição normal do cinturão de altas pressões subtropicais e deve ser mantida com apreciável continuidade; 3) A duração do evento deve ser de pelo menos seis dias.

(c) Casarin e Kousky (1982):

- 1) O escoamento de oeste divide-se em dois ramos; 2) A posição inicial e final do bloqueio são aquelas longitudes onde o módulo da vorticidade é máximo; O deslocamento total do bloqueio deve ser menor ou igual a $25^{\circ}$ de longitude durante o período total do evento; 3) A situação de bloqueio deve se manter no mínimo por seis dias consecutivos; 4) A data inicial de cada situação de bloqueio é determinada pelo aparecimento da condição expressa no primeiro item. 5) A data final é determinada pelo desaparecimento de uma, ou mais, das condições expressas no primeiro, terceiro e quarto item.

Devido à enorme dificuldade em processar tais critérios como algoritmos que traduzam o observado em informações numéricas das condições de bloqueio, tais métodos, exceto pelo conteúdo teórico, tornaram-se inadequados. Assim, iniciou-se o advento dos 
métodos objetivos (numéricos) desenvolvidos para a identificação de estruturas de bloqueio, propostos inicialmente por Dole (1978), Charney et al. (1981), e Dole e Gordon (1983). Estes métodos usaram índices baseados em dados diários com o objetivo de estudar os aspectos de persistência dos anticiclones anômalos. Por exemplo, de acordo com Charney et al. (1981), um evento de bloqueio poderia ser identificado quando detectado uma persistente e forte anomalia positiva na altura geopotencial de $500 \mathrm{hPa}$.

Mais recentemente, Lejeñas e Økland (1983) para o HN e Lejeñas (1984) para o HS, com o objetivo de produzir análises numéricas, combinaram os métodos objetivos com aqueles subjetivos baseados nas idéias anteriores de Rex (1950a, b). Assim, estabeleceram o conceito de "índice de bloqueio", o qual é uma medida proporcional à intensidade da componente zonal do vento geostrófico. Este índice é similar ao proposto por Namias (1947), mas baseado no gradiente da altura geopotencial na troposfera média. Neste sentido, para que uma determinada longitude seja considerada bloqueada, é necessário que a média latitudinal do escoamento de oeste seja de leste para cada ponto de longitude observado, isto é:

$$
Z\left(\lambda, \phi_{0}-\frac{\Delta \phi}{2}\right)-Z\left(\lambda, \phi_{0}+\frac{\Delta \phi}{2}\right)<0(E q .1)
$$

A equação (1) é calculada para cada $10^{\circ}$ de longitude e demanda que o valor médio do índice seja negativo. Deste modo, temos que $\Delta \phi$ é igual a $20^{\circ}$ e $\phi_{0}$ uma latitude central constante.

Contudo, o índice de Lejeñas (1984) não evita que baixas desprendidas deslocadas anomalamente para latitudes polares sejam confundidas com bloqueios atmosféricos. Neste sentido Tibaldi et al (1994) em estudo para o HS, similar a Tibaldi e Molteni (1990) para o HN, modificaram o índice de Lejeñas (1984) e introduziram uma segunda componente zonal para evitar respostas errôneas na freqüência de bloqueios, dada pela seguinte expressão:

$$
\frac{\left[Z\left(\lambda, \phi_{0}-\Delta \phi\right)-Z\left(\lambda, \phi_{0}\right)\right]}{\left[\left(\phi_{0}-\Delta \phi\right)-\left(\phi_{0}\right)\right]}<-10 m g p(E q .2)
$$


Onde $\phi_{\mathrm{o}}$ é uma latitude central constante igual a $50^{\circ} \mathrm{S}$. Este método foi incorporado neste trabalho e será detalhado no Capítulo 2.

Recentemente, um índice baseado nas prévias idéias de Hoskins et al. (1985) sobre o uso dos mapas de vorticidade potencial, denominado de Índice PV- $\Theta$, foi utilizado para o Hemisfério Norte em Pelly and Hoskins (2003) e no HS em Berrisford et al. (2006). Neste método, um índice de Bloqueio $\mathcal{B}$ é definido como a diferença da temperatura potencial média entre os setores de latitudes norte e sul, dado por:

$$
\mathcal{B}=\frac{2}{\Delta \phi} \int_{\phi_{0}}^{\phi_{0}+\Delta \phi / 2} \theta d \phi-\frac{2}{\Delta \phi} \int_{\phi_{0}-\Delta \phi / 2}^{\phi_{0}} \theta d \phi(E q .3)
$$

Este cálculo é realizado na superfície de PV=2 unidades, denominada de tropopausa dinâmica. Pela definição, $\mathcal{B}<0$ para escoamentos zonais de oeste e $\mathcal{B}>0$ quando há bloqueio no escoamento.

É importante notar que todos os métodos citados se referem a "escoamento zonalmente bloqueado" local e instantâneo. Todavia, o termo "bloqueio" se refere à persistência do índice para uma determinada duração. Detalhes sobre o critério de persistência mínima adotado neste trabalho serão abordados no Capítulo 2.

\subsection{ASPECTOS DINÂMICOS DOS BLOQUEIOS}

Duração, freqüência de ocorrência e localização longitudinal preferencial são as principais variáveis estatísticas atribuídas ao fenômeno de bloqueio, as quais dependem de processos dinâmicos envolvendo complexas variáveis da atmosfera, dos oceanos e topografia. A existência de ventos intensos de oeste nas latitudes médias e altas da troposfera do HS reduz significativamente a duração dos eventos de bloqueio comparativamente com o $\mathrm{HN}$ 
(van Loon 1956, Trenberth 1995, Tibaldi et al 1994, Berrisford et al 2006). Os eventos de bloqueios atmosféricos no HS estão usualmente localizados em latitudes mais baixas do que o observado no HN (Lejeñas 1984; Tibaldi et al 1994), e são muito menos freqüentes (Tibaldi et al 1994). Entretanto, Coughlan (1983) mostrou que a freqüência de bloqueios sobre a região da Austrália e Nova Zelândia tem uma magnitude comparável àquela observada no HN, e a reduzida presença de orografia no HS pressupõe a importância das variações longitudinais de temperatura da superfície do mar (TSM) como um mecanismo forçante na formação de bloqueios.

Existe na literatura um amplo debate sobre a freqüência de ocorrência e localizações longitudinais preferenciais para a formação dos eventos de bloqueio sobre o HS. Há uma ampla gama de opiniões, desde o trabalho primordial de van Loon (1956) até Lejenäs (1984) e Tibaldi et al (1994) que revelaram aspectos sinóticos importantes dos anticiclones de bloqueio no HS. Estes autores verificaram que a região de maior freqüência de bloqueios situa-se no sudoeste do Pacífico, próximo da Nova Zelândia, e destacaram o leste da América do Sul e o sudoeste do Oceano Índico como regiões de máximos secundários de ocorrência. Posteriormente, Sinclair (1996) e Marques (1996) usaram uma série maior de dados e metodologias distintas e verificaram a existência de uma quarta região de alta freqüência de bloqueios no HS situada ao oeste da América do Sul. Recentemente, Berrisford et al (2006) usaram um método desenvolvido por Pelly e Hoskins (2003) e reanálises ERA-40 do European Centre for Medium Range Weather Forecasts (ECMWF) e revelaram que eventos de bloqueio sobre as latitudes médias do HS ocorrem predominantemente no período de inverno sobre o oceano Pacífico e são mais vigorosos no Pacífico Leste; durante o verão, a freqüência de bloqueios enfraquece e confina-se no Pacífico Oeste.

Nos últimos 60 anos, diversas teorias têm sido propostas para explicar os mecanismos de formação, manutenção e decaimento do fenômeno de bloqueios atmosféricos (Berggren et 
al., 1949; Rex 1950, Dole 1986; Trenberth 1986; Mullen 1987; Holopainen e Fortelius 1987; Marques 1996). Estudos numéricos demonstraram que a interação com fenômenos de alta freqüência poderia conduzir a formação de um anticiclone de bloqueio (Shutts 1983; Metz 1986; Blackmon et al. 1986; Haines and Marshall 1987; Vautard e Legras 1988). Egger (1978) e Kalnay-Rivas e Merkine (1981) representam uma linha de idéias que propõem a formação de bloqueios por mecanismos barotrópicos. Por outro lado, Shilling (1982) mostrou que bloqueios podem ser induzidos por processos baroclínicos. Chen e Shukla (1983) conciliaram as duas idéias e mostraram num experimento numérico que bloqueios atmosféricos são formados pela interferência construtiva de ondas baroclínicas e barotrópicas. Neste contexto, outros estudos indicaram que a imprevisibilidade relativa dos distúrbios de ondas baroclínicas nos GCMs para previsão de médio-prazo pode o ser responsável pela baixa previsibilidade do fenômeno de bloqueio (Tibaldi et al.1994; Renwick and Wallace 1996a), visto que estes distúrbios parecem influenciar o ciclo de vida dos anticiclones de bloqueio (Shutts 1983; Mullen 1987; Nakamura and Wallace 1993; Renwick and Revell 1999). Blackmon et al (1986), mostrou que seis entre oito eventos analisados foram precedidos em 1 dia por uma explosiva ciclogênese corrente acima onde se formou o bloqueio.

Entretanto, a hipótese de que bloqueios atmosféricos formam-se somente pela interação com fenômenos de alta freqüência nunca foi totalmente comprovada. Por exemplo, Konrad and Colucci (1989) encontraram fortes vínculos entre os processos de ciclogênese e a formação de bloqueios. No entanto, verificaram que este processo não foi responsável pela totalidade dos casos com formação de um anticiclone de bloqueio. Assim, outra linha de pesquisa e mais recente, aborda a importância da interação com fenômenos de baixa freqüência, escalas maiores do que a escala sinótica, onde bloqueios são vistos como ondas planetárias quase-estacionárias e de grande amplitude (Austin 1980; Karoly 1983; Lindzen 1986; Lejeñas e Doos 1987; Lejeñas e Madden 1992; Stewart 1993; Nakamura 1994; 
Ambrizzi et al 1995; Naoe et al 1997; Nakamura et al 1997; Nascimento e Ambrizzi 2002). Renwick and Revell (1999) produziram dados robustos que sugerem que bloqueios na região leste do Pacífico Sul podem estar ligados com a propagação de ondas de Rossby forçadas por convecção tropical. Nakamura (1994) lançou a hipótese de que a absorção local da atividade de onda e sua re-emissão, em associação com a temporária obstrução da propagação de uma onda de Rossby conduz a formação seguida pelo decaimento de intensos bloqueios sobre a Europa, construindo a idéia de quebramento de onda associado com a formação de bloqueios. Nakamura et al. (1997), investigaram a evolução temporal de diversos bloqueios sobre a Europa e Pacífico Norte e isolaram os mecanismos de alta e baixa frequência para avaliar a contribuição de cada processo na amplificação de estruturas de bloqueios. Eles mostraram que os processos de baixa frequência explicam mais de $75 \%$ dos casos com amplificação de bloqueios sobre o Pacífico Norte. Por outro lado, os processos de baixa frequência possuem um papel secundário sobre a Europa. Mais recentemente, Nascimento e Ambrizzi (2002) realizaram um estudo semelhante para o Hemisfério Sul mostrando que em situações que antecedem um bloqueio, existe um máximo de fluxo de atividade de onda no setor longitudinal onde no período seguinte o bloqueio se formaria.

\subsection{OSCILAÇÕES ATMOSFÉRICAS E INTERAÇÕES TRÓPICOS- EXTRATRÓPICOS}

A constatação da existência dos principais padrões de oscilações atmosféricas, como se conhece atualmente, se deve às observações de Sir Gilbert Walker entre as décadas de 1920 e 30. Walker $(1925,1928)$ e Walker e Bliss (1932) abordaram a existência de três grandes oscilações atmosféricas: Oscilação do Atlântico Norte (NAO), Oscilação do Pacífico Norte 
(NPO) e Oscilação do Pacífico Sul (SPO). Lorenz (1951) foi o primeiro a admitir uma característica anular ou zonalmente simétrica para o NAO. Kutzbach (1971), Trenberth e Paolino (1981), e Wallace and Gutzler (1981), utilizaram análises de funções empíricas ortogonais (EOFs) de pressão ao nível do mar para investigar oscilações atmosféricas. Mais recentemente, Thompson and Wallace $(1998,2000)$ mostram que os padrões NAO e Oscilação do Ártico (AO) são equivalentes, devido ao fato de ambas medirem a mesma variabilidade, diferenciando-se apenas na forma da interpretação, "se um fenômeno regional controlado pelo Atlântico (NAO)” ou se "um modo anular com fortes teleconexões no setor do Atlântico (AO)" (Wallace 2000).

Alguns estudos investigaram as relações entre a dinâmica de bloqueios e as oscilações NAO e NPO (Renwick e Wallace 1996a; Wallace 2000; Ogi et al., 2003) e indicam que a variabilidade da $\mathrm{AO}$ está diretamente associada com as variações climáticas de inverno em todas as regiões continentais de médias e altas latitudes. Estas variações não se restringem apenas às condições médias, mas também à variabilidade diária, modulando padrões de precipitações, trajetória de storm tracks, frequência de ocorrência de eventos de bloqueios atmosféricos (Renwick 1998; Renwick and Revell 1999; Wallace 2000), bem como invasões de ar frio (Baldwin et al. 2003a; Wallace 2000) e contribuem eficazmente nas tendências de mudanças no clima observadas durante as décadas mais recentes (Wallace 2000).

No HS, a existência de um padrão de oscilação entre o cinturão de pressão que corta Chile e Argentina em oposição aos mares de Weddell e Bellingshausen já havia sido identificada em Walker (1928). Entretanto, somente nas ultimas décadas com a melhoria na robustez e qualidade dos dados é que tal padrão de oscilação foi corretamente descrito como o modo predominante da variabilidade de baixa freqüência dos extratrópicos no HS (Kidson 1988; Yoden et al. 1987; Shiotani 1990; Hartmann and Lo 1998; Gong and Wang 1999; Fyfe et al. 1999; Shindell et al. 1999; Thompson and Wallace 2000; Baldwin et al. 2003a; Carvalho 
et al. 2005) e denominada de Oscilação Antártica (AAO), similar ao padrão AO sobre o HN. A AAO foi postulada por Gong e Wang (1999) como a quarta oscilação revelada, com um análogo as outras três oscilações reveladas por Walker e Bliss (1932). Gong e Wang (1999) também foram pioneiros em admitir que a AAO pudesse esclarecer os regimes climáticos no HS, de forma similar ao Hemisfério Norte.

Thompson e Wallace (2000) apresentaram evidências de que os modos principais da variabilidade nos dois hemisférios são profundos, zonalmente simétricos ou estruturalmente anulares, composto por dipolos meridionais com nodos centrados na latitude de $45^{\circ}$, envolvendo troca de massa entre latitudes altas e parte de latitudes médias. Por esta razão, estes modos são também conhecidos como "modos anulares" do sul (SAM) e do norte (NAM), e são idênticos a AAO e AO, respectivamente. Entretanto, estes modos se amplificam com a altura e interagem com a baixa estratosfera em determinadas épocas do ano, denominadas de "estações ativas". Thompson e Wallace (2000) mostraram que as estações ativas para o $\mathrm{HS}(\mathrm{HN})$ ocorrem dentro da estação de primavera (inverno) em meados de outubro a dezembro (janeiro a março) quando os modos anulares parecem modular a força da circulação média lagrangeana ou "circulação de Brewer-Dobson" na altura da baixa estratosfera, a coluna total do ozônio e altura da tropopausa sobre as latitudes médias e altas, bem como a força dos ventos alísios dos dois hemisférios. A circulação de Brewer-Dobson é um modelo de circulação atmosférica simples proposta por Brewer (1949) e Dobson (1956) que postula a existência de uma corrente lenta nos meses de inverno que redistribui o escoamento de ar na baixa estratosfera. Este modelo de circulação explica porque a concentração de ozônio acumula-se sobre os pólos.

Thompson et al. (2002) investigando a dinâmica deste acoplamento troposferaestratosfera encontraram evidências de que o enfraquecimento (fortalecimento) do vórtice estratosférico polar de inverno no $\mathrm{HN}$ tende a ser seguido por episódios de temperatura do ar 
de superfície anomalamente baixas (altas) e um incremento da ocorrência de eventos de frio (calor) sobre áreas continentais densamente povoadas da América do Norte, norte da Europa e leste da Ásia. Assim, a AO pode ter um papel fundamental no controle dos mecanismos de formação, manutenção e decaimento dos eventos de bloqueio no $\mathrm{HN}$, bem como, a AAO pode ter forte representatividade no HS. Estas constatações suferem que a variabilidade dos modos anulares e o acoplamento dinâmico da troposfera com a baixa estratosfera não se restringem aos pólos e podem influenciar a evolução sinótica de latitudes médias.

Estudos adicionais têm apresentado relações significativas entre a freqüência de bloqueios e os padrões de teleconexões trópicos-extratrópicos (Blackmon et al. 1986, Renwick e Wallace 1996b, Renwick 1998, Renwick e Revell (1999). Por exemplo, Marques (1996) encontrou um aumento na freqüência de bloqueios no Pacífico Sul durante episódios frios do ENOS. Outros estudos mostraram uma elevada frequiência de bloqueios no Pacifico Sudeste associados aos episódios quentes do ENOS, mas somente na primavera e verão austrais (Rutllant e Fuenzalida 1991; Renwick e Revell 1999; Marques e Rao 2000). Com relação aos modos anulares, Wallace (2000) sugeriu que a fase negativa da AO pode ser construtiva na freqüência de bloqueios nas regiões do Alaska, Atlântico Norte e Rússia e destrutivas na região do Atlântico Norte, pelo fato da AO frequentemente se fortalecer sobre o Atlântico Norte. Carvalho et al. (2005) mostraram a importância das interações trópicosextratrópicos na variabilidade da Oscilação Antarctica (AAO) (Gong and Wang 1999) e respectivas mudanças na circulação dos altos níveis. Fogt et al. (2010) mostraram que as teleconexões com o Pacífico Sul são fortalecidas dependendo da combinação entre o ENOS e a fase diária da AAO (comumente denominada de Modo Anular do Sul - MAS ou SAM, em inglês).

Carvalho et al. (2005) observaram que durante a fase Quente do ENOS (ENOS+) há o quebramento e o enfraquecimento do modo anular, enquanto que durante a fase Fria do ENOS 
(ENOS-) há o fortalecimento do modo anular, em particular sobre o Atlântico e o Índico. Numa escala sinótica, usando um procedimento automatizado desenvolvido por Murray and Simons (1991), eles observaram a importância da AAO nas propriedades dos ciclones extratropicais, como posição e intensidade, no qual verificaram que os ciclones tendem a se formar e se mover em latitudes mais baixas do que a posição climatológica de $40^{\circ} \mathrm{S}$ durante eventos das fases negativas da AAO. Isto pode favorecer quebramentos de ondas de Rossby planetárias e conseqüente formação de bloqueios. A Figura 1.2 mostra exemplos de quebramentos de onda de Rossby extraídos de Berrisford et al., (2006). Entretanto, nenhum estudo até então tem mostrado os efeitos combinados do ENOS e AAO na frequiência de bloqueios atmosféricos. Portanto, é evidente que as relações entre a $\mathrm{AAO}$ e a freqüência de bloqueios necessitam ser exploradas. Este tópico será abordado na parte observacional deste estudo.
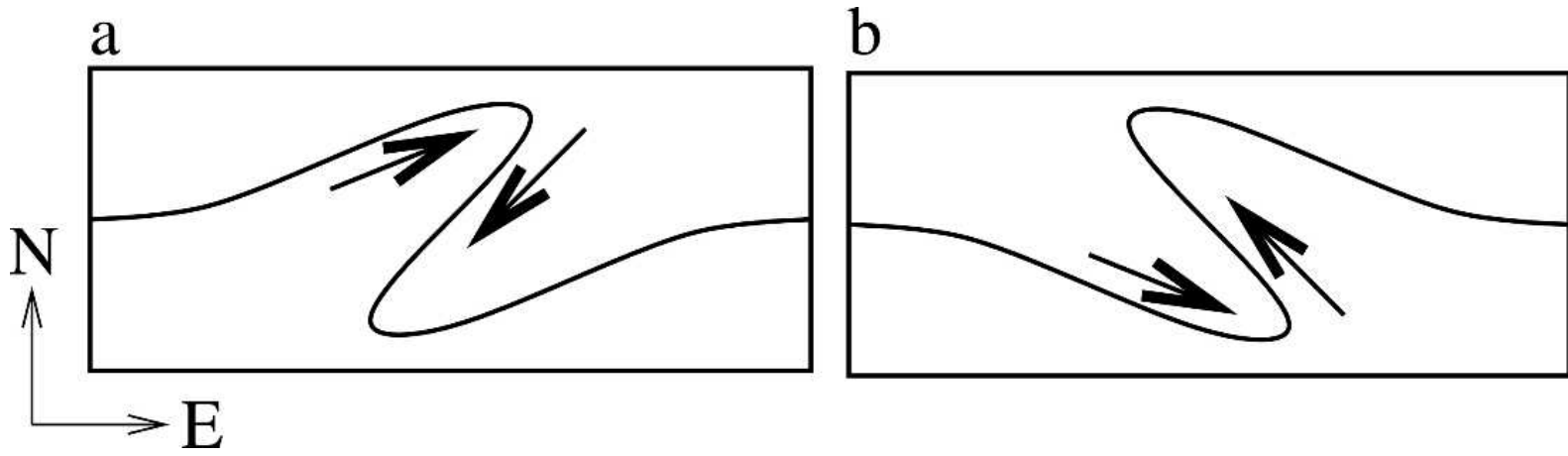

Figura 1.2 - Esquema para o Hemisfério Sul mostrando um quebramento de onda (a) ciclônico e (b) anticiclônico na alta troposfera. Estes exemplos mostram o caso particular da Temperatura Potencial na tropopausa dinâmica onde os contornos não são tão suavizados como na análise da altura geopotencial. Extraído de Berrisford et al., (2006). 


\subsection{MODELOS CLIMÁTICOS E CENÁRIOS FUTUROS}

O projeto para o diagnóstico e intercomparação dos modelos de clima (PCMDI em http://www.pcmdi.llnl.gov) é um portal incentivado pelo Painel Intergovernamental para Mudanças Climáticas (IPCC) que oferece o suporte para os estudos de mudanças climáticas. Neste portal estão disponibilizadas as saídas das rodadas de diversos modelos acoplados de clima com simulações para o clima atual e projeções dos cenários de mudanças climáticas para o restante do século 21 e século 22. O IPCC , desde o seu segundo relatório de avaliação (Second Assessment Report: Climate Change 1995, “AR-2”), tem estimulado a pesquisa de projetos com ênfase na Intercomparação dos Modelos Acoplados de Oceano e Atmosfera (CMIP) para contribuir com o avanço da modelagem da atmosfera, oceano, continentes e gelo marítimo. No portal do PCMDI, alguns dos projetos estimulados para a intercomparação dos modelos de clima são descritos a seguir:

- $\quad$ Projeto para intercomparação dos modelos atmosféricos (AMIP): é o protocolo experimental padrão para os modelos globais de circulação geral da atmosfera (MCGAs). Os AMIP não serão examinados neste trabalho.

- $\quad$ Projeto para intercomparação dos modelos acoplados oceano e atmosfera (CMIP): Os modelos acoplados oceano e atmosfera de circulação geral (MCGAOs) são os mais complexos dos modelos climáticos, envolvem o acoplamento tridimensional dos MCGAs com os modelos de circulação oceânica (MCGOs) e outros modelos que incorporam trocas de calor, momentum, e vapor d’água que ocorrem em superfícies adjacentes de continentes e gelos marítimos ou "sea ice". Esta classe de modelo permite simulações de mudanças climáticas através de ajustes em diversas forçantes climáticas, como por exemplo, o incremento atmosférico do dióxido de carbono $\left(\mathrm{CO}_{2}\right)$ pelas atividades antrópicas. Este projeto teve inicio em 1995 e as versões anteriores coletaram saídas de rodadas do modelo num 
cenário idealizado de aquecimento global onde o conteúdo de $\mathrm{CO}_{2}$ na atmosfera aumentava a uma taxa constante de $1 \%$ ao ano até dobrar no ano 70 da rodada dos modelos. As saídas destas rodadas dos modelos do CMIP estão disponíveis para estudos de projetos. Algumas destas simulações serão investigadas neste trabalho.

Além destes projetos, há o Projeto de Intercomparação de Modelos de Prognóstico Sazonal (SMIP), desenvolvido pelo CLIVAR (Climate Variability and Predictability em http://www.clivar.org) e o Projeto Experimental Aqua-Planet (APE), o qual trata de um ambiente altamente simplificado (somente oceanos) onde o foco das atenções está voltado para a distribuição e a variabilidade da convecção nos trópicos e a trajetória de perturbações atmosféricas transientes de latitudes médias.

O acoplamento do sistema oceano-atmosfera consiste de um sistema altamente integrado, multicomponente, não-linear, e diversas forçantes externas influenciam diariamente a dinâmica deste sistema devido as causas naturais ou pela atividade antrópica. Por exemplo, o aumento das taxas de $\mathrm{CO}_{2}$ na atmosfera aumenta o efeito estufa, e pode alterar o comportamento de diversos mecanismos atmosféricos e elevar as temperaturas do planeta; contudo, a fração que pode ser atribuída a estes gases no aquecimento global é ainda controvertida (Shindell et al. 1999). Conseqüentemente, durante as ultimas décadas a comunidade científica tem tratado de representar estas relações mediante o uso de modelos de circulação geral de Clima. O clima é usualmente caracterizado em termos da média e da variabilidade da temperatura, precipitação e vento variando de meses até milhões de anos, dependendo do referencial do estudo. Em meteorologia o período comumente adotado é de 30 anos. O termo "mudanças climáticas" utilizado pelo IPCC refere-se às mudanças relativas do clima ou de suas propriedades, que possam ser inferidas com o uso de testes estatísticos, mas que persistam por um período extenso, tipicamente décadas ou mais associadas a mudanças nos fatores externos, que podem ser variabilidades naturais (tais como, erupções 
vulcânicas, variação solar, condições térmicas oceânicas) ou resultados da atividade antrópica. No quarto relatório de avaliação do IPCC (Fourth Assessment Report: Climate Change 2007, “AR4"), foi consenso desta comunidade científica o aumento de $\sim 0.6 \pm 0.2^{\circ} \mathrm{C}$ desde o final do século 19, bem como, o aumento na freqüência do número de dias e noites quentes, de ondas de calor e extremos de precipitação sobre os últimos 50 anos.

O IPCC a partir do seu terceiro relatório de avaliação (Third Assessment Report: Climate Change 2001, "TAR”) publicou quatro cenários futuros ou "famílias de cenário", chamados de cenários SRES (Special reports on Emission Scenarios) A1, A2, B1 e B2 que procuram descrever relações entre as forçantes (população, economia, tecnologia, energia, uso da terra e agricultura) propulsoras de emissões de gases (efeito estufa e aerossóis) e sua evolução durante o século 21 para grandes setores regionais e globalmente. Cada cenário representa diferenciadas forçantes, por exemplo, diferentes padrões demográficos e econômicos. Basicamente, os quatro cenários tendem para duas tendências divergentes e irreversíveis: um diverge entre motivações econômicas (A1 e A2) e motivações ambientais (B1 e B2), e outro diverge entre a coordenação global (A1 e B1) e o esforço regional (A2 e B2). Os cenários são ilustrativamente mostrados na Figura 1.3 e individualmente descritos abaixo, conforme (Nakicenovic et al., 2000):

- $\quad$ A1- Um mundo futuro de rápido crescimento econômico com uma população global crescente que atinge cerca de 9 bilhões em 2050 e declina em seguida, e uma rápida introdução de novas e mais eficientes tecnologias. É um mundo que prioriza o crescimento econômico e a coordenação global, mas menor valorização ambiental. A família do cenário A1 desenvolve-se dentro de três grupos ou "sub-famílias" que descrevem caminhos alternativos para mudanças tecnológicas no sistema de energia global, sendo: A1FI o uso intensivo de fontes fósseis, A1T o uso predominante de fontes de energias não-fósseis e A1B o uso equilibrado de fontes de energia. 
- $\quad$ A2- Um mundo heterogêneo com aumento da população global e menor cooperação internacional, orientado regionalmente, de menor desenvolvimento econômico e tecnológico ajustado as condições locais. Ênfase em famílias grandes com menor rendimento pessoal e o aumento das diferenças sociais. É o cenário mais pessimista.

- $\quad$ B1- Um mundo convergente com a mesma população global do cenário A1, mas com a economia voltada para o serviço e informação e o desenvolvimento de tecnologias direcionadas para energia limpa e eficiente. Este é o cenário mais otimista, focado na globalização dos serviços e preocupado com o meio ambiente sustentável.

- $\quad$ B2- Um mundo semelhante ao B1, mas a ênfase é a solução local para as questões econômicas, sociais e o desenvolvimento sustentável. Há pouca cooperação internacional aliada com o continuo crescimento da população global, contudo menor do que no cenário A2, sendo o desenvolvimento econômico apenas intermediário.

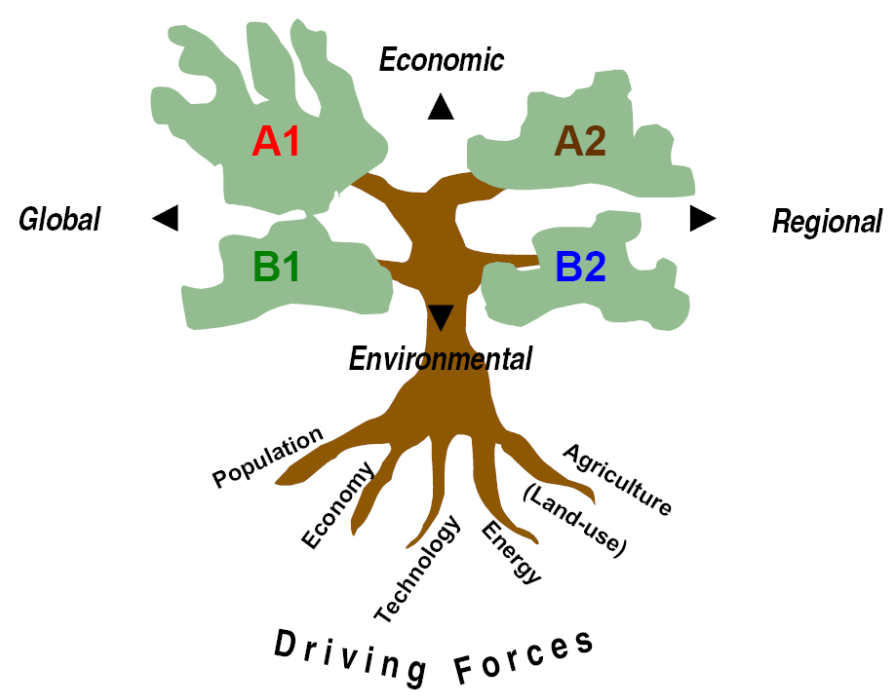

Figura 1.3 - Ilustração esquemática das famílias SRES. Fonte: site do IPCC http://sedac.ciesin.columbia.edu/ddc/observed/images/sres_tree_small.jpg. (Adaptado de Nakicenovic et al. 2000). 


\subsection{OBJETIVOS}

O objetivo principal deste trabalho é examinar em detalhes as características espaçotemporais dos bloqueios no HS durante o período de 1950 a 2007. Além disso, este trabalho investiga o potencial de alguns dos MCGAOs que fazem parte do IPCC em simular realisticamente eventos de bloqueio no clima do século XX e como estes são projetados em cenários futuros de mudanças climáticas. Para este fim, propõe-se um novo índice de bloqueio baseado no método tradicional de Tibaldi et al.,(1994) para investigar bloqueios na região extratropical do HS. Além disso, examinam-se a variabilidade temporal e espacial destes eventos e suas relações com o El Niño/Oscilação do Sul combinado com a Oscilação Antártica.

As principais questões que serão abordadas neste trabalho são:

- Quais as diferenças associadas a frequiência, local preferencial e duração do eventos de bloqueio sob diferentes modulações e intensidades do El Niño/Oscilação do Sul?

- Existem diferenças na atividade de bloqueio no modo combinado ENOS e AAO? Existindo, quais os prováveis mecanismos físicos responsáveis?

- Qual o potencial dos MCGAOs em simular bloqueios no clima presente e quais são as projeções para cenários futuros de mudanças climáticas? Quais as incertezas na previsão destes cenários?

O trabalho está organizado da seguinte forma. O capítulo 2 apresenta o conjunto de dados e discute o índice de bloqueio usado nas análises. O capítulo 3 mostra a climatologia de bloqueios com enfoque na variabilidade espacial e interanual da atividade de bloqueio. Também são discutidas tendências e influência combinada da AAO e ENSO. O capítulo 4 explora a capacidade dos MCGAOs em simular os principais aspectos de bloqueios, como freqüência de ocorrência, longitudes preferenciais e durabilidade para o clima presente (1980- 
2000) e cenário futuro de mudanças climáticas (2050-2070). Conclusões e recomendações para trabalhos futuros são apresentadas no capítulo 5. 


\section{CAPítulO 2}

\section{DADOS E METODOLOGIA}

A climatologia de bloqueios no Hemisfério Sul foi obtida com base em 59 anos (19492007) de dados médios diários da altura geopotencial ao nível de 500 hPa da reanálise I do National Center of Environmental Prediction - National Center for Atmospheric Research (NCEP/NCAR) com resolução horizontal de 2,5 x 2,5 graus de latitude por longitude. A descrição do índice de bloqueio e a definição dos setores de bloqueio são apresentadas a seguir:

\section{1 ÍNDICE DE BLOQUEIO}

O índice de Bloqueio usado neste estudo foi uma adaptação de Tibaldi et al., (1994) (doravante denominado T94). Este índice tem sido largamente empregado em diversos estudos sobre bloqueios atmosféricos (e.g, Nascimento e Ambrizzi 2002, Damião 2008 e Matsueda et al., 2010 para o HS e Trigo et al 2004 e Barriopedro et al. 2005 para o HN) e operacionalmente pelo National Weather Services (NWS/CPS/NOAA). O método foi originalmente proposto por Lejeñas (1984) para o HS, conforme discutido anteriormente. De acordo com Lejeñas (1984) a condição básica para a difluência do escoamento zonal é observada quando o valor médio do índice de bloqueio for negativo entre $30^{\circ} \mathrm{S}$ e $50^{\circ} \mathrm{S}$ e ao longo de $30^{\circ}$ de longitude. Contudo, T94 encontrou que algumas baixas desprendidas 
deslocadas anomalamente para latitudes polares também poderiam resultar em valores negativos pelo índice de Lejeñas (1984). Para excluir esta possibilidade T94 adicionou a este critério um valor limiar negativo de gradiente da altura geopotencial ao sul de $50^{\circ} \mathrm{S}$. De acordo com este método, dois gradientes de altura geopotencial dados por GHGS e GHGN devem ser calculados para cada ponto de longitude, como segue:

$$
\begin{aligned}
& \operatorname{GHGN}(\lambda)=\frac{Z\left(\phi_{0}\right)-Z\left(\phi_{N}\right)}{\phi_{0}-\phi_{N}}>0(E q .4) \\
& \operatorname{GHGS}(\lambda)=\frac{Z\left(\phi_{S}\right)-Z\left(\phi_{0}\right)}{\phi_{S}-\phi_{0}}<-10\left[m .\left({ }^{0} \text { lat }\right)^{-1}\right](\text { Eq. 5) }
\end{aligned}
$$

Onde: $\phi_{N}=35^{0} s+\Delta, \phi_{0}=50^{0} s+\Delta, \phi_{s}=65^{0} s+\Delta, e \Delta=0^{0}, \pm 2,5^{0}, \pm 5^{0}$

Onde $\mathrm{Z}, \lambda$ e $\phi$ são as alturas geopotenciais em 500-hPa, longitude e latitude, respectivamente. O índice Norte (GHGN) é o gradiente da altura geopotencial em $500 \mathrm{hPa}$ sobre as latitudes médias, similar ao proposto por Lejeñas (1984) e o índice Sul (GHGS) é o gradiente da altura geopotencial em $500 \mathrm{hPa}$ sobre as latitudes altas, criado como uma condição imposta para assegurar a exclusão de escoamentos não-bloqueados, ou seja, o GHGS impõem a presença de um alticiclone no flanco sul da região bloqueada. Os cinco deltas de latitude $(\Delta s)$ resolvidos numa grade com resolução horizontal de $2,5^{\circ}$ x $2,5^{\circ}$ do NCEP/NCAR representam uma melhoria adicional na detecção de eventos com relação ao método original de T94, o qual possuía somente três $\Delta$ s resolvidos numa grade com resolução de $3,75^{\circ} \times 3,75^{\circ}$. Adicionalmente, o índice de bloqueio foi subdividido em três bandas zonais de latitude, tais como: latitudes médias-baixas $\left(\lambda, \phi_{b}\right)$, latitudes médias $\left(\lambda, \phi_{m}\right)$ e latitudes médias-altas $\left(\lambda, \phi_{a}\right)$. Eles representam os máximos locais da altura geopotencial para as seguintes latitudes centrais de referência $\phi_{b}=45^{\circ} S, \phi_{m}=\phi_{o}=50^{\circ} S \pm 2.5^{0}$, e $\phi_{a}=$ $55^{\circ} S$. A Tabela 2.1 resume os limites norte e sul destas bandas zonais. Notar que a distância latitudinal entre as latitudes médias-baixas e médias-altas é de aproximadamente 10 graus, um 
escala razoável na detecção de sistemas sinóticos (> $1.000 \mathrm{~km})$. Também observar que as bandas zonais sobre média-baixas e médias-altas estão fixadas sobre uma latitude específica central, enquanto alguma variação é permitida para a banda zonal de latitude central. Desta forma, a variação latitudinal é investigada comparando os resultados de cada banda zonal.

Tabela 2.1 - Propriedades locais das bandas zonais, suas respectivas latitudes centrais de referência "constante", número de deltas (variação latitudinal) e os limites latitudinais para cada banda zonal aplicados ao Índice de Bloqueio.

\begin{tabular}{|c|c|c|c|}
\hline Bandas Zonais & Latitudes de referência & Número de deltas & Limites latitudinais \\
\hline Médias-baixas & $\left(\lambda, \phi_{\mathrm{b}}\right), \phi \mathrm{b}=45^{\circ}$ & 1 & $30.0^{\circ} \mathrm{S}-45.0^{\circ} \mathrm{S}$ \\
\hline Médias & $\left(\lambda, \phi_{\mathrm{m}}\right), \phi_{\mathrm{m}}=50^{\circ}$ & 3 & $32.5^{\circ} \mathrm{S}-52.5^{\circ} \mathrm{S}$ \\
\hline Médias-altas & $\left(\lambda, \phi_{\mathrm{a}}\right), \phi_{\mathrm{a}}=55^{\circ}$ & 1 & $40.0^{\circ} \mathrm{S}-55.0^{\circ} \mathrm{S}$ \\
\hline Total & $\left(\lambda, \phi_{\mathrm{T}}\right), \phi_{\mathrm{T}}=50^{\circ}$ & 5 & $30.0^{\circ} \mathrm{S}-55.0^{\circ} \mathrm{S}$ \\
\hline
\end{tabular}

De modo geral, a análise subdividida em bandas zonais pode melhorar o rastreamento do escoamento anômalo de leste pela inspeção em várias latitudes do HS e determinar a variabilidade latitudinal dos bloqueios ao longo por ponto de longitude. Isto pode ser evidenciado pelo fato do escoamento anômalo de leste ser de fato a região central da complexa estrutura do bloqueio, o qual corresponde a um anticilone de bloqueio situado no flanco Sul e uma ou duas baixas frias despreendidas no flanco Norte da estrutura complexa de bloqueio, conforme a Figura 1.1.

Na Tabela 2.1, o termo total do índice de bloqueio é representado por cinco deltas, uma generalização de T94, tal como em Trigo et al., (2004). Desta forma, representa o total de detecções do escoamento bloqueado entre $30^{\circ} \mathrm{S}$ e $55^{\circ} \mathrm{S}$ para cada ponto de longitude. Cada banda zonal foi mostrada na Tabela 2.1 e examinada separadamente. Estudos recentes (Trigo et al., 2004; e Barriopedro et al., 2006) têm sugerido que o uso de cinco $\Delta$ s de latitude deve 
levar a uma maior quantidade de detecções do escoamento bloqueado comparado com o esquema tradicional de T94.

Por uma questão de simplificação para o texto e para incorporar ambas as condições num único termo, define-se índice de bloqueio como $\operatorname{IB}(\lambda)$, dado por:

$$
I \mathcal{B}(\lambda)=G H G N>0 \text {, se } G H G S<-10 \mathrm{gpm} /{ }^{\circ} \text { lat }(\text { Eq. 6) }
$$

Aqui, $I \mathcal{B}(\lambda)$ é definido como o "Índice de Bloqueio" calculado no local e instantâneo para cada ponto de longitude que satisfaz pelo menos um $\Delta$ sobre uma determinada longitude. Em outras palavras, sempre que a condição da Eq. 6 for satisfeita para um determinado ponto de longitude, considera-se que ocorreu um dia com escoamento bloqueado para aquela longitude. A Figura 2.1 mostra um esquema com bloqueios variando latitudinalmente, conforme as alterações sugeridas por este trabalho.

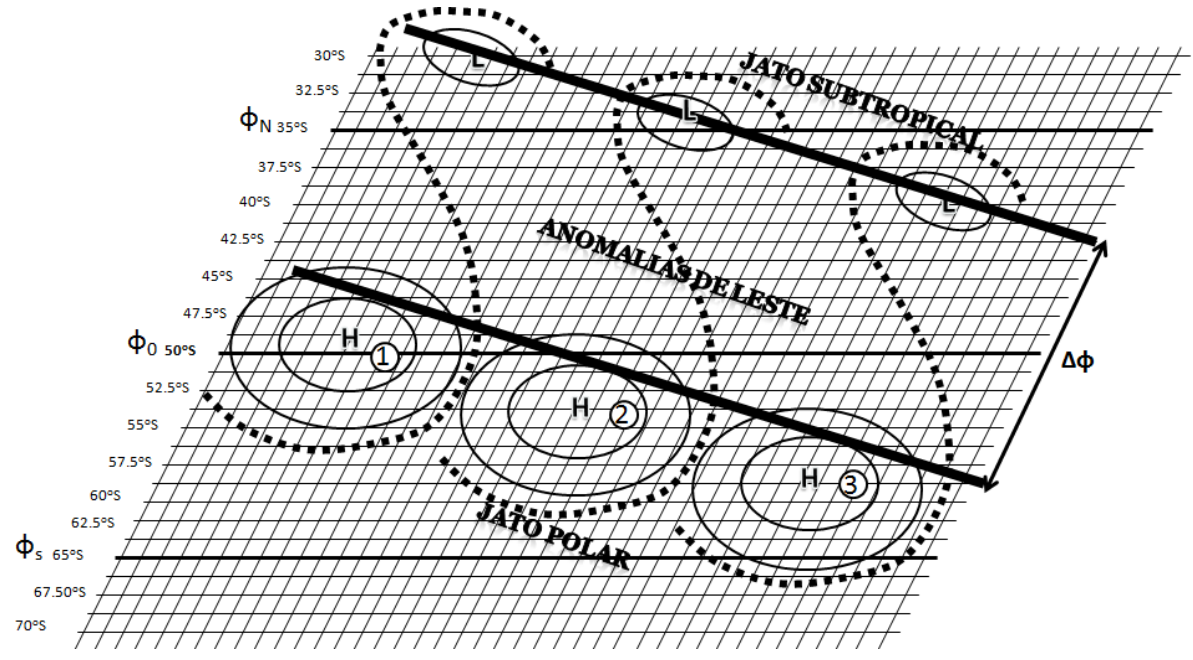

Figura 2.1 - Esquema representativo das bandas zonais do Índice de Bloqueio mostrando estruturas simples de bloqueios sobre diferentes latitudes. Na Figura, os números (1), (2) e (3) representam bloqueios sobre latitudes médias-baixas, médias e médias-altas, respectivamente e posicionados tal como são calculados. As linhas pretas grossas representam a variação latitudinal $(\Delta \phi)$. As linhas tracejadas indicam a perturbação no escoamento de oeste no entorno da estrutura de bloqueio. No centro do sistema existem anomalias de leste.

O termo $I \mathcal{B}(\lambda)$ da Eq.6 também não leva em consideração a duração e a extensão longitudinal dos eventos de bloqueio. O termo duração $(\tau)$ é definido aqui como a persistência 
(em dias) do $I \mathcal{B}(\lambda)$ para um evento paticular de bloqueio. Neste estudo, foi considerado um evento de bloqueio quando $I \mathcal{B}(\lambda)$ é detectado por pelo menos $15^{\circ}$ graus de longitude, incluso a longitude $\lambda$, e tem duração de pelo menos $\tau=3$ dias, como sugerido por Elliot ad Smith (1949) embora que outros autores tenham usado quatro (Pelly e Hoskins, 2003; Berrisford et al., 2006), cinco (Treidl et al., 1981; Tibaldi e Molteni 1990; T94; D’Andrea et al., 1998) e dez dias (Rex, 1950a). O critério adotado de três dias pode ser mais apropriado para o HS devido a natureza mais transiente da circulação neste hemisfério, comparativamente ao HN. Essa discussão será retomada no capítulo 3. Uma análise de escala foi realizada para a extensão longitudinal mínima de bloqueios $\left(L_{\mathcal{B}}\right)$ requerida pelo presente método. Assim, o raio de deformação de Rossby fornece um valor limiar da escala longitudinal para eventos de bloqueio $\left(L_{R}\right)$. Observa-se que $L_{\mathcal{B}}$ corresponde aproximadamente a 1200 e $1100 \mathrm{~km}$ sobre $\phi_{b}$ e $\phi_{a}$, respectivamente, sendo $L_{\mathcal{B}} \geq L_{R}$.

\subsection{SETORES DE OCORRÊNCIA DE BLOQUEIOS}

Estudos anteriores mostram que eventos de bloqueios são mais frequentes em específicas regiões do HS (Van Loon 1956; Lejeñas 1984; T94; Sinclair 1996; Marques 1996). Estes bloqueios podem não ser completamente estacionários e podem experimentar algum deslocamento zonal e meridional. Para investigar a variabilidade espacial dos bloqueios no HS, foram considerados cinco setores de ocorrência: Oceano Índico Sudeste (SB1), Oceano Pacífico Sudoeste (SB2), Oceano Pacífico Central (SB3), Oceano Pacífico Sudeste (SB4) e Oceano Atlântico Sudoeste (SB5). Ademais, o Pacífico Sul foi subdividido nas seguintes regiões: Pacífico Oeste (SB2 + metade oeste de SB3) e Pacífico Leste (metade 
leste de SB3+SB4). A Figura 2.2 detalha as extensões longitudinais em termos dos setores e regiões.

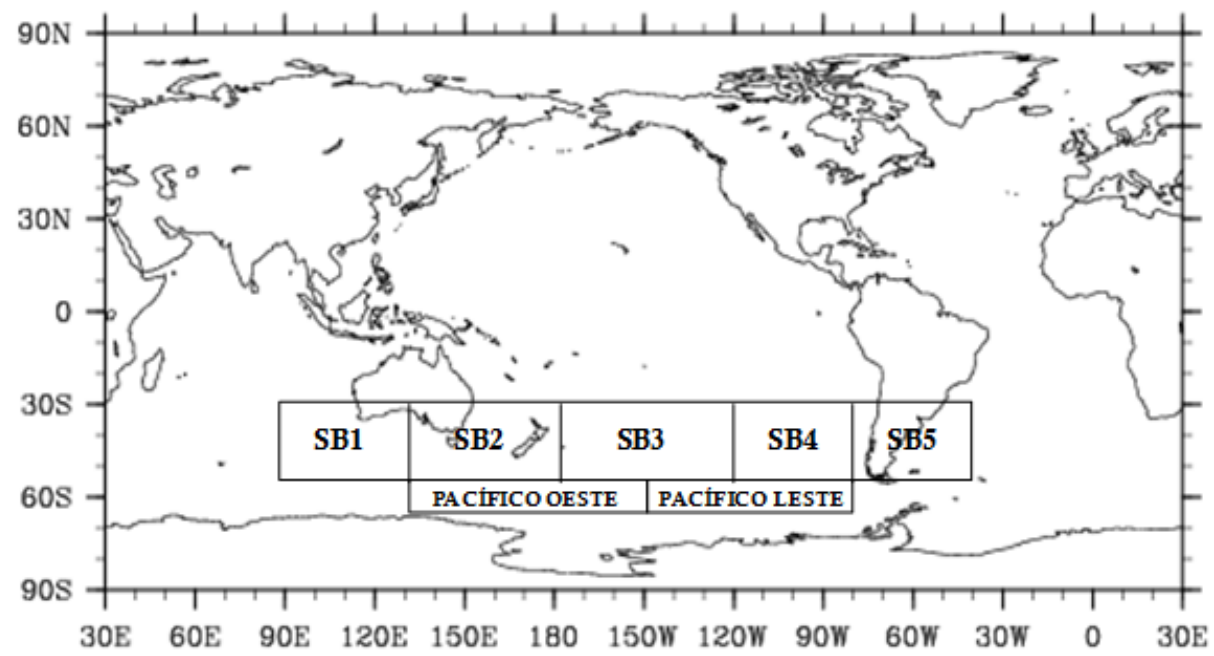

Figura 2.2 - Representação esquemática dos "Setores" de bloqueio do Índico Sudeste (SB1 $\left[90^{\circ} \mathrm{E}-\right.$ $\left.127.5^{\circ} \mathrm{E}\right]$ ), Pacífico Sudoeste (SB2[130 $\left.{ }^{\circ} \mathrm{E}-180^{\circ} \mathrm{E}\right]$ ), Pacífico Central (SB3[177. $\left.5^{\circ} \mathrm{W}-120^{\circ} \mathrm{W}\right]$ ), Pacífico

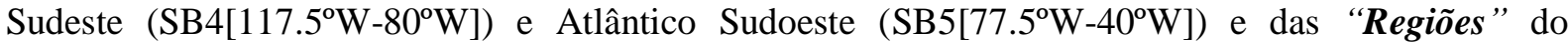
Pacífico Oeste $\left[90^{\circ} \mathrm{E}-150^{\circ} \mathrm{W}\right]$ e Pacífico Leste $\left[150^{\circ} \mathrm{W}-80^{\circ} \mathrm{W}\right]$.

\subsection{VARIABILIDADE INTERANUAL DE BLOQUEIOS E ENOS}

O ENOS consiste das fases Neutra, Quente (ENOS+) e Fria (ENOS-). Para identificar estes três padrões no Pacífico Tropical nós usamos dois métodos diferentes e comparamos os resultados. O método aplicado para os estudos observacionais com reanalises foi o Índice Oceânico do Niño (ONI), o qual é utilizado pelo National Oceanic and Atmospheric Administration (NOAA). O método aplicado na identificação das fases do ENOS nas saídas dos MCGAOs foi baseado na análise de Funções Empíricas Ortogonais (EOF) rotacionada, como será abordadado no Capítulo 4. O procedimento de cálculo da EOF rotacionada foi realizado tal como em Wilks (2006). 
O índice ONI baseia-se na análise da média móvel de 3 trimestres das anomalias das temperaturas de superfície do mar (TSM) sobre a região do Niño $3.4\left(5^{\circ} \mathrm{N}-5^{\circ} \mathrm{S}, 120^{\circ}-170^{\circ} \mathrm{W}\right)$. Neste trabalho, fases opostas do ENOS foram classificadas quando o valor limiar de $\pm 0.5^{\circ} \mathrm{C}$ ocorreu em cinco trimestres consecutivos, iniciando a análise durante o primeiro trimestre do inverno e extendendo até ultimo trimestre do verão. $\mathrm{O}$ argumento parte do principio de que um típico ENOS geralmente tem inicio entre os trimestres de outono/inverno e atinge a maturidade nos trimestres de primavera/verão. Os episódios de ENOS foram então divididos de acordo com a intensidade em fracos $\left(|0,5|-|0,9|^{\circ} \mathrm{C}\right)$, moderados $\left(|1,0|-|1,8|^{\circ} \mathrm{C}\right)$ e fortes $\left(\geq|1,9|^{\circ} \mathrm{C}\right)$

A Tabela 2.2 apresenta a classificação do período de 1949 a 2007 (59 anos), de acordo com o respectivo critério. Foram classificados 13 episódios Neutros (19 anos), 16 episódios com ENOS+, divididos em 5 fracos (6 anos), 8 moderados (10 anos) e 3 fortes ( 3 anos); e 16 episódios de ENOS-, divididos em 6 fracos (6 anos), 7 moderados (11 anos) e 3 fortes (4 anos). O principal objetivo foi encontrar relações entre a intensidade do ENSO e diferentes regimes de atividade de bloqueios.

Tabela 2.2 - Classificação das fases do ENOS de acordo como índice oceânico (ONI). Os anos separados por "-" indicam episódios de longa duração, e os anos separados por “"” indicam episódios de curta duração.

\begin{tabular}{|c|c|c|c|c|c|c|c|}
\hline & fase Quente & & & fase Fria & & \multirow{2}{*}{\multicolumn{2}{|c|}{ fase Neutra }} \\
\hline Fracos & Moderados & Fortes & Fracos & Moderados & Fortes & & \\
\hline $1951 / 52$ & $1957-59$ & $1972 / 73$ & $1961 / 62$ & $1949-51$ & $1954-56$ & $1952-54$ & $1993 / 94$ \\
\hline $1969 / 70$ & $1963 / 64$ & $1982 / 83$ & $1967 / 68$ & $1964 / 65$ & $1973 / 74$ & $1956 / 57$ & $1996 / 97$ \\
\hline $1976-78$ & $1965 / 66$ & $1997 / 98$ & $1983 / 84$ & $1970-72$ & $1988 / 89$ & 1959-61 & $2001 / 02$ \\
\hline $1992 / 93$ & $1968 / 69$ & & $1995 / 96$ & $1974-76$ & & $1962 / 63$ & $2003 / 04$ \\
\hline \multirow[t]{4}{*}{$2004 / 05$} & $1986-88$ & & $2000 / 01$ & $1984 / 85$ & & $1966 / 67$ & $2006 / 07$ \\
\hline & $1991 / 92$ & & 2005/06 & 1998-00 & & $1978-82$ & \\
\hline & $1994 / 95$ & & & 2007--- & & $1985 / 86$ & \\
\hline & $2002 / 03$ & & & & & 1989-91 & \\
\hline
\end{tabular}




\section{CAPÍtULO 3}

\section{CLIMATOLOGIA DE BLOQUEIOS NO HEMISFÉRIO SUL}

Um dos principais objetivos deste capítulo é a determinação da escala de tempo típica dos eventos de bloqueio no HS. Como discutido no Capítulo 2, o período mínimo de duração de um caso de bloqueio adotado na literatura especializada é 3 a 10 dias. Contudo, 5 dias tem sido considerado ideal na maioria dos estudos. No presente trabalho adotamos a aproximação discutida em Pelly e Hoskins (2006) para determinar a escala de tempo típica de eventos de bloqueio no HS. Esta consiste em um ajuste linear entre o número de eventos em escala logarítmica e duração dos mesmos. O intervalo típico é estimado pelo decaimento linear (gradiente) deste ajuste.

A Figura 3.1a mostra o número total de eventos detectados por ponto de longitude e distribuídos dentro de cada banda zonal, conforme o método discutido anteriormente, sem considerar sazonalidade. Pode ser observado que, a duração dos eventos decresce de forma exponencial, enquanto que o decaimento é mais suavizado nas latitudes médias-altas, indicando que os eventos tendem a ser mais persistentes sobre latitudes mais altas. Na Figura 3.1b, os mesmos dados são dispostos em escala logarítmica de base e. Assim, ressalta-se agora um decaimento linear e não mais exponencial. A estes dados ajustou-se uma regressão linear entre os pontos com similar decaimento, caso observado entre 3 a 10 dias nas latitudes médias e médias-altas e de 3 a 7 dias nas latitudes médias-baixas. A escala de tempo típico de bloqueios é assumida como o inverso do valor negativo do gradiente. A escala típica de bloqueios representa a evolução temporal dos eventos de bloqueio desde a primeira detecção 
até o ultimo dia. Desta forma, a escala típica não deve ser confundida com a duração média dos eventos, o qual considera uma distribuição a partir de um valor mínimo de dias (um critério pré-definido, por exempo, três ou cinco dias). Assim, o uso da escala típica não se restringe as distribuições de longa duração.

Assim, encontrou-se o valor típico de $\tau=2.4$ dias sobre latitudes médias e médiasaltas e de apenas 1,5 dias sobre latitudes médias-baixas. A escala típica de bloqueios está associada aos processos atmosféricos lentos, tais como, o decaimento adiabático (Pelly e Hoskins, 2003) e a constante absorção e re-emissão de ondas de Rossby quase-estacionárias e de grande amplitude (Nakamura, 1994). Devido à natureza muito mais intensa da circulação da troposféra no HS (Trenberth, 1996), estes processos atmosféricos são naturalmente menos lentos do que aqueles observados no HN. Desta forma, considerando as diferenças entre os dois hemisférios, um evento igual ou superior a 2.5 dias representa um valor razoável para o HS.

Neste trabalho consideramos o limiar de $\tau \geq 3$ dias como escala típica de um evento de bloqueio, para todas as estações do ano. Estes resultados são consistentes com aqueles de 2,0 a 2,5 dias sobre latitudes altas obtidos por Berrisford et al., (2006) para o inverno (JJA) do HS. Por outro lado, Pelly e Hoskins (2003) identificaram que o valor de 3.9 dias corresponde a escala típica de um evento de bloqueio no $\mathrm{HN}$, representando quase o dobro da escala típica encontrada para o HS. Considerando a natureza da circulação intensa na troposfera do HS, o valor de 3 dias mostra-se razoável. Ademais, os resultados sugerem que os eventos de bloqueio sobre latitudes mais altas são em média 1 dia mais persistentes do que aqueles formados sobre latitudes mais baixas. 

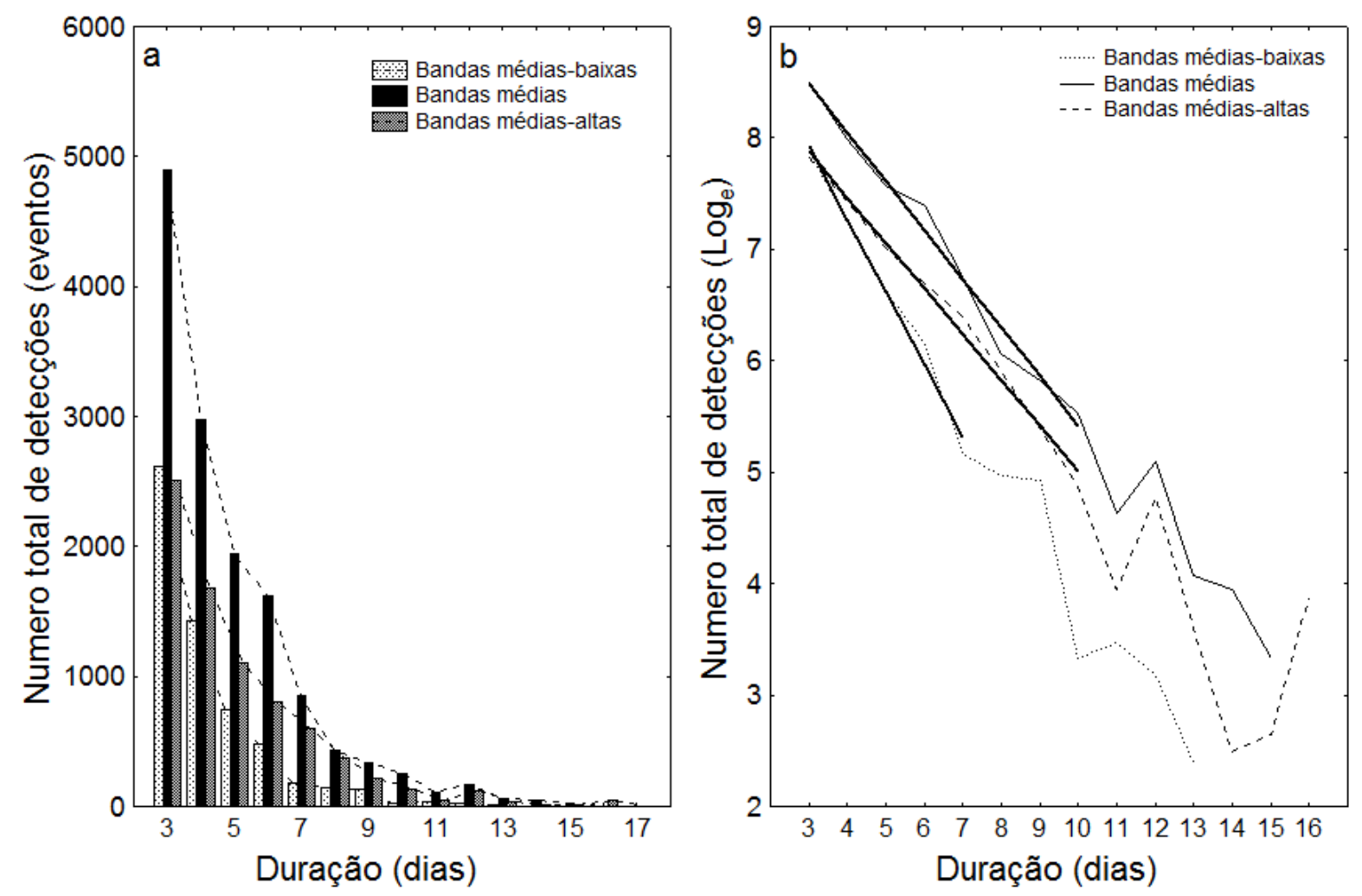

Figura 3.1 - Distribuição do número total de detecções de eventos com escoamento bloqueado por ponto de longitude. a) Número total de detecções de eventos. b) Número total de detecções de eventos em escala logarítmica de base e. As legendas no topo (à direita) indicam as bandas zonais.

A Tabela 3.1 mostra a distribuição sazonal do número total de dias com escoamento bloqueado, número total de eventos com $\tau \geq 3$ dias durante os 59 anos de estudo. Aproximadamente em $11 \%$ dos dias bloqueados foram detectados bloqueios duplos (dois eventos ocorrendo simultâneamente sobre diferentes setores). Enfatiza-se a maior e menor freqüência durante o inverno e verão com números médios de eventos de 10.9 e 6.4 eventos/ano, respectivamente. O valor médio anual foi de 8.6 eventos/ano, representando uma média inferior ao encontrado por Wiedenman et al., (2002) (9.7 eventos/ano) e superior ao encontrado por Damião (2007) ( 7 eventos/ano) e Marques e Rao (2001) ( 6 eventos/ano). Ressalta-se que todos estes trabalhos consideraram eventos com duração mínima de cinco dias. 
Tabela 3.1 - Distribuição sazonal do número total de dias com escoamento bloqueado, número de eventos com $\tau \geq 3$ dias e média de eventos/ano obtidos para os 59 anos da reanálise-I do NCEP/NCAR.

\begin{tabular}{lccc}
\hline \hline & Dias & Eventos & Eventos/ano \\
\cline { 2 - 4 } Outono & 3.003 & 550 & 9,5 \\
Inverno & 3.900 & 633 & 10,9 \\
Primavera & 2.765 & 433 & 7,5 \\
Verão & 2.368 & 371 & 6,4 \\
\hline
\end{tabular}

\subsection{COMPARAÇÃO COM OUTROS MÉTODOS}

Para exemplificar a aplicação do presente método e verificar a importância de cada banda zonal indicada na Tabela 2.1, investigamos os invernos de 1986-1987. Este período foi escolhido devido ao bem documentado evento de bloqueio discutido em Marques e Rao (1999) o qual persistiu por 21 dias (referido aqui como evento e1). A Figura 3.2 mostra diagramas de Hovmöller para ilustrar o total de dias com escoamento bloqueado sobre três distintas bandas zonais: (a) Esquema T94, usualmente adotado pelo NWS/CPC/NOAA com resolução horizontal de $5,0^{\circ} \times 5,0^{\circ}$ da reanálise do NCEP/NCAR e três deltas; (b) Esquema adotado para a banda de latitudes médias com resolução horizontal de $2,5^{\circ}$ x $2,5^{\circ}$ e três deltas; c) Esquema adotado para a banda de latitudes médias-baixas com resolução horizontal de $2,5^{\circ}$ x $2,5^{\circ}$ e um único delta; (d) Esquema adotado para a banda de latitudes médias-altas resolvido com resolução horizontal de $2,5^{\circ}$ x $2,5^{\circ}$ e um único delta. $\mathrm{Na}$ base de cada diagrama hovmöller, são mostradas a frequência relativa dos dias com escoamento bloqueado por ponto de longitude. Assim, o gráfico de frequência relativa na figura 3.2a se refere ao escoamento bloqueado para o esquema T94. Nos gráficos da frequência relativa (b), (c) e (d) comparam-se a frequência dos dias com escoamento bloqueado de cada banda zonal (linha tracejada) com a 
banda zonal total (linha cheia), de acordo com o método discutido acima. A frequência de dias com escoamento bloqueado para a banda total é igualmente representado nos gráficos de frequência (b), (c) e (d). O diagrama Hovmöller mostra a intensidade do $I \mathcal{B}(\lambda)$ em metros por grau de latitude.

A Figura 3.2 mostra maior frequiência de dias com escoamento bloqueado por ponto de longitude no esquema T94 comparado com o esquema para a banda de latitudes médias. Entretanto, o esquema T94 detectou a mesma frequência com relação à banda total de latitudes, que usa 5 deltas, como ilustrado nas Figuras 1b, 1c e 1d. Este resultado mostra que não existem diferenças relevantes entre os métodos com $5 \Delta^{\prime}$ 's e $3 \Delta$ 's no que diz respeito ao número total de dias com escoamento bloqueado. Contudo, a grande diferença observada entre a banda total e a banda de latitudes médias evidencia a existência de forte variabilidade zonal sobre toda a extensão longitudinal do Pacífico Sul. Com respeito à intensidade média do gradiente foram observados valores mais intensos nas bandas de latitudes-médias quando comparada com o esquema T94. A mais alta resolução horizontal nas latitudes médias $\left(2,5^{\circ} \times 2,5^{\circ}\right)$ em comparação com o esquema T94 $\left(5^{\circ} \times 5^{\circ}\right)$ tende a aumentar o valor do gradiente médio. Em alguns casos, o valor médio pode ser negativo (Eq.6) e neste caso o evento não é representado no diagrama de Hovmöller. 

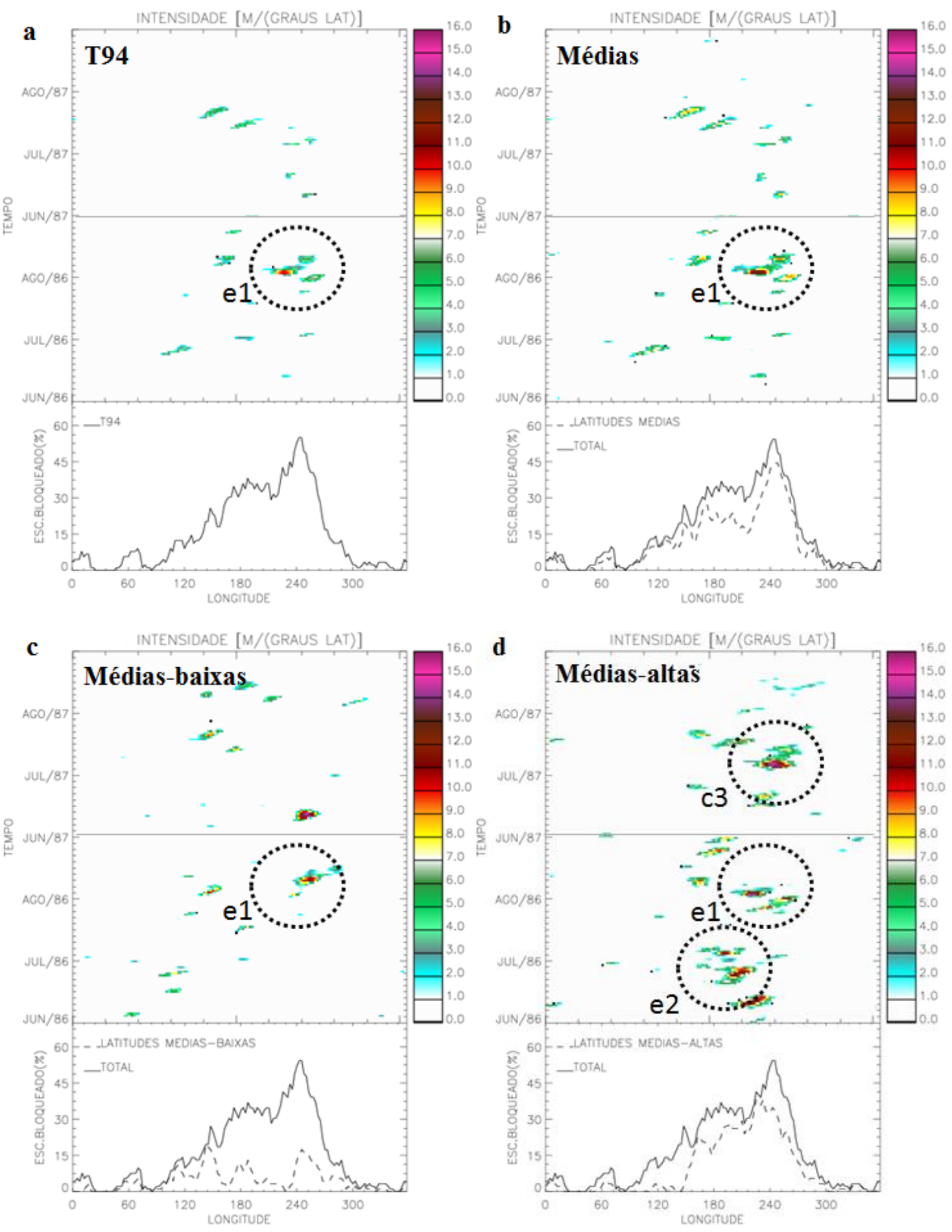

Figura 3.2 - Diagrama Howmöller (tempo-longitude) da intensidade do escoamento bloqueado $\left(\mathrm{m} /{ }^{\circ}\right.$ latitude) e a respectiva frequência relativa (na base do Hovmöller) de dias bloqueados para os invernos austrais de 1986 e 1987: (a) Esquema T94; (b) banda das latitudes médias; (c) banda das latitudes médias-baixas e (d) banda das latitudes médias-altas. A linha sólida no centro do Howmöller representa a região de descontinuidade separando os invernos de 1986 e 1987. 
As bandas zonais sobre as latitudes médias-baixas e médias-altas do índice de bloqueio (Fig. 3.2c e 3.2d, respectivamente) mostram distintas intensidades e variabilidade longitudinal do escoamento bloqueado. Notavelmente, nas latitudes médias-altas o índice de bloqueio mostra magnitudes muito mais fortes do que nas latitudes médias-baixas. Outra característica interessante mostrada nas latitudes médias-altas é a detecção de dois novos eventos muito persistentes de bloqueio (e2 e e3), que são representados no diagrama Hovmöller (Fig. 3.2d), mas que não são evidentes em outros esquemas. Os eventos e2 e e3 duraram pelo menos 17 e 14 dias, respectivamente. Ventos de altos níveis e altura geopotencial indicam que os eventos e 2 e e 3 são eventos de dipolo e $\Omega$ invertido de latitudes altas, respectivamente (não mostrado), enquanto o evento e1 foi caracterizado pela grande extensão longitudinal (cerca de 40 graus), bem como pela grande variabilidade latitudinal e isto está bem representado em cada banda de latitude proposta pelo presente método. Também foi observado que cada banda zonal representou diferentes partes do ciclo de vida de um bloqueio de grande-escala. Aqui, surge uma questão interessante. Qual o mecanismo responsável pelo local preferencial longitudinal e a variabilidade norte-sul de um evento particular de bloqueio?

\subsection{BLOQUEIOS NA FASE NEUTRA DO ENOS}

Para comparar as características dos bloqueios em fases distintas do ENOS, foram analisadas variações entre algumas propriedades estatísticas usando como referência o respectivo comportamento observado durante a fase Neutra do ENOS. Assim, a Figura 3.3 ilustra a frequência do escoamento bloqueado por ponto de longitude durante o [a] outono, [b] inverno, [c] primavera e [d] verão na fase Neutra do ENOS e de acordo com as respectivas 
bandas zonais. Os resultados indicam que o local preferencial situa-se em torno da linha de data durante grande parte do ano, exceto no inverno, onde o local preferencial é deslocado para aproximadamente $150^{\circ} \mathrm{W}$. Observa-se do outono para o inverno um aumento na freqüência do escoamento bloqueado na direção do pólo no Pacífico Leste. A frequiência do escoamento bloqueado é reduzida durante o verão, quando os eventos confinam-se sobre latitudes menores no Pacífico Oeste. Note que na primavera o escoamento bloqueado sobre latitudes médias-altas é reduzido no Pacífico Leste em comparação com o aumento da freqüência nas latitudes médias-baixas no Pacífico Oeste.

Estes resultados sugerem que a freqüência e a posição preferencial dependem da sazonalidade e variam latitudinalmente, consistentes com Berrisford et al., (2006). As frequências também são similares aos resultados apresentados na Figura 19a de T94, contudo neste trabalho a maior frequiência é verificada a leste da linha de data durante o inverno e constitui-se no principal diferencial. As variações em longitude e latitude parecem consistente com processos de baixa freqüência associado a um padrão de propagação de trens de ondas que se estendem dos trópicos em direção as altas latitudes do Pacífico Leste (Ambrizzi et al., 1995; Renwick e Revell, 1999; Nascimento e Ambrizzi, 2002), enquanto que a dependência sazonal da freqüência parece estar associada com processos de alta frequência. 

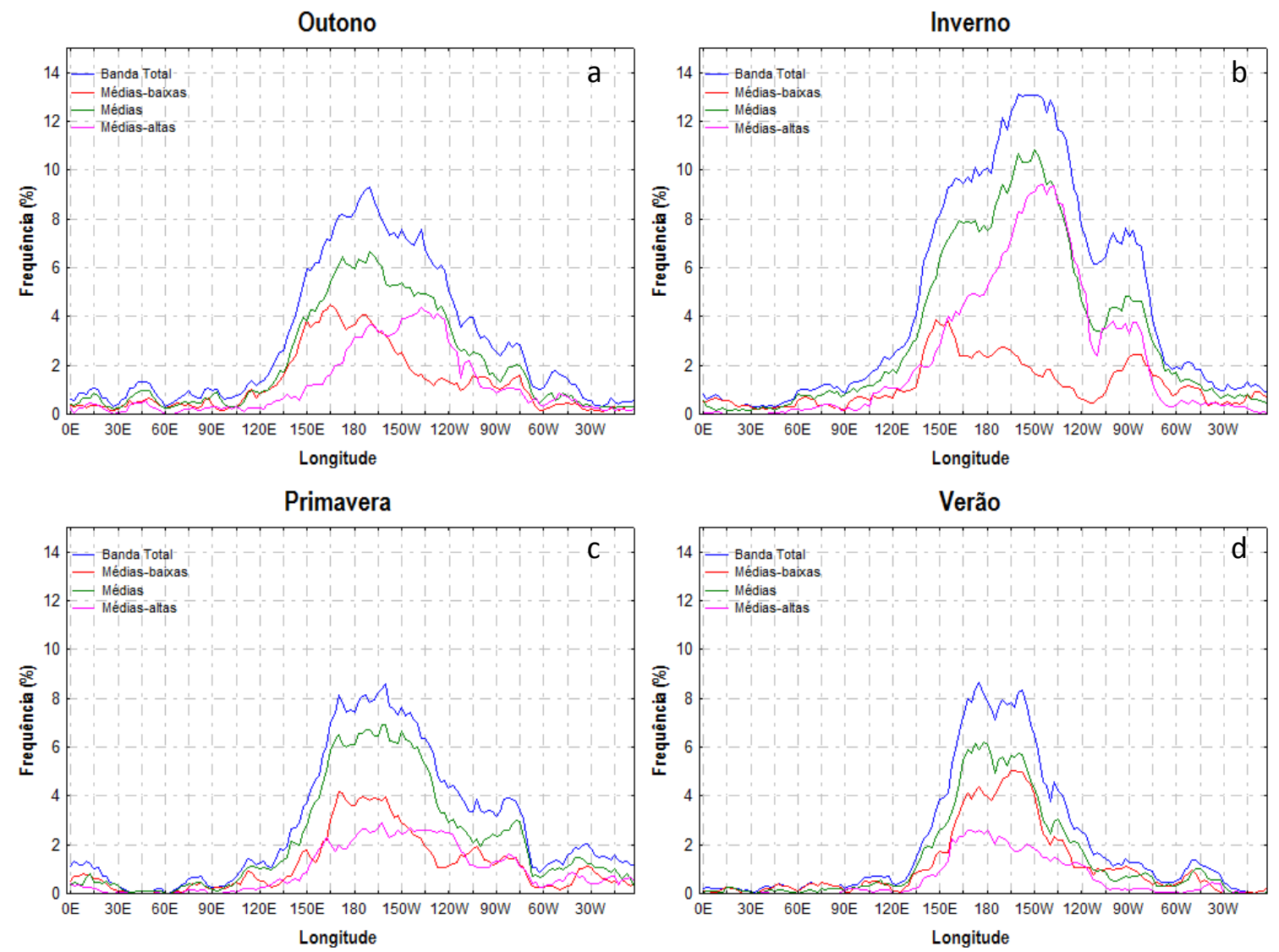

Figura 3.3 - Frequiência relativa do número total de detecções do escoamento bloqueado durante a fase Neutra do ENOS e variando latitudinalmente sobre as bandas zonais: Total (linha azul), médias-baixas (linha vermelha), médias (linha verde) e médias-altas (linha rosa). a) Outono, b) Inverno, c) Primavera e d) Verão.

O total de eventos de bloqueios observados nos 13 episódios Neutros representa aproximadamente $40 \%$ das observações. Para analisar a distribuição destes eventos no espaço bivariado $(\lambda, \tau)$, ou seja pares de longitude $(\lambda)$ versus duração $(\tau)$, utilizou-se o "Bag plot", desenvolvido por Rousseeuw et al. (1999). O Bag plot é uma extensão bivariada do Box plot. O Box plot, introduzido por Tukey (1977) consiste de uma excelente técnica para a Análise Exploratória de Dados.

Com o 'Box plot', importantes características de uma distribuição são facilmente visualizadas, tais como, localização (mediana), dispersão, assimetria e caudas (extremos e observações aberrantes) na forma de uma única coluna. Já o Bag plot generaliza esta coluna do Box plot em duas dimensões. Assim, são mostradas as características do Box plot para 
uma distribuição bivariada, tais como localização (mediana de Tukey), dispersão (tamanho da bolsa), assimetria e caudas e adicionalmente são mostradas medidas de correlação (orientação da bolsa). Isto é feito através do conceito de profundidade da localização no semi-espaço ou "profundidade de Tukey" para um determinado ponto relativo a uma série observacional bivariada, o qual extende o conceito da classificação "rank" univariada. A mediana de Tukey $\left(\mathrm{T}^{*}[\lambda, \tau]\right)$ é o ponto bivariado com a maior profundidade da observação (não necessariamente um ponto com dados, mas o semi-espaço). Desta forma, são inicialmente geradas isolinhas com profundidade $(k)$, contendo um especifico conjunto de dados $D_{k}$ para todo dado bivariado $\{(\lambda, \tau) \geq k\}$. Cada conjunto de dados $D_{k}$ é interpolado linearmente entre $D_{k}$ e $D_{k-1}$, onde rotacionando o semi-plano em $180^{\circ}$ para cada isolinha com $k$ profundidades em relação a $\mathrm{T}^{*}[\lambda, \tau]$ determina-se o número de pontos que caem em ambos os lados. Assim, as regiões com $k$ profundidades e contendo $50 \%$ das observações consiste de uma bolsa poligonal convexa. Expandindo a bolsa por um fator de 1,5 obtem-se a região do laço, "loop" em inglês, um invólucro poligonal convexo que separa as observações que não pertencem à bolsa, mas que não são observações aberrantes, sendo comparável às bigornas do Box plot. A região externa ao laço consiste de observações aberrantes.

O Bag plot da Figura 3.4 mostra a distribuição bivariada (longitude versus duração dos eventos de bloqueio com $\tau \geq 3$ dias) distribuída sazonalmente durante a fase Neutra do ENOS. Somente o último dia de cada evento por ponto de longitude foi retido. Assim, foi observado que a dispersão das observações é maior durante o inverno (Figura 3.4b) e menor durante o verão (Figura 3.4d). A assimetria da bolsa do Bag plot no inverno indicou que os eventos tendem a ter maior duração sobre o Pacífico Leste do que sobre o Pacífico Oeste. Também, a primavera (Figura 3.4c) é a estação com o máximo deslocamento dos eventos para leste da linha de data (ver a mediana bivariada), contudo, a dispersão das observações é pequena em comparação com os meses de outono (Figura 3.4a) e inverno. Os meses de primavera e verão 
têm freqüências similares, mas os eventos de bloqueio durante o verão confinam-se sobre o Pacífico Oeste. Associado a isto, os eventos tem duração mediana em torno de $\sim 5$ dias entre o outono e inverno e de $\sim 4$ dias entre primavera e verão. A diferença de $\sim 1$ dia parece estar relacionada com a progressão e/ou regressão da atividade do escoamento bloqueado variando latitudinalmente (ver Figura 3.3), já que o tempo médio dos eventos é da ordem de 1 dia superior sobre latitudes mais altas (conforme observado anteriormente), sendo então a escala típica de bloqueios consistente com a mediana bi-variada dos eventos. Os 'bag plots' evidenciam a existência de um ciclo sazonal na longitude e na duração dos eventos. Notadamente, os setores do Índico Sudeste (SB1) e do Atlântico Sudoeste (SB2) são regiões com observações aberrantes de curtíssima duração e serão deprezados no restante deste trabalho, salvo algumas excessões. Ainda no Bagplot (Fig. 3.4) é possível identificar a existência de outliers de longa duração entre os setores do Pacífico Central e Pacífico Sudeste durante outono e inverno que parecem coincidir com alta frequiência do escoamento bloqueado sobre latitudes mais altas (ver Figura 3.3). 

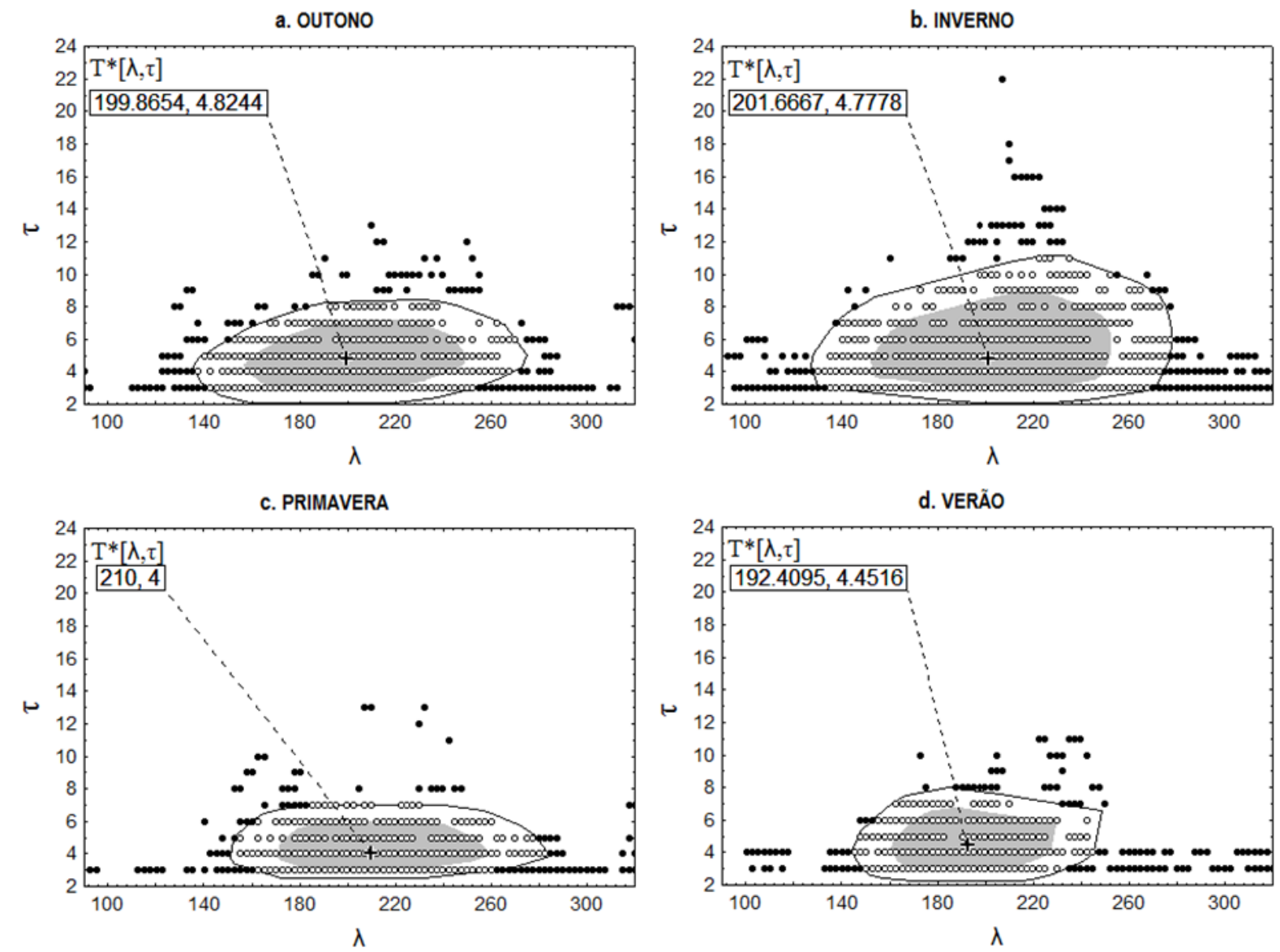

Figura 3.4 - Bagplot [longitude $(\lambda) \mathrm{x}$ duração $(\tau)$ ] da distribuição dos eventos de bloqueio com $\tau \geq 3$ dias pela reanálise do NCEP/NCAR. a) Outono, b) Inverno, c) Primavera, d) Verão. Somente o ultimo dia de cada evento por ponto de longitude foi retido. A bolsa (região cinza) mostra a extensão longitudinal bivariada onde estão $50 \%$ das observações. A cruz no centro da bolsa é a mediana de Tukey. A região branca que envolve a bolsa mostra os dados que estão no limite, similar as longas bigornas do Boxplot. As observações aberrantes são os pontos pretos que estão fora do laço poligonal convexo.

Segundo, van Loon (1964), a região favorável para a ocorrência de bloqueios é onde os jatos subtropical e polar estão zonalmente justaposicionados. A Figura 3.5 mostra o comportamento médio sazonal do vento zonal em 200 hPa durante a fase Neutra do ENOS. Pode-se observar que o jato subtropical é fortalecido no inverno com velocidades de $\sim 50 \mathrm{~m} . \mathrm{s}^{-}$ ${ }^{1}$ e é praticamente inexistente no verão. Segundo, Trenberth (1982) o fortalecimento do jato subtropical no inverno é responsável pelas mudanças na intensidade dos ventos entre as estações. Os ventos mais fracos associados com a bifurcação do jato principal, em torno de $20 \mathrm{~m} \cdot \mathrm{s}^{-1}$ são encontrados sobre a Nova Zelândia durante todo o ano. Isto mostra que o Sul da 
Austrália representa uma região climatológica para a bifurcação do jato. Marques (1996) observou este mesmo comportamento. Deste modo, a bifurcação do jato no Sul da Austrália é claramente observada desde o outono até a primavera, o que explica a maior freqüência relativa dos eventos de bloqueios no entorno da linha de data. Por outro lado, no verão há a desintensificação deste processo, o que pode estar contribuindo para o confinamento da atividade de bloqueios sobre o Pacífico Oeste. Também nota-se que os ventos mais fracos de $\sim 20 \mathrm{~m} . \mathrm{s}^{-1}$ prolongam-se muito mais para Leste durante o inverno e primavera do que durante o outono e verão, o que justifica o máximo deslocamento da atividade de bloqueios para o Pacífico Leste, nestas épocas do ano.
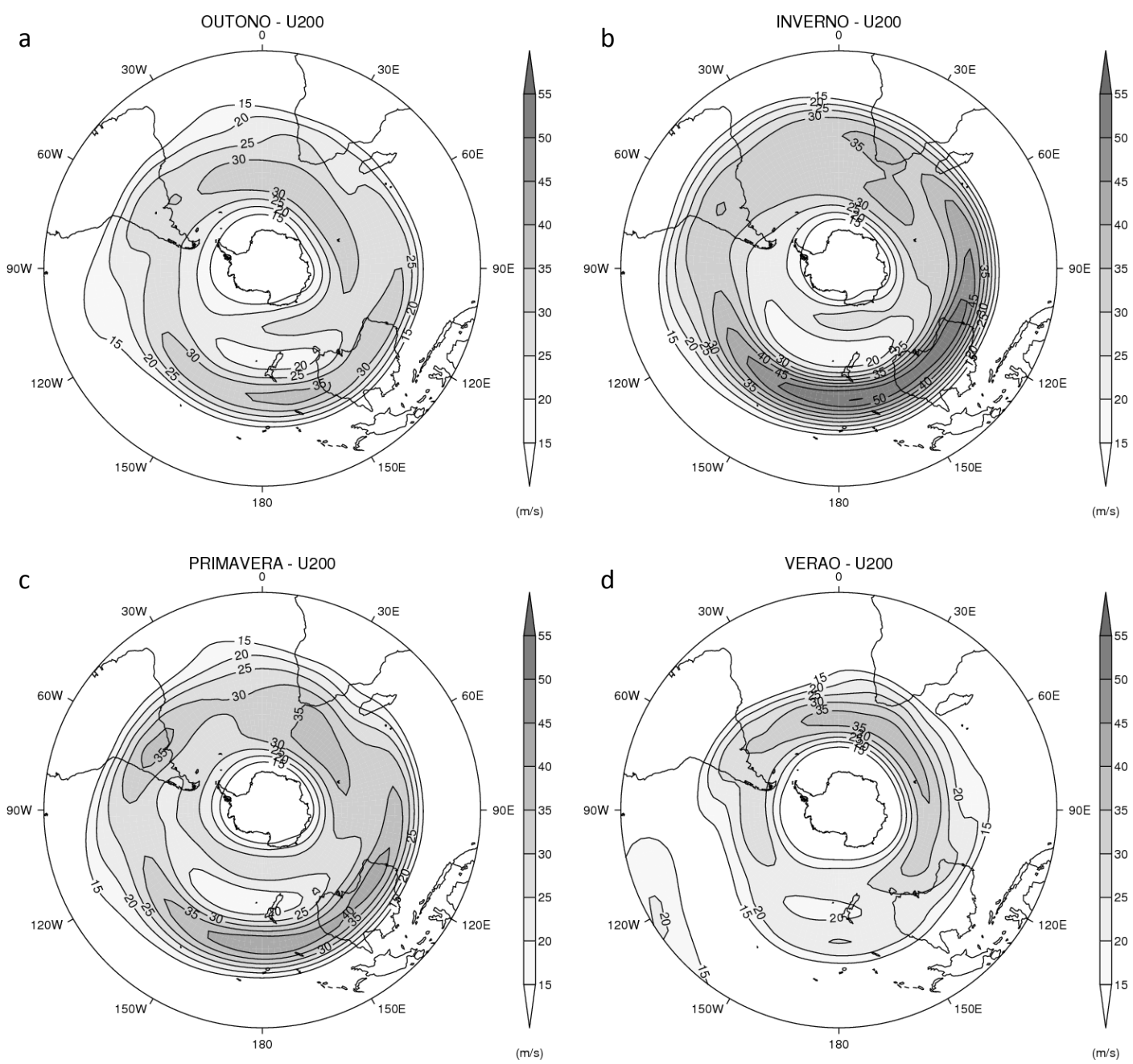

Figura 3.5 - Média sazonal do comportamento do vento zonal de oeste em $200 \mathrm{hPa}$ no Hemisfério Sul durante o (a) outono, (b) inverno, (c) primavera e (d) verão. Unid:[m.s]. 
A Figura 3.6, obtida de Trenberth (1986), representa uma relação entre a corrente de jato e os storm tracks e impactos nos distúrbios de alta frequiência. Com base nesta figura, a região dos "storm tracks" é representada no local onde ambos $\sigma(\mathrm{z})$ e $\sigma(\mathrm{v})$ são máximos. De outro modo, Trenbert (1986) observou que a assinatura local de um bloqueio pode ser identificada onde os desvios do geopotencial $\sigma(\mathrm{z})$ e do vento meridional $\sigma(\mathrm{v})$ são máximo e mínimo, respectivamente (ver Fig. 5 e Fig.6 de Trenbert 1986). A Fig. 3.6 mostra que a perturbação no geopotencial é máxima sobre a região dos storm tracks e assim as perturbações no vento zonal são maiores para norte e para sul, enquanto que as perturbações no vento meridional são máximos no centro dos storm tracks.

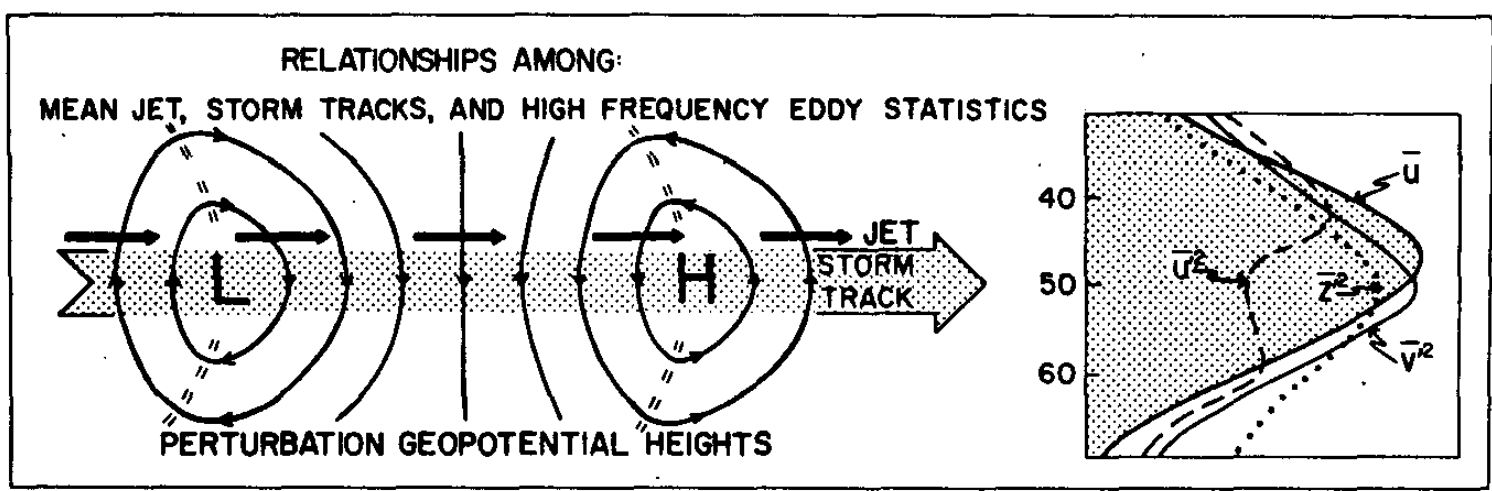

Figura 3.6 - Gráfico esquemático das relações entre a corrente de jato (setas sólidas em negrito) com os storm tracks (seta hachurada) e o impacto nos distúrbios transientes. Obtido de Trenberth (1986). Ver Trenberth (1986) para maiores detalhes.

Ao invés do uso da média dos campos do geopotencial na troposfera média e ventos de alta troposfera, tal como em Trenberth (1986), Marques (1996) e Damião (2009), optou-se por mostrar padrões anômalos da atividade de bloqueios em relação às condicões médias na média e alta troposfera. O procedimento consiste na obtenção e remoção do ciclo anual para cada ponto de grade ao longo dos 365 dias do ano (Wilks, 2006). Para este fim, foram calculados o primeiro e segundo harmônicos utilizando-se transformada discreta de Fourier (Eq. 7 e Eq. 8). Os cálculos dos coeficientes ou "harmônicos $\left(H_{k}\right)$ ", foram aproximados por: 


$$
\begin{aligned}
& A_{k}=\frac{2}{n} \sum_{t=1}^{n} y_{t} \cdot \cos \frac{2 \pi t}{n}(E q \cdot 7) \\
& B_{k}=\frac{2}{n} \sum_{t=1}^{n} y_{t} \cdot \operatorname{sen} \frac{2 \pi t}{n}(\text { Eq. } 8)
\end{aligned}
$$

Onde, $\sum y_{t}$ corresponde ao ciclo anual para cada ponto de grade e para cada passo no tempo de 365 dias. Posteriormente, determinou-se então a fase $\phi_{k}$ e a amplitude do harmônico $\mathrm{k}\left(C_{k}\right)$. A amplitude é obtida fazendo $C_{k}=\left[\left(A_{K}\right)^{2}+\left(B_{K}\right)^{2}\right]^{1 / 2}$ após o looping da somatória e a fase $\phi_{k}$ é resolvida testando o coeficiente $A_{K}$ da seguinte forma:

$$
\phi_{k}=\left\{\begin{array}{c}
\tan ^{-1}\left(\frac{B_{k}}{A_{k}}\right) A_{k}>0 \\
\tan ^{-1}\left(\frac{B_{k}}{A_{k}}\right) \mp \pi, \quad \text { ou } \mp 180^{\circ} A_{k}>0 \\
\frac{\pi}{2}, \text { ou } 90^{\circ} A_{k}=0
\end{array}\right.
$$

Então, o harmônico que representa a série de dados para cada ponto de grade é dado pela seguinte forma:

$$
H_{k}=C_{k} \cdot \cos \left(2 \pi t-\phi_{k}\right)+\bar{y}(E q \cdot 9)
$$

Onde $\bar{y}$ é a média para cada ponto de grade. Finalmente a anomalia $\left(y^{\prime}\right)$ utilizada neste trabalho é obtida fazendo o valor observado menos o harmônico. Procedimento igual é usado no cálculo das anomalias no capitulo 4 .

As Figuras de 3.7 e 3.8 mostram as anomalias da altura geopotencial (z) em $500 \mathrm{hPa}$ e o vento zonal (u) em $200 \mathrm{hPa}$, respectivamente para a banda zonal Total. Nesta análise, somente os eventos de bloqueio com $\tau \geq 3$ dias foram retidos, portanto não deve ser confundido com o escoamento bloqueado, como o exemplo da Figura 3.3. As linhas cheias indicam regiões com significância ao nível de 5\%. Foram analisados um total mínimo de 149 eventos de bloqueios no verão e um máximo de 247 eventos de bloqueios durante o inverno (Dados não representados em Tabela). Na Figura 3.7, ressalta-se a existência de dois centros com atividade de bloqueios durante a primavera (Fig. 3.7c), situados no sudeste da Nova Zelândia 
e na costa Sul do Chile. Este dois centros com atividade de bloqueios também são observados durante o outono (Fig. 3.7a), embora não estejam tão evidenciados. Por outro lado, um único centro com atividade de bloqueio é observado durante o inverno e o verão. Contudo, o centro de anomalias é mais alongado sobre o Pacífico Leste durante o inverno.

Na Figura 3.8, observa-se que as regiões com significância estatística com $p<0,05$ estão associadas às regiões de anomalias de leste em torno de $40^{\circ}-50^{\circ} \mathrm{S}$ que localmente substituem o padrão característico do vento zonal de oeste, o qual é forçado anomalamente na direção do pólo. Destaca-se que as anomalias de leste são mais fracas durante o outono e inverno, ao passo que são mais fortes durante os meses de primavera e verão. Ao longo do Pacífico Sul, as anomalias de leste são caracteristicamente mais fortes sobre o Pacífico Oeste. De forma semelhante, Marques e Rao (2001) em estudo de casos de bloqueios identificaram que os eventos de bloqueio com menor (maior) duração estavam associados com um escoamento de leste tipicamente mais (menos) intenso na média e alta troposfera, o qual suporta maior (menor) advecção zonal do vento médio $(\bar{u})$ (ver Figura 4 em Marques e Rao 2001). Deste modo, os resultados obtidos pela Fig. 3.8 estão em acordo com os resultados obtidos em Marques e Rao (2001). Isto parece justificar a menor duração dos eventos de bloqueio durante a primavera e verão, principalmente quando confinados sobre o Pacífico Oeste. A circulação mais zonal e associada com uma forte corrente anômala do jato polar sobre o Pacífico Oeste e durante a primavera pode igualmente ser um mecanismo desfavorável para a frequiência e a duração dos eventos de bloqueio, em comparação com o outono e inverno (ver Tabela 3.1).

As Figuras 3.9 e 3.10 mostram os campos do desvio padrão do vento meridional (v) em 200-hPa e altura geopotencial (z) em 500-hPa, respectivamente. Analogamente às Figuras 3.7 e 3.8, somente foram retidos os dias com eventos de bloqueio. Na Figura 3.9, investigamos a região preferencial para a bifurcação do jato, onde $\sigma(v)$ é mínimo sobre a 
região dos storm tracks. Neste sentido, observou-se no outono e inverno a maior quebra na região dos storm tracks com $\sigma(v)$ mínimo ocorrendo desde o sul da Austrália até o sudeste da Nova Zelândia. Isto proporciona uma maior quantidade de bloqueios que se formam sobre o setor do Pacífico Central. Diferentemente, na primavera a longitude preferencial para a bifurcação do jato principal parece se localizar sobre o sul da Austrália, favorecendo a alta freqüência de bloqueios no Pacífico Sudoeste. No verão a longitude preferencial para a bifurcação é similar ao observado durante a primavera. Como observado na Figura 3.7, os locais com máxima anomalia do geopotencial ocorrem obviamente para leste do local da bifurcação do jato e coincidem com aquela região climatológica de ventos mais fracos de 20.m.s ${ }^{-1}$ (Fig. 3.5).

Na Figura 3.10, observa-se qu e durante a atividade de bloqueios as regiões onde $\sigma(z)$ é máximo ocorrem exatamente sobre a extensão longitudinal a leste (em torno de $60^{\circ} \mathrm{S}$ ) daquela com maior cisalhamento do vento zonal (ver Figura 3.6 e 3.8), entre as anomalias de leste e o jato polar. Também observar que o local onde $\sigma(z)$ é máximo coincide com a extensão longitudinal preferencial da atividade do escoamento bloqueado de altas latitudes (ver linha "rosa" na Figura 3.3) e do outono a primavera, já que durante o verão a atividade bloqueios sobre latitudes mais altas é fortemente reduzida. Isto confirma que os eventos de bloqueio de altas latitudes estão preferencialmente localizados na região Pacifico Leste, onde o geopotencial tem o desvio máximo em direçao ao pólo. 
OUTONO - Anomalia (z) 500hPa

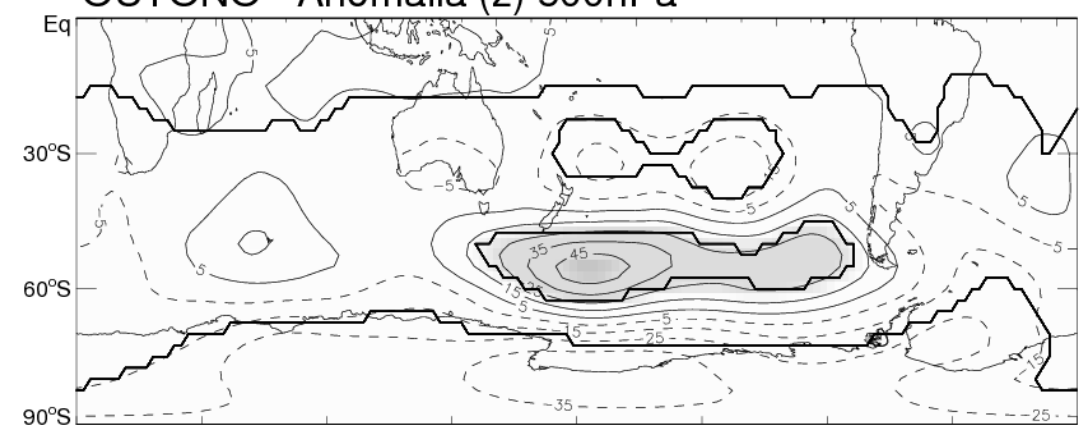

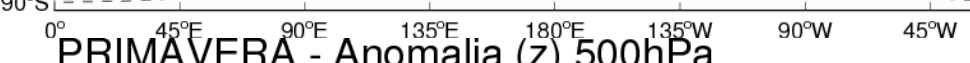
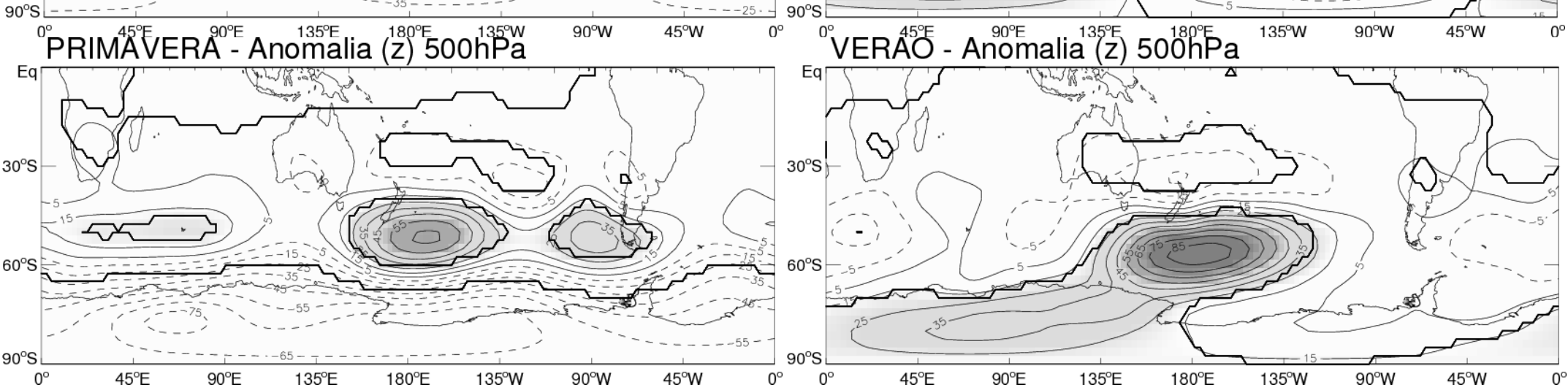

Figura 3.7 - Campo médio das anomalias da altura geopotencial no nível de $500 \mathrm{hPa}$. O ciclo anual foi removido. As linhas cheias com regiões sombreadas são anomalias positivas e as linhas tracejadas são anomalias negativas. As linhas cheias grossas representam as áreas com significância estatística de $95 \%$ de confiança. Somente dias $\operatorname{com} \tau \geq 3$ dias foram retidos. 
OUTONO - Anomalia (u) 200hPa

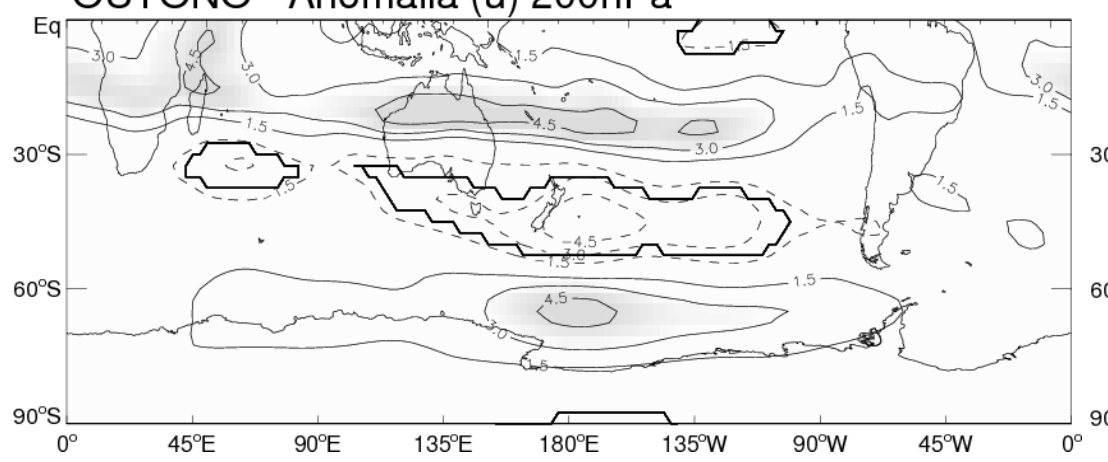

INVERNO - Anomalia (u) $200 \mathrm{hPa}$
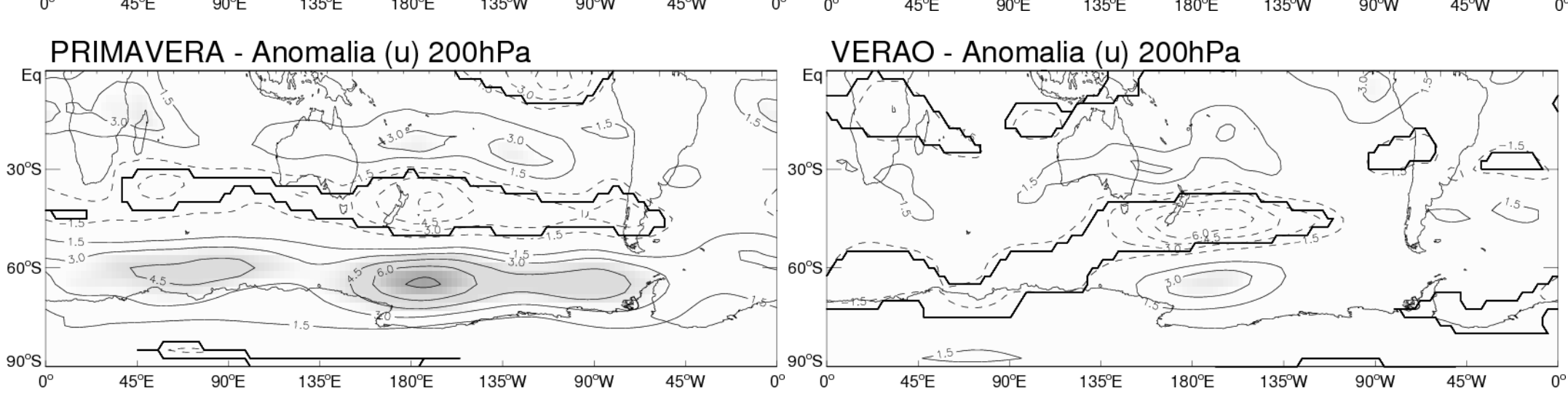

Figura 3.8 - Campo médio das anomalias do vento zonal no nível de $200 \mathrm{hPa}$. O ciclo anual foi removido. As linhas cheias com regiões sombreadas são anomalias positivas e as linhas tracejadas são anomalias negativas. As linhas cheias grossas representam as áreas com significância estatística de $95 \%$ de confiança. Somente dias $\operatorname{com} \tau \geq 3$ dias foram retidos. 
OUTONO - Desv.Padrao (v) 200hPa

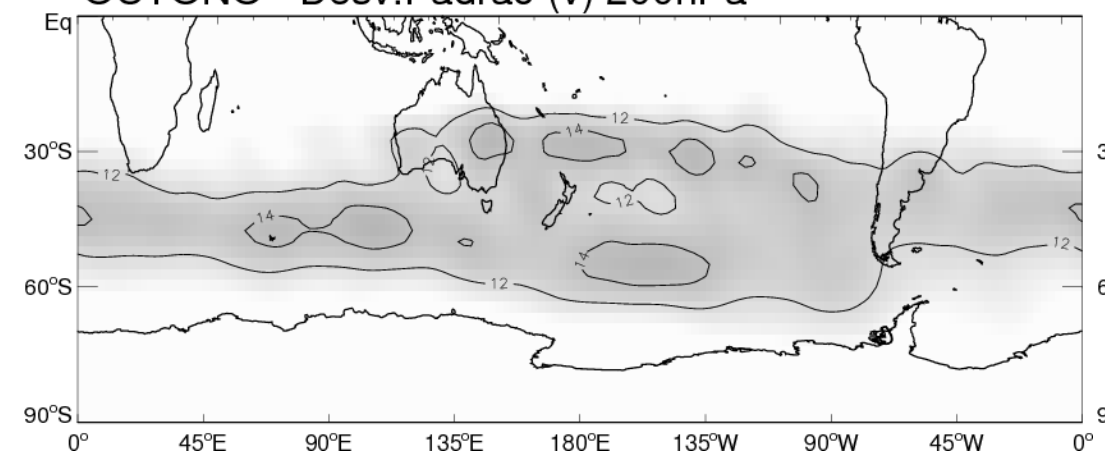

PRIMAVERA - Desv.Padrao (v) 200hPa

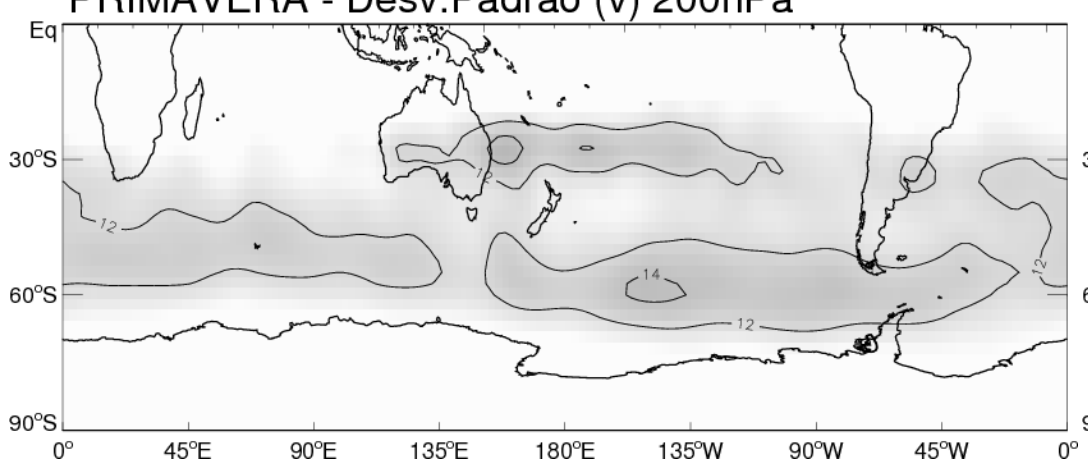

Figura 3.9 - Campo médio do desvio padrão das anomalias do vento meridional no nível de $200 \mathrm{hPa}$. O ciclo anual foi removido. Regiões sombreadas mostram valores iguais ou maiores do que $12 \mathrm{~m} / \mathrm{s}$. Somente dias $\operatorname{com} \tau \geq 3$ dias foram retidos. Unid: [m.s ${ }^{-1}$ ]
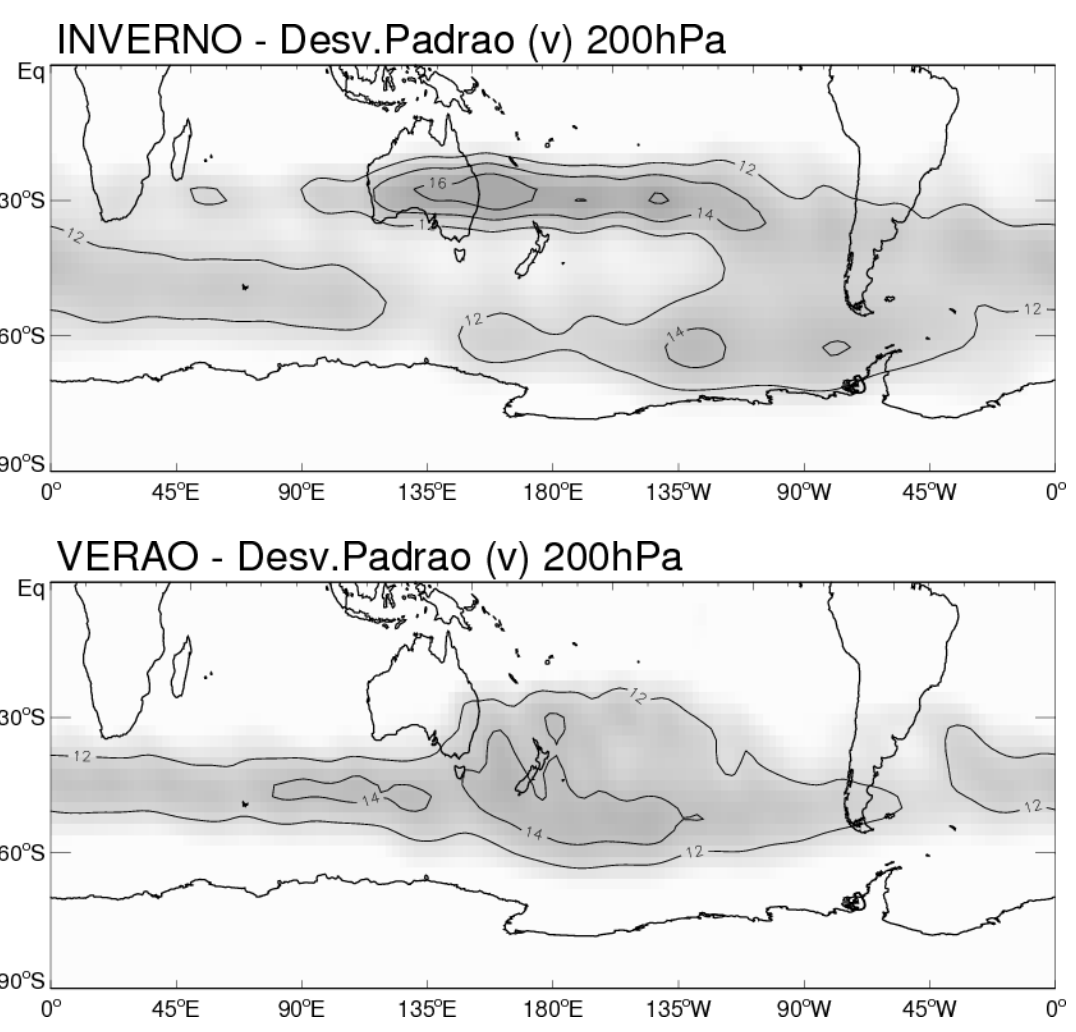

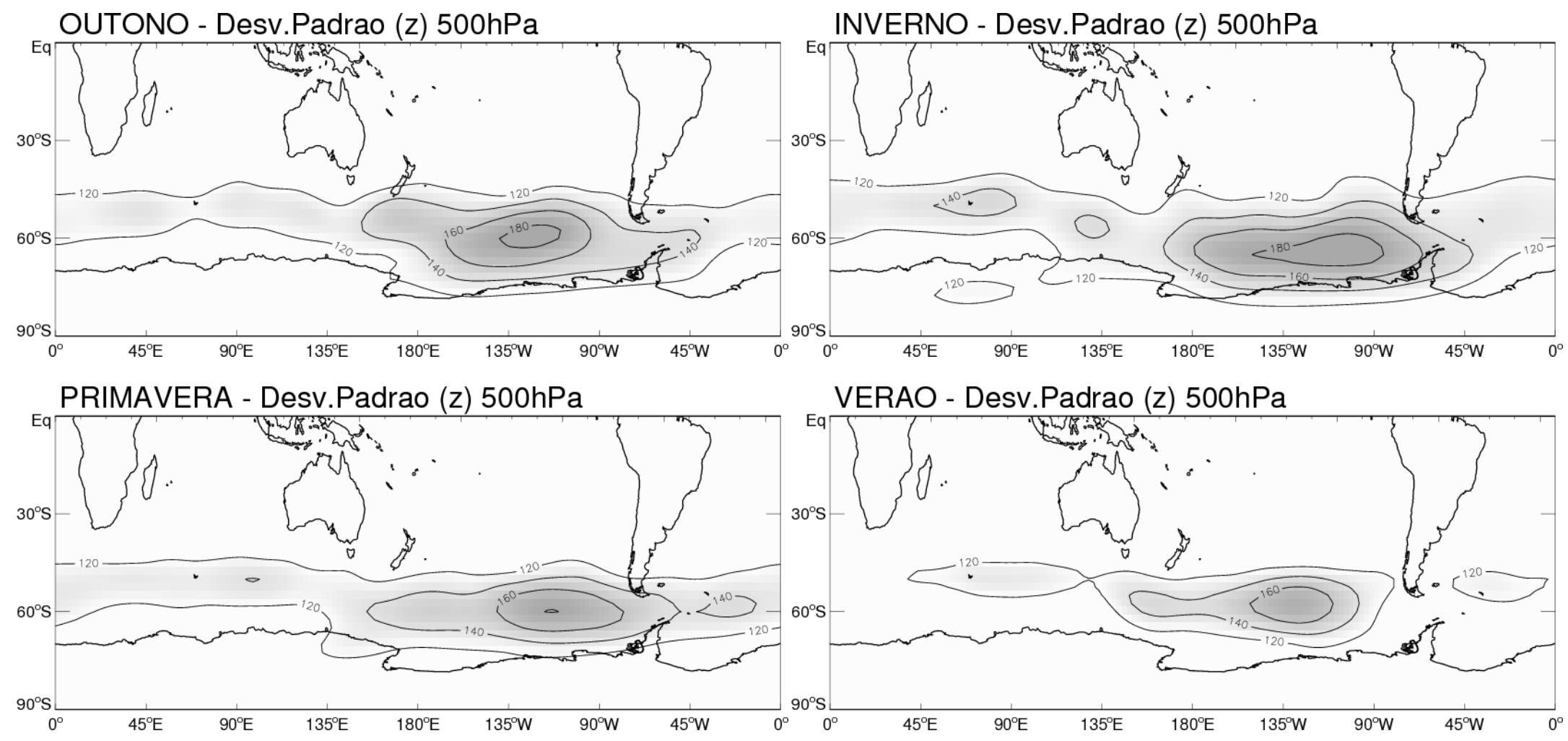

Figura 3.10 - Campo médio do desvio padrão das anomalias da altura geopotencial no nível de $500 \mathrm{hPaO}$ ciclo anual foi removido. Regiões sombreadas mostram valores iguais ou maiores do que $120 \mathrm{mgp}$. Somente dias com $\tau \geq 3$ dias foram retidos. Unid: [mgp] 


\subsection{BLOQUEIOS NAS FASES OPOSTAS DO ENOS}

Para examinar o papel do ENOS no fenômeno de bloqueio, comparou-se a freqüência relativa, local preferencial e a duração nas fases opostas do ENOS com as respectivas características observadas durante a fase Neutra do ENOS. Os episódios do ENOS foram separados de acordo com a intensidade e bandas zonais. Para mostrar estas diferenças, um teste do sinal (teste-z) para a diferença de mediana ao nível de $95 \%$ de confiança foi aplicado no escoamento bloqueado por ponto de longitude. O mesmo teste de medianas foi realizado para os eventos de bloqueio dentro de cada "Setor de Bloqueios" e para cada estação do ano.

Para a realização do teste-z, calculou-se um valor mediano para cada ponto de longitude e para cada fase do ENOS. O valor mediano local foi comparado com uma mediana comum móvel de 21 pontos de longitude ( $\sim 50^{\circ}$ graus de longitude). Aqui, a mediana comum é definida combinando as observações entre as fases do ENOS com Neutros. A estatística-z foi então aplicada da seguinte forma:

$$
z=2 \cdot \sqrt{\frac{N_{n} \cdot N_{e}}{N_{n}+N_{e}}} \cdot\left(R_{n}-R_{e}\right) \quad(E q .10)
$$

Onde os subscrito "n" e "e" representam as fases "Neutra" e "opostas (ENOS+ e ENOS-)" do ENOS, respectivamente. Assim, $N_{n}\left(N_{e}\right)$ é o número total de eventos por ponto de longitude; $R_{n}\left(R_{e}\right)$ é a fração $p / p$ ', onde $p$ é o número total de eventos acima da média comum e $p$ ' é o número de eventos durante anos neutros (ENOS) por ponto de longitude. Assim, a diferença entre as medianas é estatisticamente significativa ao nível de 5\%, para um teste bi-caudal, se o módulo de Z (Eq. 10) é maior que o valor de 1,96 (Anderson e Finn, 1996)

Inicialmente, serão discutidas as frequiências dos dias com escoamento bloqueado sobre a banda da latitude total, latitudes médias-baixas e médias-altas durante as quatro 
estações do ano com foco em diferentes intensidades do ENOS. O Enfoque maior será dado para o inverno por ser a estação de maior importância na atividade de bloqueios no HS. Posteriormente, far-se-á uma comparação entre as freqüências médias de bloqueios durante a atividade do ENOS e análises de significância estatística.

As Figuras 3.11 a 3.14 mostram uma visão integrada da variabilidade longitudinal do escoamento bloqueado filtrada em torno da média de 10 pontos de longitude, de acordo com a intensidade do ENOS para as bandas da latitude total (partes "a" e "b"), latitudes médias-altas (partes “c" e "d") e médias-baixas (partes "e" e "f"), respectivamente, durante a fase Quente (partes "a", "c" e "e") e Fria (partes "b", "d" e "f") do ENOS para o outono (Figura 3.11), inverno (Figura 3.12), primavera (Figura 3.13) e verão (Figura 3.14). Nestas figuras, os episódios Neutros estão representados pela área cheia cinza.

A Figura 3.11a mostra a freqüência de dias com escoamento bloqueado durante a fase Quente do ENOS no outono. Ressalta-se o aumento na freqüência do escoamento bloqueado entre $180^{\circ}$ e $90 \mathrm{~W}$ nas três intensidades da fase Quente. De modo oposto, uma redução do escoamento bloqueado é observada nos outonos influenciados pela fase Fria (Fig. 3.11b), exceto entre $150 \mathrm{~W}$ e $120 \mathrm{~W}$ para eventos frios fortes. Ademais, a principal diferença observada entre a fase Fria (Fig. 3.11d) e a fase Quente (Fig. 3.11c) foi a redução da frequiência do escoamento bloqueado sobre latitudes mais altas. 


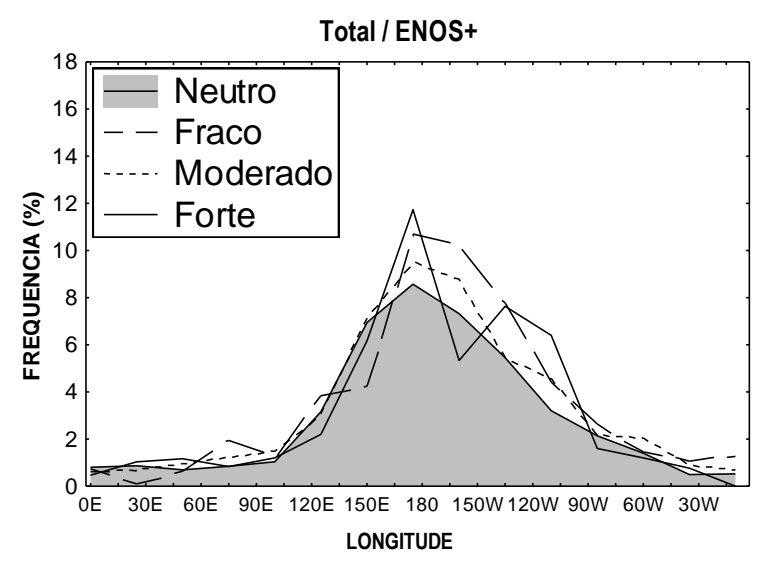

(a)

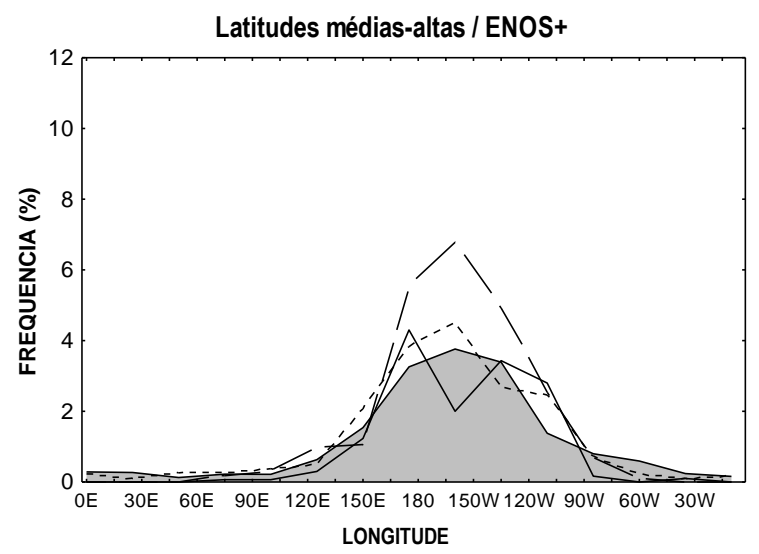

(c)

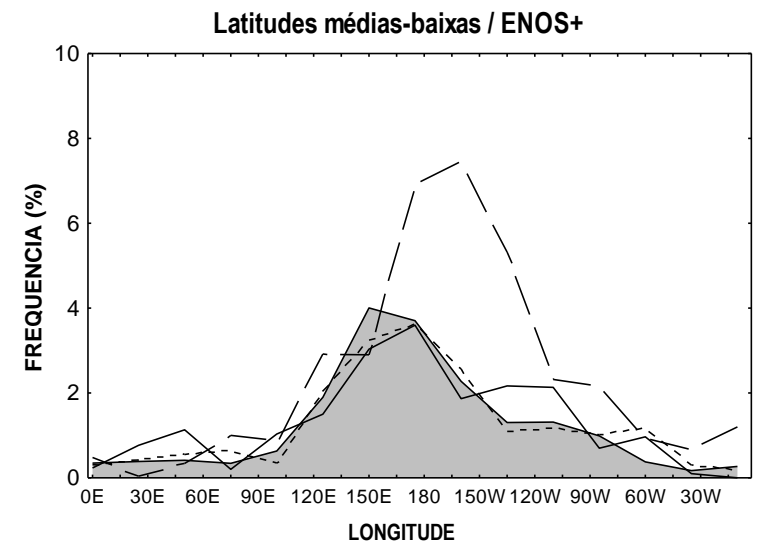

(e)

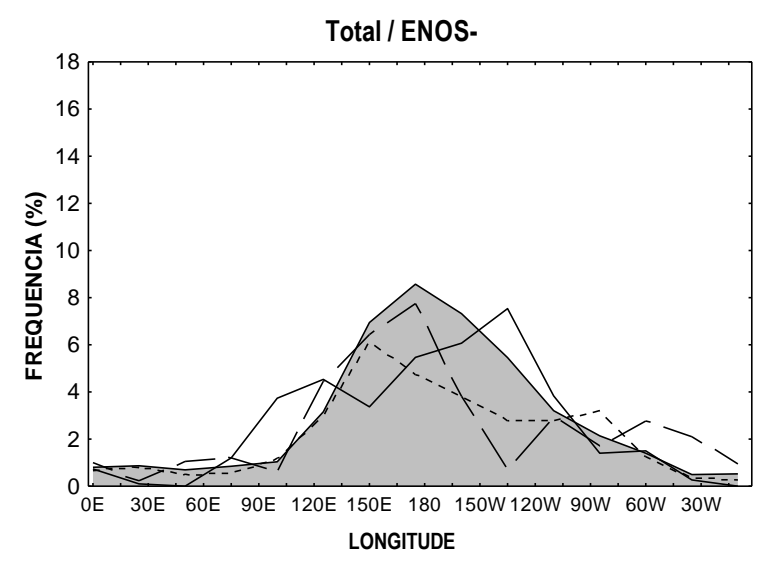

(b)

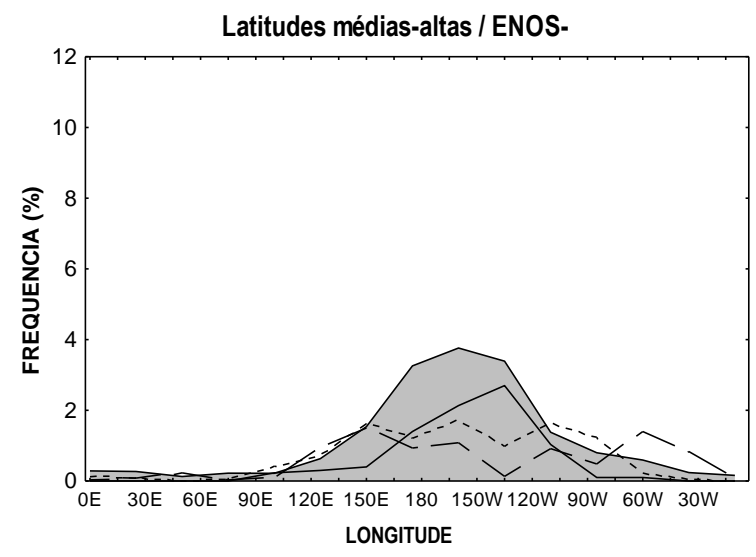

(d)

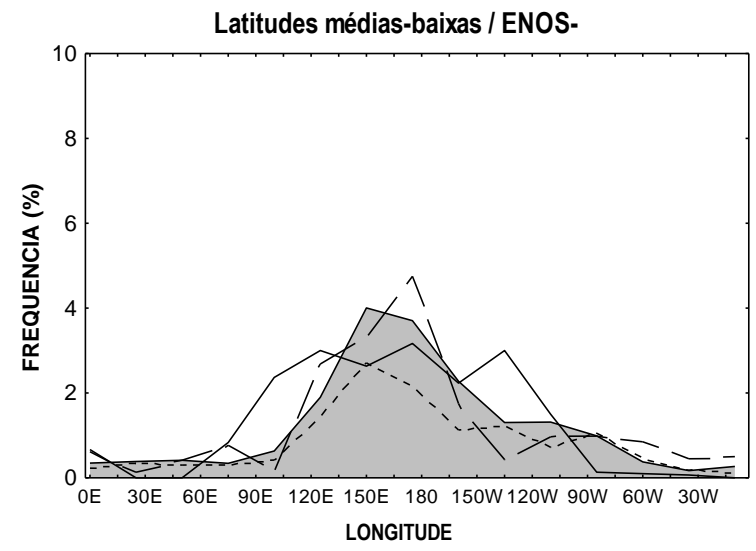

(f)

Figura 3.11 - Distribuição da freqüência do escoamento bloqueado durante o OUTONO. As áreas cheias cinzas representam a distribuição da frequência na fase Neutra do ENOS (referência de padrão). As linhas tracejadas representam episódios fracos, linhas pontilhadas representam os episódios moderados e linhas sólidas representam episódios fortes. As figuras dispostas à esquerda representam a fase Quente do ENOS e as figuras dispostas à direita representam a fase Fria. A banda zonal esta indicada no topo de cada figura.

Análogo ao outono, a Figure 3.12 mostra a frequiência de dias com escoamento bloqueado no inverno. Durante os episódios fracos da fase Quente do ENOS foi evidente o 
aumento na frequiência do escoamento bloqueado sobre o mesmo local preferencial do escoamento bloqueado na fase Neutra (Figura 3.12a). Por outro lado, nos episódios mais intensos da fase Quente (isto é, moderados a fortes) não se observou o aumento da frequiência do escoamento bloqueado, mas apenas o deslocamento do local preferencial para a região do Pacífico Leste onde bloqueios passam a ocupar latitudes mais altas (Figura 3.12c). Durante o inverno com fase fria do ENOS se observou a reduçao na freqüência do escoamento bloqueado sobre o setor do Pacífico Central (Figura 3.12b) nas três intensidades da fase Fria, concentrando grande parte da atividade bloqueada nas regiões de bordas do Pacífico Sul sobre diferentes latitudes, ou seja, sobre o Pacífico Sudoeste em latitudes médias-baixas (Figura 3.12f) e no Pacífico Sudeste em latitudes médias-altas (Figura 3.12d). De fato, a maior frequiência de eventos nas latitudes mais baixas (mais altas) parece ser predominante sobre o Pacifico Oeste (Pacífico Leste, na costa Oeste Sul-americana), independentemente da fase do ENOS.

Outras características podem ser comentadas a respeito do inverno, por exemplo, as Figuras 3.12a e 3.12b sugerem que os invernos modulados pelos episódios fracos a moderados da fase Quente do ENOS são caracterizados por um número muito maior de dias com escoamento bloqueado em comparação com os invernos modulados pelos episódios fracos a moderados da fase Fria. Interessantemente, os episódios fortes das fases opostas do ENOS representam similar aumento no número de dias com escoamento bloqueado no Pacífico Sudeste. 


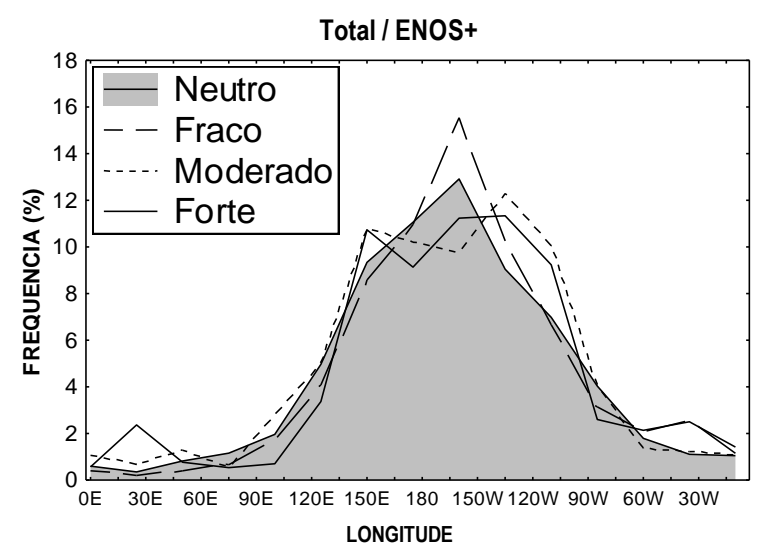

(a)

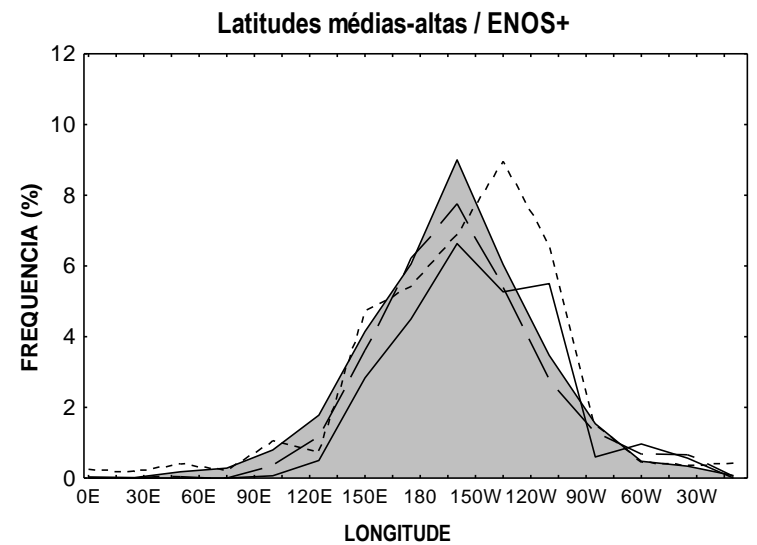

(c)

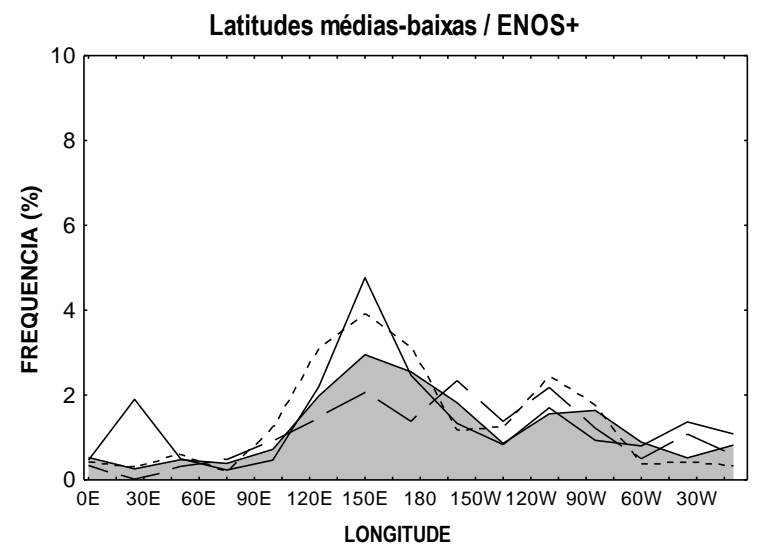

(e)

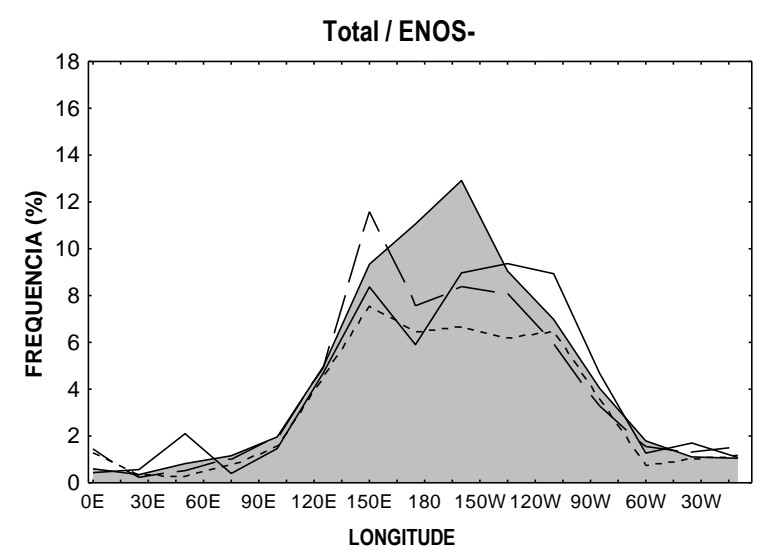

(b)

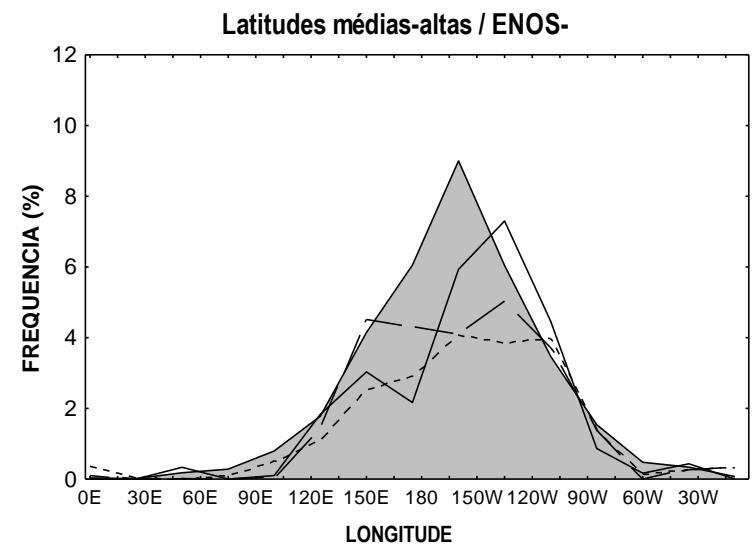

(d)

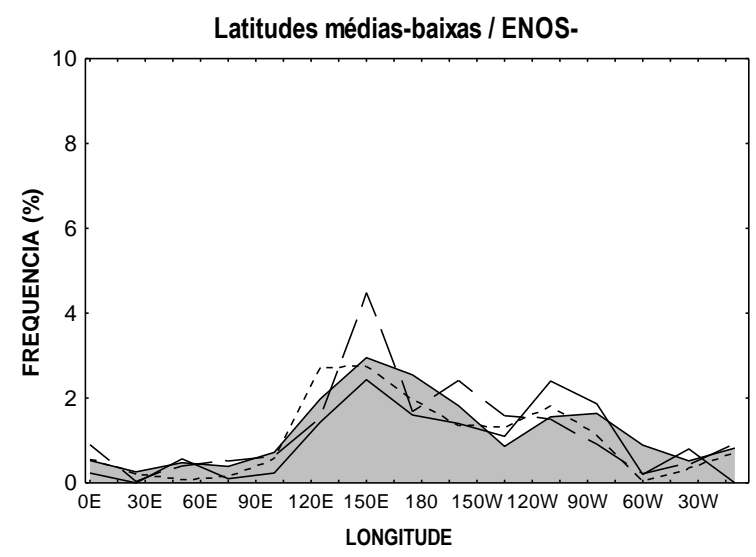

(f)

Figura 3.12 - Similar a Figura 3.11, mas referente ao INVERNO.

Durante a Primavera (Fig. 3.13) observa-se o aumento da freqüência do escoamento bloqueado na fase Quente do ENOS com deslocamento do máximo relativo Neutro para o Pacifico Leste (Fig 3.13a), principalmente sobre as latitudes médias-altas (Fig. 3.13c). Também é observada a diminuição da frequência relativa na fase Fria do ENOS (Fig 3.13b). Em termos gerais o efeito das fases opostas do ENOS na frequiência e no local preferencial é 
similar ao observado durante o outono e inverno. Contudo, a frequência sobre as latitudes médias-altas foi amplificada de duas a três vezes durante os episódios fracos da fase Quente em comparação ao observado com episódios da fase Neutra. Como característica comum, ressalta-se a diminuição no número de dias com escoamento bloqueado durante os episódios fortes da fase Quente. Durante a fase Fria, foi observada a mesma redução na atividade de dias com escoamento bloqueado relativo ao outono e inverno. Finalmente, nos meses de verão (Fig. 3.14) os resultados indicam que a modulação da fase Fria do ENOS não representa uma redução na frequência de dias com escoamento bloqueado em comparação aos demais períodos do ano.

Resumidamente, o período do inverno é caracteristicamente o principal período associado ao fenômeno de bloqueio. Neste período do ano, as anomalias de moderadas a fortes e positivas de Temperatura à Superfície do Mar (TSM) do Pacifico modificam o local preferencial mais do que a freqüência do escoamento bloqueado comparativamente à fase Neutra, enquanto que as maiores freqüências do escoamento bloqueado foram observadas durante os episódios fracos da fase Quente do ENOS. Nos meses de outono a primavera, o local preferencial também é modificado, contudo um incremento na freqüência é observado. Por outro lado, todo padrão com anomalias negativas de TSM tende ao longo do ano em reduzir a freqüência do escoamenteo bloqueado sobre o Pacífico Central, exceto durante os meses do verão.

A Figura painel 3.15 mostra um resumo da variabilidade longitudinal do escoamento bloqueado médio por ponto de longitude durante as fases do ENOS, independente da intensidade do fenômeno do ENOS para o outono, inverno, primavera e verão, respectivamente. Os resultados mostram que a frequiência do escoamento bloqueado foi relativamente aumentada durante o outono do ENOS+, enquanto que durante o inverno e 
primavera do ENOS+ observa-se apenas um ligeiro deslocamento do máximo relativo Neutro para o Pacífico Leste. No ENOS- predomina a redução na frequiência, exceto durante o verão.

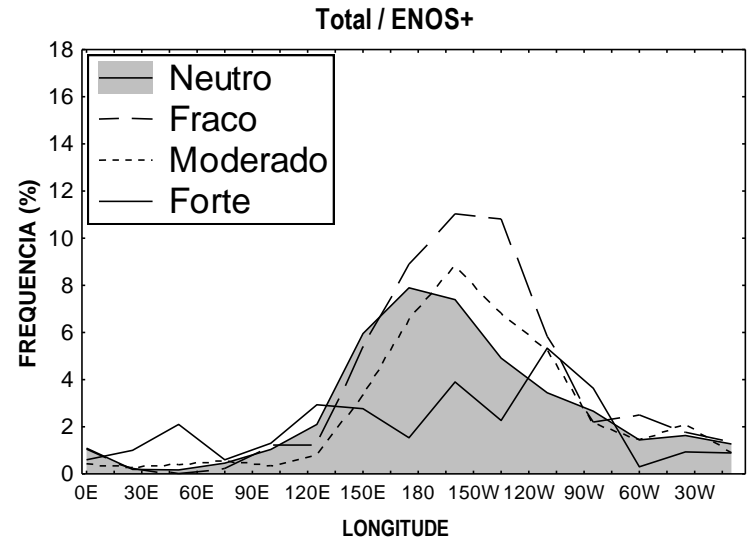

(a)

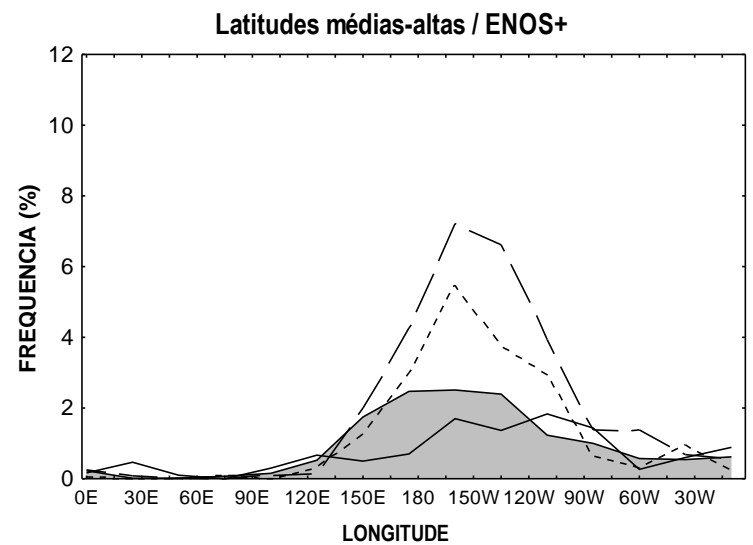

(c)

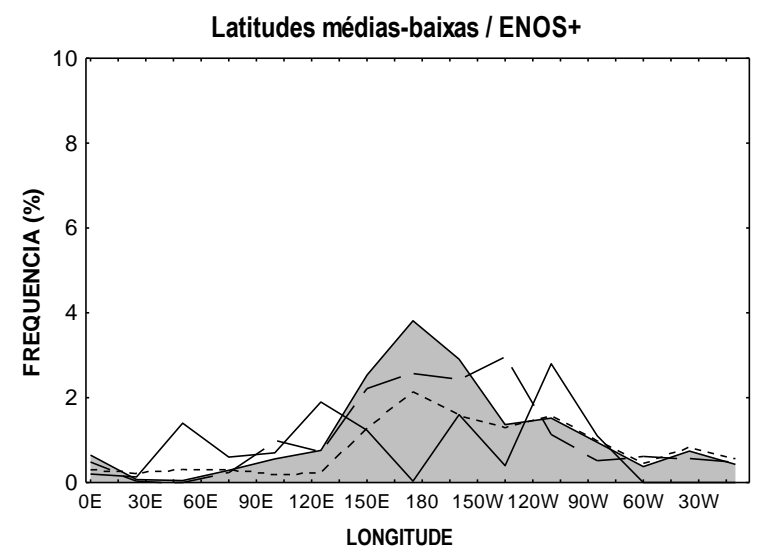

(e)

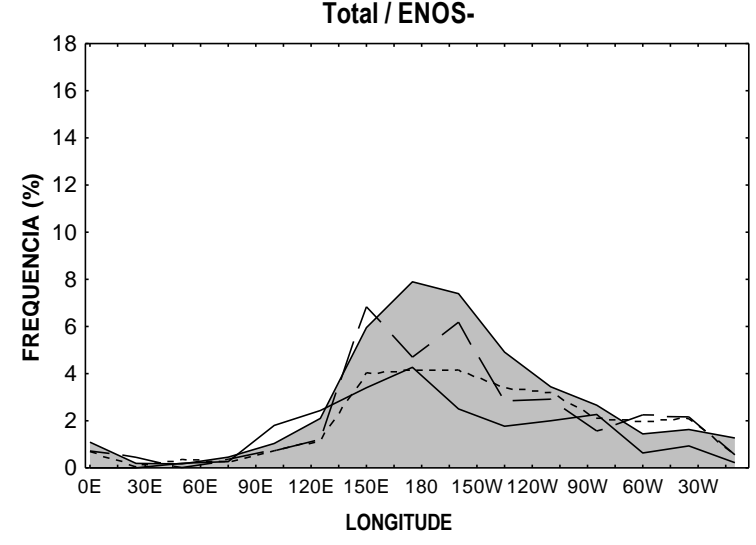

(b)

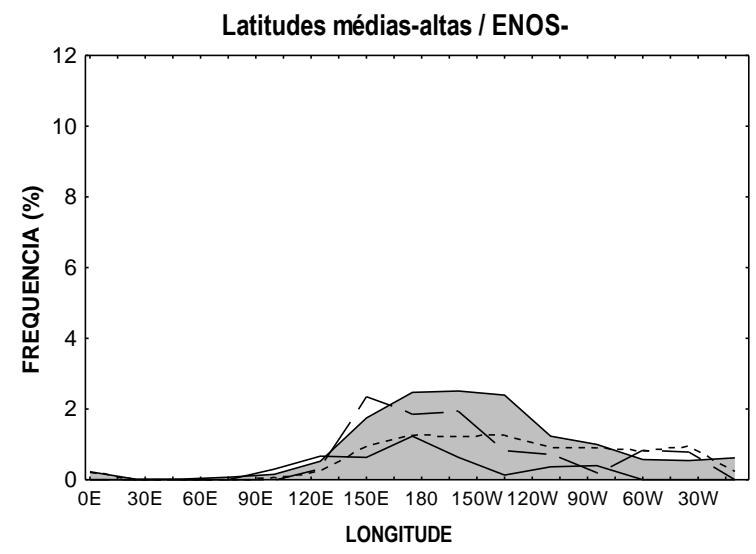

(d)

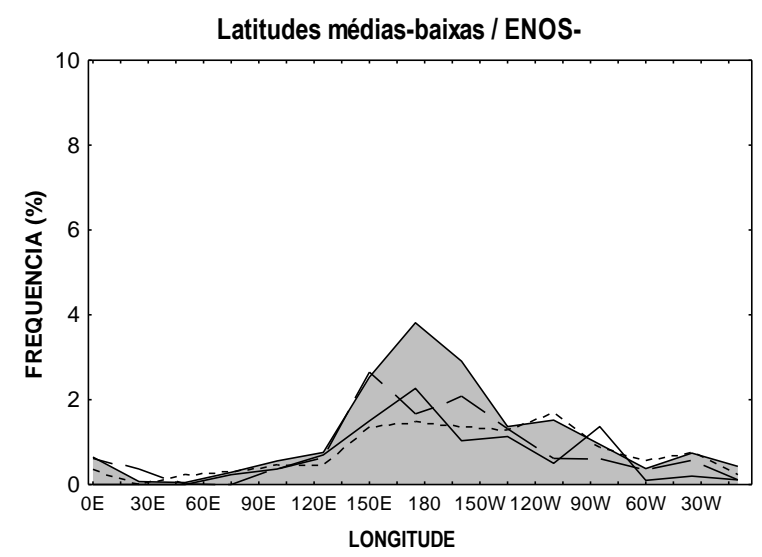

(f)

Figura 3.13 - Similar a Figura 3.11, mas referente à PRIMAVERA. 
Total / ENOS+

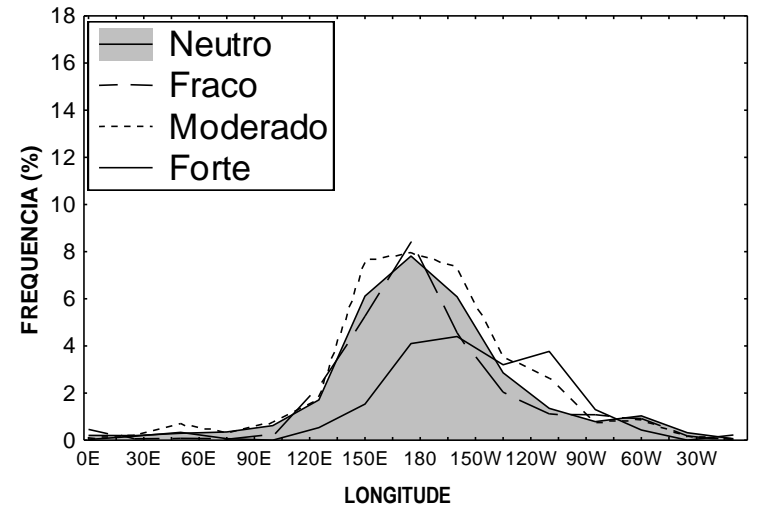

(a)

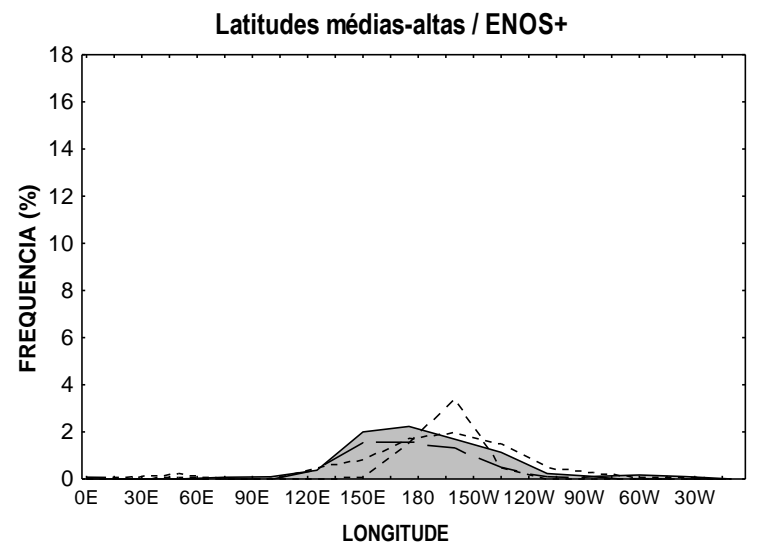

(c)

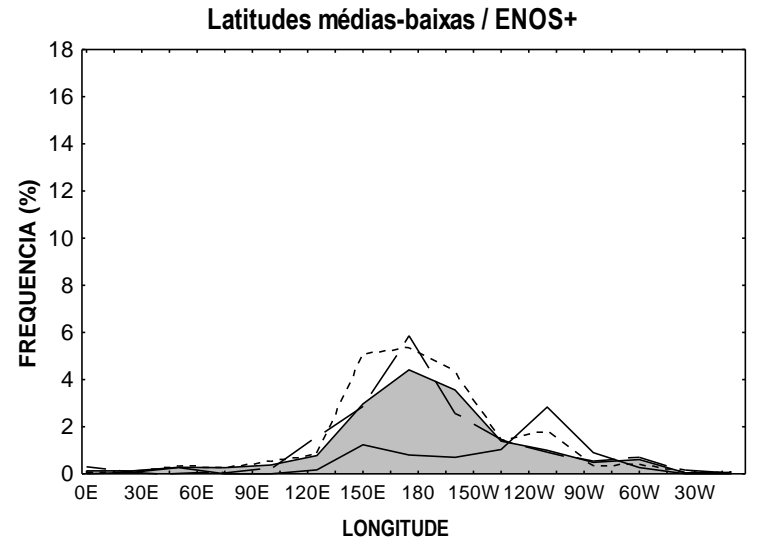

(e)

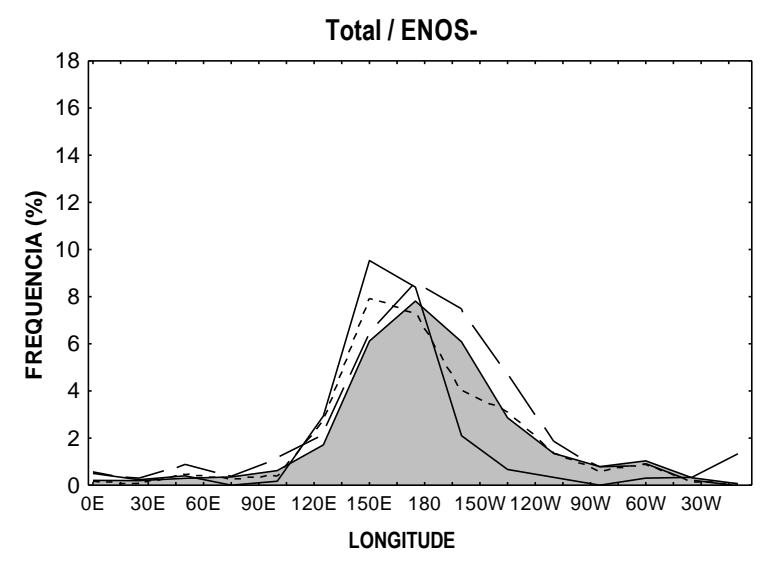

(b)

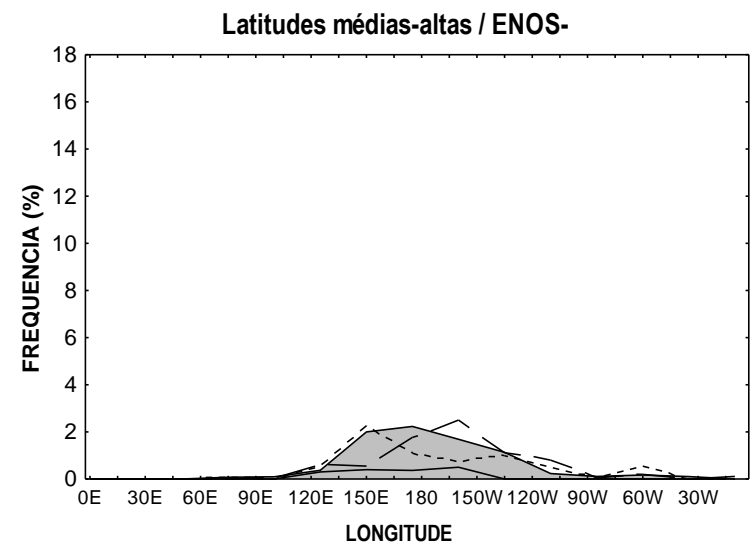

(d)

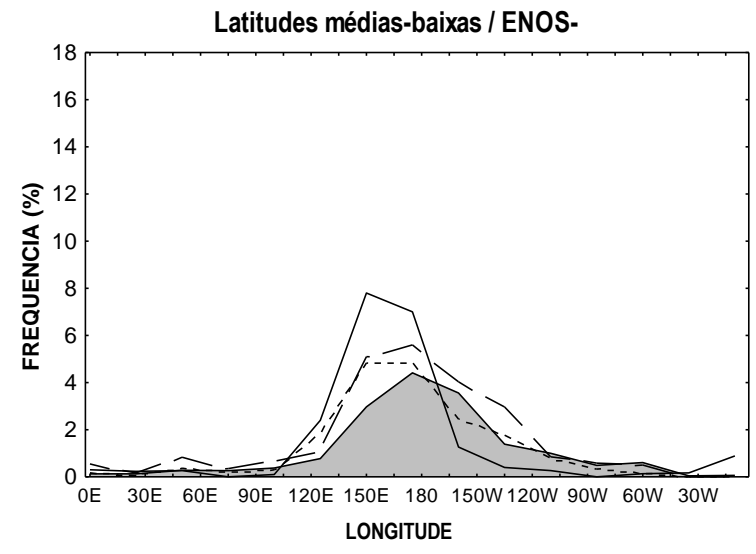

(f)

Figura 3.14 - Similar a Figura 3.11, mas referente ao VERÃO. 
a. OUTONO

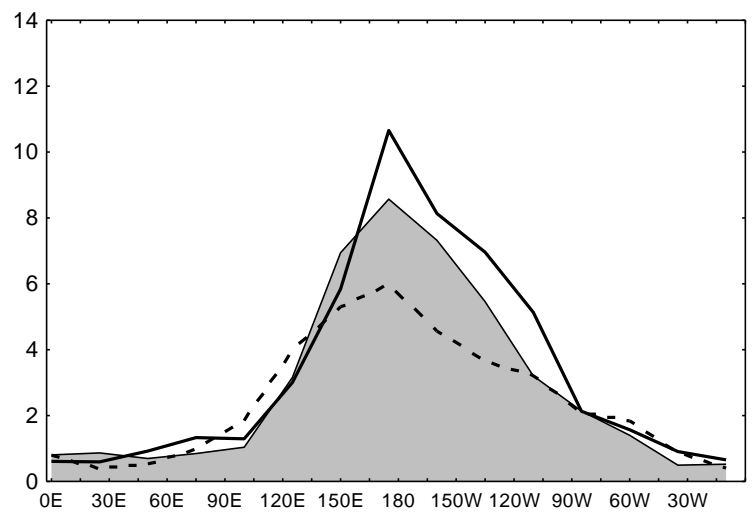

c. PRIMAVERA

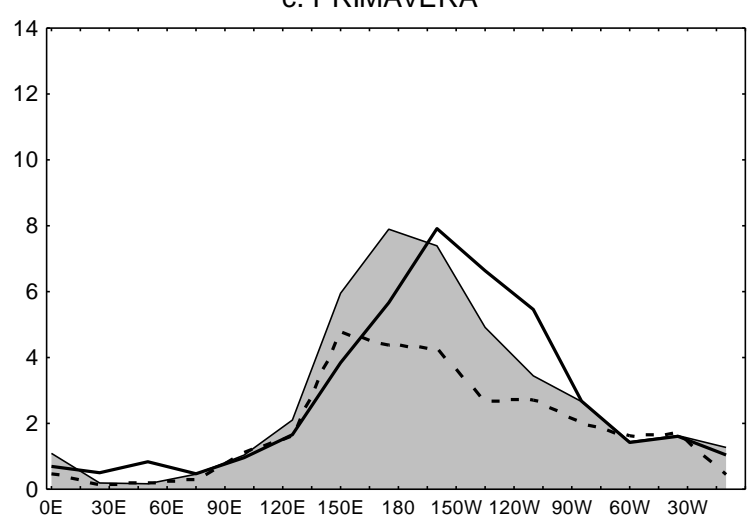

b. INVERNO

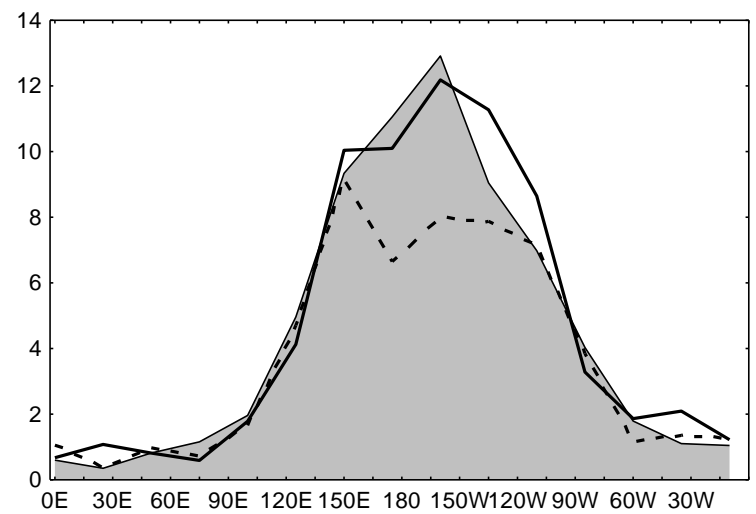

d. VERÃO

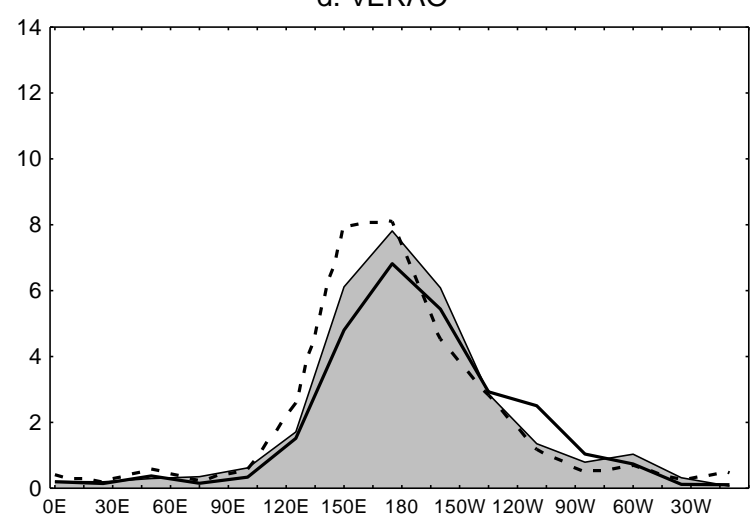

Figura 3.15 - Distribuição da frequiência sazonal do escoamento bloqueado no (a) Outono, (b) Inverno, (c) Primavera e (d) Verão para a banda zonal Total. As áreas cheias cinzas representam a distribuição da frequência referente ao padrão na fase Neutra do ENOS. As linhas pretas sólidas representam a fase Quente do ENOS, enquanto as linhas pretas tracejadas representam a fase Fria.

Os painéis da Figura 3.16 e Figura 3.17 mostram a estatística-z associada com os resultados da Fig. 3.15 para a fase Quente e Fria do ENOS, respectivamente, e para os períodos do outono (Figura 3.16a e Figura 3.17a), inverno (Figura 3.16b e Figura 3.17b), primavera (Figura 3.16c e Figura 3.16c) e verão (Figura 3.16d e Figura 3.17d). Cada figura representada no painel mostra a diferença entre cada fase oposta ENOS com relação à fase Neutra. A linha preta sólida em "negrito" destaca as regiões com significância estatística ao nível de $95 \%(\mathrm{p}<0.05)$ de confiança de acordo com o critério utilizado no teste-Z. Assim, o campo médio da Fig. 3.16 indica que nos períodos modulados pela fase Quente, o número total de dias com escoamento bloqueado aumenta sobre a "região" do Pacífico Leste com 
p<0.05, em especial sobre o "setor" do Pacífico Sudeste, sendo, observado ao longo do ano. Por outro lado, a mesma Figura 3.17, indica que durante a fase Fria houve uma redução no número de dias com escoamento bloqueado ao longo de toda a extensão do Pacífico Sul, e do outono a primavera com $\mathrm{p}<0.05$. A Figura 3.17 ainda mostra que particularmente durante o verão, a modulação pela fase Fria parece favorecer o aumento de dias com escoamento bloqueado sobre Pacífico Sudoeste com $\mathrm{p}<0.05$.
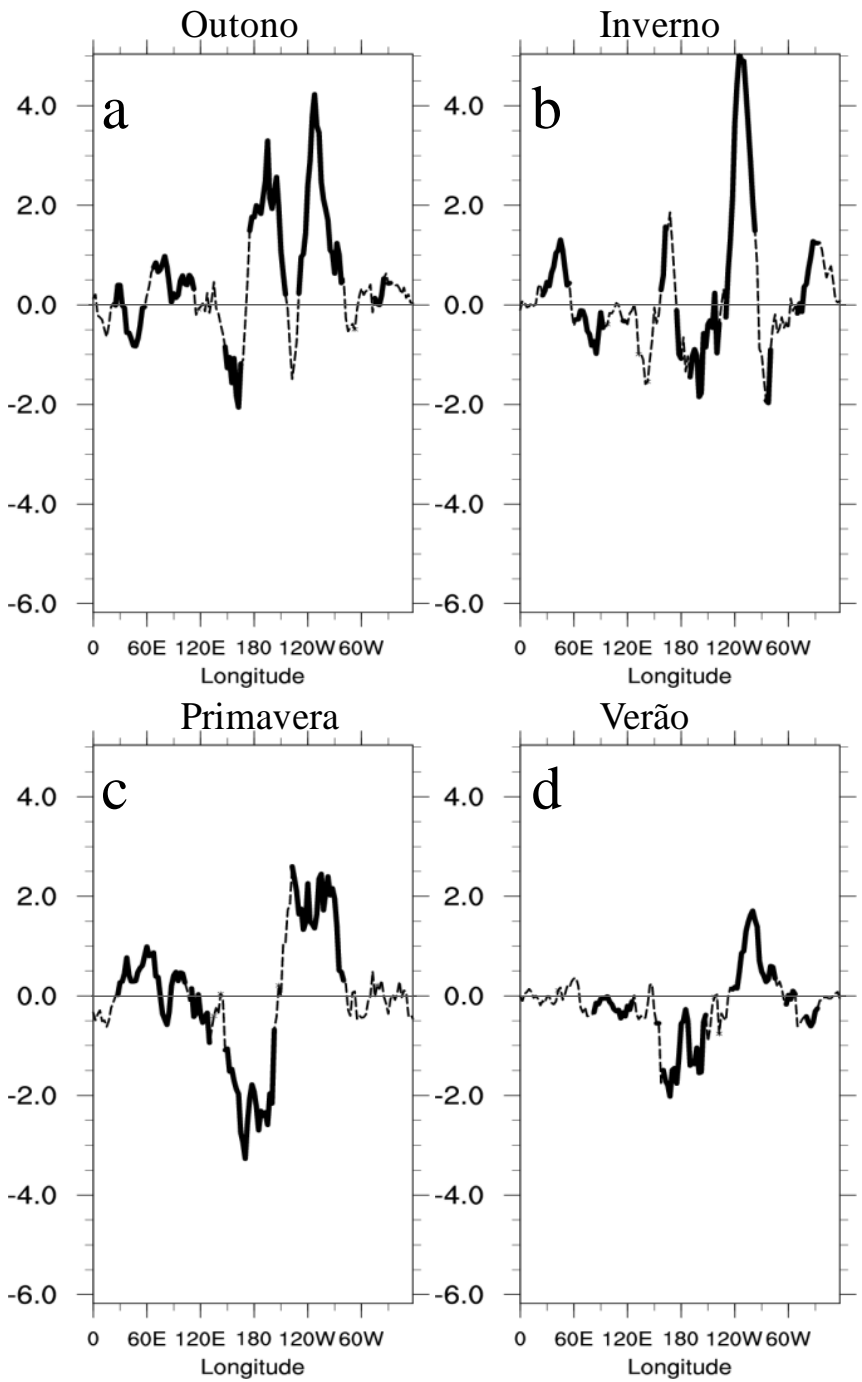

Figura 3.16 - Diferenças entre medianas do escoamento bloqueado por ponto de longitude entre o ENOS+ e o padrão Neutro. (a) ENOS+ menos Neutro durante o Outono; (b) ENOS+ menos Neutro durante o Inverno; (c) ENOS+ menos Neutro durante a Primavera e (d) ENOS+ menos Neutro durante o Verão. Linhas grossas em negrito indicam pontos de longitude com significância estatística ao nível de $\mathrm{p}<0,05$. 

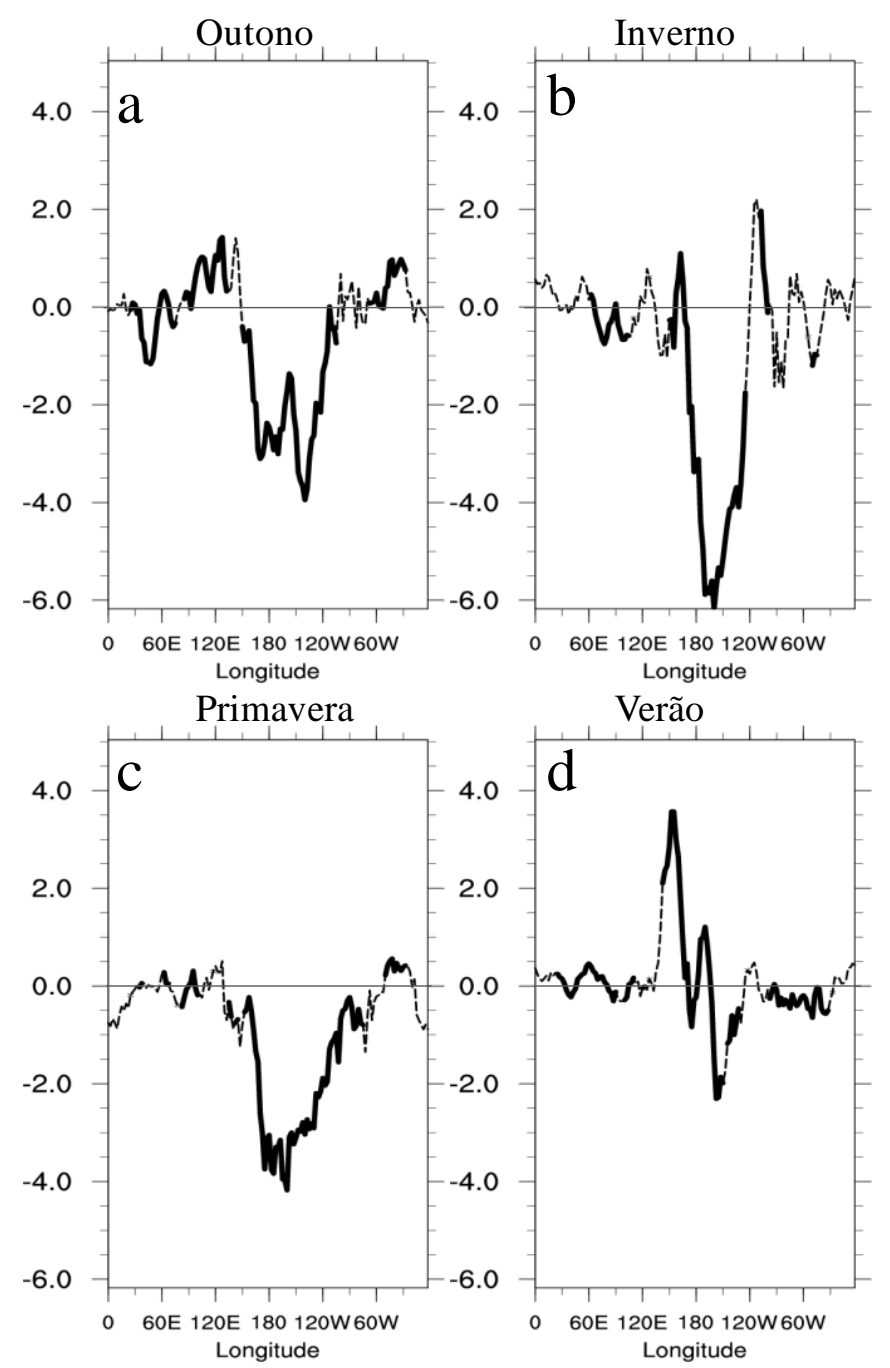

Figura 3.17 - Diferenças entre medianas do escoamento bloqueado por ponto de longitude entre o ENOS- e o padrão Neutro. (a) ENOS- menos Neutro durante o Outono; (b) ENOS- menos Neutro durante o Inverno; (c) ENOS- menos Neutro durante a Primavera e (d) ENOS- menos Neutro durante o Verão. Linhas grossas em negrito indicam pontos de longitude com significância estatística ao nível de $\mathrm{p}<0,05$.

Adicionalmente, as Tabelas 3.2 a 3.5 complementam as estatísticas dos bloqueios mostrando o número total de eventos de bloqueios ( $\tau \geq 3$ dias) e nas medidas de tendência central (média e mediana) da duração dos eventos para cada setor de ocorrência de bloqueios e para as estações do outono, inverno, primavera e verão, respectivamente. As medidas de tendência central para os períodos das fases opostas do ENOS são representadas pela respectiva diferença com relação a fase Neutra, de modo explicar visualmente o sinal da variabilidade detectada, caso a hipótese nula $\left(\mathrm{H}_{\mathrm{o}}\right)$ seja rejeitada. $\mathrm{Na}$ fase Neutra, as respectivas 
medidas foram dispostas em valores exatos. Os testes aplicados foram testes de proporção para a variável "eventos" tal como na Eq.10 e o teste-U de Mann-Whitney foi aplicado para a variável "duração", tal como encontrado em Wilks (2006). Os valores-p em "negrito" $e$ “negrito-itálico” indicam às regiões cujas estatísticas passaram nos testes com significância estatística ao nível de $90 \%$ e $95 \%$ de confiança, respectivamente.

Assim as Tabelas 3.2 (Outono), 3.3 (Inverno), 3.4 (Inverno) e 3.5 (Verão) revelam que os eventos de bloqueio ( $\tau \geq 3$ dias) ao longo do Hemisfério Sul tendem a durar em mediana um dia a mais na fase Quente do ENOS com relação aos Neutros durante os períodos de inverno e primavera com significância estatística de $\mathrm{p}<0.05$ e $\mathrm{p}<0.1$, respectivamente, mostrando a importância da fase Quente do ENOS durante este período do ano em termos de duração dos eventos. Entretanto, nenhum resultado mostra com eficiência estatística o aumento no número de eventos de bloqueios com $\tau \geq 3$ dias durante a fase Quente do ENOS. Neste sentido, conclui-se que o deslocamento da atividade de bloqueios sobre o Pacífico Leste e ocorrendo sobre latitudes mais altas contribui eficazmente com eventos de bloqueios com maior duração.

Dois fatores podem contribuir com a maior duração dos eventos sobre o Pacífico Leste, sendo: as anomalias de leste são geralmente mais fracas sobre este setor, de acordo com Marques e Rao (2001) e o centro do anticiclone está estatisticamente situado em latitudes maiores. Por outro lado, na fase Fria do ENOS, as tabelas mostram uma redução no número total de eventos de bloqueios com taxa crescente ao longo do ano de $17 \%, 20 \%$ e $37 \%$ no outono, inverno e primavera, respectivamente, ao passo que nenhum resultado mostrou mudanças na duração mediana dos eventos. Resumindo, na fase Quente do ENOS a duração mediana dos eventos é aumentada, sem alterar estatisticamente o número de eventos, enquanto que na fase Fria do ENOS o número total de eventos é reduzido, sem modificação no valor mediano da duração. 
De forma sucinta, conclui-se que o número de eventos de bloqueio é maior na fase Quente do ENSO em comparação com a fase Fria do ENOS. Estes resultados concordam os obtidos por Wiendenman et al. (2002) e Damião et al. (2008). Apesar disso, Marques (1996) encontrou mais eventos durante a fase Fria do ENOS comparado com a fase Quente, mas esta discrepância parece estar associada com a quantidade de dados, bem como a metodologia usada no critério de identificação do ENOS. Contudo, a fase Quente do ENOS é similar à fase Neutra em termos do número total de eventos, que, contudo, o local preferencial tende a ser deslocado para leste. Por outro lado, a fase Fria do ENOS também altera o local preferencial, limitando as maiores frequencias às regiões de bordas oeste e leste do Pacífico Sul. Estes resultados concordam com os resultados de Mullen (1989) e Barriopedro et al. (2006), ambos para o $\mathrm{HN}$, mas que sugeriram que o ENOS pode afetar o local preferencial, sendo que o primeiro analisou os resultados de um Modelos de Circulaçao Geral. No entanto, os resultados observados neste trabalho discordam dos resultados numéricos obtidos por Mullen (1989) no que diz respeito à frequiência e a duração dos eventos entre as fases opostas, já que frequiência e duração representam caracteristicas distintas entre as fases opostas do ENOS. 
Tabela 3.2 - Estatística do total e duração dos eventos de bloqueio de bloqueio para o OUTONO. As medidas de tendência central para os períodos das fases opostas do ENOS são representadas pela respectiva diferença ([Fases opostas]-[Fase Neutra]), no sentido de explicar visualmente o sinal da variabilidade detectada, caso a hipótese nula $\left(\mathrm{H}_{\mathrm{o}}\right)$ seja rejeitada. Nos episódios Neutros, as respectivas medidas estão dispostas em valores exatos. Os testes aplicados foram de proporção para a variável "eventos" e o teste-U de Mann-Whitney para a variável "duração". Os valores-p em "negrito" $e$ "negrito-itálico" indicam às regiões cujas estatísticas passaram nos testes com significância estatística ao nível de $90 \%$ e $95 \%$ de confiança, respectivamente.

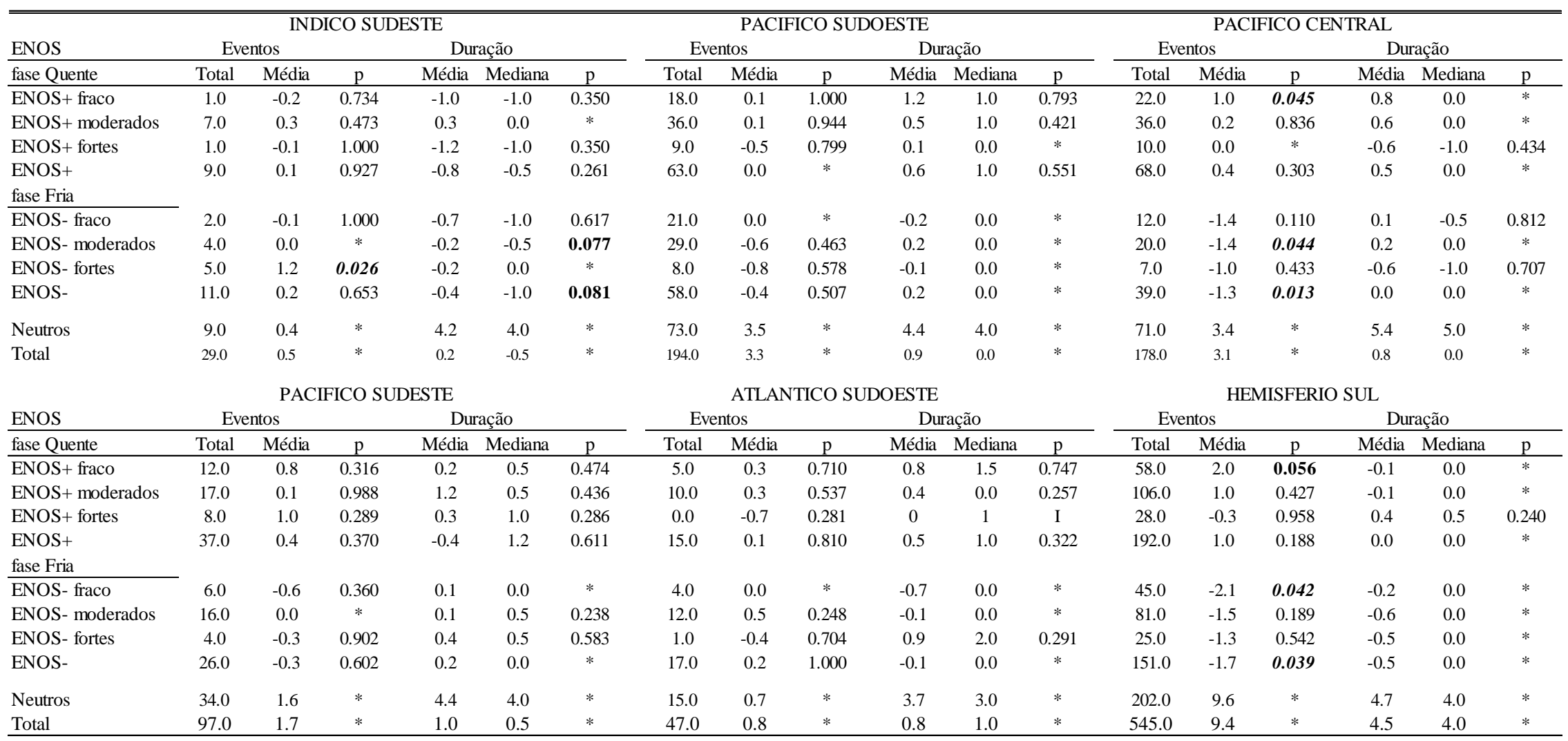


Tabela 3.3- Análogo a Tabela 3.3, exceto que referente ao período do INVERNO.

\begin{tabular}{|c|c|c|c|c|c|c|c|c|c|c|c|c|c|c|c|c|c|c|}
\hline \multirow{3}{*}{$\frac{\text { ENOS }}{\text { fase Quente }}$} & \multicolumn{6}{|c|}{ "INDICO SUDESTE } & \multicolumn{6}{|c|}{ PACIFICO SUDOESTE } & \multicolumn{6}{|c|}{ " PACIFICO CENTRAL } \\
\hline & \multicolumn{2}{|c|}{ Eventos } & \multicolumn{4}{|c|}{ Duração } & \multirow{2}{*}{\multicolumn{2}{|c|}{ Eventos }} & \multicolumn{4}{|c|}{ Duração } & \multicolumn{2}{|c|}{ Eventos } & \multicolumn{4}{|c|}{ Duração } \\
\hline & Total & Média & $\mathrm{p}$ & Média & Mediana & $\mathrm{p}$ & & & $\mathrm{p}$ & Média & Mediana & $\mathrm{p}$ & Total & Média & $\mathrm{p}$ & Média & Mediana & $\mathrm{p}$ \\
\hline ENOS+ fraco & 5.0 & 0.4 & 0.4471 & $\begin{array}{c}-0.4 \\
y\end{array}$ & 0.0 & $*$ & 16.0 & -0.7 & 0.5709 & 0.9 & 1.0 & 0.156 & 15.0 & $\begin{array}{c}-0.7 \\
-1\end{array}$ & 0.5541 & 0.2 & 0.0 & * \\
\hline ENOS+ moderados & 7.0 & 0.7 & 0.8550 & 1.0 & 1.0 & 0.098 & 37.0 & -0.2 & 0.9096 & 0.2 & 1.0 & 0.501 & 41.0 & 0.4 & 0.6241 & -0.1 & 0.0 & $*$ \\
\hline ENOS+ fortes & 0.0 & I & I & I & I & I & 8.0 & -1.2 & 0.3902 & -0.1 & 0.0 & $*$ & 10.0 & -0.3 & 0.9012 & -1.2 & -1.0 & 0.345 \\
\hline $\begin{array}{l}\text { ENOS+ } \\
\text { fase Fria }\end{array}$ & 12.0 & 0.1 & 0.8620 & 0.4 & 0.5 & 0.399 & 61.0 & -0.5 & 0.4877 & 0.4 & 1.0 & 0.267 & 66.0 & 0.0 & $*$ & -0.2 & 0.0 & 0.940 \\
\hline ENOS- fraco & 4.0 & 0.7 & 1.0000 & -0.1 & 0.0 & $*$ & 20.0 & -0.5 & 0.0049 & -0.4 & 0.0 & $*$ & 16.0 & -1.0 & 0.2893 & -0.5 & -0.5 & 0.885 \\
\hline ENOS- moderados & 4.0 & 0.4 & 0.7228 & 0.4 & 0.5 & 0.077 & 29.0 & -1.0 & 0.2130 & 0.0 & 0.0 & $*$ & 24.0 & -1.3 & 0.0798 & -0.5 & 0.0 & $*$ \\
\hline ENOS- fortes & 1.0 & 0.3 & 0.9163 & 0.4 & 1.0 & 0.357 & 10.0 & -0.5 & 0.7769 & -0.3 & 0.0 & $*$ & 8.0 & -1.0 & 0.4770 & -1.3 & -1.0 & 0.289 \\
\hline ENOS- & 9.0 & -0.1 & 0.8351 & 0.2 & 0.0 & 0.624 & 59.0 & -0.8 & 0.2269 & 0.0 & 0.0 & $*$ & 48.0 & -1.1 & 0.0474 & -0.6 & 0.0 & 0.374 \\
\hline Neutros & 12.0 & 0.6 & * & 3.6 & 3.0 & $*$ & 81.0 & 3.9 & * & 4.6 & 4.0 & $*$ & 77.0 & 3.7 & $*$ & 6.0 & 5.0 & * \\
\hline \multirow[t]{2}{*}{ Total } & 29.0 & 0.5 & * & 0.8 & 0.8 & $*$ & 201.0 & 3.5 & * & 0.7 & 0.0 & $*$ & 191.0 & 3.3 & * & 0.4 & 0.0 & $*$ \\
\hline & \multicolumn{6}{|c|}{ PACIFICO SUDESTE } & \multicolumn{6}{|c|}{ ATLANTICO SUDOESTE } & \multicolumn{6}{|c|}{ HEMISFERIO SUL } \\
\hline ENOS & & tos & & Dur: & ação & & & ntos & & Dur & ação & & & ntos & & Dur & ação & \\
\hline fase Quente & Total & Média & $\mathrm{p}$ & Média & Mediana & $\mathrm{p}$ & Total & Média & $\mathrm{p}$ & Média & Mediana & $\mathrm{p}$ & Total & Média & $\mathrm{p}$ & Média & Mediana & $\mathrm{p}$ \\
\hline ENOS+ fraco & 12.0 & $\begin{array}{l}-0.1 \\
y\end{array}$ & 1.0000 & 0.1 & 0.5 & 0.423 & 4.0 & $\begin{array}{c}-0.3 \\
-3\end{array}$ & 0.6696 & 0.9 & 1.5 & 0.130 & 52.0 & $\begin{array}{l}-1.4 \\
\end{array}$ & 0.4321 & 0.3 & 1.0 & 0.174 \\
\hline ENOS+ moderados & 36.0 & 1.1 & 0.1176 & 1.1 & 0.5 & 0.074 & 11.0 & 0.0 & $*$ & 0.6 & 0.0 & $*$ & 132.0 & 1.4 & 0.2746 & 0.5 & 1.0 & 0.055 \\
\hline ENOS+ fortes & 13.0 & 1.8 & 0.1082 & 0.2 & 1.0 & 0.367 & 1.0 & -0.8 & 0.3229 & 0.4 & 1.0 & 0.439 & 32.0 & -1.1 & 0.6450 & -0.2 & 0.0 & $*$ \\
\hline $\begin{array}{l}\text { ENOS+ } \\
\text { fase Fria }\end{array}$ & 61.0 & 0.9 & 0.1321 & -0.5 & 1.2 & 0.076 & 16.0 & -0.3 & 0.5315 & 0.6 & 1.0 & 0.185 & 216.0 & 0.2 & 0.8565 & 0.3 & 1.0 & 0.042 \\
\hline ENOS- fraco & 13.0 & -0.4 & 0.7262 & 0.0 & 0.0 & $*$ & 5.0 & -0.3 & 0.0171 & -0.6 & 0.0 & $*$ & 58.0 & -2.1 & 0.0508 & -0.4 & 0.0 & $*$ \\
\hline ENOS- moderados & 22.0 & -0.3 & 0.6715 & 0.1 & 0.5 & 0.559 & 11.0 & 0.0 & $*$ & 0.0 & 0.0 & * & 90.0 & -2.8 & 0.0236 & -0.2 & 0.0 & $*$ \\
\hline ENOS- fortes & 8.0 & 0.1 & 1.0000 & 0.3 & 0.5 & 0.534 & 3.0 & -0.1 & 1.0000 & 1.0 & 2.0 & 0.172 & 30.0 & -1.8 & 0.4222 & -0.3 & 0.0 & $*$ \\
\hline ENOS- & 43.0 & -0.3 & 0.6635 & 0.1 & 0.0 & 0.492 & 19.0 & -0.1 & 0.2463 & 0.0 & 0.0 & $*$ & 178.0 & -2.4 & 0.0069 & -0.3 & 0.0 & * \\
\hline Neutros & 53.0 & 2.5 & * & 4.5 & 4.0 & * & 24.0 & 1.1 & $*$ & 3.6 & 3.0 & $*$ & 247.0 & 11.8 & $*$ & 4.9 & 4.0 & $*$ \\
\hline Total & 157.0 & 2.7 & $*$ & 0.9 & 0.5 & $*$ & 59.0 & 1.0 & $*$ & 0.8 & 1.0 & $*$ & 637.0 & 11.0 & $*$ & 4.9 & 4.0 & $*$ \\
\hline
\end{tabular}


Tabela 3.4 - Análogo a Tabela 3.3, exceto que referente ao período da PRIMAVERA.

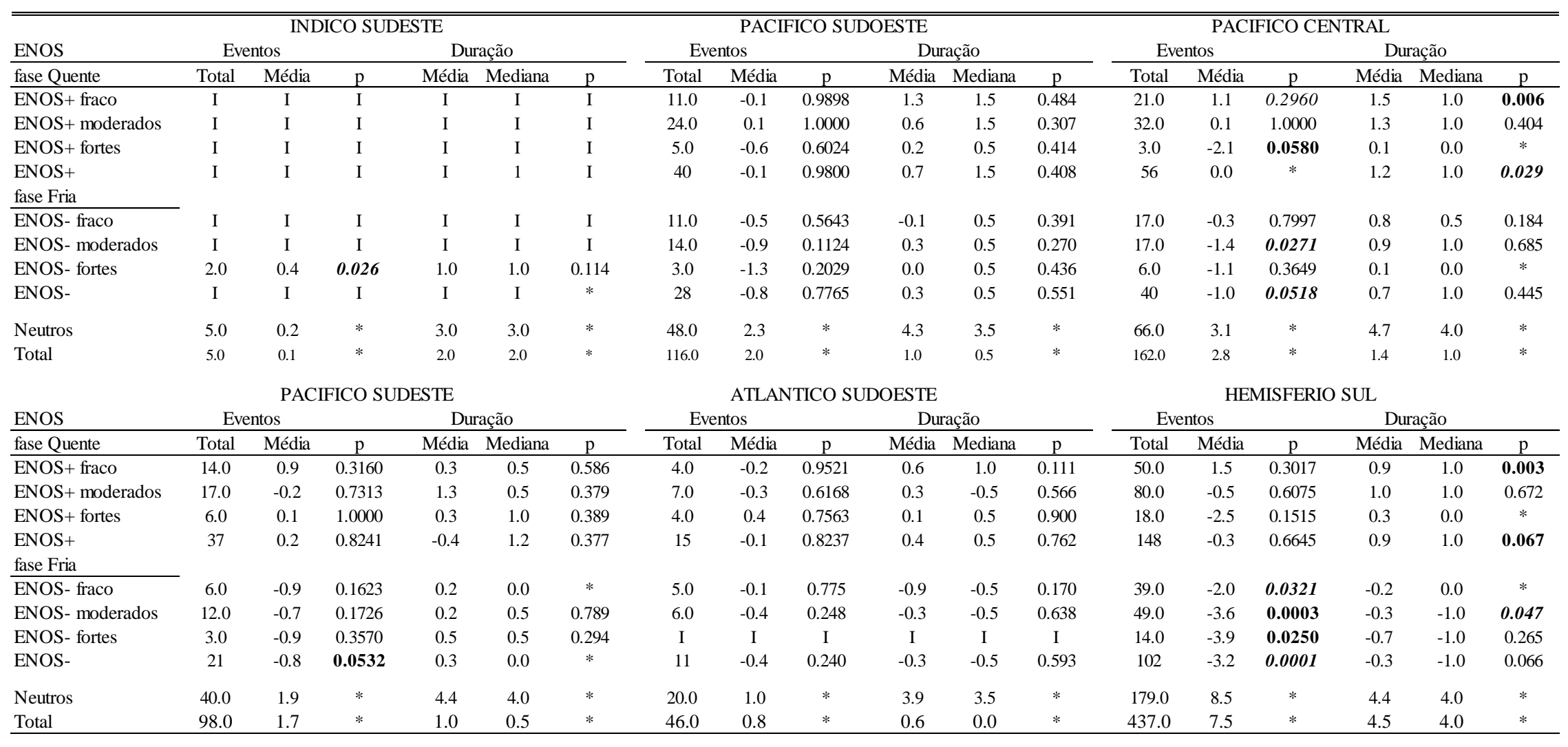


Tabela 3.5 - Análogo a Tabela 3.3, exceto que referente ao período do VERÃO.

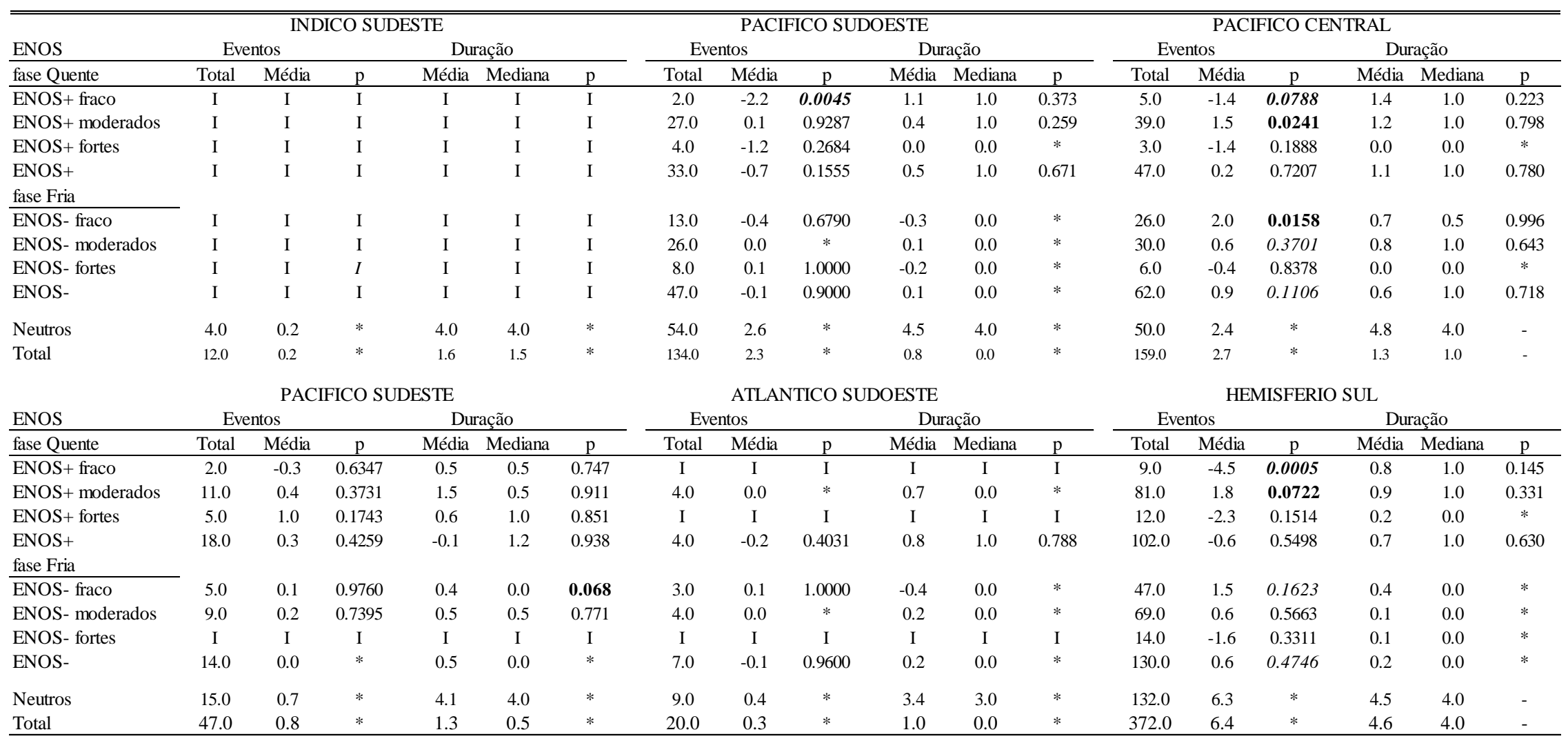




\subsection{OSCILAÇÃO ANTÁRTICA E ENOS}

Conforme verificado neste capítulo, uma questão a ser respondida é, porque há menos bloqueios durante a fase fria do ENOS? Seria o modo combinado AAO e ENOS um mecanismo de teleconexões importante na freqüência dos eventos de bloqueios? Para explorar estas relações entre a variabilidade diária do escoamento bloqueado e os principais modos de variabilidade que afetam o HS em escala intrasazonal a interanual foram investigados os dias com eventos de bloqueio de acordo com as fases das AAO e ENOS de 1979 até 2007 e somente para a estação do inverno, por ser a estação de maior frequência de bloqueios no HS. O índice diário da AAO foi obtido via FTP do Climate Prediction Center (CPC) / National Center for Environmental Prediction (NCEP) (ftp://ftp.cpc.noaa.gov/cwlinks). O índice diário da AAO foi obtido por análise de funções ortogonais empíricas (Empirical Orthogonal Function - EOF) projetados na anomalia diária do geopotencial em $700 \mathrm{hPa}$ de $20^{\circ}$ até $90^{\circ} \mathrm{S}$. A influência combinada entre as fases da AAO e do ENOS sobre a frequiência de bloqueios foi caracterizada de acordo com quatro combinações possíveis, sendo: a) AAO-|ENOS-; b) AAO-|ENOS+; c) AAO+|ENOS- e d) AAO +|ENOS+. De 1979 a 2000 houve seis anos com o ENOS+ e seis anos com o ENOS-.

A Tabela 3.6 mostra o número de dias com escoamento bloqueado e do número total de dias com bloqueios com $\tau \geq 3$ dias. Considerando o número total de dias de inverno, durante os seis anos, o número de dias com escoamento bloqueado é estatisticamente diferente $(\mathrm{p}<0.01)$ nas combinações para a AAO-|ENOS- e AAO+|ENOS-, entretanto nenhuma diferença estatística é verificada entre a AAO-|ENOS+ e AAO+|ENOS+. A combinação AAO+|ENOS- representa um mínimo em freqüência de bloqueios no HS, sendo aproximadamente $1 / 3$ do número total de eventos de bloqueio em comparação às outras três combinações. No entanto, baseado nestas proporções, isto é do número de eventos de 
bloqueios, os testes estatísticos mostram que as combinações AAO-|ENOS-, AAO-|ENOS+ e $\mathrm{AAO}+\mid \mathrm{ENOS}+$ são estatisticamente indistintos ao nível de $\mathrm{p}<0,05$. Por outro lado, é interessante observar o predomínio da AAO- no máximo de atividade de bloqueios sobre o HS independentemente da fase do ENOS, embora a AAO+ tenha parcela significativa na frequência de bloqueios durante o ENOS+. Com base nestes resultados preliminares investigou-se a dinâmica da teleconexão da AAO combinada com o ENOS e os motivos que levam a redução da atividade de bloqueios durante a AAO+|ENOS- e no ENOS-, conforme verificado na seção 3.2 .

Tabela 3.6 - Distribuição do número de dias com escoamento bloqueado e o número total de eventos de bloqueio com $\tau \geq 3$ dias durante as combinações AAO|ENOS.

\begin{tabular}{lccccc}
\hline \hline & \multicolumn{2}{c}{ ENOS+ } & & \multicolumn{2}{c}{ ENOS- } \\
\cline { 2 - 3 } \cline { 2 - 6 } & Dias & Eventos & & Dias & Eventos \\
\cline { 2 - 3 } AAO- & 127 & 22 & & 122 & 17 \\
AAO+ & 118 & 21 & & 69 & 7 \\
\hline
\end{tabular}

A Figura 3.18 mostra o número de dias com escoamento bloqueado tal como representado na Tabela 3.6 e distribuídos por ponto de longitude de acordo com as bandas zonais definidas previamente e para cada combinação AAO|ENOS conforme indicado no topo de cada figura. A banda de latitude total (linha sólida) ilustra eventual contribuição relativa às bandas de latitudes médias-baixas (linha pontilhada) e médias-altas (linha tracejada). Como observado, no ENOS- em ambas as fases da AAO, a atividade de bloqueios é reduzida sobre o Pacífico Central mas aumenta sobre os setores do Sudoeste e Sudeste do Pacífico. Durante a combinação AAO+|ENOS- o ligeiro aumento da atividade de bloqueios no sul da América do Sul e Atlântico Sudoeste não tem significância estatística. Por outro lado, a combinação AAO-|ENOS+ representa um crescimento linear no sentido de Oeste para Leste no Pacífico 
Sul, enquanto a combinação AAO+|ENOS+ representa um decrescimento linear de Oeste para Leste sobre o Pacífico Sul. Ademais, pode-se perceber que a episódios ENOS- parecem contribuir em grande parte com o enfraquecimento da atividade de bloqueios sobre o Pacífico Central, mas resultados discutidos à frente indicam que a fase da AAO tem um papel também importante. Também se ressalta na análise destas figuras que os eventos de bloqueio situamse em latitudes mais altas durante a AAO- sobre o Pacifico Leste do que sua contraparte, a $\mathrm{AAO}+$.
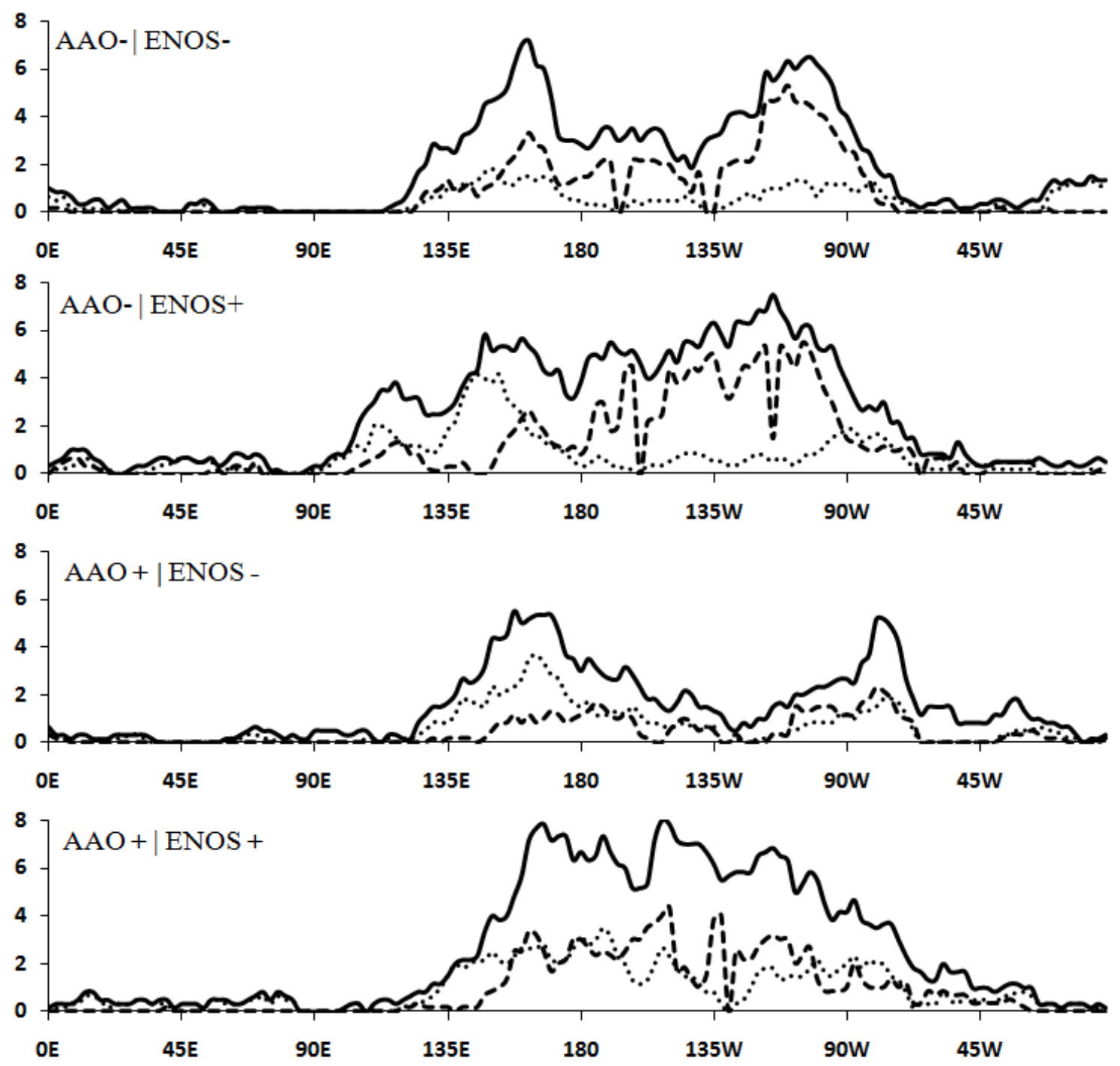

Figura 3.18 - Distribuição da frequência do escoamento bloqueado combinando o ENOS com a variabilidade diária da AAO durante o período de 1979 a 2000. (a) AAO-|ENOS-, (b) AAO-|ENOS+, (c) $\mathrm{AAO}+\mid \mathrm{ENOS}-$, (d) $\mathrm{AAO}+\mid \mathrm{ENOS}+$. As linhas sólidas representam a banda zonal total, enquanto a linhas tracejadas representam latitudes médias-altas e as linhas pontilhadas representam latitude médias-baixas. 
A Figura 3.19, extraída de Carvalho et al., (2005), mostra os padrões de teleconexões obtidos pelas anomalias do vento zonal em 200-hPa durante as fases da AAO. Na fase negativa da AAO (Fig. 3.19, acima), o jato subtropical é intensificado e está mais deslocado para o equador do que na fase positiva da AAO. Por outro lado, na fase positiva da AAO (Fig. 3.19, abaixo), o jato subtropical move-se para latitudes mais polares e o jato polar é intensificado. Desta forma, a Fig. 3.19 sugere modificações na posição e intensidade do jato subtropical, bem como na intesidade do jato polar, de forma que ondas de Rossby possam propagar-se para os pólos e tomando trajetos como em Hoskins and Ambrizzi (1993). Comparando a Fig. 3.19 com a Fig. 3.18, pode ser observado que a intensificação do jato subtropical, associado com enfraquecimento do jato polar na AAO negativa e durante a fase quente do ENOS convergem com o aumento da atividade de bloqueios de latitudes altas no Pacífico Central. Por outro lado, o fortalecimento do jato polar durante a fase positiva da AAO (Fig. 3.19, abaixo) pode estar contribuindo com a redução da atividade de bloqueios sobre o Pacífico Leste (Fig. 3.18c) e/ou os eventos de bloqueio formam-se sobre latitudes mais baixas (Fig.3.18d).
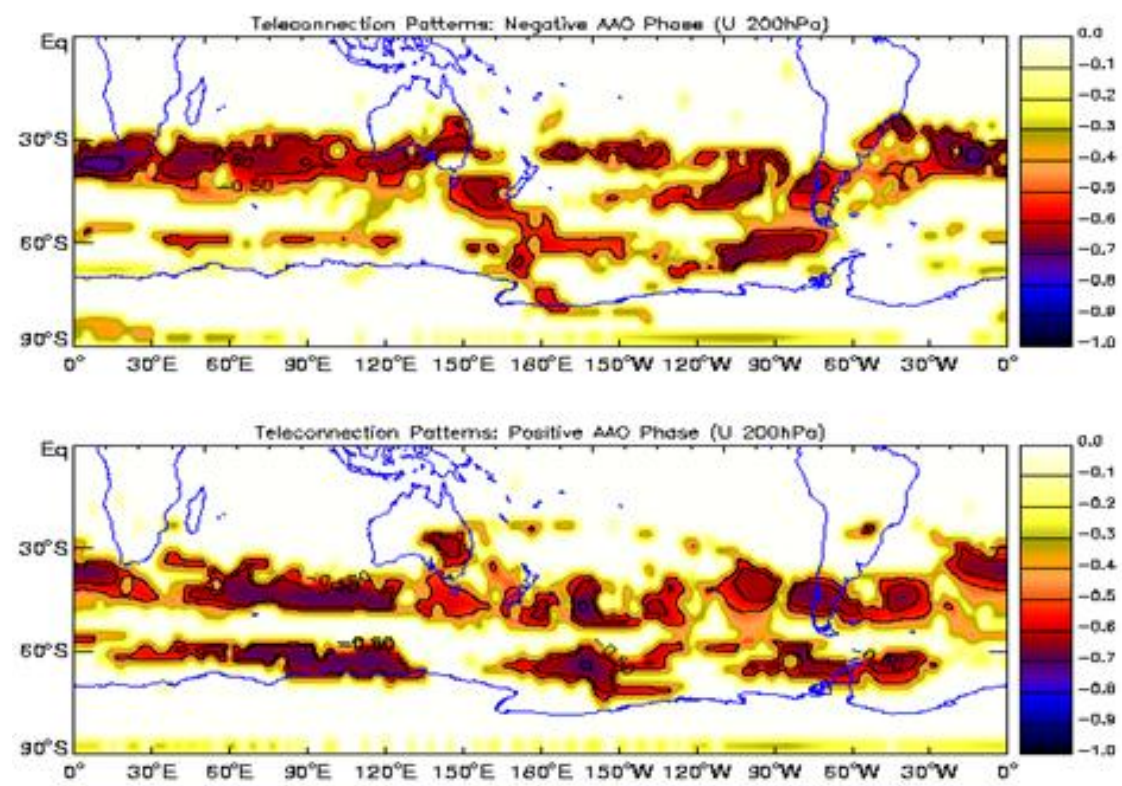

Figura 3.19 - Padrões de teleconexões obtidos pelas anomalias do vento zonal em $200 \mathrm{hPa}$ durante as fases negativa (acima) e positiva (abaixo) da AAO. Figura extraída de carvalho et al., 2005. 
Trenberth (1986) mostrou que os distúrbios transientes atuam acelerando o vento de oeste na região principal do "storm track" e para o sul do anticiclone de bloqueio, mas eles desaceleram o vento de oeste próximo da região de divisão do jato, ajudando na manutenção do bloqueio. Desde que o GHGN proporciona uma medida da intensidade do escoamento zonal, a presença de anomalias de leste entre $35^{\circ} \mathrm{S}$ e $50^{\circ} \mathrm{S}$ é importante na detecção de escoamentos bloqueados (ver Figura 3.8) e de acordo com Lejenäs (1984), a presença destas anomalias de leste indica a posição do bloqueio. Chen e van den Dool (1997a) em estudo para o HN enfatizaram que disturbios transientes em latitudes mais altas (baixas) são favoráveis (desfavoráveis) para a formação e manutenção de eventos de bloqueios. Deste modo, o fortalecimento do jato polar em latitudes menores no Pacífico Central deve criar condições desfavoráveis para a formação e manutenção dos eventos de bloqueio devido, ao fortalecimento do vento de oeste na região preferencial de formação dos eventos de bloqueio. Por outro lado, a presença e o fortalecimento do jato subtropical podem ser importantes na manutenção de bloqueios devido a sua associação com a bifurcação do jato.

Para exemplificar as discussões acima, foram feitas composições das anomalias do vento zonal em $200 \mathrm{hPa}$ (ciclo anual removido) durante eventos de bloqueio separados de acordo com o ENOS- (Figura 3.20) e o ENOS+ (Figura 3.21) e de acordo com o setor de bloqueios. Composições para as fases $\mathrm{AAO}-(\mathrm{AAO}+)$ são mostradas nas colunas da esquerda (direita) do painel de figuras, enquanto que os setores de bloqueio do Pacifico Sudoeste, Central e Sudeste são mostrados a cada linha do painel, respectivamente.

De modo geral, a maior diferença entre a $\mathrm{AAO}+$ e a $\mathrm{AAO}$ - durante o ENOS- é a maior intensidade e o cizalhamento do escoamento em latitudes médias quando a AAO esta na sua fase positiva. Nesta configuração (AAO+|ENOS-) é então observada a presença do jato polar mais intenso sobre latitudes menores em comparação com o observado na AAO-|ENOS-, forçando o anticiclone de bloqueio e as anomalias de leste (Figura 3.20b) muito mais para o 
norte, principalmente nos setores do Pacífico Sudoeste e Central. Também notar o fortalecimento destas anomalias de leste (Figura 3.20b) e dos ventos de oeste ao longo Pacífico Oeste (Figura 3.20d), seguindo a região dos Storm Tracks ao sul da Austrália, os quais representam suportar muito mais advecção zonal do vento médio $(\bar{u})$, bloqueios de curtíssima duração, bem como desfavorecendo a manutenção dos bloqueios formados sobre o Pacífico Central. O fortalecimento do vento zonal de oeste, durante a AAO+|ENOS-, explica em parte, a quase ausência de bloqueios sobre o Pacífico Central, mas o que pode explicar a baixa frequiência de bloqueios sobre o Pacífico Central durante a AAO-|ENOS-? Observa-se na Figura 3.20c o enfraquecimento do jato subtropical no setor do Pacífico Central. Assim, o jato subtropical durante a AAO-|ENOS- é enfraquecido sobre o Pacífico Central e fortalecido na bordas do Pacífico Sul, nos setores Sudoeste e Sudeste do Pacífico, desfavorecendo a atividade de bloqueios sobre o Pacífico Central e favorecendo sobre as regiões de bordas do Pacífico Sul. Na AAO+|ENOS- e sobre o setor do Pacífico Central a atividade de bloqueio é ainda menos favorável devido à aceleração do vento zonal e consequentemente do jato polar em comparação com a AAO-|ENOS-.

Os resultados obtidos acima são agora re-enfatizados observando o ocorrido durante o ENOS+. Durante o ENOS+ (Figura 3.21) o fortalecimento do jato subtropical pode ser identificado durante ambas as fases da AAO. Embora um ligeiro aumento da frequiência de dias com escoamento bloqueado tenha sido observado durante a combinação AAO-|ENOS+, não existem diferenças estatísticas no número total de eventos de bloqueio com relação ao observado na AAO-|ENOS-. Por outro lado, durante o AAO+|ENOS+ há um aumento significativo (para $\mathrm{p}<0.01$ ) na frequiência de bloqueios quando comparado com o AAO+|ENOS-. Claramente, durante condições influenciadas pelo AAO+|ENOS- (Figuras 3.20b, 3.20d e 3.20f) e AAO+|ENOS+ (Figura 3.21b, 3.21d e 3.21f) há uma intensificação do jato polar, contudo mais intenso durante a AAO+|ENOS-. Já, durante a AAO+|ENOS+ as 
anomalias de leste estão posicionadas mais para o sul e enfraquecidas nos setores sudoeste e sudeste do Pacífico Sul em comparação com a AAO+|ENOS- e o jato subtropical é fortalecido e alongado zonalmente justo posicionado ao longo do jato polar, demonstrando que o ENOS+ modula um jato tropical mais intenso, independente da fase da AAO. Este padrão de anomalias de vento da alta troposfera representa suportar menor advecção zonal do vento médio $(\bar{u})$ favorecendo a formação de bloqueios comparativamente com AAO+|ENOS-. De modo geral, da análise do modo combinado AAO|ENSO entende-se que a "intensificação" do jato subtropical (polar) pode atuar construtivamente (destrutivamente) na manutenção de um evento de bloqueio, contribuindo efetivamente com a desaceleração do escoamento de oeste próximo a região de divisão do jato.

A Figura 3.22 mostra o campo médio das anomalias do geopotencial em $500 \mathrm{hPa}$ no HS durante as combinações AAO-|ENOS- (Fig. 3.22a), AAO+|ENOS- (Fig. 3.22b), AAOENOS+ (Fig. 3.22c) e AAO+|ENOS (Fig. 3.22d). A escala da anomalia vai de $-140 \mathrm{a}+140$ mgp. As principais diferenças entre a $\mathrm{AAO}+\mathrm{e} \mathrm{AAO}$ - estão associadas às intensidades e posições preferenciais longitudinal e latitudinal. Por exemplo, durante a AAO- os centros das anomalias dos anticiclones de bloqueio são estatisticamente significativos $(\mathrm{p}<0,05)$, alongados meridionalmente e intensificados acima de 80 mgp sobre a região do Pacífico Leste. Estruturas de bloqueio com padrão alongado meridionalmente em altas latitudes devem produzir maior deformação no campo do geopotencial, bloqueando com maior eficiência o caminho normal dos distúrbios transientes de superfície e produzindo bloqueios de grande extensão espacial e possivelmente de maior longevidade, do tipo Omega invertido. 

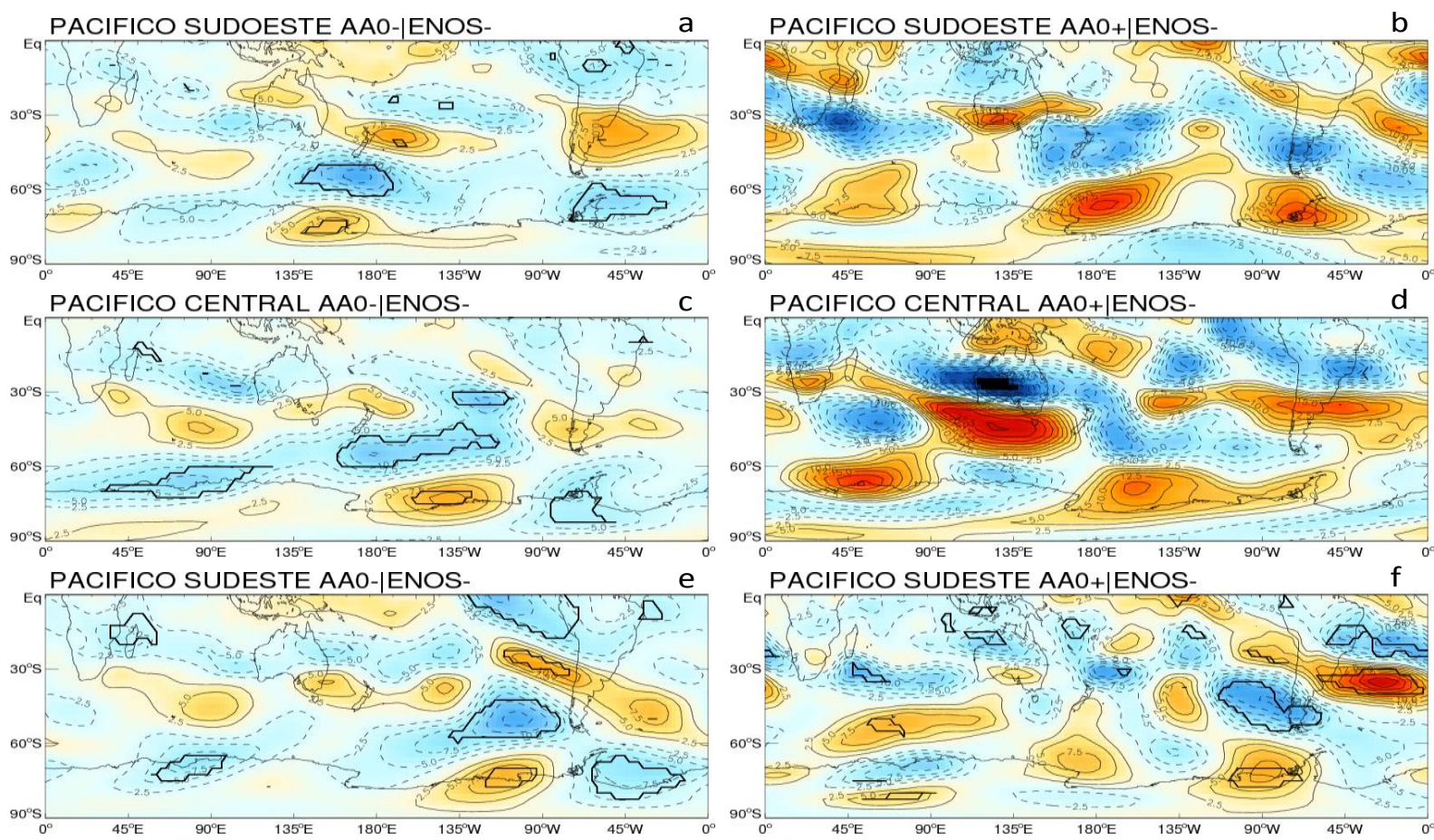

Figura 3.20 - Composições da média das anomalias do vento zonal em $200 \mathrm{hPa}$ durante os episódios de bloqueios com $\tau \geq 3$ dias para as combinações AAO-|ENOS- (à esquerda) e AAO+|ENOS- (à direita) sobre os setores do Pacífico Sudoeste (topo), Pacífico Central (meio) e Pacífico Sudeste (base). Linhas pretas em negrito são regiões com significância ao nível de $p<0,05$. Unid: [m.s ${ }^{-1}$ ]
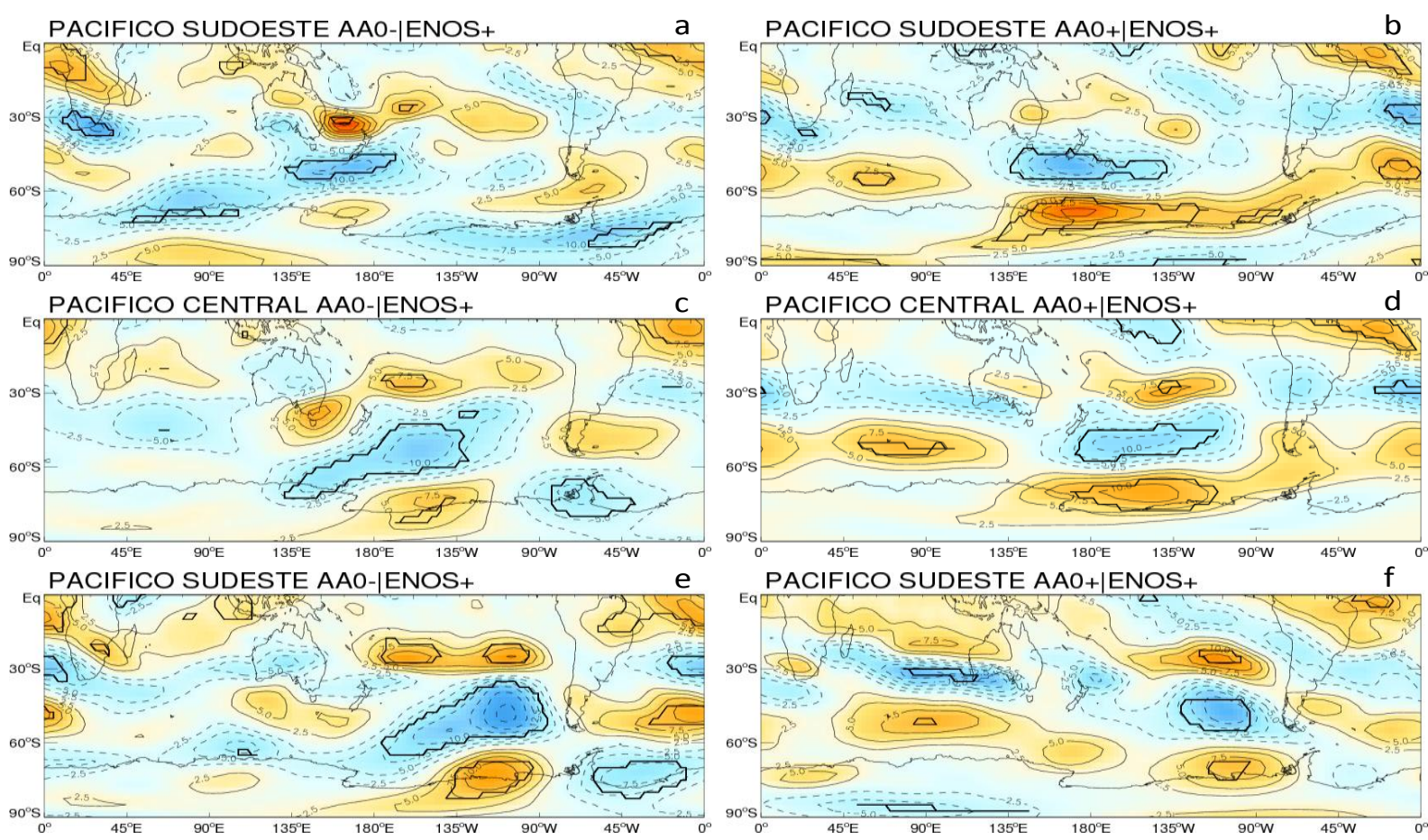

Figura 3.21 - Composições da média das anomalias do vento zonal em $200 \mathrm{hPa}$ durante os episódios de bloqueios com $\tau \geq 3$ dias para as combinações AAO-|ENOS+ (à esquerda) e AAO+|ENOS+ (à direita) sobre os setores do Pacífico Sudoeste (topo), Pacífico Central (meio) e Pacífico Sudeste (base). Linhas pretas em negrito são regiões com significância ao nível de $\mathrm{p}<0,05$. Unid: $\left[\mathrm{m} . \mathrm{s}^{-1}\right]$ 

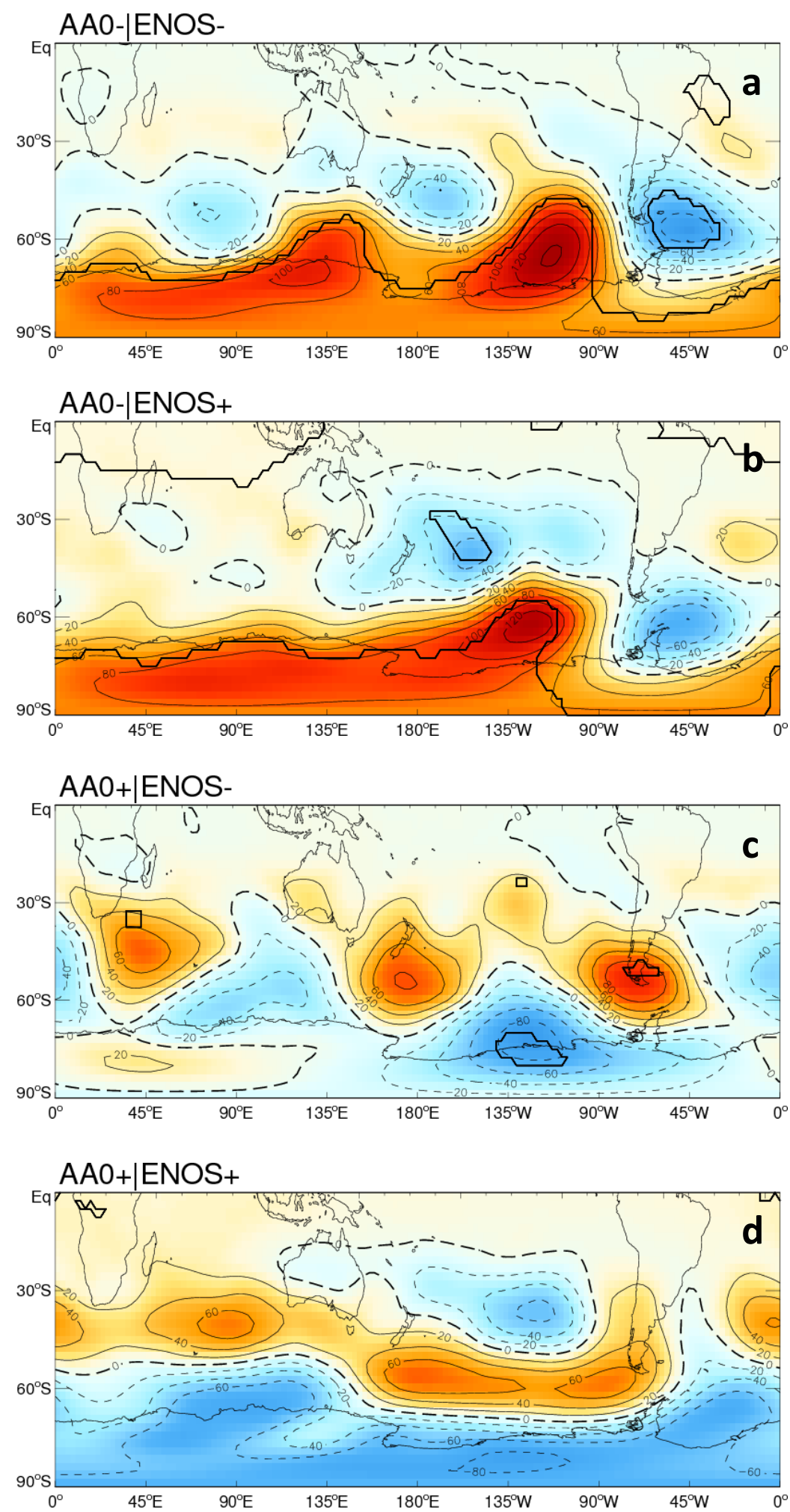

Figura 3.22 - Composições da média das anomalias da altura geopotencial no nível de 500-hPa durante os episódios de bloqueios com $\tau \geq 3$ dias para as combinações (a) AAO-|ENOS-, (b) AAO|ENOS+, (c) AAO+|ENOS-, AAO+|ENOS+ sobre o Hemisfério Sul. Unid:[mgp] 
Por outro lado, durante a fase positiva da AAO, as anomalias dos anticiclones de bloqueio são menos intensos do que sua contraparte, a AAO-, e somente têm significância estatística durante o ENOS- quando atua sobre o Sul da América do Sul, formando típicos bloqueios sobre o continente Sul Americano. Os anticiclones de bloqueio durante a $\mathrm{AAO}+\mid \mathrm{ENOS}+$ consistem de anticiclones fracos e alongados zonalmente, com preferência primaria de formação sobre o Pacífico Oeste (ver figura 3.18), contudo uns poucos eventos são observados sobre o Pacífico Leste. O padrão alongado zonalmente pode produzir preferencialmente bloqueios com menor extensão espacial, possivelmente do tipo dipolo, embora seja ainda necessário um estudo aprofundado sobre este tópico. Ainda, ressalta-se que durante a $\mathrm{AAO}+$ a estrutura de bloqueios situa-se mais ao norte, principalmente durante o ENOS- e aparentemente está associado à expansão do vórtice polar e o fortalecimento do jato polar naquela região, caracterizado pela presença de anomalias negativas no geopotencial ao sul do da região do bloqueio.

Aqui, a mais importante condição para o aumento na frequiência de bloqueios foi a presença do jato subtropical associado ao padrão clássico de bifurcação do jato (Trenberth, 1986; Marques, 1996), o qual parece ser intensificado durante anos influenciados pelo ENOS+ (Fig. 3.21) e/ou associada a persistência da AAO- (Fig 3.20a,c,e ou Fig 3.21a,c,e). O enfraquecimento do jato polar associado com os padrões do geopotencial e da pressão em superfície de latitudes médias durante a fase negativa da AAO (Carvalho et al., 2005 e ver Fig 3.19) do geopotencial parece ter um papel fundamental no relativo aumento na frequência de bloqueios na região do Pacífico Leste, como indicado nas Figuras 3.22. Outra característica que deve ser ressaltada, a variabilidade diária da AAO pode ter um papel fundamental na manutenção dos eventos de bloqueio, controlando o avanço e o retrocesso do anticiclone. Por exemplo, um anticiclone de bloqueio situado sobre o Pacífico Central durante a AAOENOS+ poderá retroceder para oeste ou avançar para leste quando a AAO passar para sua 
fase negativa, e ou ainda, bloqueios duplos poderão ser observados com avanço do anticiclone principal para leste da região de formação e a formação de um anticiclone secundário sobre o Pacífico Oeste.

O boxplot da Fig. 3.23 representa a distribuição da duração dos eventos de bloqueios para cada combinação AAO|ENOS e cada setor de bloqueios no Pacífico Sul, durante o período de 1979 a 2000. Os resultados enfatizam que os eventos de bloqueio são extremamente curtos sobre o Pacífico Oeste, destacando apenas os eventos durante a combinação AAO+|ENOS+. No Pacífico Central, três combinações são importantes, sendo que cada uma atua sobre regiões preferenciais distintas, dentro deste setor, sendo ao sul da Nova Zelândia durante as combinações AAO-|ENOS- e AAO+|ENOS+ e sobre a região do Pacífico Leste durante a AAO-|ENOS+. Já nos Pacífico Sudeste, observa-se igualmente as três combinações, contudo os eventos foram muito mais persistentes durante a AAO-|ENOS-, e eventos extremos (muito longos) foram registrados durante a AAO-|ENOS+. Ademais, a transição da AAO- para a AAO+ e vice-versa, tem um impacto crucial sobre o Pacífico Sudoeste, modulando a posição do anticiclone de bloqueio.
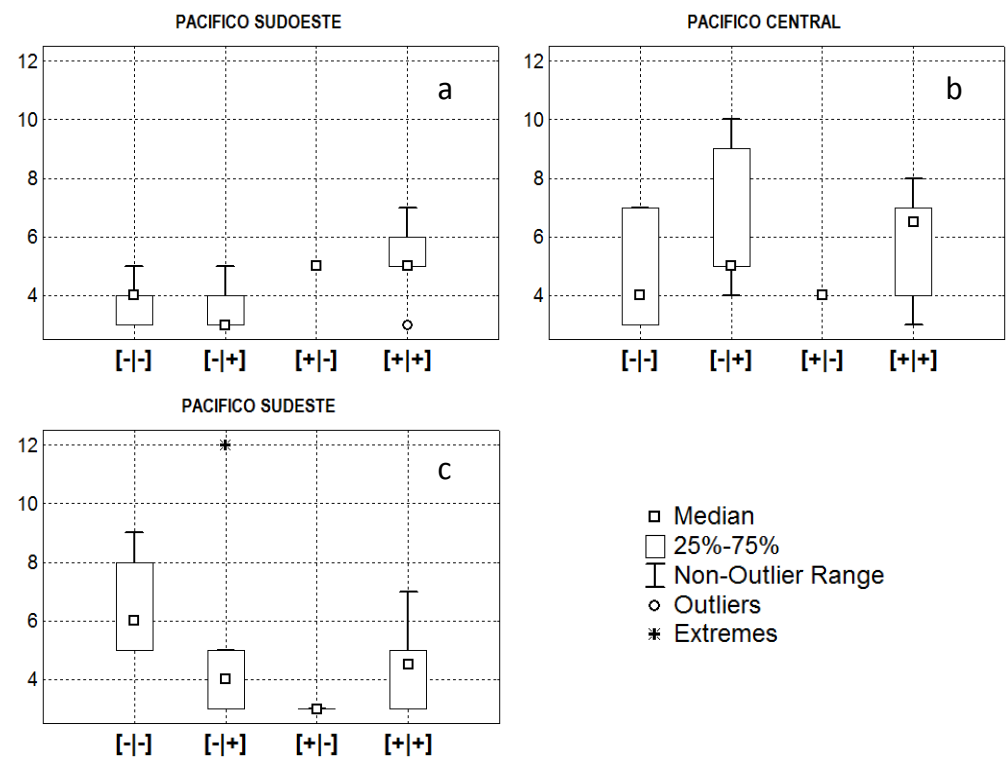

Figura 3.23 - Boxplot com estatísticas da duração dos eventos de bloqueio com $\tau \geq 3$ dias para as quatro combinações do ENOS [+|-] com a AAO [+|-] sobre os setores de bloqueio do (a) Pacífico Sudoeste, (b) Pacífico Central e (c) Pacífico Sudeste. 
Uma questão relevante para ser respondida é se a preferência observada no número total de dias com bloqueios (onde, $\tau \geq 3$ dias) é realmente diferente nas fases opostas da AAO. Um teste estatístico de proporção foi efetuado para cada setor de bloqueio e para cada fase da AAO para o nível de significância de $1 \%$. Os resultados mostram que a proporção de bloqueios aumenta em todo o Pacifico Sul na AAO- comparado com a AAO+ quando o ENOS esta na sua fase fria. Por outro lado, durante o ENOS+, o número de dias envolvendo bloqueios atmosféricos aumenta no Pacífico Oeste na $\mathrm{AAO}+$ e aumenta nos setores do Pacífico Central e Sudeste na AAO-. Deste modo, mostra-se a importância da variabilidade diária da AAO associada com o ENOS, reforçando a idéia de que a freqüência de bloqueios durante a AAO- aumenta na região do Pacífico Leste $\left(150^{\circ} \mathrm{W}-80^{\circ} \mathrm{W}\right)$.

\subsection{VARIABILIDADE INTERANUAL E TENDÊNCIAS}

Nesta seção, são investigadas possíveis tendências e variabilidades relacionadas aos eventos de bloqueios atmosféricos para o período de 1950 a 2007. A Figura 3.24 mostra a distribuição sazonal dos eventos de bloqueio ao longo do ano nos setores do Indico Sudeste (a), Pacífico Sudoeste (b), Pacífico Central (c), Pacífico Sudeste (d), e Atlântico Sudeste (e). As tendências lineares com equações estão indicadas nas figuras. A significância de cada tendência foi testada seguindo o método discutido em Jones e Carvalho (2006). O teste foi realizado randomizando as freqüências e as tendências de regressões por 2.000 vezes. O coeficiente angular real foi comparado com o $95^{\text {th }}$ percentil da distribuição de freqüência dos 2.000 coeficientes angulares obtidos pela randomização. Baseado neste teste estatístico, a tendência negativa localizada sobre o Pacífico Sudeste foi significativa ao nível $\mathrm{p}<0.05$, 
enquanto que nenhum outro setor apresentou tendências significativas. A tendência da AAO em direção a sua fase positiva (e.g. Thompson e Solomon 2002) em combinação com o ENOS+ pode estar contribuindo para a tendência negativa observada sobre o Pacífico Leste.
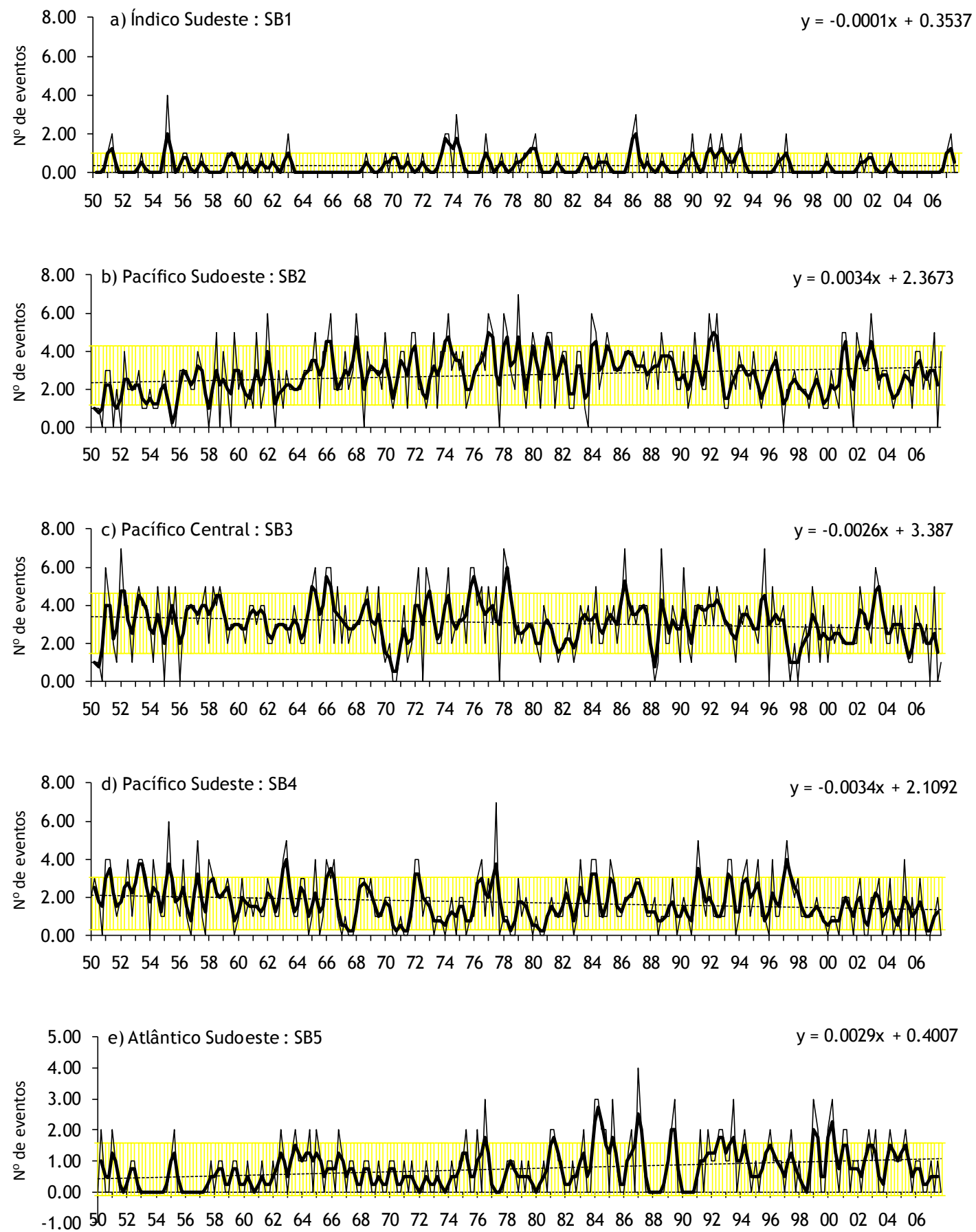

Figura 3.24 - Distribuição trimestral dos eventos de bloqueio ao longo do ano nos setores do Indico Sudeste (a), Pacífico Sudoeste (b), Pacífico Central (c), Pacífico Sudeste (d), Atlântico Sudeste (e). Áreas amarelas representam o desvio padrão para a série temporal. As linhas em negrito representam um filtro triangular 1-2-1. A reta pontilha representa a reta de regressão linear. No topo à direita de cada figura está representada a equação da tendência. 
A Fig. 3.25 mostra o número total sazonal de bloqueios para o HS e sua respectiva variância móvel para uma janela de 11 anos, com o objetivo de reconhecer a amplitude do sinal decadal. Como observado, a série temporal usada não representa qualquer tendência de longo prazo e por isso apenas a equação de regressão foi mostrada no canto superior esquerdo da figura. De outro modo, a variância móvel ajustada indica a existência de um ciclo multidecadal no número sazonal de eventos desde meados da década de 1960 até o início da década de 1990, onde existem flutuações em escala sazonal a decadal.

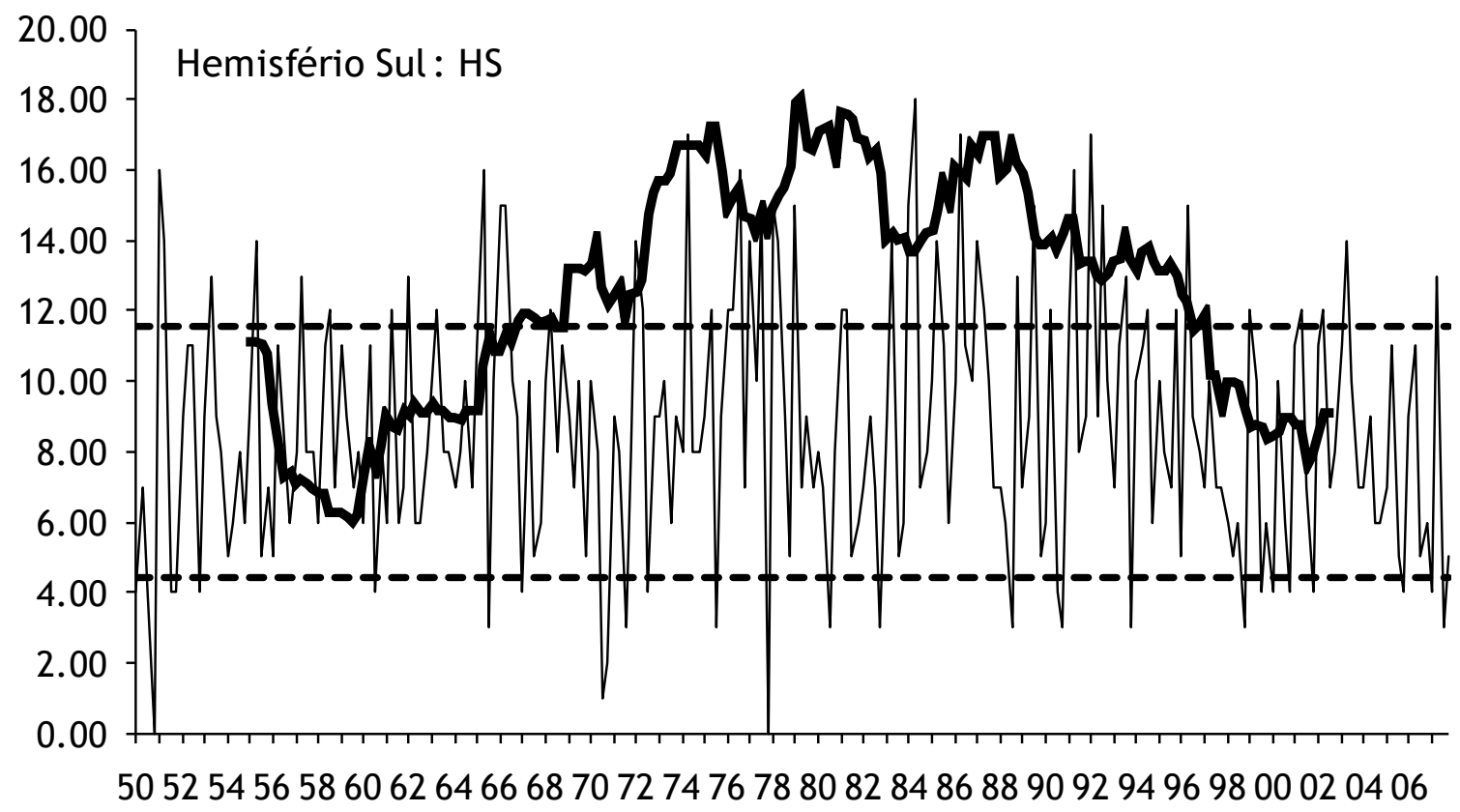

Figura 3.25 - Distribuição trimestral dos eventos de bloqueio ao longo do ano no Hemisfério Sul. As duas retas tracejadas indicam os limites do desvio padrão. A linha sólida em negrito indica a variância móvel para uma janela de 11 anos.

Segundo Desler et al., (1996), uma abrupta perturbação climática de longa-década ocorreu no período de 1970 a 1991. Alguns estudos (e.g., Trenberth e Hoar 1996; Rajagopalan et al., 1997) notaram que o padrão de variabilidade do ENOS mudou em 1976/77 com a fase Quente do ENOS tornando-se mais frequente e intensa. Esta mudança de regime de 1976/77 foi identificada como uma abrupta transição de águas muito mais frias do que o 
normal por águas muito mais quentes do que o normal em um curto intervalo de tempo $(\sim 1$ ano) no Pacífico Tropical. Giser et al (2002) sugeriram que mudanças nas TSMs do Pacifico Norte respondem as mudanças nas TSMs ao longo do Pacífio Tropical. Mantua et al., (1997) haviam anteriormente identificado este padrão de variabilidade, como de Oscilação Decadal do Pacífico (ODP), cuja escala de tempo característica é de 20-30 anos. Agora, percebe-se na Fig. 3.25 que a forte perturbação sazonal de bloqueios tem inicio no final da década de 1960 atingindo um pico de máxima freqüência durante a mudança de regime de 1976/77, prolongando-se em intervalos mais curtos até meados da década de 1990. Observa-se que o período onde a variância móvel destaca-se da mediana mais um desvio padrão, é aproximadamente aquele período descrito por Desler et al., (1996). Isto mostra como a variabilidade de bloqueios pode ser fortemente influenciada pela perturbação no regime térmico dos oceanos e aos padrões de teleconexões trópicos-extratrópicos.

No entanto é necessário obter informação da freqüência do sinal periódico para estudar a não estacionaridade da série temporal sazonal de bloqueios atmosféricos. Desta forma temse que decompor a série temporal no tempo/freqüência e espaço simultaneamente para obter informação sobre a amplitude de qualquer sinal periódico e de como isto varia com tempo. Para isto, uma analise do espectro de potência de ondeleta "Morlet" foi calculada como proposto por Torrence e Compo (1998) para o período de 0,3 meses até 58 anos. A Figura 3.26a representa esta análise espectral de ondeleta, bem como o espectro de ondeleta global (Fig. 3.26b) e as variâncias médias em função do tempo (Figura 3.26c). A área hachurada na Figura 3.26a representa o cone de influencia (COI), onde o efeito das bordas torna-se importante enquanto que a regiões pontilhadas representam regiões com $95 \%$ de confiança estatística. 
a)

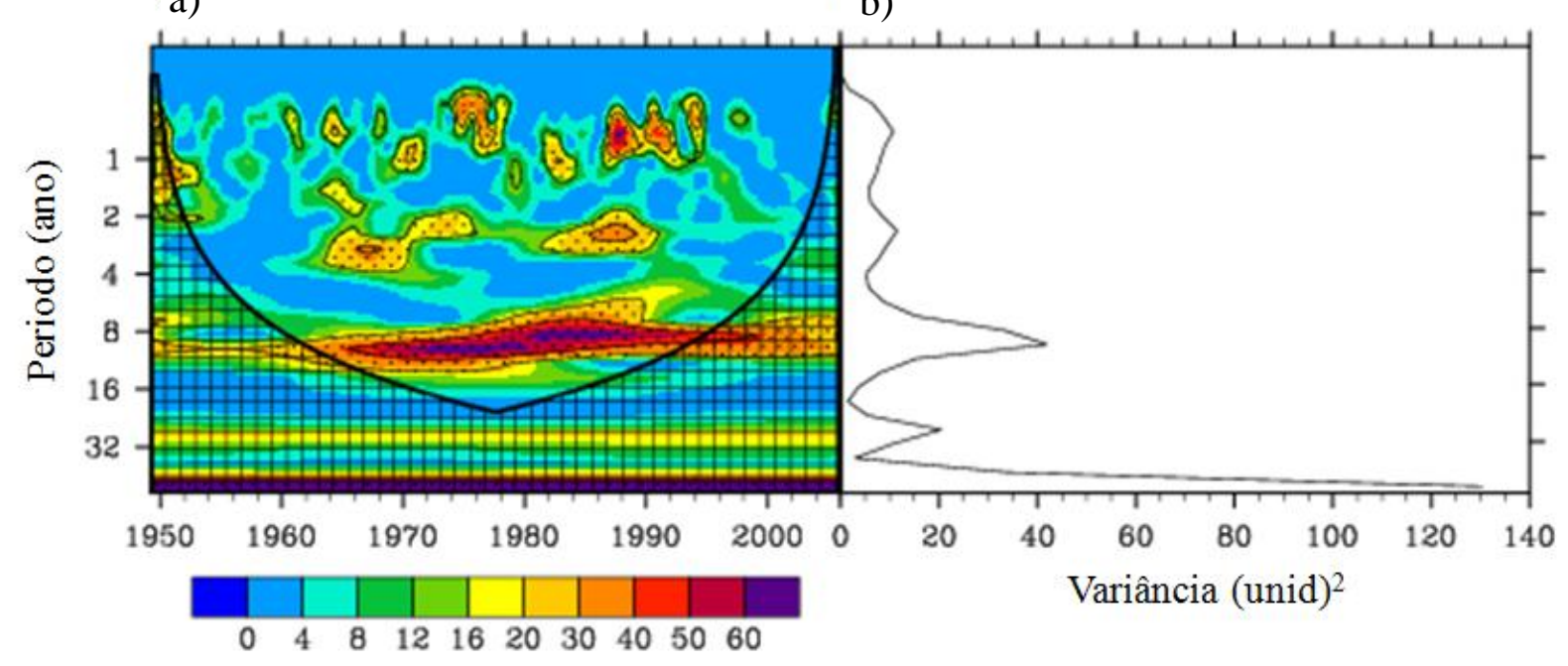

c)

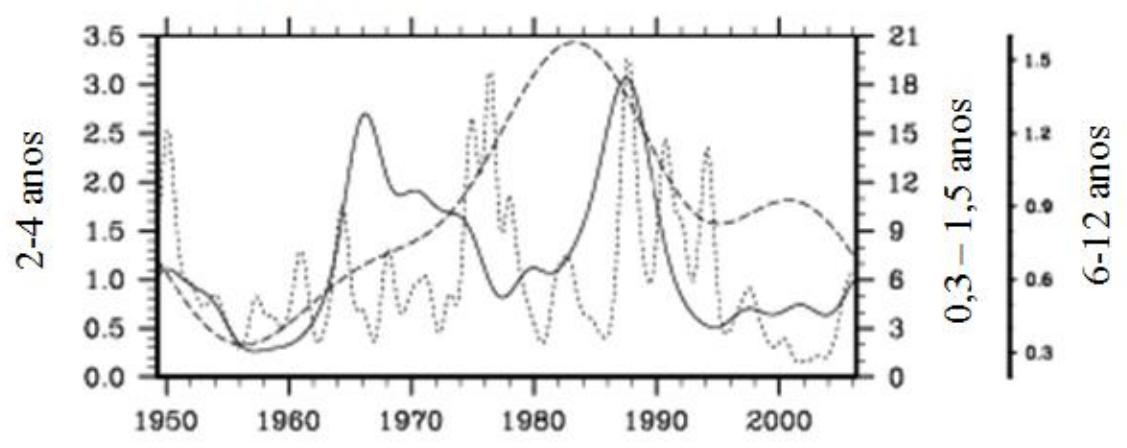

Fig. 3.26 - Análise do espectro de ondeleta "Morlet" aplicado nos dados trimestrais do numero total de eventos de bloqueio com duração mínima de 3 dias. (a) Espectro da ondeleta, (b) Ondeleta global e (c) Variâncias médias em função do tempo, sendo linhas pontilhadas para a banda de 0,3-1,5 anos, linha cheia para a banda de 2,4 anos e linha tracejada para a banda de 6-12 anos. A área hachurada (a) representa o cone de influencia (COI), onde o efeito das bordas torna-se importante enquanto que a regiões pontilhadas representam regiões com $95 \%$ de confiança estatística. Referências: Torrence, C. and G. P. Compo, 1998: A Practical Guide to Wavelet Analysis. Bull. Amer. Meteor. Soc., 79, 61-78.

Com relação ao espectro sazonal de bloqueios (Fig. 3.26a), se observa a energia máxima dos eventos entre o final de década de 1960 até metade da década de 1990 para as bandas de 0,3-1,5 anos, 2-4 anos e 6-12 anos, melhor representado no espectro de ondeleta global (Fig.3.26b). Nestas bandas de frequência dominantes, o pico máximo de energia é representado na banda de 8-12 anos durante toda a década de 70 e por uma banda mais curta de 6-10 anos durante a década de 1980 até meados de 1990. Na escala entre o sazonal e o interanual os períodos de maior energia coincidem com o período de 1974-1978, referente à 
mudança de regime climático de 1976/77 ou "Climate Shift" e durante a década de 1986 a 1996, o qual está associado ao período de maior freqüência do ENOS+. Observar que o período de maior perturbação está entre as décadas de 1970 e 1990, associado ao período de longa década com perturbação térmica no Pacífico Norte, como observado por Desler et al., (1996), o que remete uma relação entre a variabilidade de bloqueios e os padrões de teleconexões. 


\section{CAPÍTULO 4}

\section{CLIMATOLOGIA DE BLOQUEIOS NOS MODELOS ACOPLADOS DO IPCC}

Neste capítulo serão analisados alguns dos experimentos de cenários simulados pelos MCGAOs que fazem parte do Painel Intergovernamental de Mudanças Climáticas (em inglês, Intergovernamental Panel for Climate Change - IPCC). Serão investigados o clima do século XX (1980-2000) (denominado daqui por diante 20C) e o cenário idealizado A1B para o inicio da segunda metade do século XXI (1950-2070). O cenário idealizado A1B representa um futuro com $2 \mathrm{xCO}_{2}$ e taxas variando entre 550 a 600 ppm ao ano (Wigley et al., 1996; Wigley 2000) no qual existe a utilização não privilegiada entre combustíveis fósseis e outras fontes de energia, pressupõem investimentos em novas tecnologias e pode ser considerado intermediário entre os cenários B1 (otimista) e A2 (pessimista).

\subsection{MODELOS DE CIRCULAÇAO GERAL ACOPLADOS}

Os MCGAOs descrevem a dinâmica da interação entre a atmosfera e o oceano por meio de relações complexas e equações não-lineares. A maioria dos MCGAOs utiliza uma grade tridimensional (3D) sobre a esfera do globo com uma resolução horizontal espacial típica de $250 \mathrm{~km}$ e com aproximadamente entre 10 e 30 níveis na vertical. Um modelo típico oceânico possui aproximadamente uma resolução horizontal entre 125 a 250 km e resolução 
de 200 a 400 metros na vertical (Kumar et al., 2003). A dependência no tempo é calculada tomando passos no tempo tipicamente de 30 minutos. $\mathrm{O}$ acoplamento é feito forçando o modelo oceânico com fluxos de momentum (tensão de cisalhamento do vento) e calor na superfície gerada pelo modelo atmosférico. A temperatura à superfície do mar (TSM) calculada pelo modelo oceânico é utilizada como condição de contorno para o modelo atmosférico. O intervalo de troca entre os dois modelos varia tipicamente entre algumas horas para até um dia.

A crescente necessidade de se compreender as causas e mitigar os impactos das mudanças climáticas tem levado a um rápido desenvolvimento dos MCGAOs nos últimos 1015 anos. Atualmente, estes modelos são capazes de simular de forma satisfatória a complexidade do sistema climático e sua sensibilidade às forçantes naturais e antropogênicas. Neste trabalho, foram analisadas as simulações de alguns dos principais MCGAOs que fazem parte das simulações da fase-3 do World Climate Research Programme Coupled (CMIP-3) do IPCC: o modelo MIROC 3.2 e ECHAM5/MPI-OM. Trabalhos anteriores mostraram que o modelo ECHAM5/MPI-OM simulou razoavelmente o tempo de escala observado do ENOS (AchutaRao e Sperber, 2006). Van Oldenborgh et al., (2005) investigaram um conjunto de 19 modelos e concluíram que os modelos ECHAM5/MPI-OM e MIROC 3.2 fazem parte de um grupo de cinco MCGAOs que melhor reproduziram o "feedback" do ENOS. Bengtsson et al., (2006) mostraram que o ECHAM5/MPI-OM foi capaz de simular razoavelmente bem a atividade dos "storm tracks" no HS. Bombardi e Carvalho (2009) mostraram que o MIROC 3.2 representou bem os trópicos da América do Sul, sobretudo as monções. Com base nestes estudos prévios, investigou-se o desempenho destes dois modelos em simular bloqueios no Hemisfério Sul. Abaixo são descritos individualmente cada modelo, seus respectivos centros e configurações. 


\section{a) O MODELO ECHAM5/MPI-OM}

O modelo ECHAM5 foi desenvolvido a partir de uma versão anterior do modelo espectral de previsão do tempo do Centro Europeu para Previsão do Tempo de Médio e Longo Prazo (em inglês, "ECMWF”) e de um pacote de parametrizações desenvolvidos em Hamburgo pelo Instituto Max-Planck para Meteorologia (Alemanha), daí o nome usado no modelo EC (ECMWF) + HAM (Hamburgo). A primeira publicação sobre o modelo foi em 2005 (Jungclaus et al., 2006). Trata-se da quinta geração do modelo de circulação geral ECHAM. A base do modelo consiste de dois principais componentes: O modelo de atmosfera e superfície (ECHAM5) inclui um modelo hidrológico (HD, "Hidrological discharge model”) com 5 níveis para o transporte de calor e um para balanço de água e o modelo oceânico com o componente gelo (MPI/OM). A resolução do modelo atmosférico tem truncamento triangular na onda zonal de número 63 (T63) com 31 níveis verticais (L31) com o topo do modelo em $10 \mathrm{hPa}$, sendo 9 níveis acima do nível de $200 \mathrm{hPa}$ e 5 abaixo do nível de $850 \mathrm{hPa}$ e resolução temporal a cada 6 horas. Desta fora a resolução horizontal é de $1,875^{\circ}$, o que corresponde a uma grade com distancia de $200 \mathrm{~km}$ no equador. O modelo oceânico tem uma resolução de $1,5^{\circ}$ correspondente a uma grade com distancia de $160 \mathrm{~km}$ no equador e 40 níveis verticais. O modelo contém os processos que são resolvidos pela grade $3 \mathrm{D}$, bem como os não-resolvidos ou processos parametrizados, os quais são importantes para o transporte de momentum (tensão de cisalhamento do vento), energia e água nos sistema Terra. Neste trabalho analisamos três rodadas do modelo ECHAM5/MPI-OM, adiante denominadas de ECHAM5_R1, ECHAM5_R2, ECHAM5_R3.

O experimento controle foi inicializado no ano 300 com uma versão similar do modelo (mas não idêntica) e concentrações atuais dos gases do efeito-estufa. O modelo foi então rodado por 144 anos (com pequenas alterações), sob condições pré-industriais até que foi congelado no ano de 2122. Os gases do efeito-estufa bem distribuídos na atmosfera (CO2, 
CH4 e N2O) são considerados constantes, referente às concentrações de 1860. A climatologia do ozônio (Fortuin e Kelder, 1988) e emissão de aerossóis (Tanre et al., 1984) foram baseadas nos valores atuais.

b) O MODELO MIROC 3.2

O modelo MIROC 3.2 (Model for Interdisciplinary Research on Climate) foi desenvolvido pelo Center for Climate System Research (CCSR) da Universidade de Tóquio no Japão. Conforme Hasumi e Emori (2004), o MIROC 3.2 consiste de cinco componentes: atmosfera, continentes, rios, gelo marinho e oceanos. Os cinco componentes interagem da seguinte forma: a componente atmosférica interage com os continentes e o gelo marinho. As trocas entre atmosfera e oceanos são realizadas exclusivamente entre a atmosfera e as componentes do gelo marinho e não diretamente entre atmosfera e a componente oceânica, e a componente oceânica interage somente com a componente do gelo marinho. Isto é, o fluxo turbulento entre atmosfera e oceano nas áreas livres de gelo são consequentemente para a componente oceânica sem modificações, contudo isto é primeiramente passado para a componente do gelo marinho. A componente "rio" recebe a água do subsolo da componente continente e drena a água do escoamento fluvial para a componente do gelo marinho.

Duas versões do modelo foram usadas, sendo uma versão de alta resolução horizontal e outra de média resolução horizontal, adiante denominadas de MIROC 3.2-H e MIROC 3.2M, respectivamente. O método de discretização espacial é uma transformação espectral com uma grade gaussiana na horizontal e diferenciação da grade (Arakawa e Suarez, 1983) na vertical. Na discretização temporal é usado basicamente o esquema leap-frog. Para o modelo de alta resolução, a componente atmosférica tem resolução horizontal com truncamento espectral T106, equivalente a uma grade regular de $1,125^{\circ}$ e 56 níveis $\sigma$ (sigma) na vertical e T42 (grade regular de $2,8125^{\circ}$ ) com 20 níveis $\sigma$ na vertical para o modelo de baixa resolução. 
Em ambos os MCGAOs os níveis verticais são relativamente refinados na camada limite planetária. A parametrização de convecção utilizada pelo modelo atmosférico é a de Arakawa-Schubert baseada em Pan e Randall (1998) com um esquema empírico que fornece uma condição de supressão descrita em Emori (2001). O modelo oceânico tem resolução espacial de $0.1875 \times 0.28125^{\circ}$ latitude/longitude e 47 níveis verticais no modelo de alta resolução. Já para o modelo de baixa resolução a componente oceânica tem 43 níveis verticais e resolução espacial variando de $0,5^{\circ}$ de latitude no equador a $1,4^{\circ}$ de latitude em altas latitudes e $1,4^{\circ}$ de longitude. A componente gelo marinho tem a mesma resolução da componente oceano com apenas uma camada e a componente continente tem a mesma resolução da componente atmosfera com 5 camadas de transporte de calor e água (Hasumi e Emori, 2006).

O experimento controle do modelo MIROC 3.2 foi obtido de uma simulação de 109 anos do modelo acoplado inicializado a partir de uma versão anterior do modelo com valores fixos de forçantes solares e vulcânicas, concentrações de gases estufa, emissões de aerossol e cobertura do solo. Durante a simulação do clima do século $\mathrm{XX}$, estas condições foram modificadas de acordo com os registros históricos. Esta integração foi inicializada a partir do último ano do experimento controle e representa o período de 1900 a 2000 . A projeção para o experimento do cenário simulado $\mathrm{A} 1 \mathrm{~B}$ foi iniciada a partir do final da integração do experimento simulado $20 \mathrm{C}$ e as emissões de gases estufa e aerossol foram modificadas de acordo com o cenário de emissões do IPCC. 


\subsection{VARIABILIDADE INTERANUAL DO ENOS: SIMULAÇOES PARA O TEMPO PRESENTE E FUTURO}

A variabilidade interanual do ENOS foi examinada nos modelos ECHAM5/MPI-OM e MIROC 3.2 para as experimentos dos cenários simulados 20C (1980-2000) e A1B (20502070). Comparações com os dados observados das reanálises II do NCEP/NCAR foram efetuadas para o cenario 20C (1980-2000). Para este propósito, foram usados dados mensais de temperatura de película (em inglês, "skin temperature") os quais têm sido frequentemente utilizados como uma proxy para TSM (por essa razão, daqui para frente serão referidos como TSM) (Kalnay et al., 1996; Bombardi e Carvalho 2011).

Análise de Funções Ortogonais Empíricas das $\mathrm{TSM}_{\mathrm{LF}}$ foram efetuadas sobre o domínio correspondente ao Pacífico Equatorial entre $120^{\circ} \mathrm{E}-120^{\circ} \mathrm{W}$ e $30^{\circ} \mathrm{N}-30^{\circ} \mathrm{S}$. Para isolar o sinal interanual, as séries temporais de TSM foram filtradas com um filtro passa-baixa que utiliza transformada rápida de Fourier (FFT). Somente períodos acima de 12 meses foram retidos (daqui para frente referido como $\mathrm{TSM}_{\mathrm{LF}}$ ). A Figura 4.1 mostra a projeção espacial da primeira REOF rotacionada (REOF-1) obtida como a correlação entre o coeficiente temporal

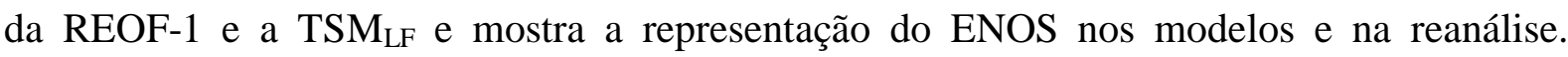
Somente regiões com significância ao nível p<0,05 são mostradas. Como pode ser observado, o mapa de correlações da REOF-1 (a qual explica 50,84\% da variância), obtida para a reanálise (Fig. 4.1a), mostra correlações positivas sobre a linha do equador e a leste de $180^{\circ} \mathrm{e}$ correlações negativas nas áreas adjacentes ao norte e ao sul do equador. O padrão espacial obtido da REOF-1 lembra o padrão ferradura, em inglês "horseshoe pattern" (e.g., Wallace et al., 1998; Myiakoda et al., 2003) associado ao El Niño/Oscilação do Sul. De modo análogo, são apresentadas em sequência as projeções espaciais da REOF-1 para as rodadas do ECHAM5/MPI-OM e para as versões do MIROC 3.2 e mostram-se os experimentos dos 
cenários simulados 20C (à esquerda) e A1B (à direita). Observa-se que todos os MCGAOs falham em representar corretamente a simetria do padrão ferradura em torno da linha do equador, já que as correlações projetadas sobre a linha do equador avançam relativamente para oeste da linha de data. Contudo, de forma geral, os MCGAOs representam razoavelmente bem o padrão espacial do mapa de correlações relacionado com o ENOS. Em oposição, o ECHAM5/MPI-OM (MIROC 3.2) tem a maior (menor) variância explicada e é melhor (pior) correlacionado com o fenômeno do ENOS, comparativamente à reanálise. Por exemplo, o modelo ECHAM5_R2 tem a mais alta variância explicada $(60,19 \%)$ entre todos os MCGAOs.
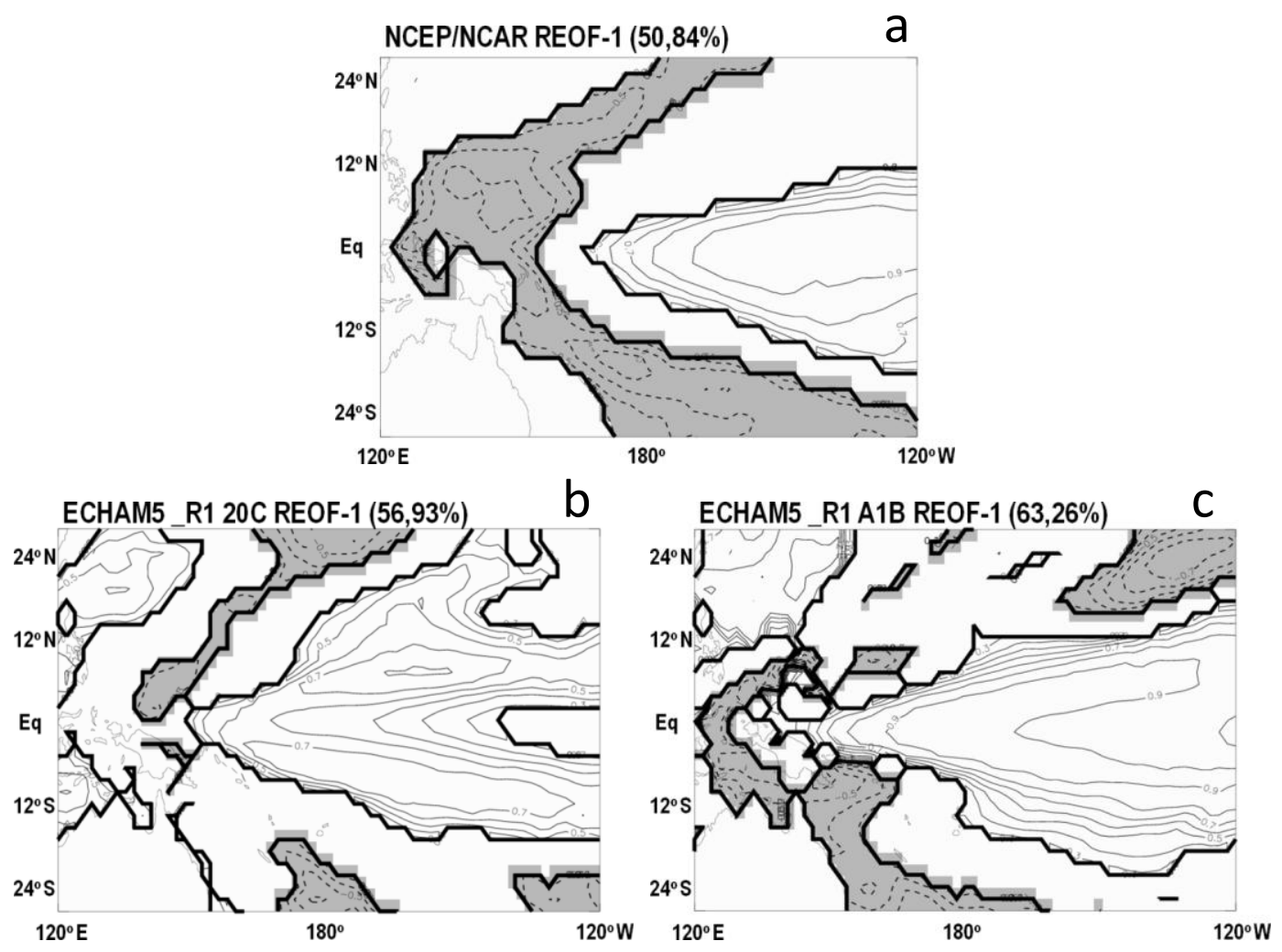

Figura 4.1 - Projeção espacial da primeira EOF rotacionada (REOF-1) para os dados de TSM de baixa frequência na região de $30^{\circ} \mathrm{S}-30^{\circ} \mathrm{N}$ e $120^{\circ} \mathrm{E}-120^{\circ} \mathrm{W}$. Regiões em cinza com linhas pontilhadas são correlações negativas. Regiões claras com linhas sólidas são correlações positivas. (a) NCEP-NCAR, (b) ECHAM5_R1 20C, (c) ECHAM5_R1 A1B, (d) ECHAM5_R2 20C, (e) ECHAM5_R2 A1B, (f) MIROC 3.2-H 20C, (g) MIROC 3.2-H A1B, (h) MIROC 3.2-M 20C, (i) MIROC 3.2-M A1B. A Figura continua. 

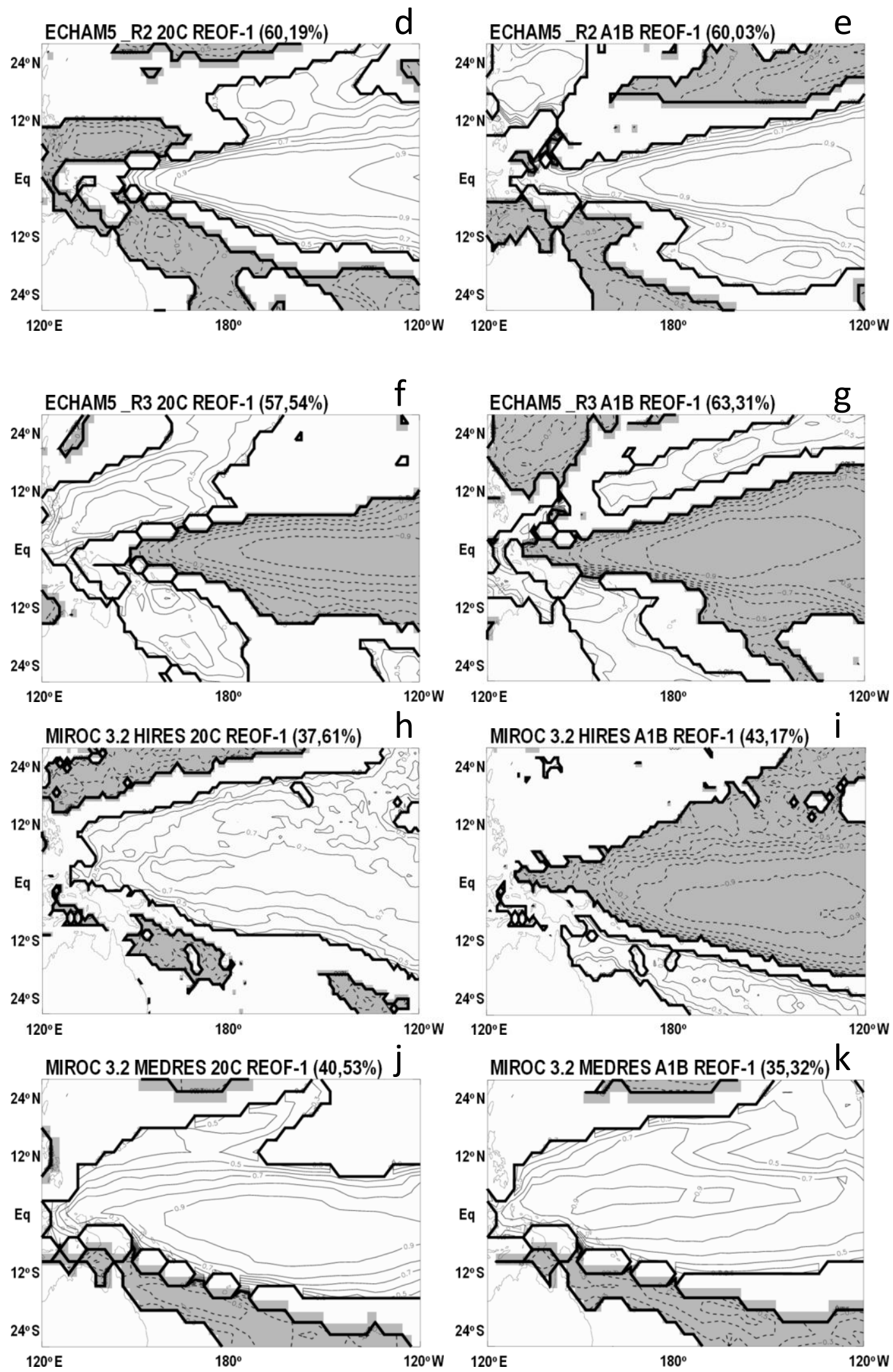

Figura 4.1 - Continuação 
Para mostrar que a primeira REOF é separável das demais, aplicou-se o teste de hipótese de North et al. (1982) . Os resultados são mostrados nas Tabelas 4.1, 4.2 e 4.3 para o observado e para o ECHAM/MPI-OM e MIROC 3.2, respectivamente. Os modos da REOF são independentes se o erro amostral de um particular autovalor $(\delta \lambda)$ é suficientemente pequeno em relação a distancia entre o particular autovalor $\left(\lambda_{k}\right)$ e o autovalor mais próximo $\left(\lambda_{k+1}\right)$, dado por $\Delta \lambda=\lambda_{k}-\lambda_{k+1}$. O erro amostral é fornecido como:

$$
\delta \lambda=\lambda_{k}\left(\frac{2}{N}\right)^{1 / 2}(E q .11)
$$

Onde $\mathrm{N}$ são os graus de liberdade, dado pelo número de eventos independentes do ENOS menos 1. Um evento independente do ENOS foi determinado quando o coeficiente temporal da REOF-1 é maior (menor) que $+(-)$ um desvio médio $\left(\frac{1}{n} \sum|x-\bar{x}|\right)$ e persiste acima (abaixo) deste limiar por um período de pelo menos cinco meses consecutivos desde o inverno ao verão austral, de modo similar ao aplicado no capítulo 3 para o ONI. Nesta análise e para o restante deste capítulo, por questão de simplificação, os eventos não foram diferenciados de acordo com suas intensidades e foram apenas definidos como fase Quente (ENOS+) e fase Fria (ENOS-) do ENOS.

A Tabela 4.1 mostra o erro e a distância entre cada autovalor e a variância explicada para a reanálise. Cada componente da REOF representa uma parte da variância total explicada da $\mathrm{TSM}_{\mathrm{LF}}$ que é proporcional ao seu respectivo autovalor. Os resultados mostram que o primeiro autovalor está suficentemente separado do segundo autovalor, o que sugere a independência do primeiro modo da REOF.

Análogo ao caso da reanálise, as Tabelas 4.2 e 4.3 resumem os cálculos para as sete primeiras REOFs, mas para os experimentos dos cenários simulados 20C (topo) e A1B (abaixo) pelo ECHAM5 (R1, R2 e R3) e MIROC 3.2 (H e M), respectivamente. No cenário simulado 20C pelo modelo ECHAM5/MPI-OM (Tab. 4.2), os resultados mostram que a 
distância entre o primeiro e o segundo autovalor é suficientemente grande considerando o intervalo de erro dos respectivos autovalores. Isto demonstra que o primeiro autovetor é bem separável do segundo. O primeiro autovalor, associado à REOF-1, explica 56,39\% (R1), $60,19 \%(\mathrm{R} 2)$ e $57,54 \%$ (R3) contra os $26,84 \%$ (R1), $25,95 \%$ (R2) e $26,89 \%$ (R3) do segundo ao sétimo autovalor. Para o cenário $\mathrm{A} 1 \mathrm{~B}$, os resultados são similares, mas a variância explicada para o primeiro autovalor aumenta relativamente no cenário 20C. Com relação ao cenário simulado 20C, para as duas versões do MIROC 3.2, os resultados são satisfatóriamente similares ao obtido para o ECHAM5/MPI-OM, mas a magnitude da distância do primeiro ao segundo autovalor é comparativamente pequena, se comparada com as rodadas dos ECHAM5/MPI-OM. Neste caso, o primeiro autovalor explica 37,61\% (H) e 40,53\% (M), respectivamente. Contudo, no experimento do cenário simulado A1B para o MIROC 3.2-M, o primeiro modo da REOF não é independente do segundo modo da REOF. À exceção do MIROC 3.2-M, experimento A1B, os resultados sugerem que o primeiro modo da REOF (REOF-1) capturou adequadamente o sinal da variabilidade do ENOS nos MCGAOs.

Tabela 4.1 - Resultados da análise da REOF observada (NCEP/NCAR). São mostradas a ordem (k) da REOF e a distancia entre os autovalores, a porcentagem e porcentagem acumulada da variância explicada.

\begin{tabular}{cccccc}
\hline \multicolumn{6}{c}{ REOF } \\
\hline $\mathrm{k}$ & \multicolumn{5}{c}{ NCEP/NCAR } \\
\hline 1 & 35.540 & \pm & 13.433 & 27.860 & 50.840 \\
2 & 7.680 & \pm & 2.903 & 4.140 & 10.980 \\
3 & 3.540 & \pm & 1.338 & 0.370 & 5.070 \\
4 & 3.170 & \pm & 1.198 & 0.110 & 4.530 \\
5 & 3.060 & \pm & 1.157 & 0.730 & 4.370 \\
6 & 2.330 & \pm & 0.881 & 0.570 & 3.340 \\
7 & 1.760 & \pm & 0.665 & 1.760 & 2.520 \\
\hline
\end{tabular}


Tabela 4.2 - Resultados da análise da REOF simulada pelo modelo ECHAM5/MPI-OM para o clima presente 20C. São mostradas a ordem (k) da REOF e a distancia entre os autovalores, a porcentagem e porcentagem acumulada da variância explicada. À esquerda são mostrados os resultados para o ECHAM5 R1 20C (topo) e ECHAM5 R1 A1B (base). No meio são mostrados os resultados para o ECHAM5 R2 20C (topo) e ECHAM5 R2 A1B (base). À direita são mostrados os resultados para o ECHAM5 R3 20C (topo) e ECHAM5 R3 A1B (base).

\begin{tabular}{|c|c|c|c|c|c|c|c|c|c|c|c|c|c|c|c|}
\hline \multicolumn{16}{|c|}{ REOF } \\
\hline \multirow[b]{2}{*}{$\mathrm{k}$} & \multicolumn{5}{|c|}{ ECHAM5/MPI-OM RUN1 20C } & \multicolumn{5}{|c|}{ ECHAM5/MPI-OM RUN2 20C } & \multicolumn{5}{|c|}{ ECHAM5/MPI-OM RUN3 20C } \\
\hline & \multicolumn{3}{|c|}{ Autovalor $\pm \delta \lambda$} & $\Delta \lambda$ & \multirow{2}{*}{$\frac{\text { Var.Exp (\%) }}{56.930}$} & \multicolumn{3}{|c|}{ Autovalor $\pm \delta \lambda$} & \multirow{2}{*}{$\frac{\Delta \lambda}{57.200}$} & \multirow{2}{*}{$\frac{\text { Var.Exp }(\%)}{60.190}$} & \multicolumn{3}{|c|}{ Autovalor $\pm \delta \lambda$} & \multirow{2}{*}{$\frac{\Delta \lambda}{45.980}$} & \multirow{2}{*}{$\frac{\text { Var.Exp }(\%)}{57.540}$} \\
\hline 1 & 49.740 & \pm & 19.510 & 39.860 & & 67.210 & \pm & 28.658 & & & 53.980 & \pm & 21.173 & & \\
\hline 2 & 8.320 & \pm & 3.263 & 5.910 & 9.530 & 10.010 & \pm & 4.268 & 2.160 & 8.960 & 8.000 & \pm & 3.138 & 2.710 & 8.530 \\
\hline 3 & 5.330 & \pm & 2.091 & 0.540 & 6.100 & 7.850 & \pm & 3.347 & 4.390 & 7.030 & 5.290 & \pm & 2.075 & 1.670 & 5.640 \\
\hline 4 & 3.630 & \pm & 1.424 & 0.160 & 4.150 & 3.460 & \pm & 1.475 & 0.520 & 3.100 & 3.620 & \pm & 1.420 & 0.120 & 3.860 \\
\hline 5 & 2.490 & \pm & 0.977 & 1.030 & 2.850 & 2.940 & \pm & 1.254 & 0.320 & 2.640 & 3.500 & \pm & 1.373 & 0.760 & 3.730 \\
\hline 6 & 2.060 & \pm & 0.808 & 0.820 & 2.360 & 2.620 & \pm & 1.117 & 0.650 & 2.350 & 2.740 & \pm & 1.075 & 0.670 & 2.920 \\
\hline \multirow[t]{2}{*}{7} & 1.620 & \pm & 0.635 & 0.000 & 1.850 & 1.970 & \pm & 0.840 & 1.470 & 1.770 & 2.070 & \pm & 0.812 & 0.805 & 2.210 \\
\hline & \multicolumn{5}{|c|}{ ECHAM5/MPI-OM RUN1 A1B } & \multicolumn{5}{|c|}{ ECHAM5/MPI-OM RUN2 A1B } & \multicolumn{5}{|c|}{ ECHAM5/MPI-OM RUN3 A1B } \\
\hline $\mathrm{k}$ & \multicolumn{3}{|c|}{ Autovalor $\pm \delta \lambda$} & $\Delta \lambda$ & Var.Exp (\%) & \multicolumn{3}{|c|}{ Autovalor $\pm \delta \lambda$} & $\Delta \lambda$ & Var.Exp (\%) & \multicolumn{3}{|c|}{ Autovalor $\pm \delta \lambda$} & $\Delta \lambda$ & Var.Exp (\%) \\
\hline 1 & 117.690 & \pm & 46.162 & 93.960 & 63.260 & 127.810 & \pm & 54.498 & 107.560 & 60.030 & 121.260 & \pm & 41.592 & 100.520 & 63.310 \\
\hline 2 & 23.730 & \pm & 9.308 & 17.140 & 12.750 & 20.250 & \pm & 8.635 & 3.810 & 9.510 & 20.740 & \pm & 7.114 & 9.420 & 10.830 \\
\hline 3 & 6.590 & \pm & 2.585 & 0.960 & 3.540 & 16.440 & \pm & 7.010 & 7.570 & 7.720 & 11.320 & \pm & 3.883 & 4.920 & 5.910 \\
\hline 4 & 5.630 & \pm & 2.208 & 1.470 & 3.030 & 8.870 & \pm & 3.782 & 2.200 & 4.170 & 6.400 & \pm & 2.195 & 1.670 & 3.340 \\
\hline 5 & 4.160 & \pm & 1.632 & 0.650 & 2.240 & 6.670 & \pm & 2.844 & 1.560 & 3.130 & 4.730 & \pm & 1.622 & 1.440 & 2.470 \\
\hline 6 & 3.510 & \pm & 1.377 & 0.190 & 1.890 & 5.110 & \pm & 2.179 & 1.350 & 2.400 & 3.290 & \pm & 1.128 & 0.190 & 1.720 \\
\hline 7 & 3.320 & \pm & 1.302 & 0.000 & 1.790 & 3.760 & \pm & 1.603 & 3.170 & 1.770 & 3.100 & \pm & 1.063 & 2.055 & 1.620 \\
\hline
\end{tabular}


Tabela 4.3 - Resultados da análise da REOF simulada pelo modelo MIROC 3.2 para o clima presente 20C. São mostradas a ordem (k) da REOF e a distancia entre os autovalores, a porcentagem e porcentagem acumulada da variância explicada. À esquerda são mostrados os resultados para o MIROC 3.2-H 20C (topo) e MIROC 3.2-H A1B (base). À direita são mostrados os resultados para o MIROC 3.2-M 20C (topo) e MIROC 3.2-M A1B (base).

\begin{tabular}{|c|c|c|c|c|c|c|c|c|c|c|}
\hline \multicolumn{11}{|c|}{ REOF } \\
\hline \multirow[b]{2}{*}{$\mathrm{k}$} & \multicolumn{5}{|c|}{ MIROC3.2 - HIRES 20C } & \multicolumn{5}{|c|}{ MIROC3.2 - MEDRES 20C } \\
\hline & \multicolumn{3}{|c|}{ Autovalor $\pm \delta \lambda$} & \multirow{2}{*}{$\frac{\Delta \lambda}{9.740}$} & \multirow{2}{*}{$\frac{\text { Var.Exp }(\%)}{37.610}$} & \multicolumn{3}{|c|}{ Autovalor $\pm \delta \lambda$} & \multirow{2}{*}{$\frac{\Delta \lambda}{9.070}$} & \multirow{2}{*}{$\frac{\text { Var.Exp (\%) }}{40.530}$} \\
\hline 1 & 14.360 & \pm & 6.769 & & & 13.860 & \pm & 6.198 & & \\
\hline 2 & 4.620 & \pm & 2.178 & 1.660 & 12.090 & 4.790 & \pm & 2.142 & 2.010 & 14.000 \\
\hline 3 & 2.960 & \pm & 1.395 & 0.350 & 7.740 & 2.780 & \pm & 1.243 & 0.530 & 8.120 \\
\hline 4 & 2.610 & \pm & 1.230 & 0.650 & 6.840 & 2.250 & \pm & 1.006 & 0.730 & 6.590 \\
\hline 5 & 1.960 & \pm & 0.924 & 0.430 & 5.140 & 1.520 & \pm & 0.680 & 0.320 & 4.460 \\
\hline 6 & 1.530 & \pm & 0.721 & 0.460 & 4.000 & 1.200 & \pm & 0.537 & 0.100 & 3.500 \\
\hline \multirow[t]{2}{*}{7} & 1.070 & \pm & 0.504 & 0.473 & 2.790 & 1.100 & \pm & 0.492 & 0.420 & 3.210 \\
\hline & \multicolumn{5}{|c|}{ MIROC3.2 - HIRES A1B } & \multicolumn{5}{|c|}{ MIROC3.2 - MEDRES A1B } \\
\hline $\mathrm{k}$ & \multicolumn{3}{|c|}{ Autovalor $\pm \delta \lambda$} & $\Delta \lambda$ & Var.Exp $(\%)$ & \multicolumn{3}{|c|}{ Autovalor $\pm \delta \lambda$} & $\Delta \lambda$ & Var.Exp (\%) \\
\hline 1 & 16.970 & \pm & 8.485 & 0.827 & 43.170 & 11.110 & \pm & 4.057 & 5.760 & 35.320 \\
\hline 2 & 2.940 & \pm & 1.470 & 0.020 & 7.480 & 5.350 & \pm & 1.954 & 2.760 & 17.000 \\
\hline 3 & 2.880 & \pm & 1.440 & 0.090 & 7.330 & 2.590 & \pm & 0.946 & 0.300 & 8.240 \\
\hline 4 & 2.620 & \pm & 1.310 & 0.248 & 6.660 & 2.290 & \pm & 0.836 & 0.570 & 7.260 \\
\hline 5 & 1.970 & \pm & 0.985 & 0.254 & 5.000 & 1.720 & \pm & 0.628 & 0.470 & 5.470 \\
\hline 6 & 1.470 & \pm & 0.735 & 0.088 & 3.730 & 1.250 & \pm & 0.456 & 0.060 & 3.960 \\
\hline 7 & 1.340 & \pm & 0.670 & 0.170 & 3.420 & 1.190 & \pm & 0.435 & 0.350 & 3.780 \\
\hline
\end{tabular}


A Figura 4.2 mostra a correlação entre o coeficiente temporal da REOF-1 para a reanálise e o índice ONI durante 1980 a 2000. A linha fina representa o índice ONI, enquanto que a linha espessa representa o coeficiente temporal da REOF-1. Os resultados mostram que o coeficiente temporal da REOF-1 é altamente correlacionado $(\sim 0,98)$ com o índice ONI. De modo claro, a figura identifica que a fase negativa da REOF-1 está associada com a fase negativa do ENOS enquanto que a fase positiva da REOF-1 representa a fase positiva do ENOS. Com o uso do coeficiente temporal da REOF-1 foram detectados os mesmos anos com ENOS+ (1982, 1986, 1987, 1991, 1994 e 1997, 6 anos) e ENOS- (1984, 1988, 1995, 1998, 1999 e 2000, 6 anos. Desta forma, o resultado demonstra que o coeficiente temporal da REOF-1 e o ONI são consistentes de forma que o coeficiente temporal da REOF-1 pode ser usado na identificação da variabilidade interanual do ENOS, produzindo resultados equivalentes ao método aplicado no Capitulo 3.

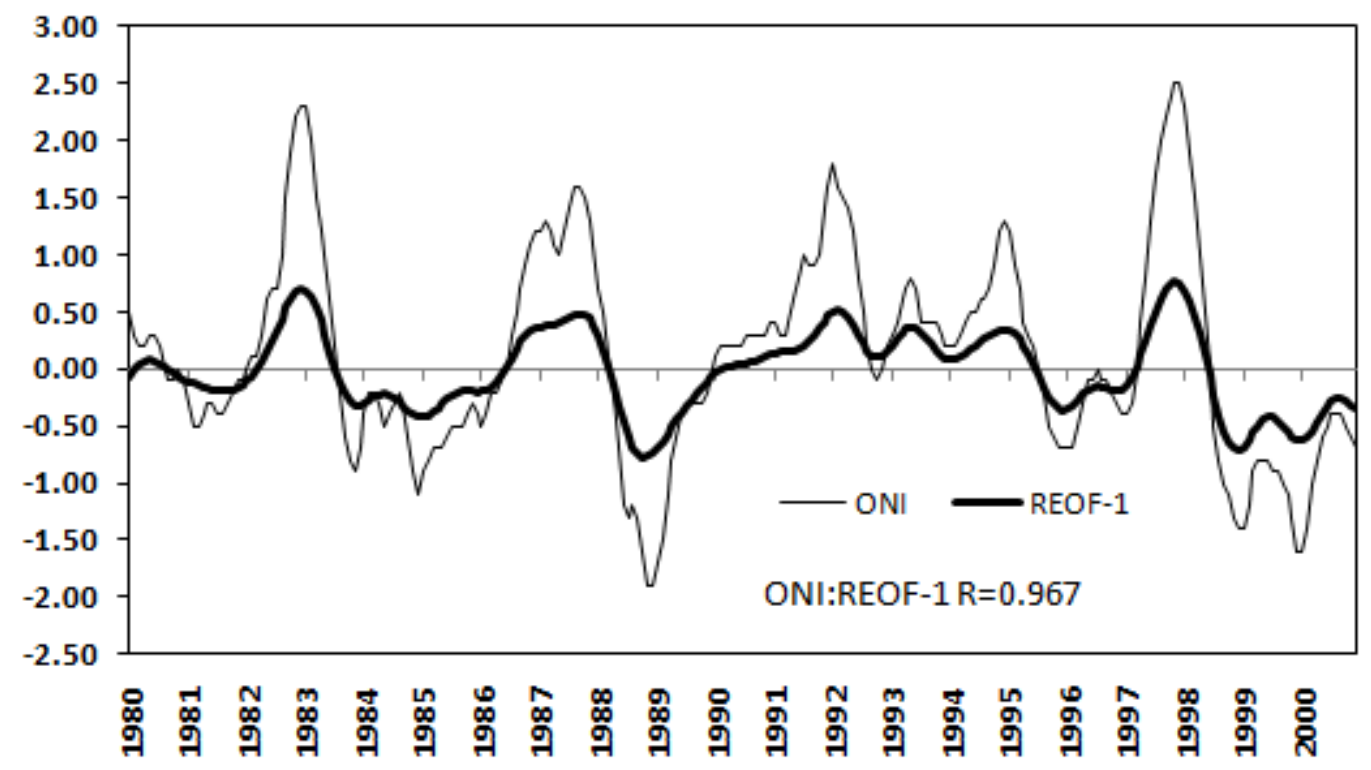

Figura 4.2 - Relação entre os índices ONI e Coeficiente temporal REOF-1 ao longo do período de 1980 a 2000. A linha fina representa o índice ONI, enquanto que a linha grossa representa o Coeficiente da REOF-1. A correlação entre as duas séries temporais é de 0,97. 
Para mostrar a estrutura espacial da REOF-1, na Figura 4.3 foram feitas composições das anomalias de TSM (nas composições não são $\mathrm{TSM}_{\mathrm{LF}}$ ) durante os períodos associados às fases negativas e positivas da REOF-1 conforme discutido acima (Fig. 4.2). As regiões em tons de azul (vermelho) representam águas superficiais anomalamente frias (quentes). Assim, a figura 4.3 (topo) representa a fase positiva da REOF-1 com anomalias positivas de TSM em torno de $1^{\circ} \mathrm{C}$ sobre a região central do Pacífico equatorial desde a linha da data até a costa oeste do Peru. Áreas adjacentes ao norte e ao sul do equador estão relacionadas com anomalias ligeiramente negativas associadas ao padrão ferradura. De modo análogo, a figura 4.3 (abaixo) representa a fase negativa da REOF-1 com anomalias negativas de TSM, em torno de $-1^{\circ} \mathrm{C}$ no Pacífico equatorial, envolvido por um padrão ferradura de anomalias ligeiramente positivas ao norte e sul do equador. Deste modo, a REOF-1 positiva representa a fase Quente do ENOS, enquanto que a REOF-1 negativa representa a fase Fria do ENOS, como anteriormente representado pela figura 4.2 .
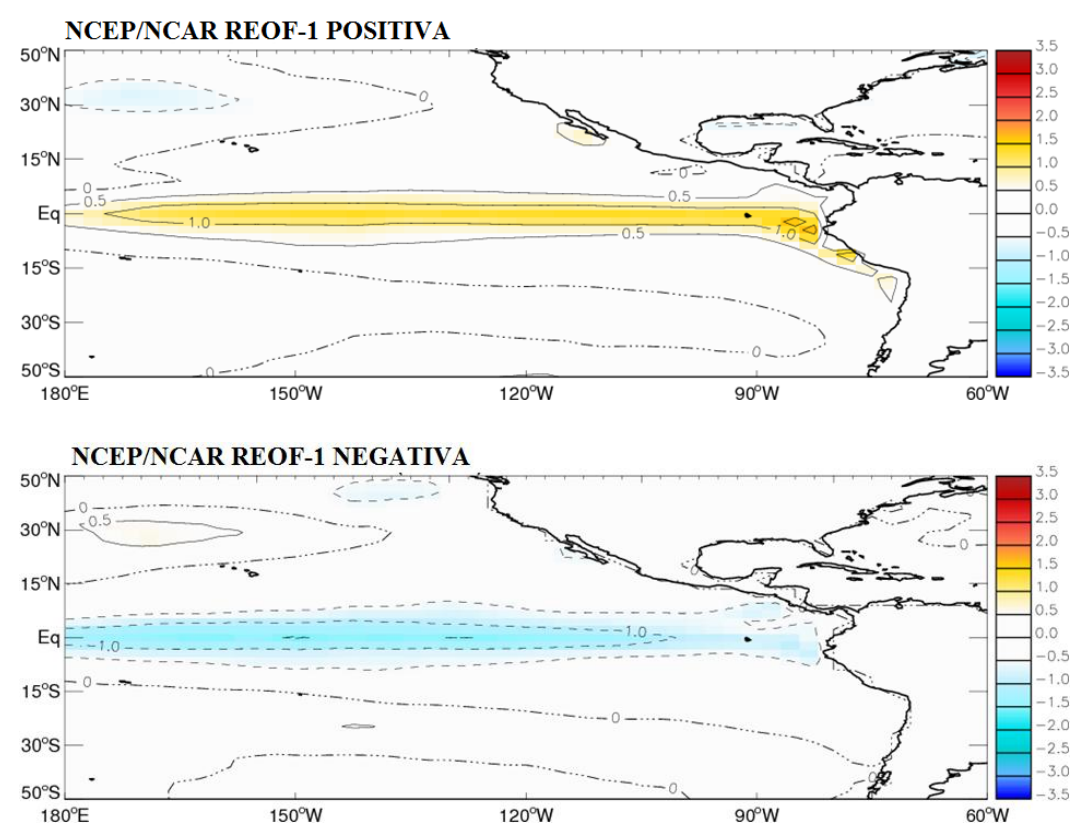

Figura 4.3 - Composição das anomalias das TSM mensais das reanálises do NCEP/NCAR referente ao período de 1980-2000. O ciclo anual foi removido. Linhas sólidas representam anomalias positivas e linhas tracejadas representam anomalias negativas. A linha do "zero" esta representada pela linha ponto-tracejadas. Devido às comparações com os MCGAOs, a escala vai de $-3,5$ a $3,5^{\circ} \mathrm{C}$. 
A Figura 4.4 representa as composições de TSM obtidas pela REOF-1 de acordo com o sinal do ENOS para o experimento do cenário simulado 20C, obtido de forma análoga à reanálise (Fig. 4.3). Em termos gerais, a distribuição das anomalias de TSM no Pacífico tropical para a fase Quente (Fria) simulados para o século XX mostra que o modelo ECHAM5/MPI-OM representa em todas suas rodadas um padrão de anomalias de $+2^{\circ} \mathrm{C}(-$ $2^{\circ} \mathrm{C}$ ) na extensão do Pacífico equatorial, enquanto que o modelo MIROC 3.2 nas versões $\mathrm{H} \mathrm{e}$ $\mathrm{M}$ representam padrões anômalos de $+0,5^{\circ} \mathrm{C}\left(-0,5^{\circ} \mathrm{C}\right)$. Em ambos os modelos, a região de anomalias são mais alongadas na direção oeste do Pacífico equatorial, com as maiores anomalias sobre o Pacífico Central, indicando um possível efeito do ENOS "modoki” (ver Fig. 2 em Ashok et al. 2007). Os valores das anomalias comparados às reanalises indicam que o modelo ECHAM5/MPIOM superestimou em $\left|1^{\circ} \mathrm{C}\right|$ e o modelo MIROC 3.2 nas versões $\mathrm{H}$ e M subestimaram em $\left|0.5^{\circ} \mathrm{C}\right|$ os padrões anômalos de TSM observados.

A Figura 4.5 é análoga a Figura 4.4, mas para os experimentos do cenário simulado A1B. Estas composições mostram que o incremento 2xCO2 com $1 \%$.ano ${ }^{-1}$ durante o século 21 elevou o campo médio das anomalias de TSM em $\sim+1^{\circ} \mathrm{C}$ no na fase Quente do ENOS e $1^{\circ} \mathrm{C}$ na fase Fria em ambas as rodadas do ECHAM5/MPI-OM e uma elevação de $\sim+0.5^{\circ} \mathrm{C}$ no ENOS+ e $\sim-0.5^{\circ} \mathrm{C}$ no ENOS- para o MIROC 3.2-H. Por outro lado, para o cenário A1B o MIROC 3.2-M não representou modificação no campo médio da anomalia de TSM na fase Quente do ENOS, embora na fase Fria haja uma redução de $\sim-0.5^{\circ} \mathrm{C}$ em relação ao cenário simulado 20C. 

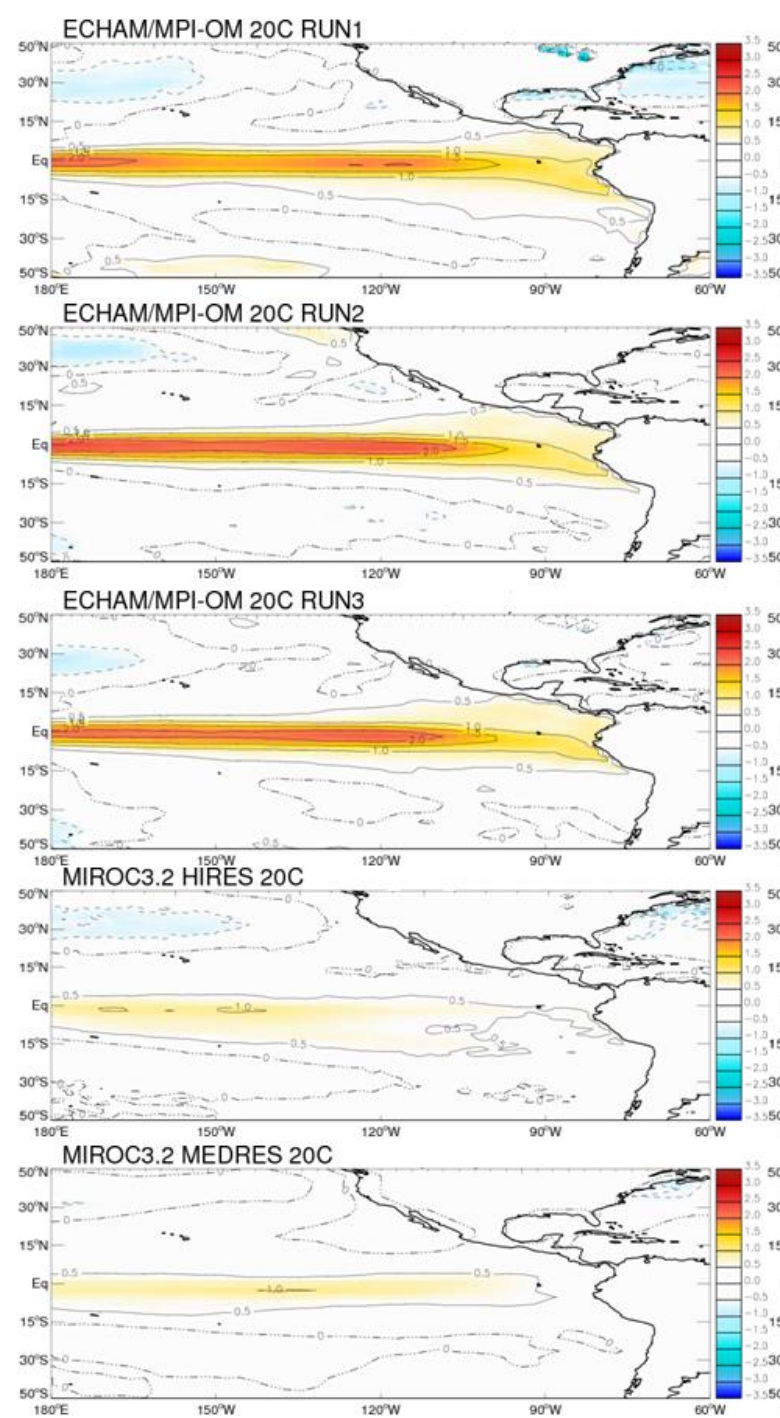
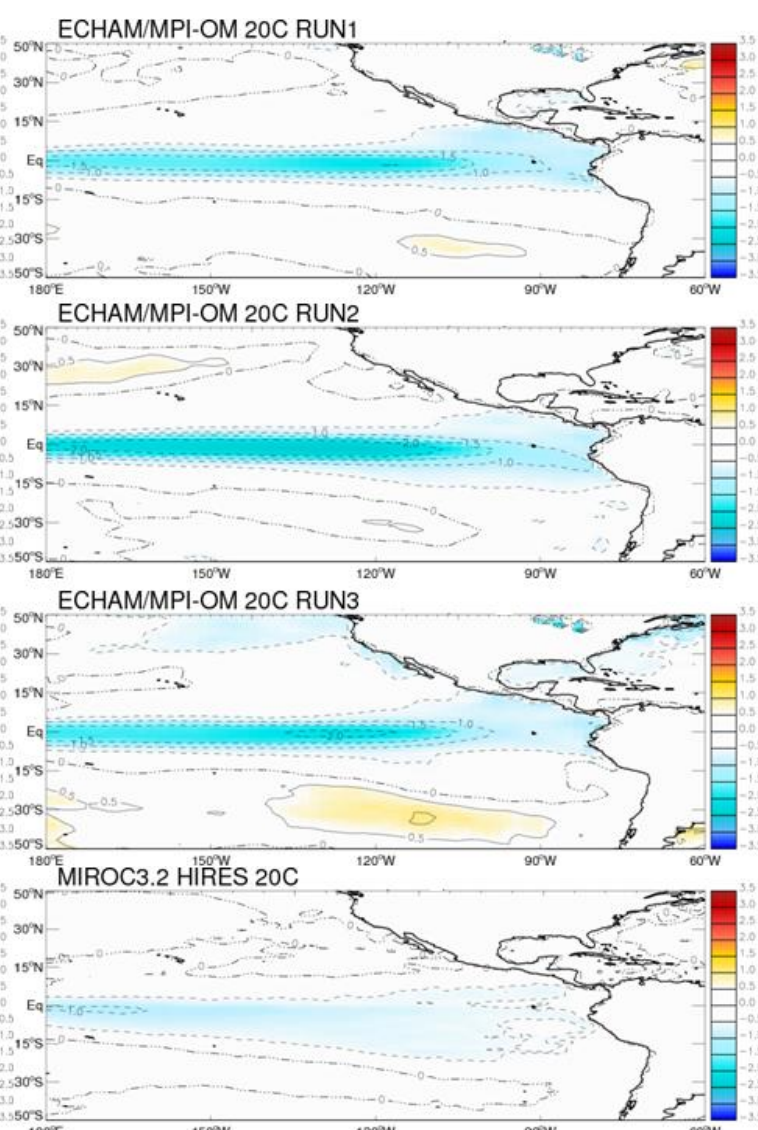

MIROC3.2 MEDRES $20 \mathrm{C}$

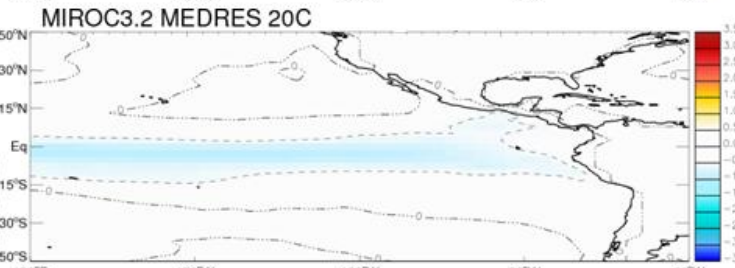

Figura 4.4 - Composição das anomalias das TSM mensais dos modelos de clima ECHAM5/MPI-OM e MIROC 3.2 referente ao cenário simulado 20C dos modelos. O ciclo anual foi removido. Linhas sólidas representam anomalias positivas e linhas tracejadas representam anomalias negativas. A linha do "zero" esta representada pelas linhas ponto-tracejadas. A escala vai de $-3,5$ a $3,5^{\circ} \mathrm{C}$. As figuras à esquerda representam a fase Quente do ENOS e às figuras do lado direito representam a fase Fria do ENOS. No topo de cada figura está representado o modelo avaliado. 

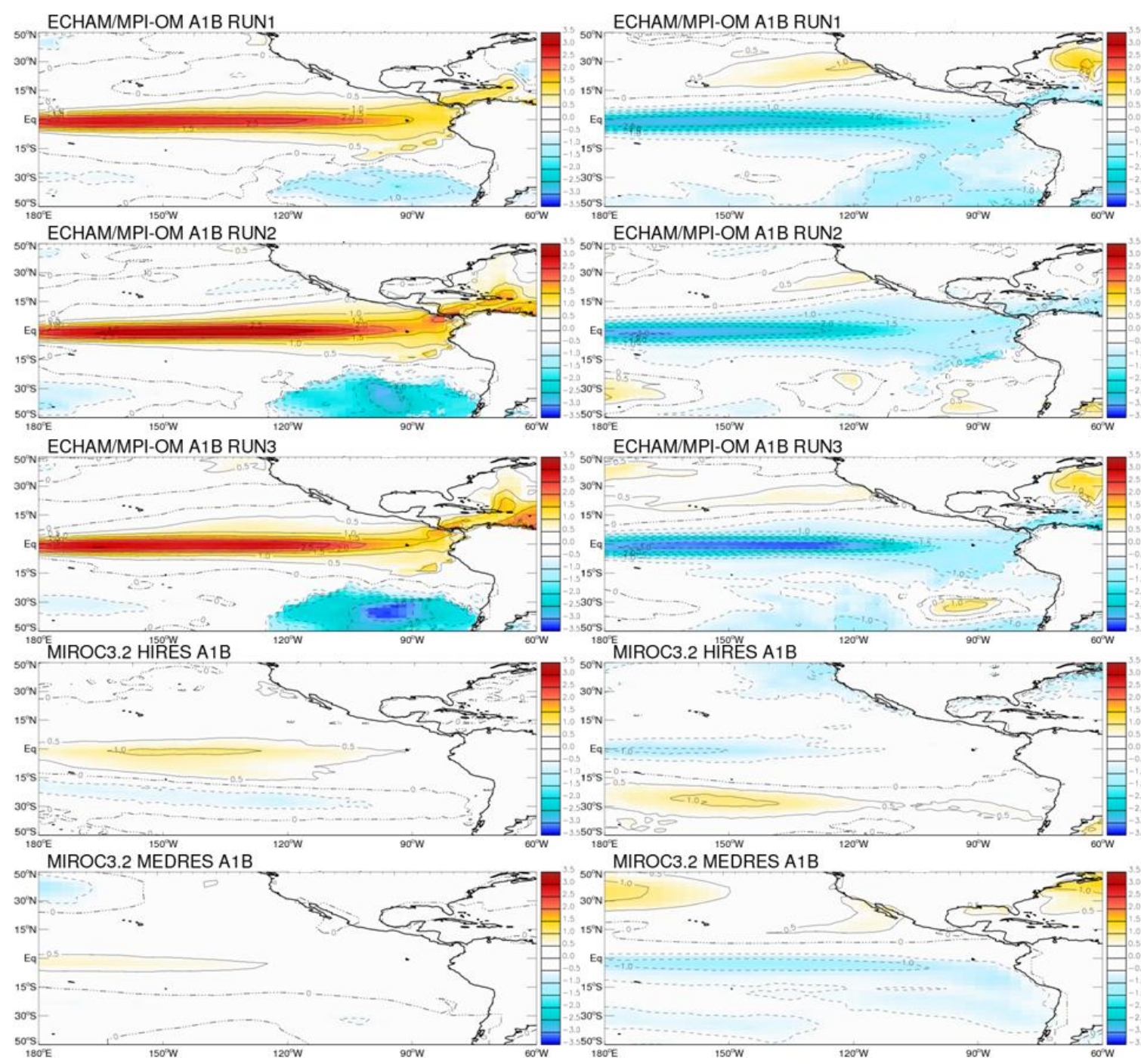

Figura 4.5 - Similar a Figura 4.4, mas referente ao cenário simulado A1B.

A Figura 4.6 mostra as simulações da variabilidade do coeficiente temporal da REOF1 nos modelos ECHAM5/MPI-OM e MIROC 3.2, que corrigido mostra o sinal positivo para o ENOS+ e o sinal negativo para o ENOS-. Do lado esquerdo estão representadas as simulações referentes ao período 1980-2000 (20C) e do lado direito as simulações referentes ao período 2050-2070 (A1B). As linhas pretas ponto-tracejadas representam o desvio médio $\left(\frac{1}{n} \sum|x-\bar{x}|\right)$ de cada modelo. No cenário 20C, a variabilidade interanual da REOF-1 nas rodadas do ECHAM-MPI-OM mostra amplitudes 2 vezes maiores do que as produzidas pelas versões do modelo MIROC 3.2. Para o cenário A1B, o sinal do coeficiente temporal da REOF-1 no 
ECHAM5/MPI-OM é intensificado em relação com o simulado 20C e é cerca de 3x maior do que as versões do MIROC 3.2.
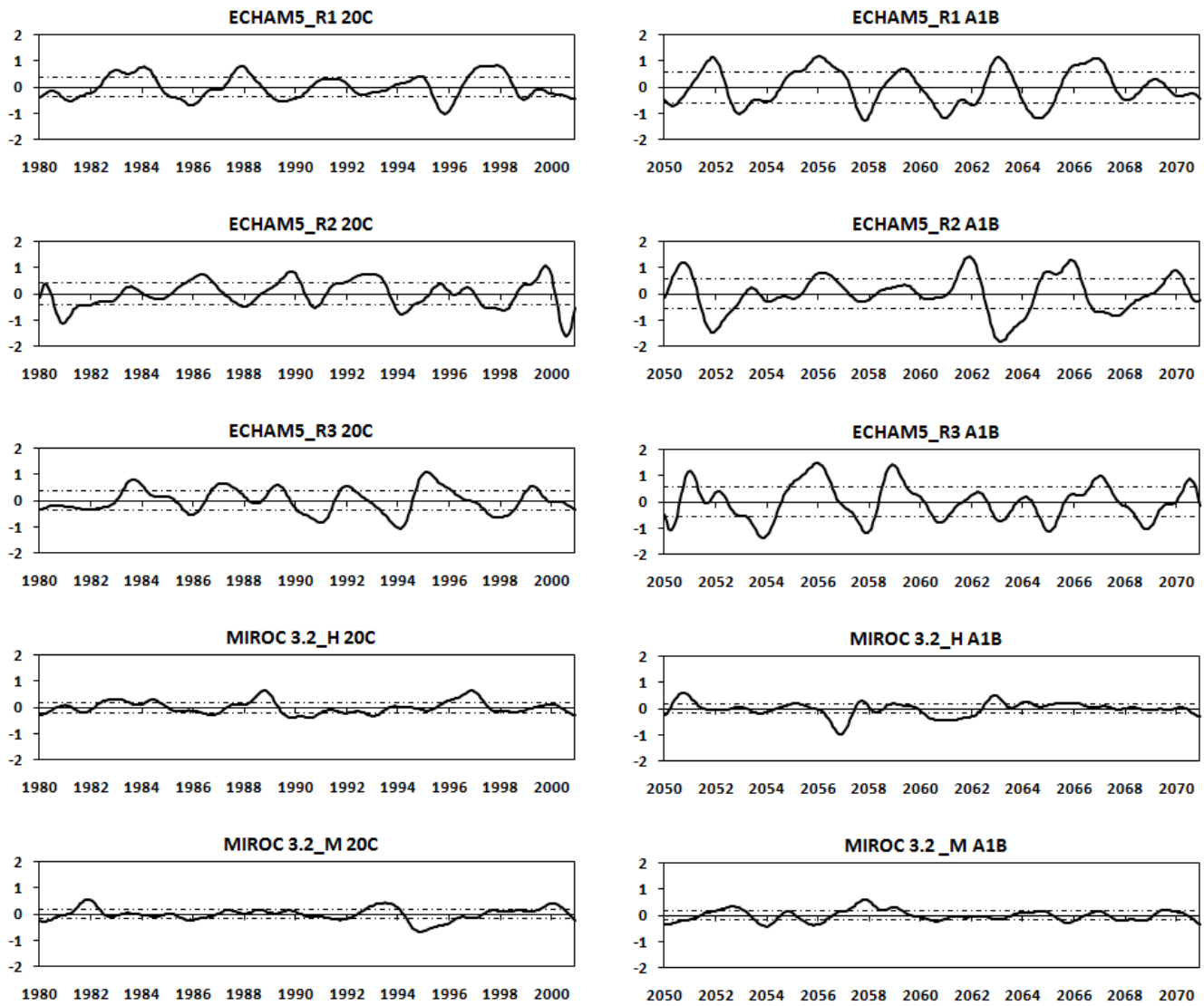

Figura 4.6 - Série temporal da REOF-1 para os MCGAOSs ECHAM5/MPI-OM e MIROC 3.2 para as simulações $20 \mathrm{C}$ (à esquerda) e A1B (à direita) que corrigido mostra o sinal positivo para o ENOS+e o sinal negativo para o ENOS-. Os modelos analisados estão indicados no topo de cada figura. Linhas tracejadas representam o desvio médio.

A Tabela 4.4 mostra os resultados do coeficiente temporal da REOF-1 em termos de número total de anos, número total de episódios e duração média de cada episódio, respectivamente. Os resultados estão separados para cada modelo e para os experimentos simulados 20C e A1B, bem como para a reanálise. Pela reanálise II de 1980 a 2000, foram classificados 9 anos Neutros, 6 anos com ENOS+ e 6 anos com ENOS-, cujas durações médias de cada episódio foram de 1.5, 1.2 e 1.5 anos, respectivamente. Considerando-se estes aspectos e para o experimento 20C, o modelo ECHAM5_R2 foi o que mais se aproximou do padrão da reanálise, com 8 anos Neutros, 6 anos com ENOS+ e 7 anos com ENOS-, embora 
os eventos tenham obtido uma duração maior com 1.6, 1.5 e 1.8 anos, respectivamente. Este resultado é consistente com trabalhos anteriores (e.g. Van Oldenbrorgh et al., 2005; AchutaRao e Sperber, 2006). Nas outras rodadas do ECHAM/MPI-OM houve um número maior de anos Neutros (11 anos) com duração média de 1.8 anos. Com relação ao modelo MIROC 3.2, a versão H do modelo representou satisfatóriamente o padrão da reanálise com 10 anos Neutros, 6 anos com ENOS+ e 5 anos com ENOS-, contudo os episódios tiveram uma duração muito superior ao observado com 2.0, 2.0 e 2.5 anos. Já a versão M do MIROC 3.2, foram 13 anos Neutros de longa duração (2.6 anos) e uns poucos episódios com ENOS+ e ENOS- de curta duração (1,3 anos).

Tabela 4.4 - Resultados da análise do Coeficiente temporal da REOF-1 para a distribuição do ENOS. Os resultados foram determinados olhando os campos da TSM, onde o Coeficiente temporal da REOF-1 persiste por 5 meses. São mostrados na seqüência os números relativos ao: total de anos/total de episódios/duração média de cada episódio. A tabela à esquerda representa os resultados para o experimento simulado $20 \mathrm{C}$ e a tabela à direita, o experimento simulado A1B.

\begin{tabular}{|c|c|c|c|c|c|c|}
\hline \multirow[b]{2}{*}{ REOF-1 } & \multicolumn{3}{|c|}{$20 \mathrm{C}$} & \multicolumn{3}{|c|}{ A1B } \\
\hline & Neutros & ENOS+ & ENOS- & Neutros & ENOS+ & ENOS- \\
\hline NCEP/NCAR & $9 / 6 / 1.5$ & $6 / 5 / 1.2$ & $6 / 4 / 1.5$ & - & - & - \\
\hline ECHAM5_R1 & $11 / 6 / 1.8$ & $5 / 5 / 1.0$ & $5 / 3 / 1.7$ & $11 / 6 / 1.8$ & $6 / 4 / 1.5$ & $4 / 4 / 1.0$ \\
\hline ECHAM5_R2 & $8 / 5 / 1.6$ & $6 / 4 / 1.5$ & $7 / 4 / 1.8$ & $8 / 4 / 2.0$ & $7 / 5 / 1.4$ & $6 / 3 / 2.0$ \\
\hline ECHAM5_R3 & $11 / 6 / 1.8$ & $4 / 4 / 1.0$ & $6 / 4 / 1.5$ & $11 / 8 / 1.4$ & $5 / 5 / 1.0$ & $5 / 5 / 1.0$ \\
\hline MIROC3.2-H & $10 / 5 / 2.0$ & $6 / 3 / 2.0$ & $5 / 2 / 2.5$ & $14 / 4 / 3.5$ & $4 / 2 / 2.0$ & $3 / 3 / 1.0$ \\
\hline MIROC3.2-M & $13 / 5 / 2.6$ & $4 / 3 / 1.3$ & $4 / 3 / 1.3$ & $10 / 7 / 1.4$ & $4 / 3 / 1.3$ & $7 / 6 / 1.2$ \\
\hline
\end{tabular}

Como observado na Tabela 4.4, os dois modelos com melhor desempenho para o experimento do cenário simulado 20C (ECHAM5_R2 e MIROC 3.2-H) representam condições distintas para o cenário A1B ao nível de $\mathrm{p}<0,05$. Notar que, no cenário A1B, os episódios Neutros no MIROC 3.2-H são relativamente longos em torno de 3.5 anos, enquanto que os episódios do ENOS- são relativamente curtos ( 1 ano). Por outro lado, o ECHAM5_R2 mostrou para o cenário A1B uma distribuição do número de eventos similar ao experimento simulado 20C, mas com eventos ligeiramente mais longos. No entanto, os 
modelos divergem em resultados para o cenário A1B: enquanto o ECHAM5_R2 projeta um futuro com distribuiçao similar em número de eventos, mas associados a episódios do ENOS mais intensos e relativamente mais duradouros, o MIROC 3.2-H projeta um futuro onde predominam episódios Neutros de longa duração. Sendo estas projeções distintas, uma questão a se responder é: como estes padrões de TSM podem influenciar nos aspectos estatísticos de bloqueios no futuro?

\subsection{BLOQUEIOS ATMOSFÉRICOS: SIMULAÇÕES PARA O TEMPO PRESENTE E FUTURO}

A variabilidade e mudanças nos bloqueios simulados dependem da capacidade dos modelos em capturar de modo realista às variações de geopotencial. Este problema foi inicialmente investigado comparando-se a capacidade de cada modelo em simular realisticamente o ciclo anual observado pelas reanalises do NCEP/NCAR. Assim, identificouse o ciclo anual do geopotencial em $500 \mathrm{hPa}$ e para cada modelo em $50^{\circ} \mathrm{S}$ no Pacífico Sul, em dois pontos longitudinais distintos, sendo $180^{\circ}$ e $90^{\circ} \mathrm{E}$, respectivamente. Para este fim, calculou-se a média diária do geopotencial para cada ponto de grade dos modelos e das reanálises II e ajustou-se o primeiro harmônico à média, conforme detalhado no capítulo 3.

A Figura 4.7 mostra o ciclo anual para os modelos (linha vermelha) e para o NCEP/NCAR reanálise II (linha azul). A linha em preto representa o primeiro harmônico. Como seria esperado, o primeiro harmônico foi suficiente para descrever a variabilidade diária da altura geopotencial em $500 \mathrm{hPa}$. Como observado pelo NCEP/NCAR, a amplitude do ciclo anual indica a forte sazonalidade do geopotencial nos extratrópicos nas longitudes de $180^{\circ}$ e $90^{\circ} \mathrm{W}$ em $50^{\circ} \mathrm{S}$ de latitude marcada pelo máximo entre verão e inicio de outono e o 
mínimo no inverno. Ambos os modelos ECHAM5_R2, MIROC 3.2-H e MIROC 3.2-M simulam corretamente a amplitude (diferença entre o máximo e o mínimo) do ciclo anual, contudo os valores médios do geopotencial são menores para os modelos em comparação aos dados do NCEP/NCAR.
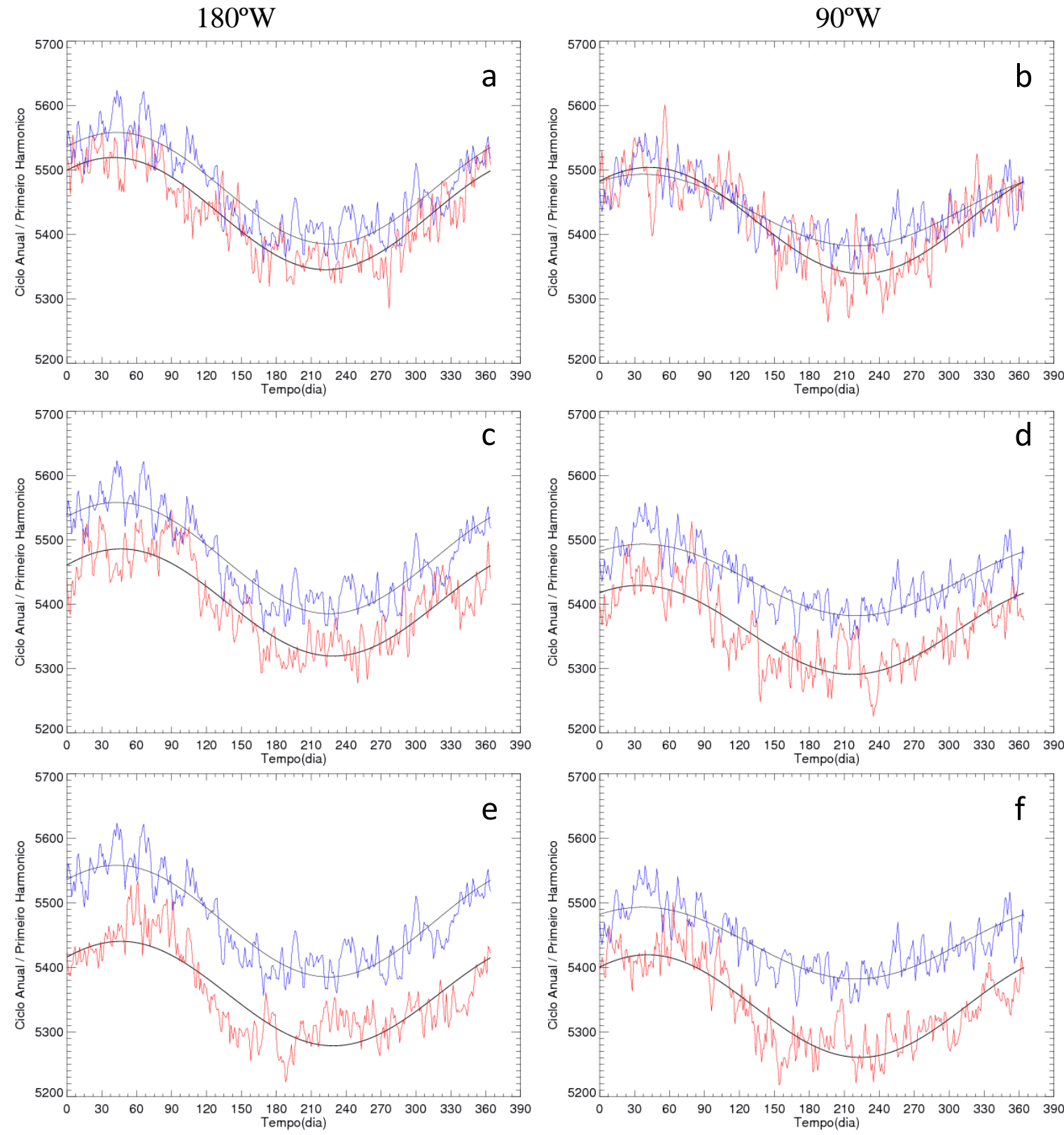

Figura 4.7 - Resultado do ciclo anual e do primeiro harmônico simulado pelos MCGAOs. As simulações (linha vermelha) são comparadas com o ciclo harmônico observado na reanálise do NCEP/NCAR (linha azul). As figuras à esquerda representam o ciclo harmônico calculado sobre a longitude $180^{\circ} \mathrm{em} 50^{\circ} \mathrm{S}$. As figuras à direita são análogas sobre a longitude de $90^{\circ} \mathrm{W}$ em $50^{\circ} \mathrm{S}$. Do topo à base são representadas as simulações realizadas pelo (a) e (b) ECHAM5_R2, (c) e (d) MIROC 3.2-H e (e) e (f) MIROC 3.2-M. 
Na presente análise não serão consideradas nenhuma separação sazonal dos resultados, conforme mostrado no Capitulo 3. Desta forma, serão feitos comentários adicionais relativos aos padrões observados na reanálise. A metodologia usada na detecção do escoamento bloqueado nos MCGAOs é a mesma utilizada nos dados de reanálises do NCEP/NCAR no capítulo 3 e detalhada no capítulo 2. No caso dos modelos a metodologia foi adaptada de acordo com a resolução de grade de cada modelo. Assim, os intervalos latitudinais empregados nos índices GHGS e GHGN são descritos como segue:

- ECHAM5/MPI-OM: Resolução da grade com $1,875 \times 1,875$ e $\phi_{\mathrm{N}}=37,25^{\circ} \mathrm{S}+\Delta, \phi_{0}=$ $50,625^{\circ} \mathrm{S}+\Delta, \phi_{\mathrm{S}}=65,625^{\circ} \mathrm{S}+\Delta$, e $\Delta=0^{\circ}, \pm 1,875^{\circ}, \pm 3,3750^{\circ}$

- MIROC 3.2-HIRES: Resolução da grade com $1,125 \times 1,125$ e $\phi_{N}=34,875^{\circ} \mathrm{S}+\Delta$, $\phi_{0}=50,625^{\circ} \mathrm{S}+\Delta, \phi_{\mathrm{S}}=66,375^{\circ} \mathrm{S}+\Delta$, e $\Delta=0^{\circ}, \pm 2,25^{\circ}, \pm 2,25^{\circ}$.

- MIROC 3.2-MEDRES: Resolução da grade com 2,8125x2,8125 E $\phi_{\mathrm{N}}=36,5625^{\circ} \mathrm{S}$ $+\Delta, \phi_{\mathrm{N}}=50,6250^{\circ} \mathrm{S}+\Delta, \phi_{\mathrm{N}}=64,6875^{\circ} \mathrm{S}+\Delta$, e $\Delta=0^{\circ}, \pm 2,8125^{\circ}, \pm 2,8125^{\circ}$.

\subsubsection{FREQÜÊNCIA LONGITUDINAL}

Nesta seção investigou-se o potencial de cada MCGAO em simular a freqüência e o local preferencial variando latitudinalmente. A Figura 4.8 mostra a variabilidade anual do escoamento bloqueado para as simulações 20C para a banda de latitude total, separadas conforme os episódios Neutros (a), ENOS+ (b) e ENOS- (c). O campo da reanálise referente a um período com o a mesma quantidade de anos (1980 a 2000) é utilizado na comparação com as simulações dos MCGAOs. A legenda inserida em cada gráfico indica o ao respectivo modelo sob análise. 
A Figura 4.8a mostra que ambos os MCGAOs subestimaram a freqüência do escoamento bloqueado durante a fase Neutra do ENOS na região do Pacífico Oeste. Por outro lado o ECHAM5_R2 superestimou a freqüência sobre a região do Pacífico Leste. Na Figura 4.8b o ECHAM_R2 representou muito bem a freqüência e o local preferencial durante a fase Quente do ENOS (exceto pelo pico em $120^{\circ} \mathrm{W}$ ), enquanto as duas versões do MIROC 3.2 subestimaram a frequiência e o local preferencial foi simulado sobre estreita faixa longitudinal. Durante a fase Fria do ENOS (Figura 4.8b), o modelo ECHAM5_R2 superestimou a freqüência ao longo da extensão do Pacífico Sul, mas esteve em acordo com o local preferencial observado. Por outro lado, o modelo MIROC 3.2-H simulou adequadamente a freqüência e o local preferencial. É possível notar também, que as duas versões do MIROC 3.2 representam adequadamente a ausência de bloqueios sobre o Indico e Atlântico, enquanto que o ECHAM5_R2 superestima a freqüência sobre estas mesmas regiões.

Um aspecto negativo e comum em todos os MCGAOs foi que nenhum deles simulou adequadamente a freqüência do escoamento bloqueado durante a fase Neutra do ENOS. Já o modelo ECHAM5_R2 possui evidentemente um erro sistemático sobre o Pacífico Leste que induz a altas freqüências durante as fases Neutra e Fria do ENOS sobre este setor. A principal diferença entre as duas versões do MIROC 3.2 está no aumento da frequiência de bloqueios no modelo com maior resolução horizontal, mostrando que a mais alta resolução horizontal nos modelos pode contribuir para um melhor desempenho na detecção de eventos de bloqueio. Este último resultado confirma o obtido recentemente por Matsueda et al., (2010). 

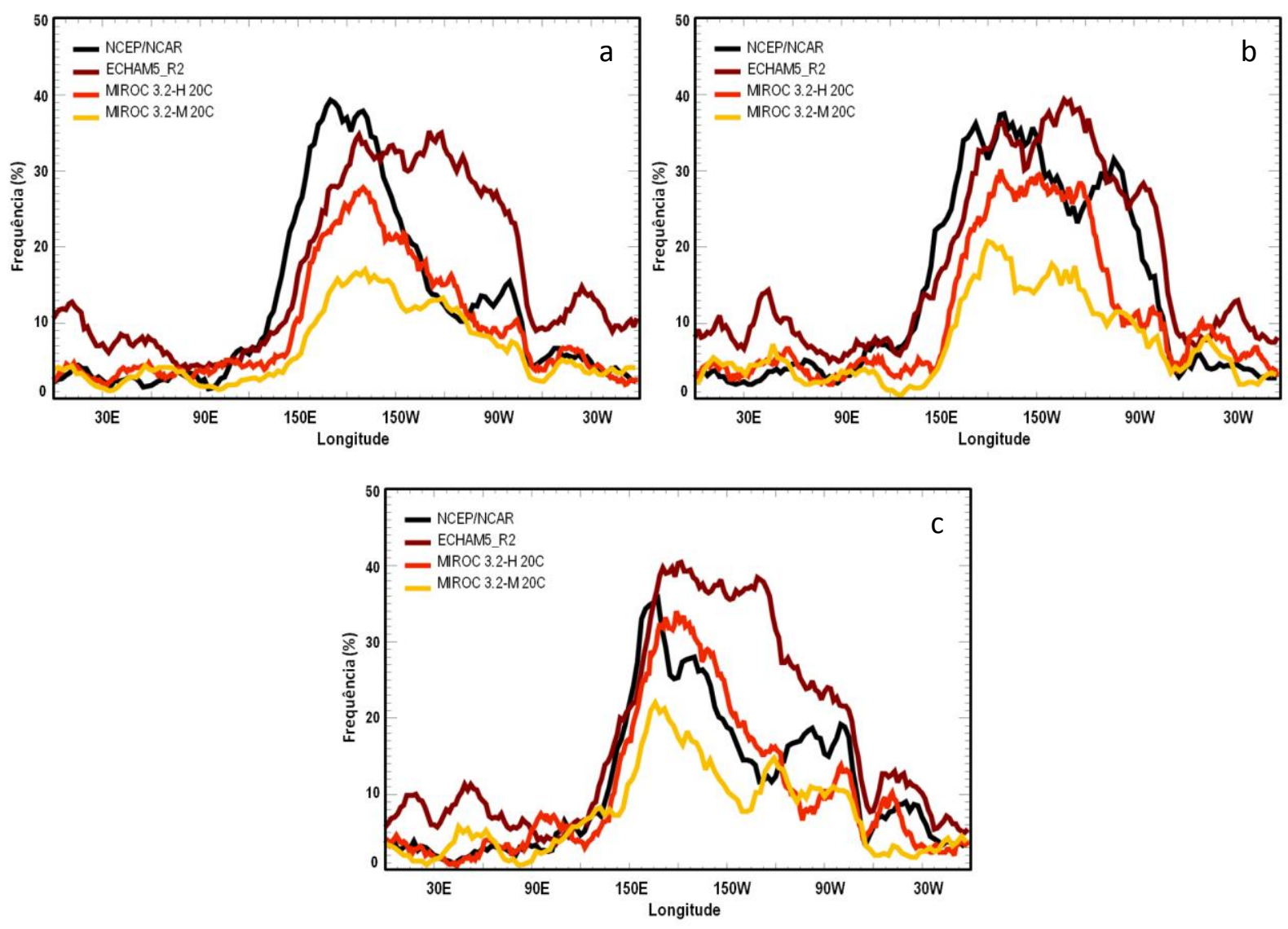

Figura 4.8 - Freqüência do número de detecções do escoamento bloqueado por ponto de longitude para o cenário simulado 20C sobre a banda zonal total: a) Períodos Neutros, b) ENOS+, c) ENOS-. O observado e as simulações estão representados da seguinte forma: Observado NCEP/NCAR (linha preta), ECHAM5_R2 (linha marrom), MIROC 3.2-H (linha laranja) MIROC 3.2-M (linha amarela).

De forma similar, a Figura 4.9 mostra a distribuição da freqüência do escoamento bloqueado durante as fases Neutra, Quente e Fria sobre latitudes médias-altas (topo) e médiasbaixas (base). Assim, investigou-se a habilidade dos modelos em simular o local preferencial do escoamento bloqueado para cada fase do ENOS e quanto a sua variação latitudinal. Conforme as reanálises, o local preferencial da atividade dos bloqueios de latitudes altas é expandido para o Pacífico Leste na fase Quente do ENOS e são suprimidos na fase Fria do ENOS, onde predominam eventos de latitudes mais baixas, caracteristicamente sobre o Pacífico Sudoeste. Como pode ser observado, o MIROC 3.2-H, exceto na Fase Fria do ENOS, simulou preferencialmente e com bom desempenho a frequiência dos eventos de latitudes altas 
do que os eventos situados sobre latitudes menores. Diferenças entre as figuras 4.9c e 4.9f são evidências de que o MIROC 3.2-H tende a superestimar os eventos sobre altas latitudes durante a fase Fria do ENOS. Por outro lado o ECHAM5_R2 obteve alto desempenho na fase Quente do ENOS representando adequadamente os eventos sobre altas e baixas latitudes, embora com um erro sistemático sobre o Pacifico Leste que leva a altas frequencias nas fases Neutra e Fria do ENOS. Adicionalmente, o ECHAM5_R2 superestimou a freqüência de bloqueios sobre a região do oceano Índico em latitudes mais baixas, um aspecto que foi bem representado no MIROC 3.2. Assim, ambos os modelos apresentam contrastes quanto à teleconexões com o ENOS. 

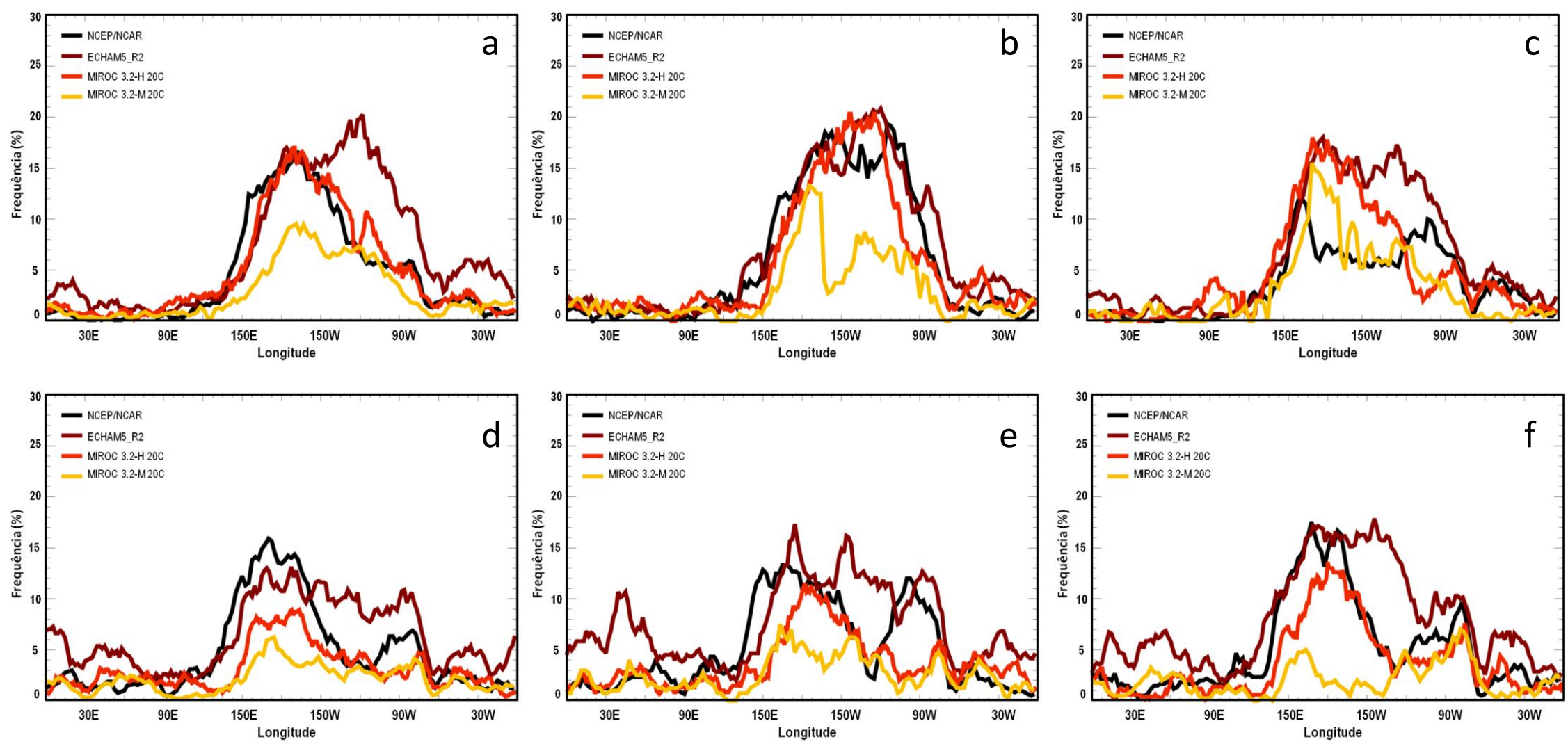

Figura 4.9 - Freqüência do número total de detecções do escoamento bloqueado por ponto de longitude para o cenário simulado $20 \mathrm{C}$ sobre as bandas de latitudes médias-altas (topo) e médias-baixas (base) e para a fase Neutra do ENOS (à esquerda, partes "a"e "d", fase Quente (no meio, partes "b" e "e", c), fase Fria (à direita, partes "c"e "f". O observado e as simulações estão representados da seguinte forma: Observado NCEP/NCAR (linha preta), ECHAM5_R2 (linha marrom), MIROC 3.2-H (linha laranja), MIROC 3.2-M (linha amarela). 
A Figura 4.10 compara as frequiências do escoamento bloqueado por ponto de longitude, nos experimentos simulados para os cenários 20C e A1B. Na fase Neutra do ENOS (Fig. 4.10a), as simulações para o cenário A1B mantiveram a mesma distribuição longitudinal com relação ao cenário simulado 20C nos três MCGAOs. Contudo, o ECHAM5_R2 mantem a mesma freqüência e o mesmo tipo de erro apresentado no cenário simulado 20C sobre a região do Pacífico Leste. Por outro lado, as duas versões do MIROC 3.2 reduzem a freqüência de eventos. Na fase Quente do ENOS (Fig. 4.10b) o ECHAM5_R2 simula um aumento da frequiência sobre o setor do Pacífico Sudeste, ressaltando que o ECHAM5_R2 obteve alto desempenho para a fase Quente do ENOS no cenário 20C, contudo permanecem dúvidas se o erro observado sobre esta específica região do Pacífico não é a causa da amplificação da frequência no cenário A1B. Observa-se que o MIROC 3.2-H reduz drasticamente a freqüência dos eventos durante a fase Quente do ENOS, reforçando ainda mais os contrastes nas teleconexões do ENOS entre os MCGAOs. Na fase Fria do ENOS (Fig. 4.10c) os três MCGAOs reduzem drasticamente a frequência dos eventos. 

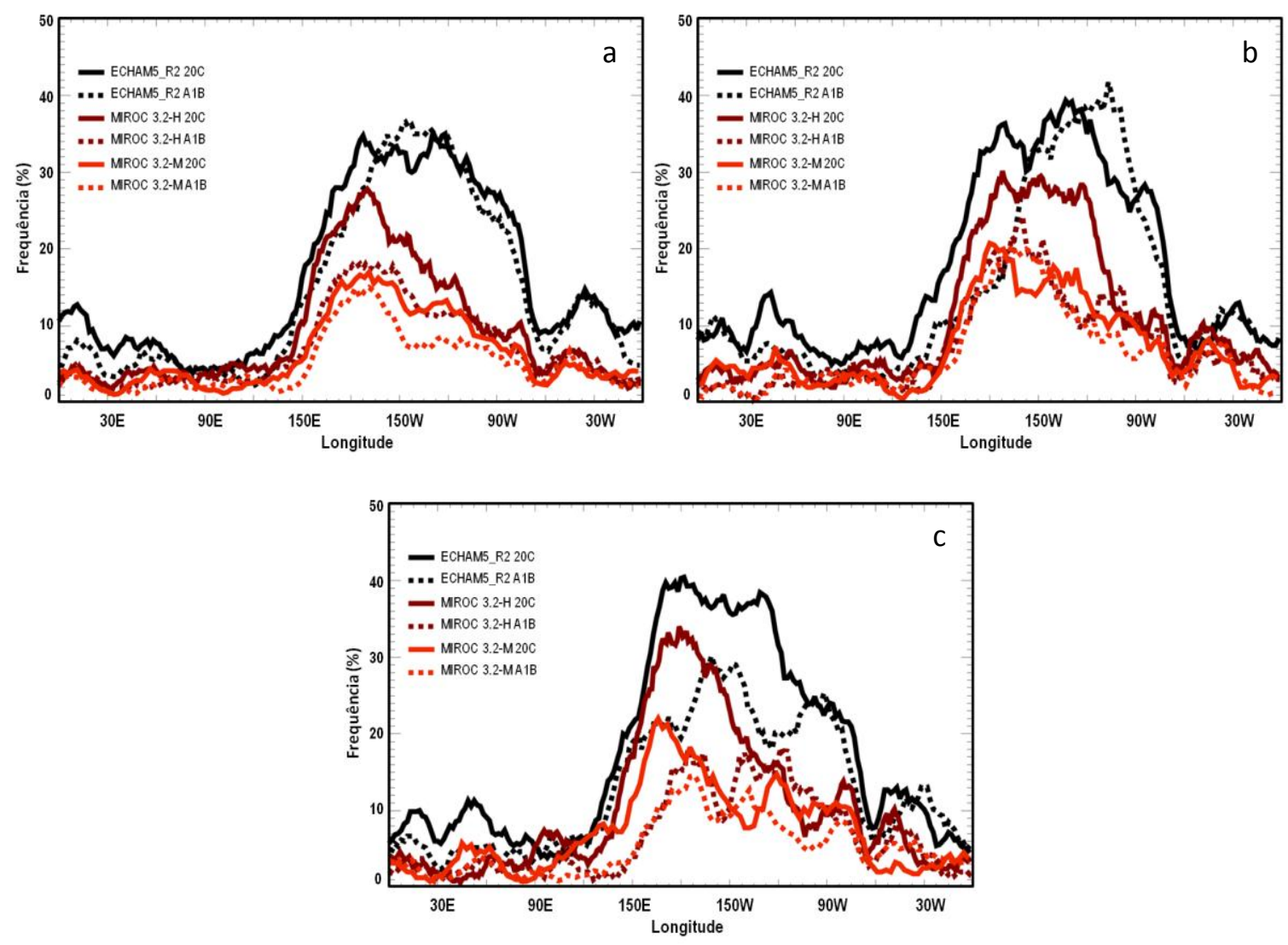

Figura 4.10 - Freqüência do número de detecções do escoamento bloqueado por ponto de longitude comparando os cenários simulados 20C e A1B sobre a banda zonal total nos nas fases a) Neutra, b) Quente e c) Fria do ENOS. O simulado para o clima presente 20C é representado por linhas sólidas enquanto que o simulado para o cenário $\mathrm{A} 1 \mathrm{~B}$ é representado por linhas tracejadas. A legenda no topo à esquerda de cada figura indica o modelo.

A variabilidade anual dos eventos de bloqueio $(\tau \geq 3$ dias) nos MCGAOs foram examinadas em termos de frequência da banda de latitude total separadas de acordo com sinal do ENOS. Ressalta-se que nenhum modelo simulou adequadamente a freqüência dos eventos no cenário 20C (ver Figura 4.8). Testes entre proporções ao nível de significância de 5\% foram realizados para averiguar se as diferenças observadas nas respostas dos modelos são distintas do observado em termos de eventos de bloqueio.

Inicialmente não faremos distinção entre o sinal do ENOS. Desta forma, a figura 4.11 representa o número total de eventos de bloqueio para o observado versus os cenários simulados 20C e A1B pelos MCGAOs. Foram representados nesta figura aqueles setores de 
bloqueio estatisticamente significativos, conforme capítulo 3, sendo o Pacífico Sudoeste, Pacífico Central e Pacífico Sudeste, respectivamente. Asteriscos sobrepostos as barras dos totais significam diferenças estatísticamente significativas ao nível de $p<0,05$.

Assim, na Fig. 4.11 e referente ao total anual da reanálise dos eventos de bloqueio observou-se igualdade entre os setores de bloqueio do Pacífico Sudoeste e Pacífico Central, ressaltando que os eventos sobre o Pacífico Central tendem a ter maior longevidade e sobre latitudes mais altas. Ambos os MCGAOs representaram o maior total de eventos sobre o Pacífico Central em ambos os cenários simulados. Notar que o MCGAO MIROC 3.2-H representou razoavelmente bem a proporção dos eventos nos setores para o cenário 20C, dado que nenhum resultado representou diferenças significativamente estatísticas ao nível de $\mathrm{p}<0,05$. Por outro lado o modelo simulou para o cenário A1B uma redução na freqüência dos eventos de bloqueio. Contudo diferenças significativas foram observadas entre as proporções do Pacífico Sudoeste (que diminui) e Pacífico Central (que aumenta) ao nível de $p<0,05$. Isto representa um deslocamento significativo da atividade de bloqueios para o leste de $180^{\circ}$ no cenário A1B. Com relação ao modelo ECHAM5_R2, o cenário simulado 20C é realmente diferente estatisticamente ao nível de $\mathrm{p}<0,05$ para os eventos formados sobre os setores do Pacífico Sudoeste e Sudeste, sendo indiferente sobre o Pacífico Central. Esta super frequiência sobre o Pacífico Sudeste está atribuída ao erro sistemático do modelo sobre este setor. Para o cenário A1B, o modelo ECHAM5_R2 realçou ainda mais as diferenças entre os setores do Pacífico Sudoeste e Sudeste. Como resultado comum, os dois modelos concordam com a redução da atividade de bloqueios sobre o Pacífico Sudoeste. 


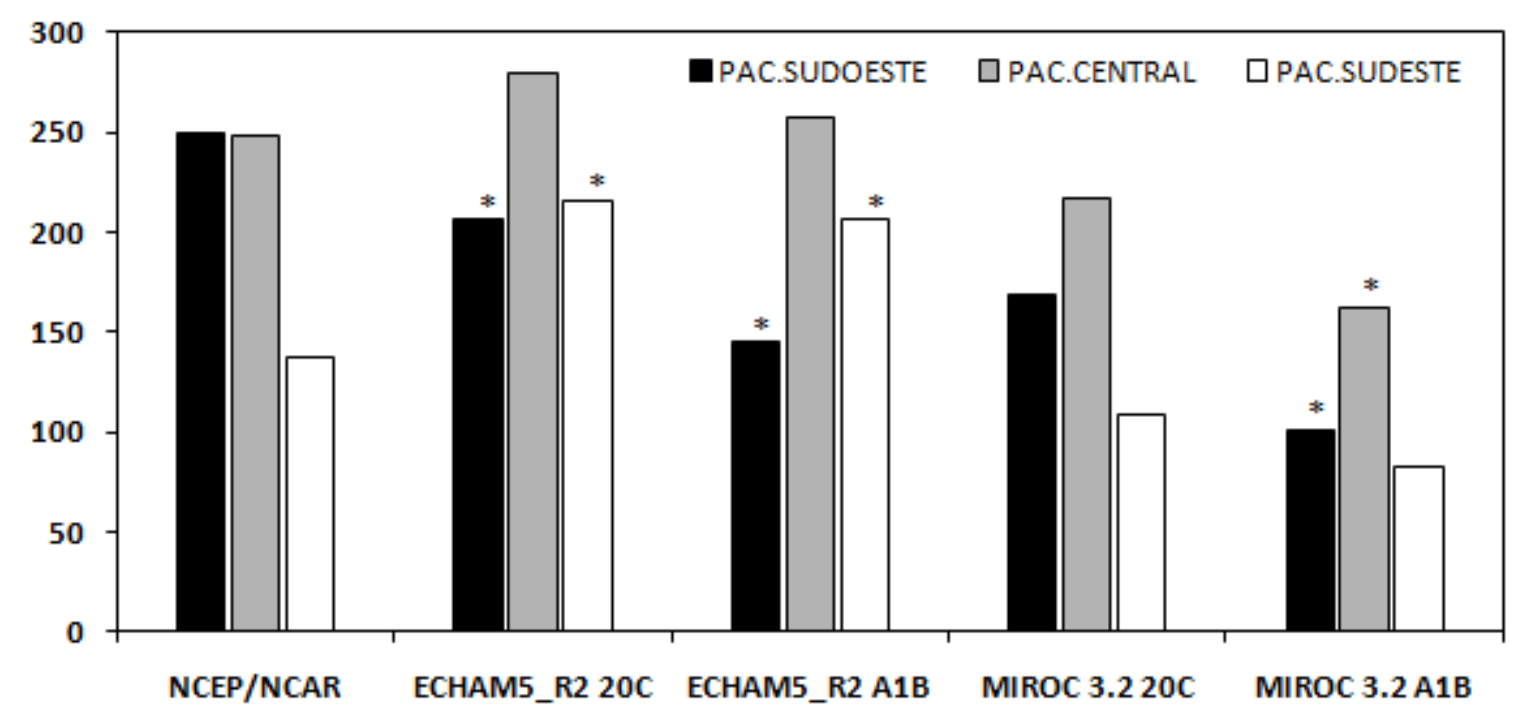

Figura 4.11 - Freqüência total dos eventos de bloqueio para o observado NCEP/NCAR versus o cenário simulado 20C pelos MCGAOs (ECHAM5_R2, MIROC 3.2-H e MIROC 3.2-M) para os setores de bloqueio do a) Pacífico Sudoeste, b) Pacífico Central e c) Pacífico Sudeste. Asteriscos indicam que as proporções simuladas são estatisticamente diferentes ao nível de $\mathrm{p}<0,05$ em comparação com as proporções obtidas para a reanálise.

A Figura 4.12, mostra a freqüência anual dos eventos de bloqueio de acordo com a variabilidade do sinal do ENOS para o experimento de cenário simulado 20C. Asterisco dentro de barra de frequiência indica diferenças significativas ao nível de $p<0,05$ entre as proporções simuladas versus o observado. Observando a freqüência total dos eventos sobre o HS (Fig. 4.12d), os resultados mostram que o modelo ECHAM5_R2 reproduz estatisticamente as altas frequencias durante a fase Fria do ENOS e associadas ao erro do modelo, o que gera incertezas em prognosticar eventos para o cenário A1B. O erro torna-se crítico sobre o Pacífico Central (Figura 4.12b). Por outro lado, também são geradas altas frequências sobre o Pacífico Sudeste (Figura 4.12c) em ambas as fases do ENOS, embora não sejam evidenciados diferenças entre as proporções. Já o modelo MIROC 3.2-H aparentemente subestima a freqüência dos eventos de bloqueio no HS (Figura 4.12d) nas fases Neutra e Quente do ENOS. Contudo, não existem diferenças significativas entre as proporções o que 
sugere que o MIROC 3.2-H simulou razoavelmente a distribuição dos eventos de acordo com as fases do ENOS.
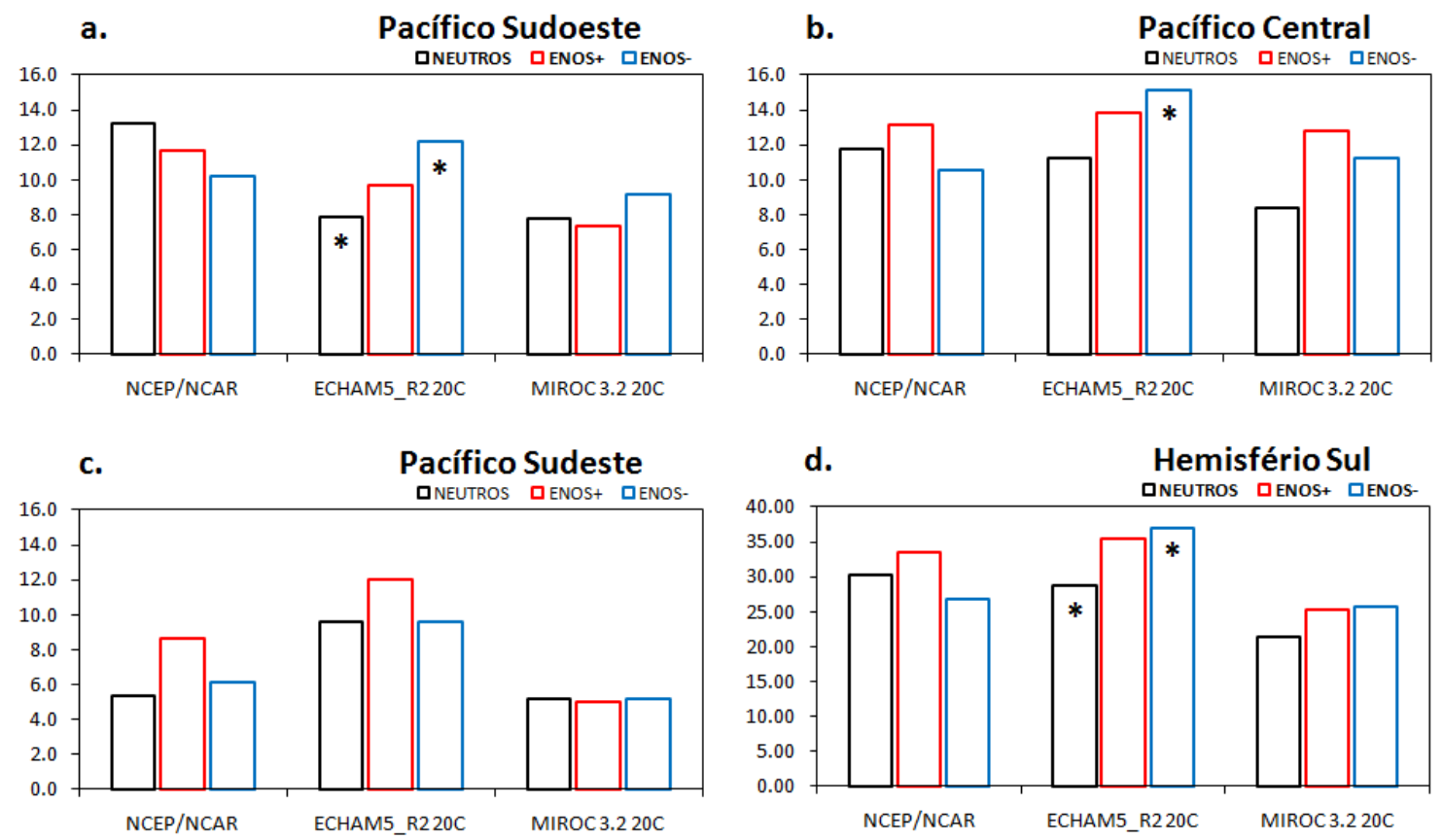

Figura 4.12 - Freqüência total dos eventos de bloqueio distribuída dentro das fases do ENOS para o observado NCEP/NCAR versus o simulado 20C pelos MCGAOs (ECHAM5_R2, MIROC 3.2-H e MIROC 3.2-M) e para os setores de bloqueio: a) Pacífico Sudoeste, b) Pacífico Central e c) Pacífico Sudeste. A legenda no topo de cada figura identifica as fases do ENOS. Asteriscos indicam que as proporções simuladas são estatisticamente diferentes ao nível de $\mathrm{p}<0,05$ em comparação com as proporções obtidas para a reanálise.

A Figura 4.13 mostra a freqüência anual dos eventos de bloqueios objetivando mostrar diferenças entre a frequiência simulada para o clima presente e projeções para o cenário futuro A1B. Análogo a Figura 4.12, os asteriscos dentro das barras de frequiência indicam diferenças entre as proporções. Neste aspecto, ambos os MCGAOs simularam para o cenário A1B uma redução na frequiência de bloqueios estatisticamente significativa ao nível de $\mathrm{p}<0,05$ (Figura 4.13d). Contudo, os dois MCGAOs representam contrastes quanto à teleconexões do ENOS na atividade de bloqueios em um futuro idealizado, visto que representam distinções com relação às proporções. Por exemplo, ambos projetam uma redução no número de eventos, mas 
enquanto o ECHAM5_R2 simulou diferenças entre as fases Neutra e Fria do ENOS, o MIROC 3.2-H evidencia diferenças entre as fases Neutra e Quente.
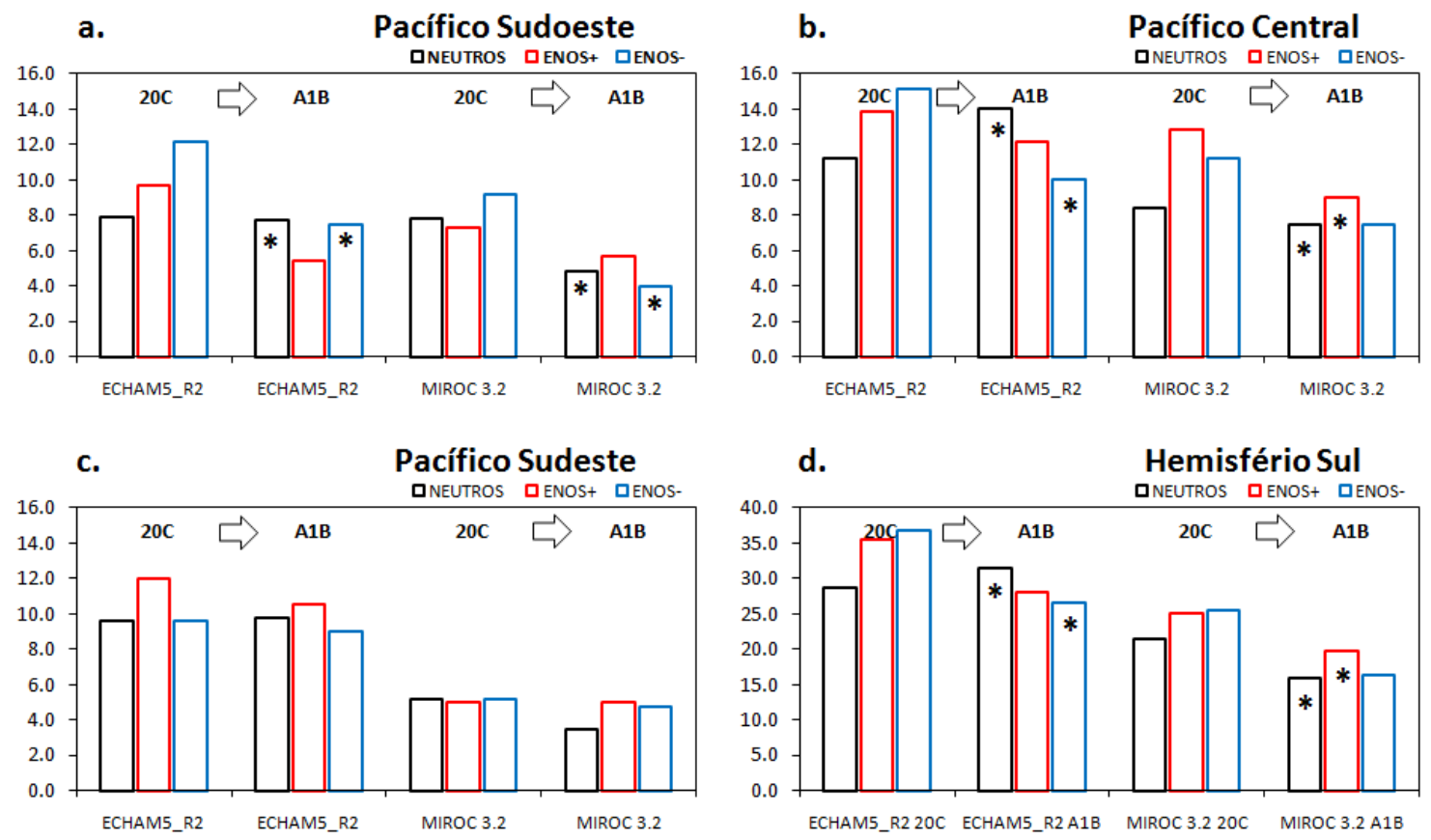

Figura 4.13 - Freqüência total dos eventos de bloqueio distribuída dentro das fases do ENOS para o simulado 20C versus o simulado A1B pelos modelos (ECHAM5_R2, MIROC 3.2-H e MIROC 3.2-M) para os setores de bloqueio: a) Pacífico Sudoeste, b) Pacífico Central e c) Pacífico Sudeste. A legenda no topo identifica as fases do ENOS. Asteriscos indicam que as proporções simuladas entre os dois cenários são estatisticamente diferentes ao nível de $\mathrm{p}<0,05$.

Por ultimo, a Figura 4.14 mostra as diferenças mensais das "médias" dos dias com bloqueios entre o experimento simulado do cenário $20 \mathrm{C}$ e o observado nas fases Neutra (à esquerda), Quente (meio) e Fria (à esquerda) e para os setores de bloqueio do Pacífico Sudoeste (topo), Pacífico Central (meio) e Pacífico Sudeste (base). O erro padrão da média amostral das diferenças com $95 \%$ de confiança também é mostrado.

Assim, o MIROC 3.2-H reproduziu erros associados com diferenças negativas sobre o setor do Pacífico Sudoeste na fase Neutra do ENOS (Fig 4.14a) sendo no outono e inverno as maiores diferenças, Pacífico Central nas fases Neutra e Quente do ENOS (Fig. 4.14b e 4.14e) 
e no setor do Pacífico Sudeste na fase Quente do ENOS (Fig. 4.14f) e associado com diferenças positivas no setor do Pacífico Central na fase Fria do ENOS. As diferenças negativas são mais pronunciadas durante o outono no Pacífico Central e ao longo do ano sobre o Pacífico Sudoeste, exceto no Pacífico Sudeste na fase Quente do ENOS, onde o MIROC 3.2-H subestimou os eventos durante a primavera. Nas diferenças positivas, o maior de erro amostral foi observado durante a fase Fria do ENOS no Pacífico Central nos meses de inverno (Fig. 4.14h). Por outro lado o ECHAM5_R2 reproduziu os maiores erros geralmente associados com diferenças positivas, preferencialmetne sobre o setor do Pacífico Central na fase Fria do ENOS (Fig. 4.14h) nos meses de inverno e verão. Os resultados mais comuns entre os dois modelos são as tendências em superestimar bloqueios no Pacifico Central durante o período do inverno e verão na fase Fria do ENOS, e o de subestimar bloqueios no Pacífico Sudoeste na fase Neutra do ENOS e ao longo do ano. 
NEUTROS
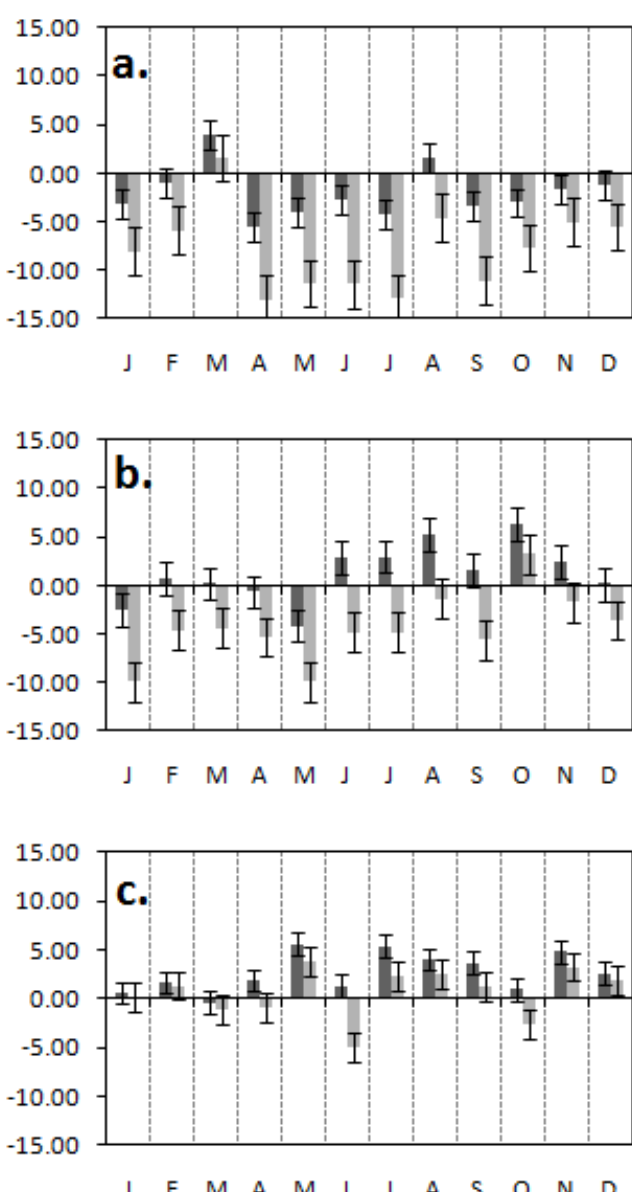

ENOS+
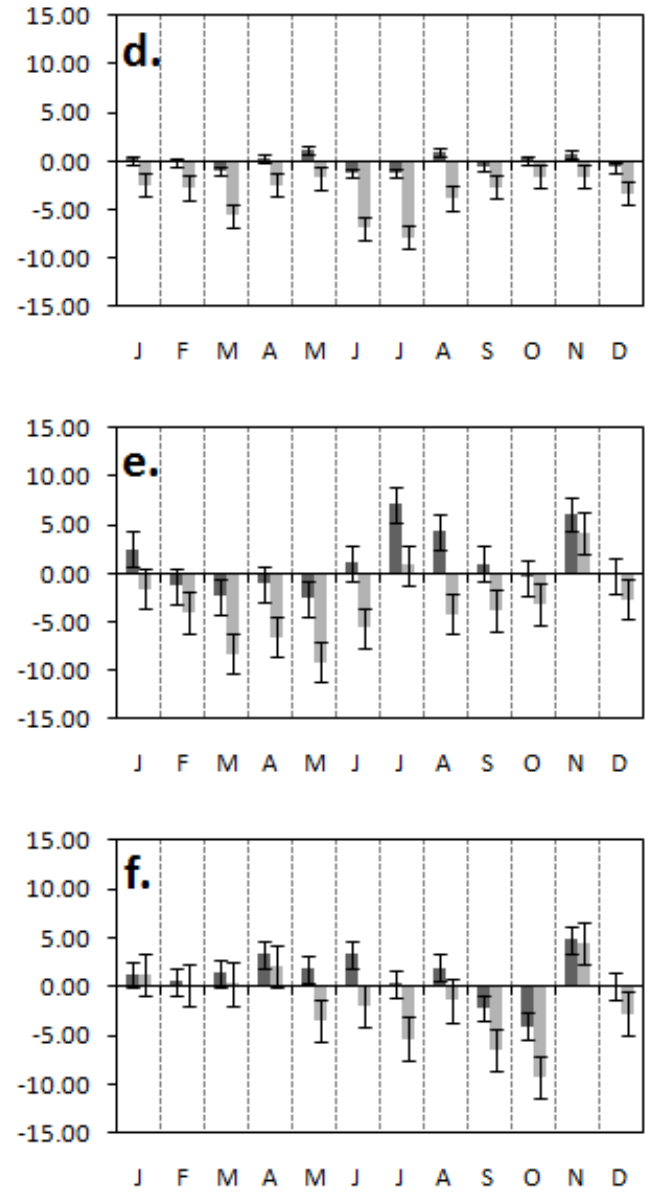

ENOS-
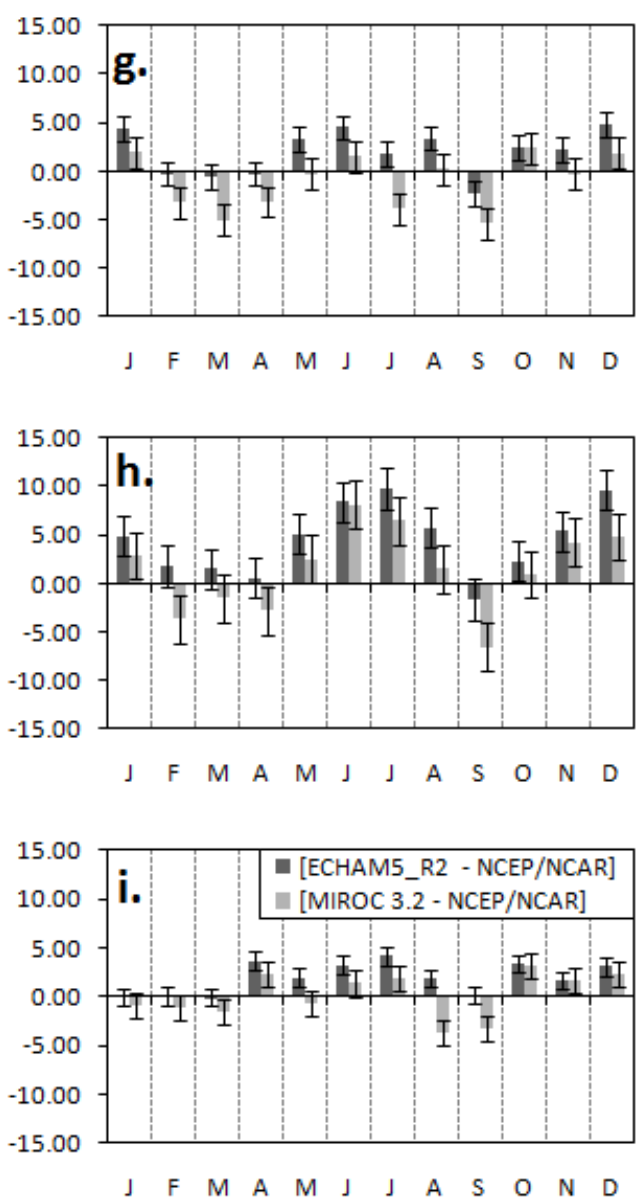

Figura 4.14 - Numero médio mensal dos dias com bloqueios com $\tau \geq 3$ dias na fase Neutra do ENOS (à esquerda), na fase Quente (no centro) e na fase Fria (à direita) nos setores de bloqueio do Pacífico Sudoeste ("a", "d", e "g”) Pacífico Central ("b", "e", e "h") e Pacífico Sudeste ("c", "f”, e “i”). Barras de erros com $95 \%$ de confiança são mostradas para cada mês. 


\subsubsection{ESCALA DE TEMPO TÍPICA NOS MCGAOs.}

Nesta seção investiga-se a escala de tempo típica de bloqueios simulados pelos MCGAOs ECHAM5_R2 e MIROC 3.2-H para o cenário 20C. O procedimento foi análogo ao cálculo da escala típica no Capítulo 3. O cálculo da escala típica é um excelente procedimento para validar a evolução dos sistemas de bloqueios simulados. Por fim, fez-se uma análise das propriedades estatísticas da duração dos episódios de bloqueios durando pelo menos 3 dias.

Analisando a escala típica dos eventos nos MCGAOs, pretende-se verificar se os valores se aproximam do observado entre 1,5 e 2,4 dias. A Figura 4.15, representa o número total de detecções de bloqueios por ponto de longitude durando $\tau$ dias na escala logarítmica de base e. Nesta figura, o procedimento é mostrado para as latitudes médias-baixas (a), médias (b) e médias-altas (c), respectivamente. Na Figura 4.15d, resume-se os resultados com o devido erro padrão. Como se nota na Figura 4.15, em todas as bandas de latitude os gradientes simulados são similares ao observado, dado pelo decaimento no valor do logaritmo onde a duração dos eventos varia de 3 a 11 dias nos modelos e de 3 a 10 dias para o observado. É possível então observar na Figura 4.15d que os MCGAOs simularam adequadamente a escala de tempo típico em função da posição latitudinal do bloqueio, tal como no observado, sendo os eventos mais persistentes sobre as latitudes mais altas. Sobre as latitudes médias-baixas, o MIROC 3.2-H simulou uma escala típico de 1,6 dias, similar ao observado, enquanto o ECHAM5_R2 simulou eventos mais persistentes, em torno de 2 dias. Contudo, nas latitudes médias, nenhum AOGCM obteve escala de tempo superior ao observado de 2,4 dias. Já para os episódios de bloqueios sobre latitudes médias-altas, o ECHAM5_R2 obteve uma escala de tempo de 2.5 dias, similar ao observado de 2,4 dias. A análise da barra de erro padrão indica que o tempo de escala característico de bloqueio nos modelos oscila dentro de um patamar 
comum como observado, exceto o ECHAM5_R2 sobre as latitudes médias-baixas, onde o modelo superestima o tempo de escala com respeito ao observado.
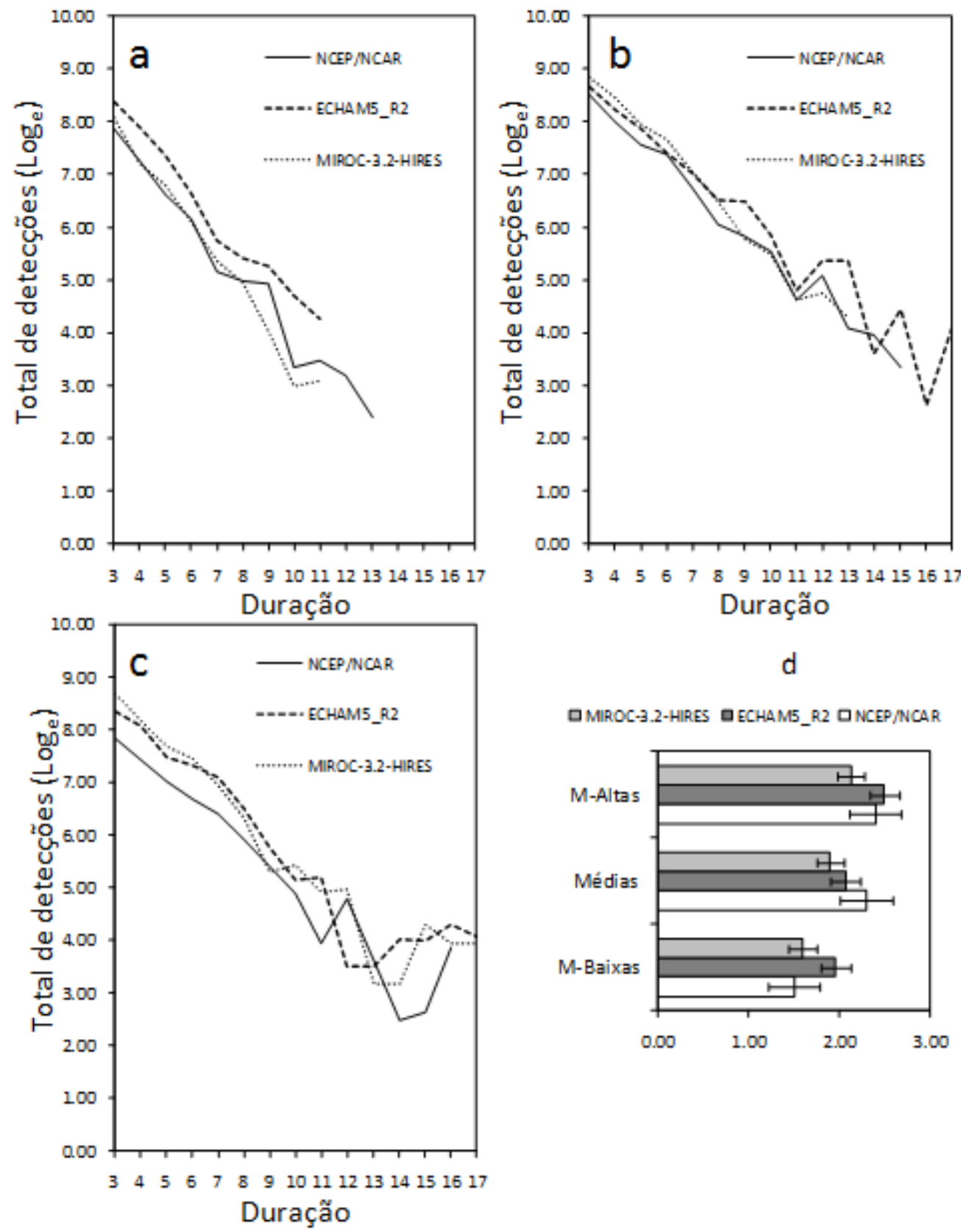

口MIROC-3.2-HIRES DECHAM5_R2 QNCEP/NCAR

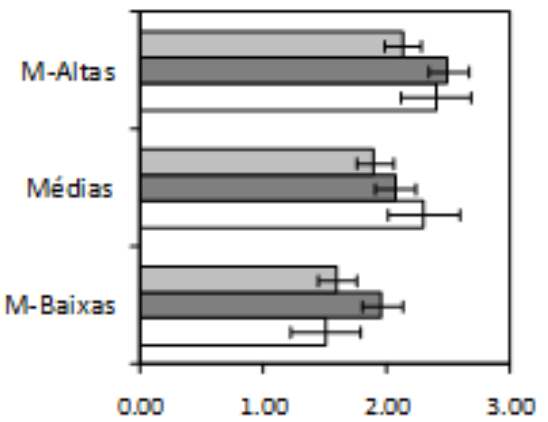

Figura 4.15 - Comparação das escalas de tempo médias das simulações para o cenário simulado 20C pelos MCGAOs versus a reanálise do NCEP/NCAR. Nas figuras estão representas as escala típica de bloqueios para a) latitudes médias-baixas, b) latitudes médias e c) latitudes médias-altas. $\mathrm{O}$ gráfico (d) representa um resumo das figuras "a", "b"e "c" com intervalos do erro médio. 
Finalmente, analisamos as propriedades estatísticas da duração dos episódios de bloqueio simulados para os experimentos 20C e A1B. A Figura 4.16 mostra gráficos Bag plot para uma análise bivariada $(\lambda, \tau)$ anual dos eventos de bloqueio para o observado e para os simulados 20C e A1B. Comparando os gráficos das figuras 4.16b e 4.16d com 4.16a, observou-se que todos os MCGAOs, tal como na escala típica, também simularam adequadamente a duração mediana dos eventos em torno de 4 e 5 dias. O ECHAM5_R2 no experimento simulado $20 \mathrm{C}$ representa a maior dispersão entre as simulaçoes (inclusive um evento irrealístico de 35 dias) contrastando com a redução nas observações para o cenário A1B. Com relação ao MIROC 3.2-H é interessante observar a redução no número de observações aberrantes, significando uma redução nos eventos extremos. Também observar que em ambos os MCGAOs o local preferencial onde estão 50\% dos dados é ligeiramente deslocado para leste durante o cenário A1B. Este último resultado confirma a significativa redução no número de eventos sobre o Pacífico Sudoeste simulado pelos MCGAOs. 

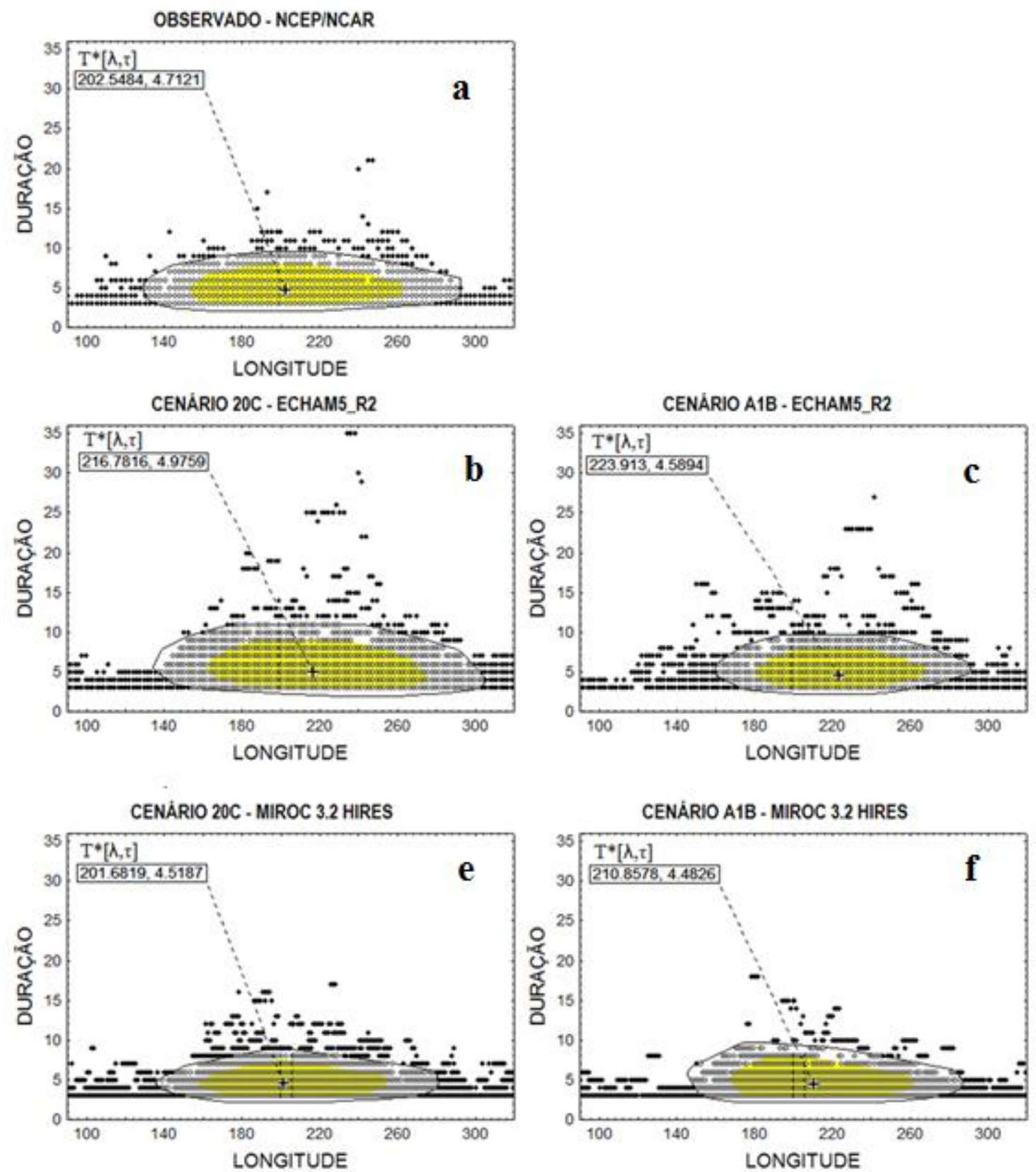

Figura 4.16 - Bagplot [longitude $(\lambda) \mathrm{x}$ duração $(\tau)$ ] da distribuição dos eventos de bloqueio com $\tau \geq 3$ dias pela reanálise do NCEP/NCAR. a) Observado NCEP/NCAR, b) ECHAM5_R2 20C, c) ECHAM5_R2 A1B, d) MIROC 3.2 20C, e) MIROC 3.2 A1B. Foram retidos apenas o valor de máxima duração de um evento sobre um determinado ponto de longitude. A bolsa (região amarela) mostra a extensão longitudinal bivariada onde estão $50 \%$ das observações. A cruz no centro da bolsa é a mediana de Tukey. A região branca que envolve a bolsa mostra os dados que estão no limite, similar as longas bigornas do Boxplot. As observações aberrantes são os pontos pretos que estão fora do laço poligonal convexo. 


\section{CAPÍTULO 5}

\section{CONCLUSÕES}

O objetivo deste estudo foi elaborar uma climatologia longa e detalhada de bloqueios para o Hemisfério Sul. Para este fim, propôs-se um novo índice de bloqueio baseado na tradicional metodologia de T94. Foram analisadas a freqüência e distribuição espaço-temporal e sazonal dos bloqueios. Foram processados e examinados 59 anos de dados anuais das reanálises I do NCEP/NCAR. Outro importante objetivo deste estudo foi a investigação das relações do ENOS e do modo combinado AAO|ENOS. As análises foram realizadas sobre cinco setores de bloqueios (Índico Sudoeste, Pacífico Sudoeste, Pacífico Central, Pacífico Sudeste e Atlântico Sudoeste) e foram discutidos aspectos sobre duas grandes regiões principais (Pacífico Oeste e Pacífico Leste). Com base nesta nova climatologia, avaliamos o potencial de dois MCGAOs (ECHAM5/MPI-OM e MIROC 3.2) em simular a atividade de bloqueios para o clima presente e para um cenário futuro com $2 \mathrm{xCO}_{2}$.

Os cinco intervalos $(\Delta s)$ de latitude propostos no presente estudo não resultaram na maior detecção de dias bloqueados em comparação com os $3 \Delta$ s propostos em T94. Contudo, esta nova abordagem enfatizou uma significativa variação latitudinal, provavelmente associada com ondas planetárias que se estendem de latitudes mais baixas sobre o Pacífico Oeste seguindo em direção para latitudes mais altas sobre o Pacífico Leste. Alem disso, foi mostrada que a escala típica de bloqueios sobre o HS depende desta posição latitudinal. Desta forma, bloqueios nos extratrópicos do HS e com uma extensão mínima de $15^{\circ}$ de longitude têm uma escala de tempo média de 1,5 a 2,5 dias para latitudes mais baixas e mais altas, respectivamente. Eventos de bloqueios sobre latitudes altas são um dia mais persistentes do 
que aqueles sobre latitudes menores. Baseado nesta escala média de tempo definiu-se um evento de bloqueio quando um evento persistiu por pelo menos 3 dias.

Durante os anos neutros, a maior frequência de bloqueio foi observada próximo de $180^{\circ} \mathrm{E}$ durante grande parte do ano, mas durante o inverno o máximo é deslocado até $150^{\circ} \mathrm{W}$, o que corresponde com o flanco oeste do setor do Pacífico Central. Os eventos de bloqueio têm maior longevidade nas estações do outono ao inverno, quando a frequiência de ocorrência expande sobre o Pacífico Leste, encontrando as maiores latitudes e as menores longevidades entre primavera e verão, quando a freqüência regride sobre latitudes menores sobre o Pacífico Oeste, próximo a linha de data. No verão a atividade de bloqueios é confinada sobre o Pacífico Oeste. Os eventos mais intensos do ENOS+ estão associados com o deslocamento do local preferencial para o Pacífico Leste, onde os eventos são em torno de um dia mais persistentes (ao nível de $\mathrm{p}<0,05$ ). No entanto, estes episódios intensos do ENOS+ não estão associados com aumento da frequiência de eventos. Por outro lado, durante os episódios fracos do ENOS+ a freqüência do escoamento bloqueado é aumentada significativamente ao nível de $\mathrm{p}<0,05$. Similar deslocamento do local preferencial sobre o Pacífico Leste foi também observado durante os episódios fortes do ENOS-. Ambas as intensidades do ENOS- estão associados com a redução do escoamento bloqueado sobre o Pacífico Central. O número de eventos de bloqueios ( $\tau \geq 3$ dias) mostra redução estatística somente durante o ENOS-. Nenhuma mudança significativa no tempo de vida dos eventos de bloqueios foi observada durante o ENOS-.

Uma tendência linear negativa foi observada sobre o setor do Pacífico Sudeste ao nível de $\mathrm{p}<0,05$. O período de máxima perturbação na atividade de eventos de bloqueio coincidiu com à mudança de regime climático de 1976/77 ou "Climate Shift" e durante a década de 1986 a 1996, o qual está associado ao período de maior frequiência do ENOS+, o que associa a variabilidade de bloqueios com os padrões de teleconexões. 
Fogt et al., (2010) encontrou que a magnitude das teleconexões no Pacífico Sul é fortemente dependente da fase do Modo Anular do Sul (Aqui referido como AAO). Eles mostraram que somente quando os episódios do ENOS ocorrem com uma fraca AAO ou quando o ENOS- (ENOS+) ocorre com uma AAO+ (AAO-) são observadas teleconexões sobre o Pacífico Sul. Neste presente estudo, mostramos que a AAO- está associada com o máximo da freqüência do escoamento bloqueado, independente da fase do ENOS. Consistentemente, a AAO+ está associada a menor freqüência do escoamento bloqueado em ambas as fases do ENOS-, exceto para o aumento do escoamento bloqueado sobre o Pacífico Oeste. A tendência da AAO em direção a sua fase positiva (e.g. Thompson and Solomon 2002) em combinação com o ENOS+ pode estar contribuindo para a tendência negativa observada sobre o Pacífico Leste. O fortalecimento (enfraquecimento) do jato polar durante a AAO+ (AAO-) gera condições desfavoráveis (favorável) para a formação de bloqueios em $60^{\circ} \mathrm{S}$. O ENOS+ está associado com o fortalecimento do jato subtropical em ambas as fases da AAO. Além disto, durante a AAO+|ENOS+ o fortalecimento do jato polar zonalmente justaposicionado com o jato subtropical no Pacífico Oeste gera condições favoráveis para o escoamento bloqueado comparativamente como a AAO+|ENOS-.

Testes estatísticos sugerem que a AAO- está associada com o aumento na proporção do escoamento bloqueado sobre o Pacífico Leste, sem nenhuma diferença com respeito as fases do ENOS. Por outro lado, verificou-se que a frequiência de bloqueios sobre os setores do Pacífico Sudoeste e Sudeste aumentam durante a AAO-|ENOS-, enquanto que durante o ENOS+ parece não haver diferenças estatísticas na frequiência dos eventos sobre estes setores.

Os MCGAOs ECHAM5_R2 e MIROC 3.2-H simularam adequadamente a variabilidade interanual do ENOS no cenário simulado 20C, contudo divergem em resultados para o cenário simulado A1B. Enquanto o ECHAM5_R2 projeta um futuro com distribuiçao do ENOS similar ao cenário simulado 20C, apesar de episódios mais intensos e relativamente 
mais duradouros, o MIROC 3.2-H projeta um futuro com predominância de episódios da fase Neutra do ENOS e longa duração.

Ambos os MCGAOs, ECHAM5_R2 e MIROC-3.2_H simularam corretamente a amplitude (diferença entre o máximo e o mínimo) do ciclo anual, contudo os valores médios do geopotencial são menores para os modelos em comparação aos dados do NCEP/NCAR. Também, estes modelos simularam adequadamente o tempo de escala típico e a duração mediana dos eventos de bloqueio, bem como o local preferencial. No entanto, os MCGAOS representam contrastes entre si e com o observado quanto às teleconexões com o ENOS na freqüência dos eventos de bloqueio. Fato que, nenhum MCGAOs no experimento do cenário simulado 20C simulou adequadamente a freqüência do escoamento bloqueado durante a fase Neutra do ENOS, bem como tendem a superestimar a frequiência de bloqueios no Pacífico Central durante a fase Fria do ENOS, assim como tendem a subestimar a frequiência sobre o Pacífico Sudoeste na fase Neutra do ENOS. O ECHAM5_R2 reproduz sistemáticamente um erro sobre o Pacífico Leste que induz à superestimativas durante as fases Neutra e Fria do ENOS sobre esta região do Pacífico. As diferenças detectadas entre as duas versões do MIROC 3.2 evidenciam que a maior resolução horizontal nos modelos pode contribuir para um melhor desempenho na detecção de eventos de bloqueio.

De forma geral, os resultados mostraram que o ENOS mais intenso no cenário A1B pelo incremento $2 \mathrm{xCO}_{2}$ não está associado com um aumento na frequência de bloqueios. De fato, na parte observacional deste estudo também não foi encontrada esta associação. Por outro lado, os MCGAOs possuem contrastes de teleconexões entre si e com a reanálise no que diz respeito à frequiência de eventos de bloqueio. Além disso, a possível predominância do ENOS "modoki" nos MCGAOs pode representar diferenças não investigadas na parte observacional deste trabalho. Uma possível intensificação do jato polar no cenário A1B associado com o aumento da fase postiva da AAO poderia contribuir efetivamente na redução 
da atividade de bloqueios no futuro. Entretanto, torna-se necessário investigar nos modelos do IPCC o modo combinado AAO e ENOS. 


\section{SUGESTÕES PARA TRABALHOS FUTUROS}

Na parte observacional, houve a necessidade de explorar as possíveis diferenças na atividade de bloqueios entre os episódios do ENOS do tipo "canônico" e "modoki". Havendo diferenças, este tópico poderia ser investigado nos modelos e poderiam explicar algumas das diferenças observadas entre a reanálise e os modelos, dado a provável maior freqüência do ENOS 'modoki' nos modelos em comparaçao com a reanálise. Por exemplo, seria o ENOS 'modoki' nos modelos o responsável pela superestimativa do ECHAM5_R2 sobre o Pacífico Leste.

Também o modo combinado, AAO|ENOS necessita ser melhor entendido na parte observacional e investigado nos modelos de clima do IPCC. Por exemplo, os tipos de bloqueios, Omega e dipolo parecem ser modulados pelo modo combinado AAO|ENOS, conforme sugerido neste trabalho observacionalmente. Também, investigar a modulação do modo combinado na progressão e/ou regressão dos eventos de bloqueio, bem como bloqueios duplos sobre o oceano Pacífico. Questões como, qual o modo predominante da AAO combinado com o ENOS nos modelos? Existe uma tendência entre os dois cenários simulados? Por exemplo, uma tendência de aumento da fase positiva da AAO nos modelos para o cenário A1B poderia explicar a redução de bloqueios no futuro, caso os modelos representassem realisticamente o modo combinado. Ademais, dado a importância predominate da fase Neutra nos modelos, como seria a influência da AAO combinada com a fase Neutra do ENOS. São questões que poderiam ser respondidas em trabalhos futuros. Adicionalmente, muitas destas observações seriam importantes se fossem investigadas em experimentos “ensemble" destes modelos.

Complementando, é sugerido a geração de estados básicos a partir do conjunto de eventos de bloqueios para simulação de propagação de ondas de Rossby estacionárias com um 
modelo baratotrópico e/ou baroclínico. Por fim, investigar os impactos climáticos na região Sul e Sudeste do Brasil relacionado à atividade de bloqueios usando técnica de “downscalling” nas saídas dos MCGAOs do IPCC mediante o uso de modelos regionais, tais como o WRF (Weather Research and Forecasting) ou BRAMS, mas considerando os temas discutidos acima. 


\section{REFERÊNCIAS}

ACHUTARAO, K.; SPERBER, K.R. ENSO Simulation in Coupled Ocean-Atmosphere Models: Are the Current Models Better? Clim. Dyn. 27:1-15, 2006.

AMBRIZZI, T.; HOSKINS, B.J.; HSU, H-H. Rossby wave propagation and teleconnection patterns in the Austral Winter. Journal of Atmospheric Sciences 52: 3661-3672, 1995.

ANDERSON T. W.; Finn J. D. The new statistical analysis of data. Spring-Verlang: NewYork, 1996. 712 p.

ARAKAWA, A.; SUAREZ, M. J. Vertical differencing of the primitive equations in sigma coordinates, Mon. Wea. Rev., 111, 34-45, 1983.

ASHOK, K.; BEHERA, S.K.; RAO, S.A.; WENG, H.; YAMAGATA, T.El Niño Modoki and its possible teleconnection. J. Geophys. Res., 112, C11007, 2007. doi:10.1029/2006JC003798.

AUSTIN, J.F. The blocking of middle latitude westerly winds by planetary waves. Quart.J.Royal.Meto.Soc.,106, 327-350, 1980.

BALDWIN, M.P., D.W.J. THOMPSON, E.F. SHUCKBURGH, W.A. NORTON, AND N.P. GILLETT. Weather from the Stratosphere?. Science, 301, 317-318, 2003a.

BARRIOPEDRO, D.; GARCIA-HERRERA, R.; LUPO, A.R.; HERNÁNDEZ, E. A climatology of Northern Hemisphere blocking. Journal of Climate 19: 1042-1063, 2005.

BENGTSSON, L.; HODGES, K. I.; ROECKNER, E. Storm tracks and climate change. Journal of Climate 19: 3518-3543, 2006.

BERGGREN, R.; BOLIN, B.; ROSSBY, C.-G. An aerological study of zonal motion, its perturbations and breakdown. Tellus, 1(2), 14-37, 1949. 
BERRISFORD, P.; HOSKINS, B.J.; TYRLIS, E. Blocking and Rossby wave breaking on the Dynamical Tropopause in the Southern Hemisphere. Journal of Atmospheric Sciences 64: 2881-2898, 2006.

BLACKMON, M.L.; MULLEN, S.L.; BATES, G.T. The climatology of blocking events in a perpetual simulation of a spectral general circulation model. Journal of Atmospheric Sciences 43: 1379-1405, 1986.

BOMBARDI, R.J.; CARVALHO, L.M.V. Sea surface temperature patterns and variations in the characteristics of the South America Monsoon system in the WCRP-CMIP3 multimodel simulations. Climate Dynamics 36: 2091-2102, 2009.

BOMBARDI, R.J.; CARVALHO, L.M.V. The South Atlantic dipole and variations in the characteristics of the South American Monsoon in the WCRP-CMIP3 multimodel simulations. Climate Dynamics, 36: 11, 2091-210,(DOI 10.1007/s00382-010-0836-9), 2011.

BREWER A. W. Evidence for a world circulation provided by the measurements of helium and water vapour distribution in the stratosphere, Quart.J.Royal.Meto.Soc., 75, 351-363, 1949.

BROWN, M.L. Anticyclones in the Australia-New Zealand region. New Zealand Meteor. Service Tech. Note 228, 16 pp, 1975.

CARVALHO, L.M.V.; JONES, C.; AMBRIZZI, T.; Opposite phases of the Antarctic Oscillation and relationships with intraseasonal to interannual activity in the Tropics during the Austral Summer. Journal of Climate 18: 702-718, 2005.

CASARIN, D.P; KOUSKY, V.E. Um estudo observacional sobre os sistemas de bloqueio no Hemisfério Sul. Anais do II Congresso Brasileiro de Meteorologia 2: 225-253, 1982.

CHARNEY, J.G.; SHUKLA, J.; MO, K.C. Comparison of a barotropic blocking theory with observation. J.Atmos.Sci., 38, 762-779. 1981 
CHEN, W.Y.; VAN DEN DOOL, H.M. Asymmetric impact of tropical SST anomalies on atmospheric internal variability over the North Pacific. Journal of Atmospheric Sciences 54: 725-740, 1997a.

CHEN, T. C.; SHUKLA, J. Diagnostics analysis and spectral energetics of a blocking event in GLAS climate model simulation. Mon. Wea. Rev., 111, 3-23, 1983.

COUGHLAN, M.J. A comparative climatology of blocking action in the two hemispheres. Aust. Met. Mag., 31, 3-13, 1983.

D'ANDREA, F.; TIBALDI, S.; BLACKBURN, M.; BOER, G.; DÉQUÉ. M.; DIX, M.R.; DUGAS, B.; FERRANTI, L.; IWASAKI, T.; KITOH, A.; POPE, V.; RANDALL, D.; ROECKNER, E.; HALL, C.; STRAUS, D.; STERN, W.; VAN DEN DOOL, H.; WILLIAMSON, D. Northern Hemisphere atmospheric blocking as simulated by 15 atmospheric general circulation models in the period 1979-1988. Climate Dynamics 14: 1979-1988, 1998.

DESLER, C.; ALEXANDER, M.A.; TIMLIN, MS. Upper ocean thermal variations in the North Pacific Journal of Climate 9: 1840- 1855, 1996.

DOBSON, G. M. Origin and distribution of the polyatomic molecules in the atmosphere, Proc. R.Soc. Lon. Ser.-A, 236, 187-193, 1956. 13831, 1956.

DOLE, R.M. The objective representation of blocking patterns. Colóquio NCAR/CQ-6+1978ASP, 406-426, 1978.

DOLE, R. M.; GORDON, N.D. Persistent anomalies of the extratropical Northern Hemisphere wintertime circulation: Geographical distribution and regional persistence characteristics, Mon. Weather Rev., 111, 1567- 1586, 1983.

DOLE, R.M. The Life Cycles of Persistent Anomalies and Blocking over North Pacific. Advances in Geophysics 29: 31-69, 1986.

EGGER, J. Dynamics of blocking highs. J Atmos Sci 35: 1788-1801, 1978. 
ELLIOTT, R.D; SMITH, T.B. A study of the effects of large blocking highs on the general circulation in the northern-hemisphere westerlies. Journal of Meteorology 6(2): 67-85. ISSN 0095-9634, 1949.

FOGT, R.L.; BROMWICH, D.; HINES, K.M.; Understanding the SAM influence on the South Pacific ENSO teleconnection. Climate Dynamics. DOI: 10.1007/s00382-010-0905$0,2010$.

FORTUIN, J.P.F.; KELDER, H. An ozone climatology based on ozonesonde and satellite measurements. J. Geophys. Res., 103, 31,709-31734, 1998.

FUENTES, M.V. Climatologia de bloqueios próximos a América do Sul e seus efeitos. Dissertação de Mestrado, Instituto Nacional de Pesquisas Espaciais, 70pp, São José dos Campos, São Paulo, 1997.

FYFE, J.C.; BOER, G.J.; FLATO, G.M. The Artic and Antarctic Oscillations and their Project Changes under Global Warming. Geophys.Res. Lett., 26, 1601-1604, 1999.

GIESE, B.S.; URIZAR, S.C.; FUČKAR, N.S. Southern Hemisphere Origins of the 1976 Climate Shift. Geophysical Research Letters 29: 1014-1017, 2002. DOI: 10.1029/2001GL013268.

GONG, D.; WANG, S. Definition of Antarctic Oscillation index. Geophysical Research Letters 26: 459-462, 1999.

HAINES, K.; MARSHALL, J. Eddy-forced coherent structures as a prototype of atmospheric blocking. Quart. J. Roy. Meteor.Soc., 113, 681-704, 1987.

HARTMANN, D. L.; LO, F. Wave-driven Zonal Flow Vacillation in the Southern Hemisphere. J. Atmos. Sci., 55, 1303-1315, 1988.

HASUMI H.; EMORI S. K-1 Coupled GCM (MIROC) Description. 2006. Disponível em: <http://www.ccsr.u-tokyo.ac.jp/kyosei/hasumi/MIROC/tech-repo.pdf.>. Acesso em: 6 Jun 2011. 
HOLOPAINEN, E.O.; FORTELIUS, C . High-frequency transient eddies and blocking. J. Atmos. Sci., 40, 1632-1645, 1987.

HOSKINS, B.J; MCINTYRE, M.E.; ROBERTSON, A.W. On the use and significance of isentropic potential vorticity maps. Quarterly Journal of the Royal Meteorological Society 111: 877-946, 1985.

HOSKINS, B.J; AMBRIZZI, T. Rossby Wave propagation on a realistic longitudinally varying flow. Journal of the Atmospheric Sciences, 50:1661-1671, 1993.

JONES, C.; CARVALHO, L.M.V. Changes in the activity of the Madden-Julian oscillation during 1958-2004. Journal of Climate 19: 6353-6370, 2006.

JUNGCLAUS, J.H.; BOTZET, M.; HAAK, H.; KEENLYSIDE. N.; LUO, J.J.; LATIF, M.; MAROTZKE, J.; MIKOLAJEWICZ, U.; ROECKNER, E. Ocean circulation and tropical variability in the coupled model ECHAM5/MPI-OM. J Clim 19:3952-3972, 2006.

KALNAY, E.; COAUTHORS. The NCEP/NCAR 40-Year Reanalysis Project. Bulletin of American Meteorological Society 77: 437-471, 1996.

KALNAY-RIVAS, E.; MERKINE, L.O. A simple mechanism for blocking. Journal of Atmospheric Sciences 38: 2077-2091, 1981.

KAROLY, D.J., Atmospheric teleconnections, forced planetary waves and blocking. Aust. Meteo. Mag, 31, 51-56, 1983.

KAYANO, M.T.; KOUSKY, V.E. Southern Hemisphere Blocking: A comparison Between to Indices. Meteorology and Atmospheric Physics, 42, 165-170. 1990.

KIDSON, J. W. Interannual Variations in the Southern Hemisphere Circulation. J. Climate, 1, $1177-1198,1988$.

KONRAD, C. E.; COLUCCI, S. J. An Examination of Extreme Cold Air Outbreaks over Eastern North America. Mon. Wea. Rev., 117, 2687-2700, 1989. 
KUMAR, K.R.; KUMAR, K.K.; PRASANNA, V.; KAMALA, K.; DESHPANDE, N.R.; PARWARDHAN, K; PANT, G.B. C. Future Climate Scenarios. Climate change and India: Vulnerability assessment and adaptation. University Press. Chapter 3, pp 69-125, 2003.

KUTZBACH, J. E. Large-scale Features of Monthly Mean Northern Hemisphere Anomaly Maps of Sea-level Pressure. Mon. Wea. Rev., 98, 708-716, 1971.

LEJENÃS, H.; ØKLAND, H. Characteristics of Northern Hemisphere Blocking as Determined from a Long Time Series of Observational Data. Tellus 35A: 350-362, 1983.

LEJENÃS, H. Characteristics of Southern Hemisphere Blocking as determined from a time series of observational data. Quarterly Journal of the Royal Meteorological Society 110: 967-979, 1984.

LEJENÄS, H.; DOOS, B.R. The behavior of the stationary and traveling planetary scale waves during blocking - A Northern Hemisphere data study. J. Meteo. Soc. Japan, 65, 709-725, 1987.

LEJENÄS, H.; MADDEN, R.A.Traveling planetary-scale waves and blocking. Mon. Wea. Rev., 120, 2821-2830, 1992.

LINDZEN, R.S. Stationary planetary waves, blocking and interannual variability. Advances in Geophysics, 29 (Anomalous Atmospheric Flows and Blocking), pp. 251-273. R. Benzi, B. Saltzman, A.C. Wiin-Nielsen (Eds.), 1986.

MANTUA, N.J.; HARE, S.R.; ZHANG, Y.; WALLACE, J.; FRANCIS, R.C. A Pacific interdecadal climate oscillation with impacts on salmon production. Bulletin of the American Meteorological Society, 78 (6): 1069-1079, 1997.

MARQUES, R.F. Bloqueios Atmosféricos no Hemisfério Sul. Tese de doutorado, INPE, 1996. 
MARQUES, R.F.C.; RAO, V.B. Bloqueio Atmosférico no Hemisfério Sul durante o período de 1980 a 1993. Climanálise Especial, Cap 8, INPE, 1996.

MARQUES, R.F.C.; RAO, V.B. A Comparison of Atmospheric Blockings over the Southeast and Southwest Pacific Ocean. J. Meteo. Soc. Japan, 79, 863-874, 2001.

DAMIÃO, M.C.M.;Bloqueios atmosféricos sobre o Hemisfério Sul: Diagnóstico, impacto climático e mecanismos físicos associados. Tese de doutorado, Universidade de Lisboa, 2007.

DAMIÃO, M.C.M.; TRIGO, R.M.; CAVALCANTI, F.A.I.; DACAMARA, C.C. Blocking Episodes in the Southern Hemisphere: Impact on the Climate of Adjacent Continental Areas. Pure and Applied Geophysics 165: 1941-1962. DOI: 10.1007/s00024-008-0409-4, 2008.

METZ, W. Transient cyclone-scale vorticity forcing of blocking highs. J. Atmos. Sci., 43, 1467-1483, 1986.

MULLEN, S.L. Transient Eddy Forcing and Blocking Flows. Journal of Atmospheric Sciences 44: 3-22, 1987.

MARQUES, R.F.C.; RAO, V.B. Interannual variations of blocking in the Southern Hemisphere and their energetics. Journal of Geophysical Research 105: 4625-4636, 2000.

MATSUEDA, M.; HIROZAKU, H.; MIZUTA, R. Future change in Southern Hemisphere summertime and wintertime atmospheric blockings simulated using a 20-km-mesh AGCM. Geophysical Research Letters 37: LO2803. DOI: 10.1029/2009GL041758. 2010.

MULLEN, S.L. Model experiments on the impact of Pacific sea surface temperature anomalies on blocking frequency. Journal of Climate 2: 997-1013, 1989.

MURRAY, R. J.; AND SIMMONDS, I. A Numerical Scheme for Tracking Cyclone Centers From Digital Data. Part I: Development and operation of the scheme. Aust. Meteor. Mag., 39, 155-166, 1991. 
MIYAKODA, K.; KINTER, J.L.; YANG, S. The role of ENSO in the south Asian monsoon and pre-monsoon signals over the Tibetan plateau. Journal of the Meteorological Society of Japan, 81(5), 1015-1039, 2003.

NAKAMURA, H.; WALLACE, J.M. Synoptic behaviour of baroclinic eddies during blocking onset. Mon. Wea. Rev., 121, 1982-1903, 1993.

NAKAMURA, H. Rotational evolution of potential vorticity associated with a strong blocking flow configuration over Europe, Geophys. Res. Lett., 21(18), 2003-2006, 1994.

NAKAMURA, H.; NAKAMURA, M.; E ANDERSON, J.L. The role of high and low frequency dynamics in blocking formation. Mon. Wea. Rev., 125, 2074-2093. 1997. NAKIC'ENOVIC', N.; ALCAMO, J.; DAVIS, G.; DE VRIES, B.; FENHANN, J.; GAFFIN, S.; GREGORY, K.; GRÜBLER, A.; JUNG. T.Y.; KRAM, T.; LA ROVERE, T.L.; MICHAELIS, L.; MORI, S.; MORITA, T.; PEPPER, W.; PITCHER, H.; PRICE, L.; RAIHI, K.; ROEHRL, A.; ROGNER, H.-H.; SANKOVSKI, A.; SCHLESINGER, M.; SHUKLA, P.; SMITH, S.; SWART, R.; VAN ROOIJEN, S.; VICTOR, N.; DADI, Z. IPCC Special. Report on Emissions Scenarios, Cambridge University Press, Cambridge, United Kingdom and New York, NY, USA, 599 pp, 2000.

NAMIAS, J. Extending Forecasting by mean circulation methods. U.S. Weather Bureau, 1947, 88 pp.

NAOE, H.; MATSUDA, Y.; E NAKAMURA, H. Rossby wave propagation in idealized and realistic zonally varying flows. J. Meteo. Soc. Japan, 75, 687-700, 1997.

NASCIMENTO, E.L. Influência dos bloqueios atmosféricos na propagação de ondas de Rossby em escoamentos de Inverno no Hemisfério Sul. Dissertação de Mestrado. Instituto Astronômico, Geofísico e de Ciências Atmosféricas. Universidade de São Paulo IAG/USP, 1998. 
NASCIMENTO, E.L.; AMBRIZZI, T. The influence of Atmospheric blocking on the Rossby Wave propagation in Southern Hemisphere winter flows. Journal of the Meteorological Society of Japan 80: 139-159, 2002.

OGI, M.; TACHIBANA, Y.; YAMAZAKI, K. Impact of the Wintertime North Atlantic Oscillation (NAO) on the Summertime Atmospheric Circulation. Geophysis Res. Lett, 30 (13), 1704, doi:10.1029/2003GL017280, 2003.

PAN, D.-M.; RANDALL, D.A. A cumulus parameterization with a prognostic closure,Q. J. R. Meteorol. Soc., 124, 949-981, 1998.

PELLY, J. HOSKINS, B.J. A new perspective on blocking. Journal of Atmospheric Sciences 60: 743-755, 2003a.

PELLY, J. HOSKINS, B.J. How well does the ECMWF Ensemble Prediction System predict blocking? Q. J. R. Meteorol. Soc., 129, pp. 1683-1702.doi: 10.1256/qj.01.173, 2003 b.

RAJAGOPALAN, B., LALL, U.; CANE, M.A. Anomalous ENSO Occurrences: An Alternate View, J. Clim., 10, 3251-2357, 1997.

RENWICK, J.; WALLACE, J.M. The influence of Sampling Variability upon Model Output Error Statistics. Mon. Wea. Rev., 124, 1981-1991, 1996a.

RENWICK, J.; WALLACE, J.M. Relationships Between North Pacific Wintertime Blocking, El Niño, and the PNA pattern. Mon. Wea. Rev.,124, 2071-2076, 1996 b.

RENWICK, J.A. ENSO-Related Variability in the Frequency of South Pacific Blocking. Monthly Weather Review.126: 3117-3126, 1998.

RENWICK, J.A.; REVELL, M.J. Blocking over South Pacific and Rossby Wave Propagation. Monthly Weather Review 127: 2233-2247, 1999.

REX, D.F. Blocking Action in the middle troposphere and its effect upon regional climate, Part I: An aerological study of blocking action. Tellus, 2(3):196-211, 1950a. 
REX, D.F. Blocking action in the middle troposphere and its effect upon regional climate, Part II: The climatology of blocking action. Tellus, 2(4):275-301, $1950 \mathrm{~b}$.

ROUSSEEUW, P.J.; RUTS, I.; TUKEY, J.W. The bagplot: A bivariate boxplot. The American Statistician, 53:382-387, 1999.

RUTLLANT, J.; FUENZALIDA, H. Synoptic aspects of the central Chile rainfall variability associated with the Southern Oscillation. International Journal of Climatology 11: 63-76, 1991.

SCHILLING, H.-D. A numerical investigation of the dynamics of blocking waves in a simple two-level model. J. Atmos. Sci., 39, 998-1017, 1982.

SHINDELL, D.T.; MILLER, R.L; SCHMIDT, G.; PANDOLFO, L. Simulation of the Arctic Oscillation Trend by Greenhouse Forcing of a Stratospheric Model, Nature, in press, 1999.

SHIOTANI, M. Low-frequency Variations of the Zonal Mean State of the Southern Hemisphere Troposphere. J. Meteor. Soc. Japan, 68, 461-471, 1990.

SHUTTS, G. J. The Propagation of Eddies in Diffluent Jet Streams: Eddy Vorticity Forcing of Blocking Flow Fields. Quart. J. Roy.Meteor. Soc., 109, 737-761, 1983.

SINCLAIR, M.R. A Climatology of Anticyclones and Blocking for the Southern Hemisphere. Monthly Weather Review 124: 245-263, 1996.

STEWART, D. A. Persistent anomaly forcing in a two-level global circulation model. J. Atmos. Sci.,50, 2710-2730, 1993.

TALJAARD, J. J. Synoptic meteorology of the Southern Hemisphere. In: Newton, C. W. ed. Meteorology of the Southern Hemisphere, Meteorological Monographs, Boston,MA, American Meteorological Society, 13, n.35, 139-213,1972.

TANRE, D.; GELEYN, J.-F.; SLINGO, J.M. First results of the introduction of an advanced aerosol-radiation interaction in the ECMWF low resolution global model. In: Aerosols 
and their Climatic Effects, H. Gerber and A. Deepak (Eds.), 133-177, A. Deepak, Hampton, Virginia, 1984.

THOMPSON, D. W. J.; WALLACE, J. M. The Arctic Oscillation Signature in the Wintertime Geopotential Height and Temperature Fields. Geophys. Res. Lett., 25, 12971300, 1998.

THOMPSON, D. W. J.; WALLACE, J. M. Annular Modes in the Extratropical Circulation. Part I: Month-to-month variability. J. Climate, 13, 1000-1016, 2000.

THOMPSON, D.W.J.; SOLOMON, S. Interpretation of recent Southern Hemisphere Climate Change. Science 296: 895-899, 2002.

THOMPSON, D.W.J.; BALDWIN, M.O.; WALLACE, J.M. Stratospheric connection to Northern Hemisphere wintertime weather: Implications for prediction. J. Climate, 15, 1421-1428, 2002.

TIBALDI, S.; MONTENI, F. On the operational predictability of blocking. Tellus 42A: 343$365,1990$.

TIBALDI, S.; TOSI. E.; NAVARRA. A.; PEDULLI, L. Northern and Southern Hemisphere variability of blocking frequency and predictabilty. Monthly Weather Review 122: 19712003, 1994.

TIBALDI, S.; D’ANDREA, F.; TOSI, E.; ROECKNER, E. Climatology of northern hemisphere blocking in the ECHAM model. Clim. Dyn., 13, 649-666, 1997.

TORRENCE, C.; COMPO, G.P. A practical guide to wavelet analysis. Bull. Amer. Meteor. Soc., 79, 61-78, 1998.

TRENBERTH, K.E.; PAOLINO, D. A. Characteristic Patterns of Variability of Sea-level Pressure in the Northern Hemisphere. Mon. Wea. Rev., 109, 1169-1189, 1981.

TRENBERTH, K.E. Seasonality in Southern Hemisphere eddy statistics at $500 \mathrm{mb}$. Journal of Atmospheric Sciences, 30(11):2507-2520, 1982. 
TRENBERTH, K.E.; MO, K. Blocking in the Southern Hemisphere. Monthy Weather Review $113,2-21,1985$.

TRENBERTH, K. E.; HOAR, T.J. The 1990-1995 El Niño-Southern Oscillation Event: Longest on record.Geophys. Res. Lttrs., 23, 57-60, 1996.

TRENBERTH, K.E.; The signature of a Blocking Episode on the General Circulation in the Southern Hemisphere. Journal of Atmospheric Sciences, 43(19):2061-2069, 1986a.

TRENBERTH, K.E. An assessment of the impact of transient eddies on the zonal flow during a blocking episode using localized Eliassen-Palm flux diagnostics. Journal of Atmospheric Sciences 43(19): 2070-2087, 1986.

TREIDL, R.A.; BIRCH, E.C.; SAJECKI, P. Blocking action in the Northern Hemisphere: A climatological study. Atmosphere-Ocean, 19(1): 1-23, 1981.

TRIGO, R.M.; TRIGO, I.F.; DACAMARA, C.C.; OSBORN, T.J. Winter blocking episodes in the European-Atlantic sector: Climate impacts and associated physical mechanisms in the Reanalysis. Climate Dynamics 23: 17-28, 2004.

TUKEY, J.W. Exploratory Data Analysis. Reading. M.A: Addison-Wesley, 1977.

VAN LOON, H. Blocking Action in the Southern Hemisphere, Part I. Notos, 5(3):171-175, 1956.

VAN LOON, H. Mid-season average zonal winds at sea level and at $500 \mathrm{mb}$ south of 25 degrees south, and a brief comparison with the Northern Hemisphere. J. Appl. Meteor., 3, $554-563,1964$.

VAN OLDENBORGH, G.J.; PHILIP, S.Y.; COLLINS, M. El Niño in a changing climate: a multi-model study. Ocean Science, 1, 81-95, 2005.

VAUTARD, R.; LEGRAS, B. On the source of midlatitude low frequency variability: nonlinear equilibration of weather regimes. J Atmos Sci 45 :2845Đ2867, 1988. 
WALKER, G.T. Correlation in Seasonal Variations of Weather - A Further Study Of World Weather. Mon. Wea. Rev., 252-254, 1925.

WALKER, G. T. World weather. Quart. J. Roy. Meteor. Soc.,54, 79-87, 1928.

WALLACE, J. M.; GUTZLER, D.S. Teleconnections in the Geopotential Height Field During the Northern Hemisphere Winter. Mon. Wea. Rev., 109, 784-812, 1981.

WALLACE, J. M.; RASMUSSON, E.M.; MITCHELL, T.P.; KOUSKY, V.E.; SARACHIK, E.S.; VON STORCH, H. On the structure and evolution of ENSO-related climate variability in the tropical Pacific: Lessons from TOGA. J. Geophys. Res., 103, 14 241-14 260, 1998.

WALLACE, J. M. North Atlantic Oscillation/Annular Mode: Two Paradigms - One Phenomenon. Quart. J. Roy. Meteor. Soc., 126, 791-806, 2000.

WIEDENMANN, J.M,; LUPO, A.R.; MOKHOV, I.I,; TIKHONOVA, E.A. The Climatology of Blocking Anticyclones for the Northern and Southern Hemispheres: Block Intensity as a Diagnostic. Journal of Climate 15: 3459-3473, 2006.

WIGLEY, T.M.L.; RICHELS, R.; EDMONDS, J.A. Economic and environmental choices in the stabilisation of atmospheric CO2 concentrations. Nature, 379, 242-245, 1996.

WIGLEY, T.M.L. TAR version of MAGICC forcing. Disponível em: <http://www.acacia.ucar.edu>. Acesso em: Mar 2000.

WILKS, D. S. Statistical methods in the Atmospheric Sciences. Academic Press: New York, 2ed, 2006, 627 p.

WILLET, H.C. Long period fluctuations of the general circulation of the atmosphere. J. Meteo., 6, 34-50, 1949.

WRIGHT, A.D. Blocking action in the Australian Region. Department of Science Bureau of Meteorology (Technical Report 10), 1974, 29pp. 
YODEN, S.; SHIOTANI, M.; HIROTA, I. Multiple Planetary Flow Regimes in the Southern Hemisphere. J. Meteor. Soc.Japan, 65, 571-586, 1987. 